\title{
Sistemas criptográficos baseados em identidades pessoais
}

\author{
Walldyr Dias Benits Júnior
}

\author{
Dissertação apresentada \\ ao \\ Instituto de Matemática e Estatística \\ da \\ Universidade de São Paulo \\ para \\ obtenção do grau \\ de \\ Mestre em Ciência da Computação
}

Área de Concentração: Criptografia

Orientador: Prof. Dr. Routo Terada

São Paulo - novembro - 2003 


\section{Sistemas criptográficos baseados em identidades pessoais}

Este exemplar corresponde à redação final
da dissertação de Mestrado devidamente
corrigida e defendida por
Waldyr Dias Benits Júnior
e aprovada pela comissão julgadora.

São Paulo, dezembro de 2003.

Banca examinadora:

- Prof. Dr. Routo Terada (Orientador) - IME-USP

- Prof. Dr. Ricardo Dahab - IC-UNICAMP

- Prof. Dr. Arnaldo Mandel - IME-USP 
"Existem homens de bom senso que, por serem incapazes de decifrar as coisas que são 'grego' para eles, convencem-se de que a lógica e a filosofia estão acima deles. Pois bem, gostaria que vissem que, assim como a natureza os dotou de olhos com os quais podem enxergar as obras dela, também lhes concedeu cérebros para penetrar e compreendê-las"

Galileu Galilei 
Para minha esposa Luciana e para minha mãe Vilma, que compreenderam minha dedicação e abdicaram de minha atenção integral, em prol do desenvolvimento desta dissertação. 


\section{Agradecimentos}

A Deus, que me deu a vida e saúde, permitindo que eu concluísse este trabalho.

A minha amada esposa Luciana pelo seu constante incentivo e apoio, principalmente nos momentos em que eu pensava que iria dar tudo errado.

A minha mãe Vilma, por sempre acreditar em mim e também por toda a dedicação e amor que tem me dado em todos os momentos de minha vida.

A meu pai Waldyr, que apesar de não estar mais entre nós, certamente está vibrando comigo e me ajudando em tudo que preciso.

A minha tia Wilméa, por ter me dado a oportunidade de estudar e chegar onde cheguei.

Ao amigo Paulo Sérgio Licciardi Messeder Barreto, por toda a paciência que teve comigo e pelas incontáveis vezes em que contribuiu enormemente para o aprimoramento e aperfeiçoamento em muitas das idéias aqui contidas, sobretudo pelas valiosas dicas sobre mapeamentos bilineares e emparelhamentos, me proporcionando o conhecimento necessário para que eu realizasse, da melhor maneira possível, minha pesquisa.

A meu orientador, Routo Terada, pela sugestão do tema e pelo seu empenho a fim de enriquecer esta dissertação.

Aos amigos Mehran Misaghi e Eduardo Takeo Uêda, por todas as dicas e paciência na revisão técnica desta dissertação.

Ao amigo Afonso Celso Lopes Francisco, pela valorosa ajuda com a revisão gramatical.

Finalmente, mas não menos importante, ao pessoal da Comissão de PósGraduação, em especial ao Pinho, pela dedicação e atenção dispensadas. 


\section{Abstract}

Nowadays, several activities - like purchases and bank operations of small or big value - can be done through the Internet, allowing users to share resources, and resulting with this an economy gain in scale. Unfortunately, the information on the Web can be easily observed by anyone, many times ill-intentioned. It is necessary, however, a constant concern with the security in the transport and storage of sensitive information. We cannot even think of a "secure environment" if the information is not protected by a strong cryptography and other security devices. The public-key cryptosystems which follow the PKI pattern have some problems, such as the necessity of a complex key-managing infrastructure and the need of a public-key owner to prove his/her identity with digital certificates. Recently, the use of elliptic curves in cryptography allowed the development of an asymmetric cryptography in that the public key of a user is not a random string, but an identity that characterizes him in a unique way, as for example, his e-mail address. Based on this property, we can establish a secure communication without exchanging secrets, without exchanging certificates and without keeping a public key directory. This asymmetric cryptography scheme, that will be presented in this Master Thesis, is nowadays known as ID-based cryptosystems. 


\section{Resumo}

Nos dias de hoje, diversas operações — como compras e transações bancárias de pequena e grande monta - podem ser feitas através da Internet, possibilitando um compartilhamento de recursos, o que, por sua vez, propicia um ganho de economia em escala. Infelizmente, as informações que circulam na grande rede podem ser facilmente observadas por terceiros, muitas vezes mal-intencionados. Faz-se necessário, portanto, uma preocupação constante com a segurança no transporte e armazenamento de informações sensíveis. É impensável se falar em "ambiente seguro" se as informações não estiverem protegidas por uma criptografia forte e outros mecanismos de segurança. Os sistemas criptográficos de chave pública que seguem o padrão PKI apresentam alguns problemas, como a necessidade de uma complexa infra-estrutura de gerenciamento de chaves e a necessidade de o detentor de uma chave pública provar sua identidade, por meio de certificados digitais. Mais recentemente, o emprego de curvas elípticas em criptografia permitiu o desenvolvimento de uma criptografia assimétrica em que a chave pública de um usuário não é uma seqüência aleatória de bits e sim um identificador que caracteriza esse usuário de forma única, como por exemplo seu número de CPF ou seu endereço eletrônico. Tal fato possibilitou que se estabeleça uma comunicação segura sem troca de segredos, sem troca de certificados digitais e sem a necessidade de se manter um diretório público de chaves. Este esquema de criptografia assimétrica, que será apresentado nesta dissertação, é hoje conhecido como criptografia baseada em identidades (ID-based cryptosystems). 


\section{Conteúdo}

Abstract iv

Resumo $\quad$ v

Lista de Figuras $\quad$ xi

$\begin{array}{lc}\text { Lista de Tabelas } & \text { xiii }\end{array}$

1 Introdução 1

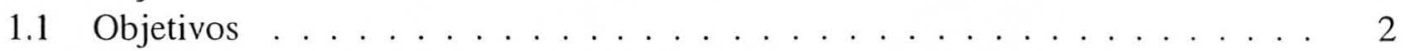

1.2 Organização . . . . . . . . . . . . . . . . . 2

1.3 Contribuições desta dissertação . . . . . . . . . . . . . . 5

2 Conceitos preliminares $\quad 6$

2.1 Introdução . . . . . . . . . . . . . . . . . . . . . 6

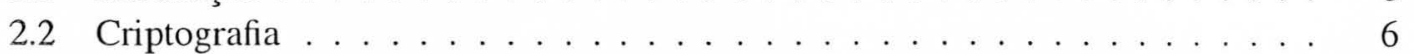

2.2 .1 Terminologia . . . . . . . . . . . . . . . . . . 8

2.2 .2 Requisitos de segurança . . . . . . . . . . . . . . . . . . . 9

2.2 .3 Tipos de ataque . . . . . . . . . . . . . . . . . . . . . 10

2.2 .4 Criptografia Simétrica . . . . . . . . . . . . . . . . . . . . 13

2.2 .5 Criptografia Assimétrica . . . . . . . . . . . . . . . . 15

2.2.6 Problemas a serem gerenciados . . . . . . . . . . . . . . . . . 19

2.3 Infra-estrutura de Chaves Públicas (ICP) . . . . . . . . . . . . . 21

2.3.1 Definições . . . . . . . . . . . . . . . . . . . . . 22

2.3.2 Obtenção de um certificado digital . . . . . . . . . . . . . . . . . . . . . . 24

2.3.3 Modelos de certificação . . . . . . . . . . . . . . . . . . . . . 25

2.3 .4 Caminhos de certificação . . . . . . . . . . . . . . . . . . . . 26

2.3 .5 Verificação de um certificado . . . . . . . . . . . . . . . . . . . . . . 27

2.3 .6 Revogação de certificados . . . . . . . . . . . . . . . . . . . 28

2.3.7 Principais problemas e vulnerabilidades da ICP . . . . . . . . . . . . . 29

2.4 Resumo . . . . . . . . . . . . . . . . . . . . . . . 30 
3 Sistemas baseados em identidades 31

3.1 Histórico e Introdução . . . . . . . . . . . . . . . . . . . . . 31

3.2 Definiçōes e notações iniciais . . . . . . . . . . . . . . . . . . 33

3.2.1 Gerador de chaves particulares $(\mathrm{PKG}) \ldots \ldots . \ldots . \ldots 33$

3.2 .2 Problema do Logaritmo Discreto (PLD) . . . . . . . . . . . . . 34

3.2 .3 Curvas elípticas . . . . . . . . . . . . . . . . . . . . . 36

3.2 .4 Emparelhamento . . . . . . . . . . . . . . . . . . . . 39

3.2 .5 Nomenclatura utilizada nesta dissertação . . . . . . . . . . . . . . . 41

3.2 .6 Bilinearidade . . . . . . . . . . . . . . . . . . . 42

3.2.7 Segurança de sistemas baseados em identidades . . . . . . . . . . . . . 43

3.2 .8 Chaves utilizadas . . . . . . . . . . . . . . . . . . . . . . . 47

3.3 Assinaturas compactas . . . . . . . . . . . . . . . . . . . . 48

3.3 .1 Assinatura . . . . . . . . . . . . . . . . . . . . . . . . . . . 49

3.3 .2 Verificação . . . . . . . . . . . . . . . . . . . . . 50

3.3 .3 Demonstração . . . . . . . . . . . . . . . . . . . 50

3.4 Criptografia em sistemas baseados em identidades . . . . . . . . . . . . 51

3.4 .1 Criptografia . . . . . . . . . . . . . . . . . . 51

3.4 .2 Decriptografia . . . . . . . . . . . . . . . . 51

3.4 .3 Demonstração . . . . . . . . . . . . . . . . . . . . 52

3.4.4 Importância da escolha do elemento aleatório $r \ldots \ldots . . . . .53$

3.4.5 Variação no esquema de Boneh \& Franklin . . . . . . . . . . . . . . 54

3.4.6 Vantagem de um intruso caso o BDHP seja fácil . . . . . . . . . . . . 57

3.5 Assinatura em sistemas baseados em identidades . . . . . . . . . . . . 58

3.5 .1 Assinatura . . . . . . . . . . . . . . . . . . 58

3.5 .2 Verificação . . . . . . . . . . . . . . . . . . . . . . 58

3.5 .3 Demonstração . . . . . . . . . . . . . . . . . . . . . . . . 59

3.5.4 Segurança na assinatura de Hess . . . . . . . . . . . . . . 60

3.6 Vantagens e desvantagens . . . . . . . . . . . . . . . . . . . . . . 60

3.7 Resumo . . . . . . . . . . . . . . . . . . . . . . . . . . 66

4 Criptassinatura $\quad \mathbf{6 8}$

4.1 Definição . . . . . . . . . . . . . . . . . . . . . . . . . 68

4.2 Utilizando esquemas conhecidos de criptografia e assinatura . . . . . . . . . . 69

4.2.1 Contabilização de custo computacional . . . . . . . . . . . 70

4.3 Esquema de Malone-Lee . . . . . . . . . . . . . . . . . . . . . . 72

4.3 .1 Assinatura e criptografia . . . . . . . . . . . . . . . . 73

4.3.2 Decriptografia e verificação da assinatura . . . . . . . . . . . . 73

4.3 .3 Demonstração . . . . . . . . . . . . . . . . . . . . . . . . . . 74

4.3.4 Importância da escolha do elemento aleatório $z \ldots \ldots$. . . . . . . . 75

4.3.5 Contabilização de custo computacional . . . . . . . . . . . . 76

4.4 Esquema de Nalla \& Reddy . . . . . . . . . . . . . . . . . . . . . . . . . 77

$4.4 .1 \quad$ Assinatura e criptografia . . . . . . . . . . . . . . . . 78

4.4.2 Decriptografia e verificação da assinatura . . . . . . . . . . . . . 78

4.4 .3 Demonstração . . . . . . . . . . . . . . . . . . . 78 
4.4.4 Segurança no esquema de Nalla \& Reddy . . . . . . . . . . . . . . . . 79

4.4 .5 Contabilização de custo computacional . . . . . . . . . . . . 82

4.5 Comparação entre os esquemas BFH, MALONE-LEE e NALLA \& REDDY . . . 83

4.6 Resumo . . . . . . . . . . . . . . . . . . . . . . 86

5 Aplicações e hierarquia de sistemas baseados em identidades $\quad 87$

5.1 Aplicações . . . . . . . . . . . . . . . . . . . . . . . . . . . . . . . . 87

5.1 .1 Revogação de chaves públicas . . . . . . . . . . . . . . . 88

5.1 .2 Delegação para um notebook . . . . . . . . . . . . . . . . . . . . . 89

5.1 .3 Delegação de serviços . . . . . . . . . . . . . . . . . . . . . . . . . . . . 90

5.1 .4 Criação de grupos . . . . . . . . . . . . . . . . . . . . . . . 91

5.1 .5 Adição de assinaturas . . . . . . . . . . . . . . . . . . 92

5.2 Hierarquia . . . . . . . . . . . . . . . . . . . . . . . . 93

5.2.1 Modelo híbrido PKI / IBE . . . . . . . . . . . . . . . . . . . . . . 994 94

5.2.2 Certificados usando assinaturas compactas . . . . . . . . . . . 94

5.2.3 Hierarquia de PKG relacionados com chaves baseadas em identidades . 95

5.2 .4 Transferindo confiança . . . . . . . . . . . . . . . . . . 96

5.2 .5 Delegação de direitos . . . . . . . . . . . . . . . . . . . . . . . . 97

5.3 Resumo . . . . . . . . . . . . . . . . . . . . . . . . . . . . . 99

6 Variações em esquemas de assinaturas $\quad 101$

6.1 Assinatura em anel (ring signature) _. . . . . . . . . . . . . . . . 102

6.1 .1 Geração da assinatura em anel . . . . . . . . . . . . . . . . 102

6.1.2 Verificação da assinatura . . . . . . . . . . . . . . . . . 103

6.1 .3 Demonstração . . . . . . . . . . . . . . . . . 103

6.1 .4 Comparação com o esquema de Hess . . . . . . . . . . . . . . 105

6.2 Assinatura cega (blind signature) . . . . . . . . . . . . . . . . . 106

6.2 .1 Assinatura . . . . . . . . . . . . . . . . . . . . . . 109

6.2 .2 Verificação . . . . . . . . . . . . . . . . . . . . . . . . 109

6.2 .3 Demonstração . . . . . . . . . . . . . . . . . . . . . . 110

6.2.4 Comparação com o esquema de Hess . . . . . . . . . . . . . . . . 112

6.3 Resumo . . . . . . . . . . . . . . . . . . . . . . . . . . 112

7 Esquemas com PKG não confiável $\quad \mathbf{1 1 3}$

7.1 Assinatura com PKG não-confiável . . . . . . . . . . . . . . . . . . . . . 114

7.1 .1 Geração de chaves . . . . . . . . . . . . . . . . . . . . . . 114

7.1 .2 Assinatura . . . . . . . . . . . . . . . . . . . 115

7.1 .3 Verificação . . . . . . . . . . . . . . . . . . . . . 116

7.1 .4 Demonstração . . . . . . . . . . . . . . . . . . . . . . 116

7.1 .5 Personificação . . . . . . . . . . . . . . . . . . . . . . 116

7.1 .6 Comparação com o esquema de Hess . . . . . . . . . . . . . . 118

7.2 Criptografia com múltiplos PKG . . . . . . . . . . . . . . . . 118

7.2 .1 Criptografia . . . . . . . . . . . . . . . . . . . . . 119 
7.2 .2 Decriptografia . . . . . . . . . . . . . . . . . . . . 120

7.2 .3 Demonstração . . . . . . . . . . . . . . . . . . . . . . . . . 120

7.3 Trabalhos relacionados . . . . . . . . . . . . . . . . . . . . . 121

7.4 Resumo . . . . . . . . . . . . . . . . . . . . . . . . . 122

8 Implementação: principais passos e dificuldades $\quad 123$

8.1 Componentes e programas utilizados . . . . . . . . . . . . . . . . 123

8.2 Escolha de parâmetros . . . . . . . . . . . . . . . . . . . . . . . . . 124

8.3 Escolha da estrutura de dados . . . . . . . . . . . . . . . . . . . . . . . . . 127

8.4 Função de espalhamento . . . . . . . . . . . . . . . . . . . . . . . . 127

8.4.1 Função de espalhamento $H_{1}$. . . . . . . . . . . . . . . . . . . 127

8.4 .2 Função de espalhamento $H_{2}$. . . . . . . . . . . . . . . . . . . . . . . . . 129

8.4 .3 Função de espalhamento $H_{3}$. . . . . . . . . . . . . . . . . . . . . . . . . 129

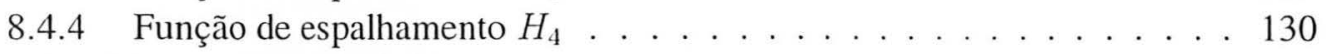

8.5 Aritmética em curvas elípticas . . . . . . . . . . . . . . . . . . . . 131

8.6 Cálculo do par de chaves baseadas em identidades . . . . . . . . . . . . . 132

8.7 Aritmética no corpo estendido . . . . . . . . . . . . . . . . . . . . 133

8.8 Cálculo do emparelhamento . . . . . . . . . . . . . . . . . . . . 136

8.8 .1 Funções de linha . . . . . . . . . . . . . . . . . . . . . . 136

8.8.2 Versão determinística do algoritmo de Miller . . . . . . . . . . . . . . 137

8.8.3 Algoritmo de Miller simplificado: eliminação de denominadores . . . . 138

8.8 .4 Exponenciação final . . . . . . . . . . . . . . . . . . . . . . . 138

8.8.5 Verificação do valor do emparelhamento . . . . . . . . . . . . . . . . 139

8.9 Entrada de dados . . . . . . . . . . . . . . . . . . . . . . . . . . . . . . . . 140

8.10 Simulação . . . . . . . . . . . . . . . . . . . . . . . . . . . . . . 141

8.10 .1 Tela inicial - parâmetros do sistema . . . . . . . . . . . . . . 141

8.10 .2 Menu de opções . . . . . . . . . . . . . . . . . . . . . . . . . . . 141

8.10 .3 Assinatura compacta Boneh, Lynn e Shacham . . . . . . . . . . . 142

8.10 .4 Verificação da assinatura BLS . . . . . . . . . . . . . . . . 143

8.10 .5 Assinatura Hess . . . . . . . . . . . . . . . . . . . . . . . . . . . . 144

8.10 .6 Verificação da assinatura Hess . . . . . . . . . . . . . . . . . . . . . 145

8.10 .7 Criptografia Boneh e Franklin . . . . . . . . . . . . . . . . . 146

8.10 .8 Decriptografia B-F . . . . . . . . . . . . . . . . . . 147

8.10 .9 Criptassinatura Nalla e Reddy . . . . . . . . . . . . . . . . . . . . 148

8.10.10 Decriptografia e verificação da assinatura N-R . . . . . . . . . . 148

8.11 Mudança de parâmetros . . . . . . . . . . . . . . . . . . . . . 151

8.12 Resumo . . . . . . . . . . . . . . . . . . . . . . . 152

9 Conclusões e trabalhos futuros 154

9.1 Conclusões . . . . . . . . . . . . . . . . . . . . . . . . . . . . . . . . 154

9.2 Trabalhos futuros . . . . . . . . . . . . . . . . . . 158 
A Curvas elípticas $r$

A.l Complexidade de algoritmos . . . . . . . . . . . . . . . . . . . . . 159

A.2 Aritmética modular . . . . . . . . . . . . . . . . . . . . . . 160

A.3 Álgebra de grupos . . . . . . . . . . . . . . . . . . . . . . . 160

A.3.1 Grupo ....................... 160

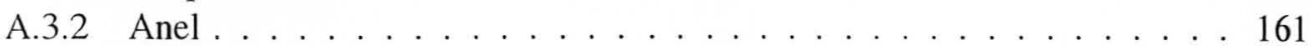

A.3.3 Corpo . . . . . . . . . . . . . . . . . . . 162

A.4 Criptografia com curvas elípticas . . . . . . . . . . . . . . . . 162

A.4.1 Soma de pontos - método algébrico . . . . . . . . . . . . . 163

A.4.2 Soma de pontos - método geométrico . . . . . . . . . . . 163

A.4.3 Exemplos de cálculos com curvas elípticas . . . . . . . . . 163

$\begin{array}{ll}\text { B Sugestões ao artigo de Nalla e Reddy } & 167\end{array}$

B.1 Problemas no artigo publicado em 28/03/2003 . . . . . . . . . . . . . . . . 167

B.2 Íntegra do correio eletrônico enviado a um dos autores do artigo . . . . . . . . . 169

B.3 Resposta de Divya Nalla ao e-mail enviado . . . . . . . . . . . . . . . . 171

C Código fonte da implementação 172

Referências Bibliográficas $\quad 189$

$\begin{array}{ll}\text { Índice Remissivo } & 195\end{array}$ 


\section{Lista de Figuras}

2.1 Modelo de Criptografia Simétrica _. . . . . . . . . . . . . . . . . . . . 14

2.2 Modelo de Criptografia Assimétrica . . . . . . . . . . . . . . . . . . . . . . . . . . . . . . . . . . . . . . .

2.3 Assinatura digital . . . . . . . . . . . . . . . . . . . . . . . . . 18

2.4 Modelo de certificado X-509 . . . . . . . . . . . . . . . . . . . . 23

2.5 Exemplos de certificado digital . . . . . . . . . . . . . . . . . . . . . . . . . 24

2.6 Modelo hierárquico em árvore . . . . . . . . . . . . . . . . . . . 26

2.7 Modelo hierárquico em floresta . . . . . . . . . . . . . . . . . . . . . . . . 26

2.8 Verificação de um certificado . . . . . . . . . . . . . . . . . . 28

3.1 Tamanho de chaves para um mesmo nível de segurança . . . . . . . . . . . 63

4.1 Assinar-e-depois-criptografar . . . . . . . . . . . . . . . . 70

6.1 Analogia de assinatura cega com envelope . . . . . . . . . . . . . . 108

8.1 Seleção da curva . . . . . . . . . . . . . . . . . . . . . . . . . 125

8.2 Função MapToPoint . . . . . . . . . . . . . . . . . . . . . . . . . . . . . . 128

8.3 Função ExpandeChave . . . . . . . . . . . . . . . . . . . . . . . . . . 130

8.4 Algoritmo de Euclides estendido . . . . . . . . . . . . . . . . . . . . . 132

8.5 Algoritmo duplica-e-soma . . . . . . . . . . . . . . . . . . . . . . 132

8.6 Algoritmo multiplicação de polinômios . . . . . . . . . . . . . . . . . . 134

8.7 Algoritmo divisão de polinômios . . . . . . . . . . . . . . . . . . 135

8.8 Funções de linha . . . . . . . . . . . . . . . . . . . . . . . . . . . . . . . . 137

8.9 Miller simplificado com eliminação de denominadores . . . . . . . . . . . . . 139

8.10 Algoritmo Tatepower . . . . . . . . . . . . . . . . . . . . . . 140

8.11 Tela inicial . . . . . . . . . . . . . . . . . . . . . . . . . . . . . . . . 141

8.12 Menu de opções . . . . . . . . . . . . . . . . . . . . . . . . . . . . . 142

8.13 Assinatura compacta BLS . . . . . . . . . . . . . . . . . . . . . . . 143

8.14 Verificação assinatura BLS . . . . . . . . . . . . . . . . . . . . . . . . . . . . . 144

8.15 Assinatura BLS rejeitada . . . . . . . . . . . . . . . . . . . . . . . . . . 144

8.16 Assinatura Hess . . . . . . . . . . . . . . . . . . . . . . . 145

8.17 Verificação assinatura Hess . . . . . . . . . . . . . . . . . . . . . . . . . . . . . . . . . . . . . . . . . . . . . .

8.18 Assinatura Hess rejeitada . . . . . . . . . . . . . . . . . . . . . . . 146

8.19 Criptografia B-F . . . . . . . . . . . . . . . . . . . . . . 147 


\section{Lista de Tabelas}

$2.1 \quad \mathrm{~N}^{\mathrm{o}}$ de chaves entre $n$ usuários . . . . . . . . . . . . . . . . . . . . . 20

2.2 Dificuldades nas criptografias simétrica e assimétrica . . . . . . . . . . . 21

3.1 Desempenho de esquemas de assinatura RSA $\times$ BLS . . . . . . . . . 65

3.2 Desempenho de esquemas de criptografia de Boneh e Franklin . . . . . . . . 66

4.1 Operações realizadas pelo esquema BFH . . . . . . . . . . . . . 72

4.2 Operações realizadas pelo esquema Malone-Lee . . . . . . . . . . . . . . . 77

4.3 Operações realizadas pelo esquema Nalla \& Reddy . . . . . . . . . . . . . . 83

4.4 Comparação entre os esquemas BFH, MALONE-LEE e NALLA \& REDDY . . . . 83

5.1 Certificados usando assinaturas compactas . . . . . . . . . . . . . . . 95

5.2 Hierarquia de $\mathrm{PKG}$ com chaves ID . . . . . . . . . . . . . . . . . . . 96

A.1 Complexidade de algoritmos . . . . . . . . . . . . . . . . . . 160 


\section{Capítulo 1}

\section{Introdução}

Nos dias de hoje, diversas operações — como compras e transações bancárias de pequena e grande monta - podem ser feitas através da Internet. Tal fato possibilita um compartilhamento de recursos, o que, por sua vez, propicia um ganho de economia em escala. Infelizmente, as informações que circulam na grande rede podem ser facilmente observadas por terceiros, nem sempre bem-intencionados. Faz-se necessário, portanto, uma preocupação constante com a segurança no transporte e armazenamento de informações sensíveis. É impensável se falar em "ambiente seguro" se as informações não estiverem protegidas por uma criptografia ${ }^{1}$ forte e outros mecanismos de segurança, como assinatura digital.

Atualmente, podemos fazer uso de criptografia simétrica ou assimétrica para garantir a segurança necessária, mas cada uma delas apresenta certas desvantagens. Mais recentemente, as curvas elípticas permitiram o desenvolvimento de uma criptografia assimétrica em que a chave pública de um usuário não é uma cadeia aleatória de bits e sim um identificador que caracteriza esse usuário de forma única, como, por exemplo, seu número de CPF ou seu endereço eletrônico (e-mail). Tal fato possibilitou que se estabeleça uma comunicação segura sem troca de segredos, sem troca de certificados digitais e sem a necessidade de se manter um diretório público de chaves. Desta forma, podemos conceber uma troca de mensagens da mesma maneira em que ocorre no correio físico: se você conhece o endereço de uma pessoa, você pode enviar-lhe uma correspondência. Este esquema de criptografia assimétrica é hoje

\footnotetext{
${ }^{1}$ A palavra criptografia tem origem grega (kriptos = escondido, oculto e grapho $=$ grafia), ou seja, escrita secreta. Seguem-se as definições do Novo Dicionário Aurélio [Ferreira 1999] para o termo: "1.Arte de escrever em cifra ou em código. 2. Conjunto de técnicas que permitem criptografar informações (como mensagens escritas, dados armazenados ou transmitidos por computador etc.)."
} 
conhecido como criptografia baseada em identidades (IBE - Identity-Based Encryption) e, por não ter nenhuma literatura em língua portuguesa sobre o assunto, motivou seu estudo e será o tema para esta dissertação de Mestrado.

\subsection{Objetivos}

Esta dissertação tem como objetivos principais estudar os sistemas criptográficos baseados em identidades, juntamente com os conceitos básicos de criptografia com curvas elípticas e mapeamentos bilineares, fundamentais para o entendimento de tais sistemas. Estudaremos os principais esquemas de criptografia e assinatura, esquemas de assinatura \& criptografia em um único passo (signcryption), principais aplicações práticas de sistemas baseados em identidades, variações em esquemas de assinaturas e também a possibilidade de se conseguir uma hierarquia de certificação de chaves públicas baseadas em identidades. Finalmente, mostraremos uma implementação de protótipos de sistemas baseados em identidades, implementação essa utilizando parâmetros pequenos, com o objetivo maior de mostrar de uma forma didática que os esquemas de fato funcionam.

Destacamos ainda que, até o momento em que concluímos esta dissertação, não tivemos conhecimento de análises formais de segurança realizadas nos esquemas que aqui apresentamos ${ }^{2}$ e deixamos a realização desse tipo de análise como sugestão de trabalho futuro, juntamente com uma otimização da implementação apresentada, adaptação para parâmetros usados na prática e realização de testes contra os ataques de segurança conhecidos.

\subsection{Organização}

Esta dissertação está estruturada como a seguir:

O capítulo 2 apresenta uma revisão sucinta dos conceitos básicos de criptografia e infra-estrutura de chaves públicas ( $\mathrm{PKI}$ ) padrão, onde procuraremos mostrar suas mais relevantes características, vantagens e desvantagens, principais problemas a serem gerenciados e possíveis vulnerabilidades. Estes conceitos são necessários para um melhor entendimento

\footnotetext{
${ }^{2}$ Não estamos levando em consideração as análises feitas pelos próprios autores.
} 
do restante da dissertação e, também, para familiarizar o leitor que não seja conhecedor de criptografia com os jargões utilizados no universo criptográfico.

O capítulo 3 apresenta os sistemas criptográficos baseados em identidades (ID-PKC ${ }^{3}$ ), começando com um breve histórico e com as definições e notações que serão utilizadas ao longo de toda a dissertação. Serão introduzidos alguns conceitos utilizados em curvas elípticas, como os emparelhamentos. Ainda nesse capítulo, serão apresentados os esquemas de assinatura compacta [Boneh, Lynn e Shacham 2001], criptografia [Boneh e Franklin 2001] e assinatura [Hess 2002] baseados em identidades. Como contribuições principais deste capítulo, apresentaremos uma variação no esquema de Boneh \& Franklin, para utilizá-lo como um protocolo de troca de chaves, faremos uma análise sobre a necessidade da escolha de um elemento aleatório no esquema de Boneh \& Franklin e faremos também uma comparação entre esquemas baseados em identidade e esquemas de chave pública padrão PKI, através de um levantamento de vantagens e desvantagens.

O capítulo 4 introduz o conceito de criptassinatura (signcryption), onde uma mensagem é assinada e criptografada em um único passo, permitindo a comunicação autenticada e sigilosa entre duas partes de uma forma mais eficiente do que a tradicional "assinare-depois-criptografar". Nesse capítulo, serão apresentados dois esquemas de criptassinatura [Nalla e Reddy 2003, Malone-Lee 2002] e será feita uma comparação entre esses esquemas e o esquema tradicional. Como contribuições deste capítulo, faremos uma análise da necessidade da escolha de um elemento aleatório nos esquemas de Malone-Lee e Nalla \& Reddy.

O capítulo 5 mostra as principais aplicações envolvendo sistemas criptográficos baseados em identidades, como revogação de chaves públicas [Boneh e Franklin 2001] (onde o prazo de validade de uma chave pública é acrescentado ao identificador, garantindo a validade daquela chave apenas durante o período desejado), delegação para um notebook [Boneh e Franklin 2001] (onde um usuário pode gravar em seu notebook as chaves particulares baseadas em identidade correspondentes apenas aos dias de uma viagem, a fim de não haver risco de comprometimento de sua chave particular padrão), delegação de serviços [Boneh e Franklin 2001] (em que cada departamento de uma empresa pode decriptografar as mensagens de sua responsabilidade, sem contudo, conseguir decriptografar as mensagens dos

\footnotetext{
${ }^{3}$ Identity-based Public Key Cryptosystems.
} 
outros departamentos, mas o Presidente da empresa consegue decriptografar todas as mensagens), criação de grupos [Chen et al. 2002] (onde você pode enviar uma mensagem para um determinado grupo sem que saiba quem são os componentes desse grupo) e adição de assinaturas [Chen et al. 2002] (onde um grupo de pessoas pode assinar um mesmo documento, como por exemplo, um Tratado Internacional). O mesmo capítulo exibe a hierarquia e certificação de sistemas baseados em identidades, apresentando um modelo híbrido de certificação PKI-IBE [Chen et al. 2002], descrevendo como assinaturas compactas podem ser utilizadas para certificar autoridades de confiança e como conseguir uma hierarquia de autoridades de confiança relacionadas com chaves baseadas em identidades. Veremos ainda, como transferir confiança e delegar direitos dentro da hierarquia baseada em identidades.

O capítulo 6 mostra esquemas de assinatura que, embora sejam menos eficientes em termos computacionais do que o esquema de Hess [Hess 2002], são utilizados para fins específicos, não atendidos por tal esquema. Veremos assinaturas cegas [Zhang e Kim 2002] (que permitem a um usuário obter uma assinatura legítima de uma mensagem sem que o assinante tenha conhecimento do conteúdo da mesma) e assinaturas em anel [Lin e Wu 2003] (em que você pode ter certeza de que determinada mensagem foi assinada por um grupo, mas não tem como saber quem do grupo assinou).

O capítulo 7 apresenta esquemas de criptografia e assinatura baseados em identidades em que consideramos a hipótese de o gerador de chaves não ser uma entidade totalmente idônea [Chen, Zhang e Kim 2003]. Tal fato pode ser importante quando o conhecimento das chaves particulares pelo gerador de chaves for uma desvantagem.

No capítulo 8, descreveremos os principais passos e dificuldades na implementação em ANSI-C de esquemas baseados em identidades — uma das contribuições desta dissertação — bem como os principais resultados obtidos.

O capítulo 9 apresenta a conclusão desta dissertação e relaciona os possíveis trabalhos futuros a serem desenvolvidos nesta área de pesquisa.

$\mathrm{O}$ anexo A apresenta a base matemática para alguns dos pontos abordados nesta dissertação, como complexidade de algoritmos, Aritmética modular, Álgebra de grupos e principais operações em curvas elípticas.

$\mathrm{O}$ anexo B apresenta as sugestões que foram feitas pelo autor desta disser- 
tação ao artigo Signcryption scheme for Identity-based Cryptosystems [Nalla e Reddy 2003], sugestões essas que foram aceitas e alteradas no artigo original. Ainda nesse anexo, o leitor poderá ver, integralmente, o e-mail que foi enviado a Divya Nalla, um dos autores do artigo citado, bem como a resposta dada pelo autor. Tais sugestões constituem uma das contribuições desta dissertação.

Finalmente, o anexo C apresenta o código em ANSI-C da implementação descrita no capítulo 8 .

\subsection{Contribuições desta dissertação}

- [Capítulos 3 a 7] Elaboração de um documento em língua portuguesa sobre sistemas criptográficos baseados em identidade, abordando os principais sistemas conhecidos, suas aplicações mais usuais, suas vantagens e desvantagens, haja vista que, até o momento em que concluímos esta dissertação, só tivemos conhecimento de literatura sobre o assunto em língua estrangeira;

- [Seções 3.4.4, 4.3.4 e 4.4.4] Análise sobre a necessidade da escolha de um elemento aleatório para cada mensagem a ser enviada;

- [Seção 3.4.5] Apresentação de uma variação no esquema original de criptografia de Boneh \& Franklin [Boneh e Franklin 2001], obtendo um esquema que pode ser usado, em conjunto com um esquema de assinatura, como um protocolo (seguro) de negociação de chaves simétricas (robustas);

- [Seção 3.6] Comparação entre esquemas baseados em identidade e esquemas de chave pública padrão PKI, através do levantamento de vantagens e desvantagens;

- [Capítulo 8] Apresentação dos principais passos e dificuldades na implementação de um protótipo de sistemas baseados em identidades;

- [Anexo B] Sugestões feitas ao artigo Signcryption scheme for Identity-based Cryptosystems [Nalla e Reddy 2003] publicado em 28/03/2003, através de correio eletrônico enviado pelo autor desta dissertação a um dos autores do artigo em questão. 


\section{Capítulo 2}

\section{Conceitos preliminares}

\subsection{Introdução}

Este capítulo destina-se a dar uma visão geral dos conceitos básicos de criptografia e infra-estrutura de chaves públicas, considerados fundamentais para um melhor entendimento do assunto que iremos estudar. Procuraremos mostrar suas mais relevantes características, vantagens e desvantagens, principais problemas a serem gerenciados e possíveis vulnerabilidades. Os leitores que se sentirem perfeitamente familiarizados com estes assuntos poderão passar direto para o capítulo 3 sem prejuízo de conteúdo.

\subsection{Criptografia}

Desde os tempos mais remotos, o Homem já se preocupava em guardar segredo de informações importantes. Não se pode precisar quando surgiu a primeira forma de criptografia, mas tem-se conhecimento [Tkotz 1999] que uma das primeiras formas de escrita cifrada ocorreu cerca de 1900 a.C., numa vila egípcia perto do rio Nilo chamada Menet Khufu. Khnumhotep II era um arquiteto do faraó Amenemhet II. Ele construiu alguns monumentos para o faraó, que precisavam ser documentados. Nem é preciso dizer que as informações sobre a localização dos monumentos, escritas em tabletes de argila, não eram para cair no domínio público. O escriba de Khnumhotep II teve a idéia de substituir algumas palavras ou trechos de texto destes tabletes. Caso o documento fosse roubado, o ladrão não encontraria o caminho que o levaria ao tesouro - morreria de fome, perdido nas catacumbas da pirâmide. Na Roma 
Antiga, alguns cifradores eram utilizados para esconder informações sensíveis, como as Cifras ${ }^{1}$ de César e Vigenère, que hoje são conhecidamente fracas e vulneráveis, mas que para a época, atendiam perfeitamente às necessidades, como por exemplo, esconder planos de guerra.

Até o final da década de 70, todos os algoritmos criptográficos eram secretos, principalmente aqueles utilizados pela diplomacia e forças armadas de cada país [Terada 2000]. Um exemplo disso é a máquina de rotores ENIGMA, muito utilizada pelos alemães até a Segunda Guerra Mundial. Com o advento dos computadores, ficou impraticável o uso apenas dos métodos mais elementares de criptografia, como substituição e transposição simples, pelo fato de poderem ser decriptografados em poucos segundos por um computador. Mais tarde, no final da década de 70 , provou-se que a segurança de sistemas criptográficos deveria residir no segredo da chave e não nos algoritmos, que deveriam ser de domínio público. Com isso, foi desenvolvido o primeiro algoritmo de criptografia simétrica de domínio público, conhecido como DES ${ }^{2}$, onde uma mesma chave é utilizada nos dois extremos da comunicação.

Podemos citar três grandes problemas na criptografia simétrica. O primeiro deles é que, como dizia um velho provérbio árabe: "quando um segredo é compartilhado por duas ou mais pessoas deixa de ser um segredo" e ficava muito difícil encontrar um método seguro de transmitir esse segredo entre as partes, principalmente se estivessem distantes geograficamente umas das outras, pois a chave secreta, neste caso, não podia ir, por exemplo, via um mensageiro de confiança; o segundo problema é como gerenciar a grande quantidade de chaves necessárias para se realizar uma comunicação segura entre muitos participantes; o terceiro problema é a impossibilidade de irretratabilidade, ou seja, não é possível determinar qual dos detentores da chave secreta criptografou determinada mensagem, e portanto não é possível se criar uma assinatura digital usando criptografia simétrica. Para resolver esse problema de gerenciamento e distribuição de chaves, surgiu então, em 1976, com o artigo pioneiro New Directions in Cryptography [Diffie e Hellman 1976] de W. Diffie e M. Hellman, o conceito de criptografia de chave pública, também conhecida como criptografia assimétrica, sistema esse que, por suas características, garantiu o requisito de irretratabilidade em uma comunicação.

No contexto da criptografia assimétrica, as chaves de criptografia e decrip-

\footnotetext{
${ }^{1}$ Conjunto de procedimentos e conjunto de símbolos (letras, nomes, sinais etc) usados para substituir as letras de uma mensagem. São geralmente classificadas como cifras de transposição e cifras de substituição.

${ }^{2}$ Sigla que representa o termo em inglês "Data Encryption Standard", ou padrão de criptografia de dados.
} 
tografia são distintas uma da outra, sendo uma aleatória e a outra calculada em função da primeira e a dedução de uma a partir da outra reside na solução de algum problema matemático intratável $^{3}$. Porém, se por um lado não havia mais o compartilhamento de segredos, por outro o detentor de uma chave pública deveria provar sua identidade e, com isso, surgiu a necessidade de certificados digitais e autoridades certificadoras, o que envolve um elevado custo para se manter a infra-estrutura necessária. Mais recentemente, as curvas elípticas surgiram no mundo da criptografia assimétrica como mais uma opção de "problema matemático intratável", juntamente com o problema da fatoração de números inteiros, que é usado no RSA ${ }^{4}$ [Rivest, Shamir e Adleman 1978].

Nesta seção, faremos uma revisão dos conceitos básicos de criptografia, começando com os requisitos de segurança e os principais tipos de ataques. Em seguida, definiremos as criptografias simétrica e assimétrica, discutindo suas mais relevantes características, vantagens e desvantagens, bem como os principais problemas a serem gerenciados em cada uma delas.

\subsubsection{Terminologia}

Ao longo desta dissertação, utilizaremos uma série de termos, amplamente empregados no jargão técnico do meio criptográfico, e que serão a seguir definidos de modo a melhor ambientar os leitores que não estejam familiarizados com o assunto. Cabe ainda ressaltar que não procuramos esgotar toda a terminologia utilizada em criptografia, e sim, apenas aquelas que julgamos ser as mais úteis para um entendimento inicial desta pesquisa. Demais definições serão dadas à medida que forem necessárias, no decorrer dos capítulos.

Alice, Beto e Carlos: Nomes utilizados no jargão criptográfico, onde Alice e Beto representam dois usuários que desejam estabelecer uma comunicação segura e Carlos representa um intruso ou um criptanalista que tentará ter acesso ao conteúdo da mensagem sem ter autorização para tal;

\footnotetext{
${ }^{3}$ Dizemos que um problema matemático é intratável ou computacionalmente difícil quando não se conhece nenhum algoritmo de tempo polinomial para resolvê-lo.

${ }^{4}$ Algoritmo de criptografia assimétrica tradicional criado por Rivest - Shamir - Adleman.
} 
Chave: Conjunto de bits em forma de arquivo, usado para criptografar e decriptografar uma mensagem;

Criptanálise: Arte e ciência que estuda métodos para analisar textos criptografados, com o objetivo de decriptografá-los;

Criptografar: Operação de transformar um texto legível em texto criptografado;

Criptografia: Na falta de uma tradução mais adequada ${ }^{5}$, resolvemos adotar nesta dissertação os termos criptografia e decriptografia como traduções, respectivamente, de encryption e decryption, embora saibamos que, hoje em dia, o termo criptografia tenha um significado muito mais amplo.

Criptologia: Área da Matemática que estuda a criptografia e criptanálise;

Decriptografar: Operação inversa a de criptografar, ou seja, recuperar um texto legível a partir de um texto criptografado, através do uso da chave apropriada;

Texto Cifrado, Texto Ilegível: Sinônimos de texto criptografado;

Texto Criptografado: Resultado de uma transformação aplicada ao texto legível de modo que não se consiga ter conhecimento da informação, a menos que se conheça a chave adequada;

Texto Legível: Mensagem ou informação cuja privacidade se deseja salvaguardar;

Texto Limpo, Texto Claro, Texto Pleno: Sinônimos de texto legível.

\subsubsection{Requisitos de segurança}

Para que possamos estabelecer uma comunicação de forma segura, faz-se necessário que sejam atendidos os seguintes requisitos, segundo W. Stallings [Stallings 2002]:

\footnotetext{
${ }^{5}$ O Novo Dicionário Aurélio [Ferreira 1999] não registra o termo "encriptação".
} 
CONFIDENCIALIDADE

Garantia de que as informações armazenadas em um sistema de computação ou transmitidas via rede de computadores sejam acessadas ou manipuladas somente pelos usuários devidamente autorizados;

AUTENTICIDADE

Garantia de que os participantes de uma comunicação sejam corretamente identificados, tendose certeza absoluta das identidades dos mesmos;

INTEGRIDADE

Garantia de que a informação processada ou transmitida chegue ao seu destino exatamente da mesma forma em que partiu da origem;

AUTORIA GARANTIDA（OU IRRETRATABILIDADE）

Garantia de que nem a origem nem o destino das informações possam negar, posteriormente, sua transmissão, recepção ou posse. Só é possível garantir irretratabilidade com criptografia assimétrica.

\subsubsection{Tipos de ataque}

Segundo [GLOSSÁRIO de segurança 2003], ataque pode ser definido como "o ato de tentar burlar os controles de segurança de um sistema. O fato de um ataque estar acontecendo não significa necessariamente que ele terá sucesso. O nível de sucesso depende da vulnerabilidade do sistema ou da atividade e da eficácia de contramedidas existentes." Em outras palavras, podemos dizer que ataque é qualquer tentativa de criptanálise. Um ataque pode ser classificado em ativo ou passivo. Um ataque ativo, tem por resultado a alteração dos dados. Os ataques de Interrupção, Modificação e Fabricação, que veremos a seguir, são os chamados ataques ativos. 
INTERRUPÇÃO OU BLOQUEIO

Tipo de ataque que ocorre quando um intruso se interpõe entre os dois extremos da comunicação, impedindo que a mensagem transmitida chegue ao seu destino;

\section{MODIFICAÇÃO}

Tipo de ataque em que o intruso, além de bloquear a mensagem transmitida, consegue alterar o seu conteúdo e transmiti-la ao destino. Dizemos que um ataque de modificação é bem sucedido se os participantes da comunicação não conseguem verificar se a mensagem foi alterada. Tal ataque, por ter como característica a presença de um intermediário entre os dois extremos da comunicação, é conhecido na literatura específica como man-in-the-middle ("homem no meio");

FABRICAÇÃO

Tipo de ataque em que o intruso é capaz de fabricar suas próprias mensagens e transmiti-las. Dizemos que este ataque é bem sucedido se os participantes não conseguem verificar a autenticidade das mensagens recebidas.

Quando um ataque é dito passivo, ele tem por resultado a liberação dos dados, como ocorre no ataque de interceptação.

\section{INTERCEPTAÇÃO}

Tipo de ataque passivo que ocorre quando um intruso consegue ter acesso à mensagem transmitida sem, contudo, impedir que a mesma chegue ao seu destino. Dizemos que um ataque de interceptação é bem sucedido quando o intruso consegue ter acesso à informação contida na mensagem, isto é, ao texto legível, e não apenas aos dados transmitidos de forma codificada.

Dizemos que a segurança de uma mensagem foi comprometida quando um criptanalista consegue quebrar um texto criptografado, (isto é, quando consegue transformar o texto criptografado de volta ao texto legível correspondente) ou quando consegue quebrar a chave (isto é, descobre a chave que foi utilizada para criptografar a mensagem, no caso de 
criptografia simétrica, ou a chave de decriptografia, no caso de criptografia assimétrica, e com isso, consegue quebrar TODOS os textos legíveis que foram criptografados com essa chave). Para alcançar um destes objetivos, ele pode lançar mão dos seguintes ataques, segundo R. Terada [Terada 2000]:

1. Ataque por só-texto-ilegível: O criptanalista Carlos tenta adquirir conhecimento útil à quebra, analisando apenas um ou mais ilegíveis $y$. Se este tipo de ataque for computacionalmente viável, o algoritmo em questão é considerado totalmente inseguro e inútil;

2. Ataque por texto legível conhecido: O criptanalista Carlos possui e analisa pares $(x, y)$ de legível e ilegível correspondentes. Neste e nos tipos de ataque a seguir o criptanalista tem acesso ao algoritmo (sem conhecer a chave $k$ ) e não é necessariamente um malintencionado ou intruso: pode ser um especialista que objetiva descobrir se o algoritmo é vulnerável a este tipo de ataque, sendo que o algoritmo fora projetado por outra pessoa, eventualmente;

3. Ataque por texto legível escolhido: Além do suposto no tipo anterior, o criptanalista Carlos pode escolher os legíveis $x$ e obter os $y$ correspondentes. Ele vai escolher $x$ que apresente alguma característica estrutural que aumente o seu conhecimento do algoritmo e da chave em uso. Com o conhecimento adquirido, ele pode deduzir o legível correspondente a um ilegível novo;

4. Ataque adaptativo por texto legível escolhido: Além do suposto no tipo anterior, a escolha de um novo $x$ pelo criptanalista Carlos pode depender dos ilegíveis $\bar{y}$ analisados anteriormente. Desta forma, a escolha de um novo $x$ é condicionada ao conhecimento já adquirido pela análise dos $\bar{y}$ já analisados;

5. Ataque por texto ilegível escolhido: O criptanalista Carlos escolhe inicialmente o ilegível $y$ e então obtém o legível $x$ correspondente. Supõe-se que o criptanalista Carlos tenha acesso apenas ao algoritmo de decriptografia (sem ter acesso à chave) e o seu objetivo é, mais tarde, sem ter mais acesso à decriptografia, ser capaz de deduzir $x$ correspondente a um $y$ novo; 
6. Ataque adaptativo por texto ilegível escolhido: Além do suposto no tipo anterior, a escolha de um novo $y$ pelo criptanalista Carlos pode depender dos legíveis $\bar{x}$ analisados anteriormente. Desta forma, a escolha de um novo y é condicionada ao conhecimento já adquirido pela análise dos $\bar{x}$ anteriores;

7. Ataque por chave conhecida: O criptanalista Carlos conhece algumas chaves já usadas e utiliza tal conhecimento para deduzir chaves novas; e

8. Ataque por dicionário: Muito usado para deduzir senhas quando o criptanalista Carlos tem acesso ao arquivo de senhas legítimas criptografadas; Carlos calcula antecipadamente as senhas legítimas criptografadas $y$ correspondentes às senhas $x$ mais comuns (como nome de pessoas combinadas com números de telefone etc. ) e compara com os $y$ calculados e armazenados no arquivo de senhas legítimas; se encontrar um $y$ igual no arquivo, ele já possui a senha $x$ válida correspondente.

Além disso, um texto cifrado ou uma chave podem ser quebrados com uso de ameaça, chantagem, suborno ou tortura. Estes são ataques poderosos e, freqüentemente, a melhor maneira de se quebrar um algoritmo.

\subsubsection{Criptografia Simétrica}

Este tipo de criptografia é também conhecido como criptografia de chave secreta e se baseia no uso de uma mesma chave (segredo) compartilhada entre os dois extremos da comunicação. Sua principal característica é a necessidade de um canal totalmente seguro, que deve ser usado para transmitir a chave que será utilizada na comunicação. Após a transmissão da chave por meio desse canal seguro, é necessário haver um gerenciamento adequado da mesma, a fim de garantir segurança no seu armazenamento. Outra importante característica é que o número de chaves necessárias cresce em uma ordem de grandeza proporcional ao quadrado do número de participantes, visto que entre cada par de usuários existe uma, e somente uma, chave e essa não pode ser usada para se comunicar com um terceiro usuário. Portanto, em um total de $n$ participantes, o número de chaves necessárias é dado pela fórmula abaixo, que representa o 
número de combinações de $n$ usuários, dois a dois:

$$
\text { Quantidade de chaves }=\frac{n(n-1)}{2} .
$$

Além disso, como na criptografia simétrica existe somente uma única chave nos dois extremos da comunicação, não se pode provar qual dos dois criptografou determinada mensagem, ou seja, não existe o requisito de irretratabilidade na criptografia simétrica.

Observe a figura $2.1^{6}$ para entender melhor como é um esquema de criptografia simétrica.

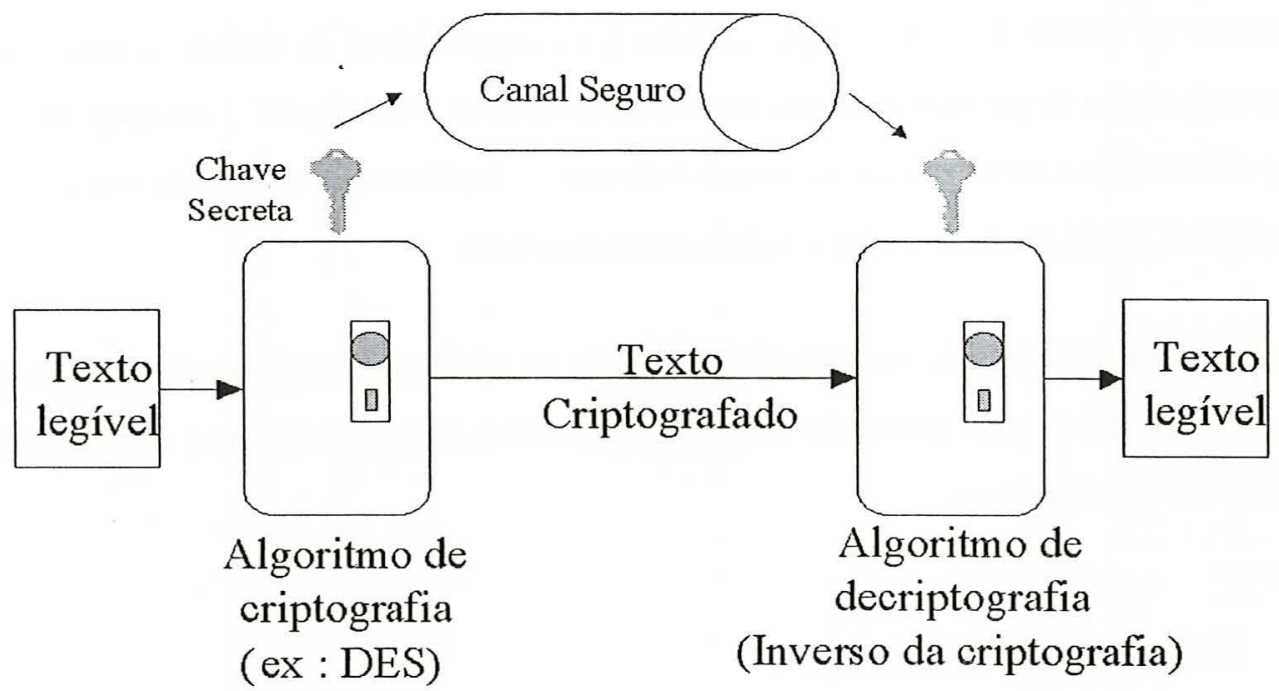

Figura 2.1: Criptografia Simétrica - Primeiramente, Alice e Beto, através de um canal seguro, entram em acordo sobre a chave secreta $k$ que será usada por eles. Após a negociação dessa chave, Alice criptografa $m$ com a chave secreta $k$, produzindo o texto criptografado $\mathcal{C}$ e transmite $\mathcal{C}$ para Beto. Esse, ao receber $\mathcal{C}$, usa sua chave secreta $k$ para recuperar o legível $m$. Note que somente quem possui a chave secreta $k$ poderá recuperar o legível $m$.

Suponha que Alice queira enviar uma mensagem $m$ para Beto usando criptografia simétrica. Primeiramente, Alice e Beto, através de um canal seguro, entram em acordo sobre a chave secreta que será usada por eles na comunicação. Seja $k$ a chave secreta que será usada por Alice e Beto. Sejam $C($ ) e $D($ ) os algoritmos de criptografia e decriptografia, respectivamente, tal que $D($ ) é o inverso de $C($ ). Após a negociação dessa chave, Alice criptografa $m$ com a chave secreta $k$, produzindo o texto criptografado $\mathcal{C}$, tal que $C_{k}(m)=\mathcal{C}$ e

\footnotetext{
${ }^{6}$ Retirada de [Stallings 2002] e traduzida para o Português.
} 
transmite $\mathcal{C}$ para Beto. Esse, ao receber $\mathcal{C}$, usa sua chave secreta $k$ para recuperar o legível $m$, pois $D_{k}(\mathcal{C})=m$. Note que somente quem possui a chave secreta $k$ poderá recuperar o texto legível $m$.

\subsubsection{Criptografia Assimétrica}

O conceito de criptografia assimétrica foi visto pela primeira vez no artigo New Directions in Cryptography [Diffie e Hellman 1976], em 1976. Neste artigo, os autores propuseram um modelo de criptografia assimétrica, também conhecida como criptografia de chave pública, em que, diferentemente da criptografia simétrica, cada usuário possui um par de chaves, sendo uma de conhecimento exclusivo de seu detentor, chamada chave particular (ou privada) e a outra de domínio público, conhecida como chave pública. Cada usuário gera seu próprio par de chaves, sendo uma aleatória e a outra calculada em função da primeira. Após isso, ele publica uma das chaves e mantém a outra em seu poder.

Apresentaremos a seguir os principais requisitos necessários para o funcionamento desse esquema, apontados por W. Diffie e M. Hellman no artigo New Directions in Cryptography. Os termos destacados em negrito equivalem à tradução do contido no artigo, e em seguida a cada requisito, há uma breve explicação do mesmo. Considere, ainda, as seguintes notações:

$C_{k}, D_{k}:$ algoritmos de criptografia e decriptografia, respectivamente

$P_{b}$ : chave pública do usuário Beto

$S_{b}$ : chave particular do usuário Beto

$\mathbb{K}$ : universo de todas as chaves possíveis

M: universo de todas as mensagens possíveis

a) Para todo $k \in\{\mathbb{K}\}, C_{k}$ é a inversa de $D_{k}$. Em outras palavras, os algoritmos de criptografia e decriptografia devem poder ser aplicados em qualquer ordem, ou seja: $m=C_{P_{b}}\left[D_{S_{b}}(m)\right]$. Tal requisito aplica-se à assinatura digital, que será vista mais adiante;

b) Para todo $k \in\{\mathbb{K}\}$ e $m \in\{\mathbb{M}\}$, os algoritmos $C_{k}$ e $D_{k}$ são computacionalmente fáceis de se calcular. Em outras palavras, deve ser computacionalmente fácil para um usuário Alice, conhecendo a chave pública de Beto e a mensagem $m$, produzir o texto criptografado $\mathcal{C}$, tal que $\mathcal{C}=C_{P_{b}}(m)$ e deve ser computacionalmente fácil para um usuário Beto decriptografar o texto ilegível $\mathcal{C}$, usando sua chave particular $S_{b}$ e obter a mensagem $m$, tal que : 
$m=D_{S_{b}}(\mathcal{C})=D_{S_{b}}\left[C_{S_{b}}(m)\right]$

c) Para quase $\mathbf{e}^{7}$ todo $k \in\{\mathbb{K}\}$, cada algoritmo computacionalmente fácil equivalente a $D_{k}$ é computacionalmente inviável de se derivar de $C_{k}$. Ou seja, deve ser computacionalmente inviável para um oponente, conhecendo a chave pública $P_{b}$, determinar a chave particular $S_{b}$, assim como também deve ser computacionalmente inviável para um oponente, conhecendo a chave pública $P_{b}$ e o texto criptografado $\mathcal{C}$, recuperar o texto original $m$;

d) Para cada $k \in\{\mathbb{K}\}$, é computacionalmente fácil obter pares inversos $P_{b} \mathbf{e} S_{b}$. Isto quer dizer que deve ser computacionalmente fácil para um usuário Beto gerar um par de chaves $\left(P_{b}\right.$ : pública e $S_{b}$ : particular).

O modelo proposto por Diffie e Hellman inspirou o surgimento dos diversos algoritmos de criptografia assimétrica que conhecemos hoje, como o RSA. Veremos, mais adiante, que cada um desses requisitos também é atendido na criptografia de chaves públicas baseadas em identidades.

Vejamos na figura $2.2^{8}$ como funciona a criptografia assimétrica.

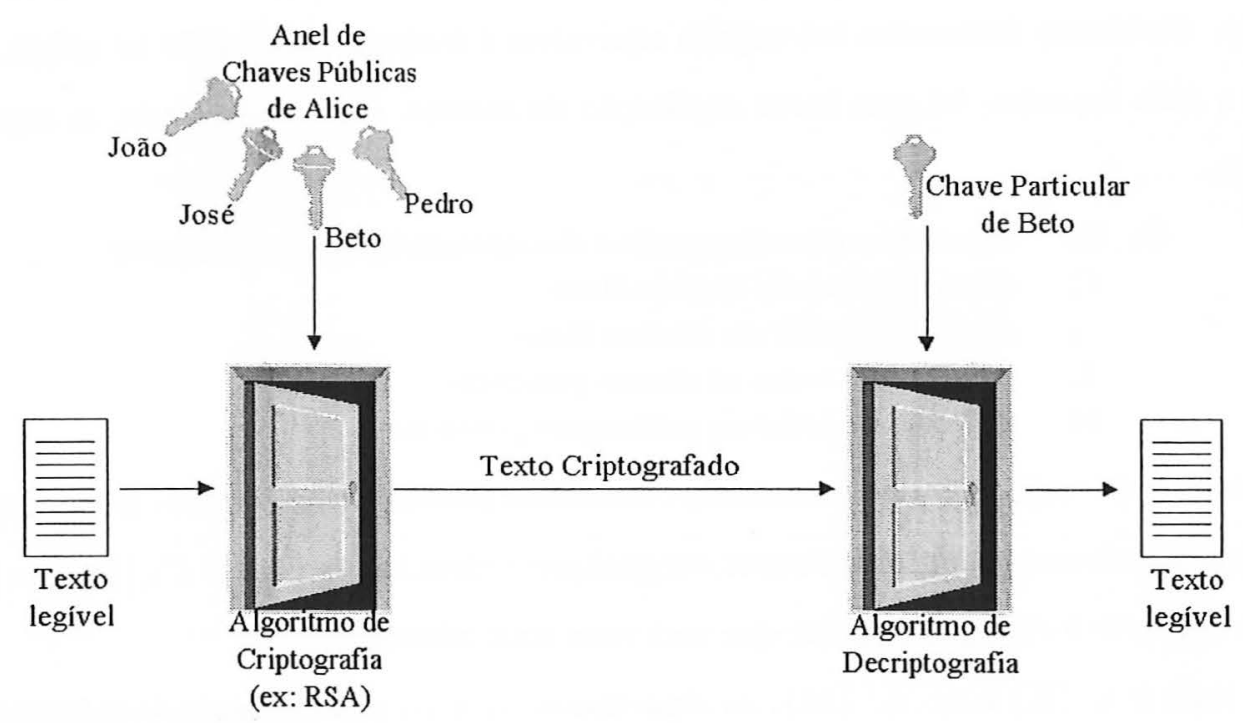

Figura 2.2: Criptografia Assimétrica - Quando Alice deseja enviar uma mensagem $m$ para Beto, ela criptografa $m$ com a chave pública de Beto, produzindo o texto criptografado $\mathcal{C}$. Beto, ao receber $\mathcal{C}$, usa sua chave particular para decriptografar $\mathcal{C}$ e recuperar $m$.

\footnotetext{
${ }^{7}$ Existem alguns $k$, denominados "chaves fracas", para os quais é fácil recuperar $m$ a partir de $C$.

${ }^{8}$ Retirada de [Stallings 2002] e traduzida para o Português.
} 
Se Alice quer enviar uma mensagem para Beto usando criptografia assimétrica, ela primeiramente procura em um diretório público a chave de Beto e criptografa a mensagem desejada com essa chave, produzindo o texto criptografado $\mathcal{C}$. Beto, ao receber $\mathcal{C}$, utiliza sua chave particular para decriptografar $\mathcal{C}$ e recuperar o legível $m$. Somente Beto consegue recuperar $m$, pois somente ele possui a chave apropriada.

\subsubsection{Assinatura digital}

Definimos como assinatura digital o processo de criptografar uma mensagem (ou um código associado univocamente à ela) com uma chave particular. Desta forma, garantimos a autenticidade da origem, pois somente quem possui a chave particular usada na criptografia poderá ter produzido o código gerado. Neste caso, a chave pública do usuário que criptografou a mensagem é utilizada para verificação da assinatura.

Cabe ressaltar que a assinatura digital só é possível na criptografia assimétrica, tendo em vista que na criptografia simétrica, como os dois extremos da comunicação possuem a mesma chave, não é possível garantir qual dos dois enviou a mensagem.

Descreveremos a seguir os passos necessários para geração de uma assinatura digital.

- Dada uma mensagem $m$ de tamanho variável, utiliza-se uma função não-inversível $(\text { hash })^{9}$ para se produzir um código de tamanho fixo, associado univocamente à mensagem;

- Com a chave particular de quem deseja assinar a mensagem, criptografa-se o código gerado anteriormente;

- A assinatura digital é diferente para cada documento assinado e estabelece uma relação única entre o texto sendo assinado e a pessoa que está assinando.

Na figura 2.3 podemos ver um esquema do processo de assinatura digital.

\footnotetext{
${ }^{9}$ Definiremos uma função de espalhamento ou hash no capítulo 3.
} 


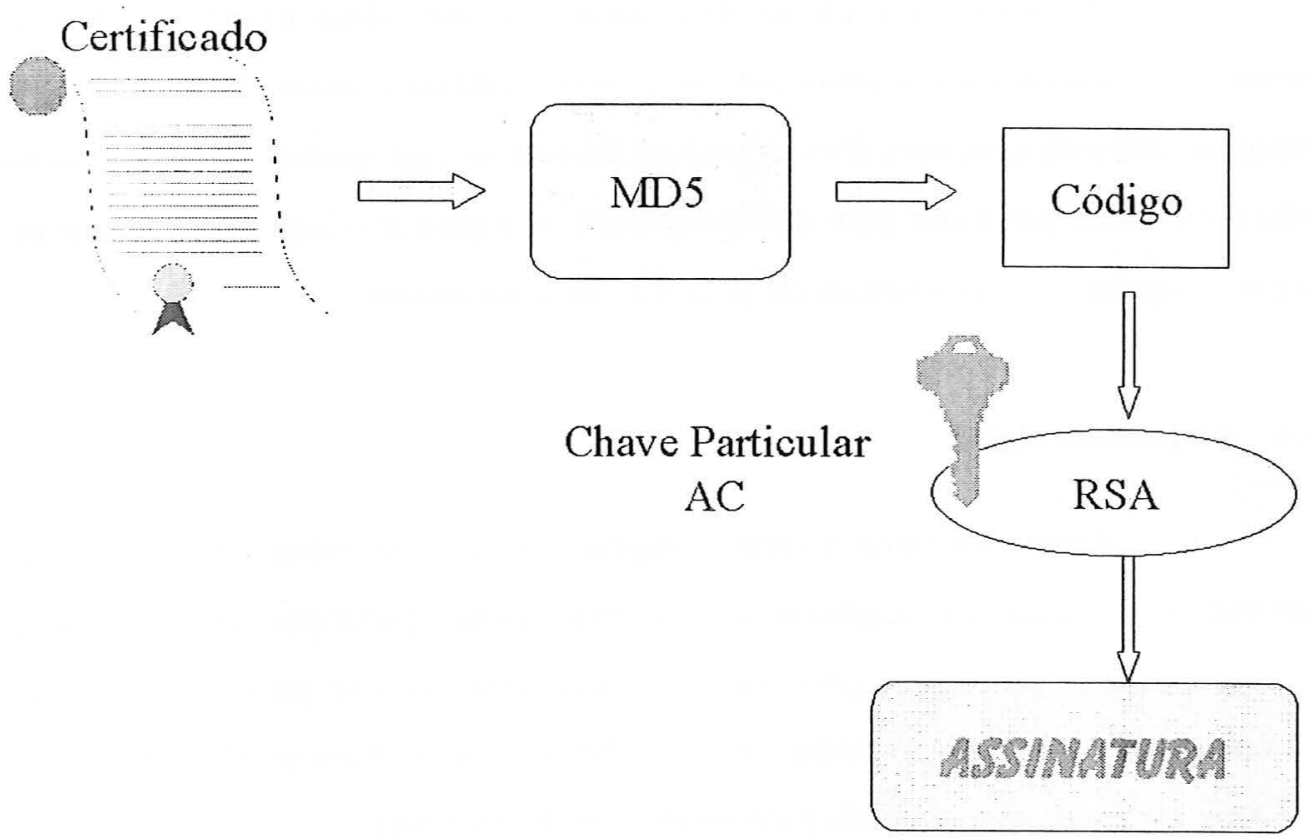

Figura 2.3: Assinatura em um certificado digital - Na figura, o certificado digital é a mensagem $m$ a ser assinada. Utiliza-se uma função não-inversível (no caso, função de hash MD-5) para se produzir um código de tamanho fixo, associado univocamente à mensagem. Com a chave particular da $\mathrm{AC}$, criptografa-se o código gerado anteriormente (usando, por exemplo, RSA).

\subsubsection{Autenticidade da origem e do destino}

Na maioria dos algoritmos de criptografia assimétrica, qualquer uma das chaves pode ser utilizada para criptografar uma mensagem, sendo que, quando utilizamos a chave pública de um usuário para criptografar, estamos garantindo a autenticidade no destino da comunicação, pois somente quem possui a chave particular correspondente àquela chave pública pode recuperar o texto original. Por outro lado, quando utilizamos nossa chave particular para criptografar uma mensagem, estamos garantindo a autenticidade na origem da comunicação, pois somente quem possui a chave particular usada na criptografia poderia ter produzido o correspondente texto criptografado. Para que possamos garantir a autenticidade em ambos os extremos da comunicação é preciso que utilizemos um esquema combinado de assinatura e criptografia. 


\subsubsection{Problemas a serem gerenciados}

Vimos que tanto a criptografia simétrica quanto a assimétrica possuem diversas características, bem como inúmeros problemas, que precisam ser gerenciados. Destacaremos a seguir os principais problemas que foram citados anteriormente, no que diz respeito às criptografias simétrica e assimétrica.

Na criptografia simétrica, a principal dificuldade é estabelecer um canal totalmente seguro para que os participantes de uma comunicação possam negociar as chaves secretas que serão utilizadas. Nos tempos antigos, esse "canal seguro" muitas vezes era representado por um mensageiro de confiança de ambas as partes, que transportava consigo a chave secreta que seria usada. Hoje em dia, porém, face à grande distância que os participantes podem estar um dos outros e à sempre presente necessidade de rapidez na comunicação como, por exemplo, em transações bancárias, o uso de um mensageiro tornou-se totalmente inviável.

Portanto, para que a segurança de uma criptografia simétrica não seja comprometida, é preciso que a chave secreta seja transmitida por esse canal "totalmente seguro" e, na prática, muitas vezes se utiliza a criptografia assimétrica como meio seguro na transferência das chaves, haja vista que os algoritmos simétricos de criptografia são muito mais rápidos do que os algoritmos de criptografia assimétrica, pois estes últimos normalmente envolvem cálculos mais complexos, como exponenciação de valores muito grandes ou, mais recentemente, cálculos com curvas elípticas.

Uma outra grande dificuldade na criptografia simétrica é o elevado número de chaves necessárias na comunicação de $n$ pessoas, conforme vimos na equação (2.1). Claramente, quando temos um número muito grande de participantes na comunicação, teremos um número excessivo de chaves a serem gerenciadas, seja no momento de sua transmissão ou no armazenamento, o que trará uma dificuldade adicional para a criptografia simétrica.

Outro problema que ocorre na criptografia simétrica é a impossibilidade de irretratabilidade, uma vez que ambos os extremos da comunicação usam a mesma chave para criptografar uma mensagem e portanto, não é possível determinar qual dos dois é o autor do texto criptografado.

Na criptografia assimétrica, estas dificuldades acima não ocorrem, pois a co- 
municação é estabelecida sem haver troca de segredos, o uso de uma chave particular garante a irretratabilidade e o número de chaves necessárias para a comunicação de $n$ pessoas é da mesma ordem de grandeza do número de participantes, ou mais precisamente, exatamente 0 dobro do número de pessoas, considerando que cada uma delas possui um par de chaves particular/ pública. Na tabela 2.1 podemos ver um quadro comparativo do número de chaves necessárias. Vimos, também, que quando Alice quer enviar uma mensagem para Beto usando

Tabela 2.1: Quantidade de chaves necessárias em uma comunicação entre $n$ participantes

\begin{tabular}{|c|c|c|}
\hline $\mathrm{N}^{\mathbf{0}}$ de participantes $(n)$ & Simétrica $\left(\frac{n(n-1)}{2}\right)$ & Assimétrica $(2 n)$ \\
\hline \hline 2 & 1 & 4 \\
\hline 4 & 6 & 8 \\
\hline 8 & 28 & 16 \\
\hline 16 & 120 & 32 \\
\hline
\end{tabular}

criptografia assimétrica, ela recorre a um diretório público para ter acesso a chave pública de Beto. Uma outra forma de Alice ter acesso a essa chave seria recebê-la diretamente de Beto. Mas como Alice pode ter certeza de que essa chave pertence realmente a Beto? E se um intruso mal-intencionado enviasse sua chave pública para Alice, dizendo ser a chave de Beto, ou se conseguisse alterar o diretório público? Para que esse problema possa ser evitado, surgiu a necessidade de autenticar as chaves públicas através de certificados digitais, assinados por uma entidade que possui fé pública, chamada de autoridade certificadora. Veremos esse processo com maiores detalhes na seção 2.3 .

A principal dificuldade na criptografia assimétrica está na obrigatoriedade de certificação das chaves públicas por meio de certificados digitais. Estes certificados precisam ser assinados por autoridades certificadoras, cujas chaves públicas também foram assinadas por outras autoridades certificadoras, e assim por diante, até que chegamos na chamada autoridade certificadora raiz, em quem devemos confiar, pois ela própria certifica sua chave pública. Esse caminho de certificação, desde a entidade final (usuário) até a autoridade raiz, motivou a criação de uma infra-estrutura de chaves públicas, que no Brasil é chamada de ICP-Brasil. Essa infra-estrutura, à medida que aumenta o número de participantes na comunicação, torna- 
se extremamente complexa e difícil de ser gerenciada, e pode ser apontada como uma outra dificuldade na criptografia assimétrica.

Outro grande problema na criptografia assimétrica ocorre quando há o comprometimento de uma chave particular, sendo necessária uma solicitação de revogação de um certificado. Na maioria das vezes o usuário não sabe imediatamente que sua chave foi comprometida, e desde esse momento até o momento em que seu certificado é efetivamente revogado e é publicada uma nova lista de certificados revogados, a segurança pode ter sido seriamente comprometida. Veremos com maiores detalhes os certificados digitais na seção seguinte.

Daqui por diante, sempre que nos referirmos à criptografia assimétrica padrão PKI estudada nesta seção, iremos chamá-la de criptografia assimétrica tradicional. Na tabela 2.2 fazemos um pequeno resumo das principais dificuldades apresentadas pelas criptografias simétrica e assimétrica.

Tabela 2.2: Dificuldades nas criptografias simétrica e assimétrica

\begin{tabular}{|c|l|}
\hline Criptografia & Dificuldade \\
\hline \hline Simétrica & $\begin{array}{l}\text { • Como distribuir e armazenar as chaves secretas de forma segura. } \\
\text { — Quantidade de chaves necessárias para uma comunicação segura entre } n \text { pessoas. } \\
\text { - Impossibilidade de irretratabilidade. }\end{array}$ \\
\hline Assimétrica & $\begin{array}{l}\text { - Como garantir que o detentor da chave pública é realmente quem diz ser. } \\
\text { - Necessidade de uma infra-estrutura para armazenar as chaves públicas. } \\
\text { - Tempo decorrido entre o comprometimento de uma chave e sua revogação. }\end{array}$ \\
\hline
\end{tabular}

\subsection{Infra-estrutura de Chaves Públicas (ICP)}

Vimos na seção 2.2 que na criptografia assimétrica tradicional, precisamos ter certeza de que uma determinada chave pública de fato pertence a um usuário, ou seja, precisamos autenticar uma chave pública. Comentamos brevemente que essa autenticação é conseguida por meio de um certificado digital assinado por uma entidade que possua fé pública. Cabe ressaltar que existem outras formas de se autenticar uma chave pública sem que seja 
necessário o uso de certificados, como por exemplo usando o software PGP (Pretty Good Privacy) criado por P. Zimmermann (disponível em http : / / www .pgpi . org).

Podemos fazer uma analogia, dizendo que o certificado digital é um documento registrado em cartório que comprova que uma chave realmente pertence a um determinado usuário, onde o cartório seria representado por essa tal entidade, chamada de Autoridade Certificadora. Veremos nesta seção a infra-estrutura necessária ao processo de verificação da autenticidade de uma chave pública por meio de um certificado digital, que é conhecida como infra-estrutura de chaves públicas. É importante observar que o objetivo desta seção é dar uma visão geral dessa infra-estrutura, focando nas principais dificuldades encontradas. Caso o leitor queira maiores detalhes de como funciona a infra-estrutura de chaves públicas no Brasil (chamada de ICP BRASIL), poderá consultar a crítica feita por Ricardo Custódio [Custodio 2001].

\subsubsection{Definições}

Veremos a seguir as definições dos principais termos empregados na infraestrutura de chaves públicas. A maioria das definições utilizadas foi retirada de notas de aula de R. Custódio [Custodio 2002].

\section{- Certificado Digital}

É um documento com formato padronizado (X-509), legível, assinado por uma autoridade certificadora, que serve para identificar um indivíduo, equipamento ou entidade. Sua principal função é autenticar chaves públicas. Contém os seguintes campos principais:

- Nome da Instituição;

- Chave pública da Instituição;

- Nome da Entidade Certificadora;

- Assinatura da Entidade Certificadora;

- Período de validade; 
- Número de série;

- Nome do domínio da Instituição;

- Algoritmo utilizado para assinar.

Na figura $2.4^{10}$, vemos o modelo de certificado digital padrão X-509. Na figura 2.5 vemos exemplos do certificado digital do Banco Bradesco, na forma como aparece na Internet.

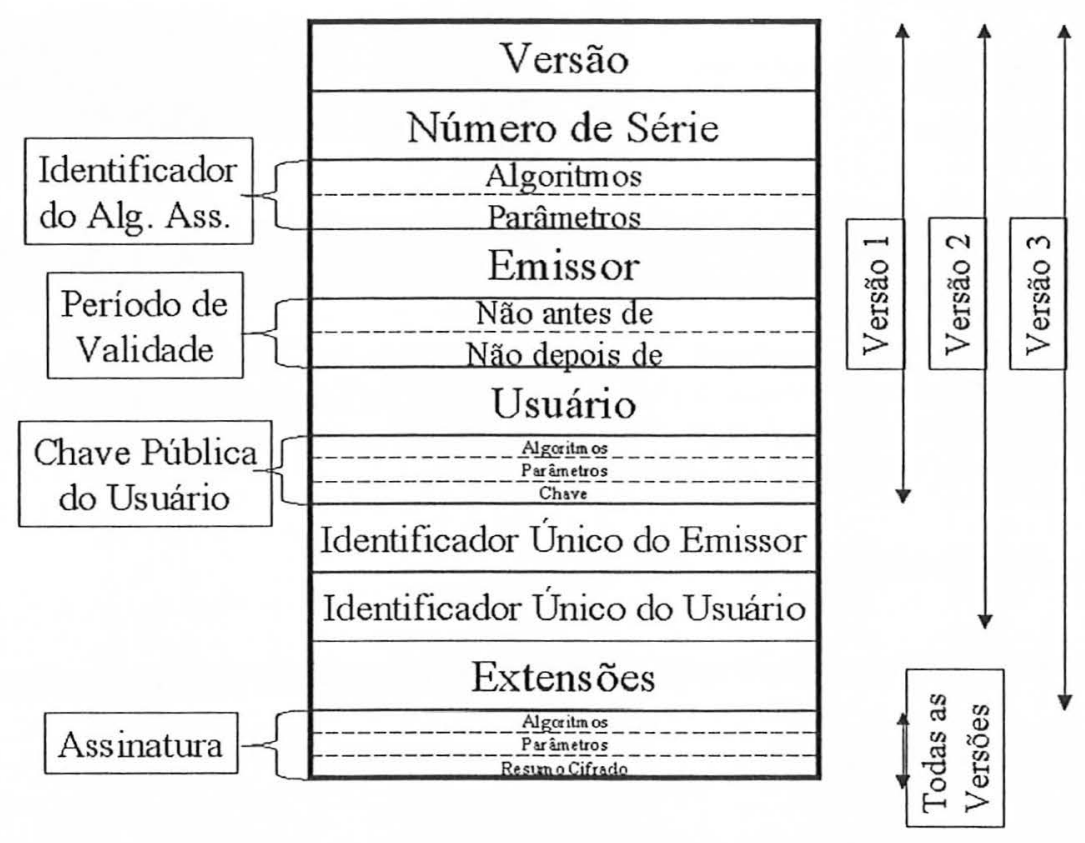

Figura 2.4: Modelo de certificado X-509 - Nesta figura, vemos as informações contidas no modelo de certificado digital padrão X-509.

\section{- Autoridade Certificadora}

Uma Autoridade Certificadora $(\mathrm{AC})$ é uma entidade jurídica com diversas atribuições, dentre as quais destacamos:

- Emissão de certificados digitais;

- Agendamento da data de expiração de um certificado;

- Publicação de certificados revogados em uma Lista de Certificados Revogados (LCR).

\footnotetext{
${ }^{10}$ Retirada de [Custodio 2002].
} 

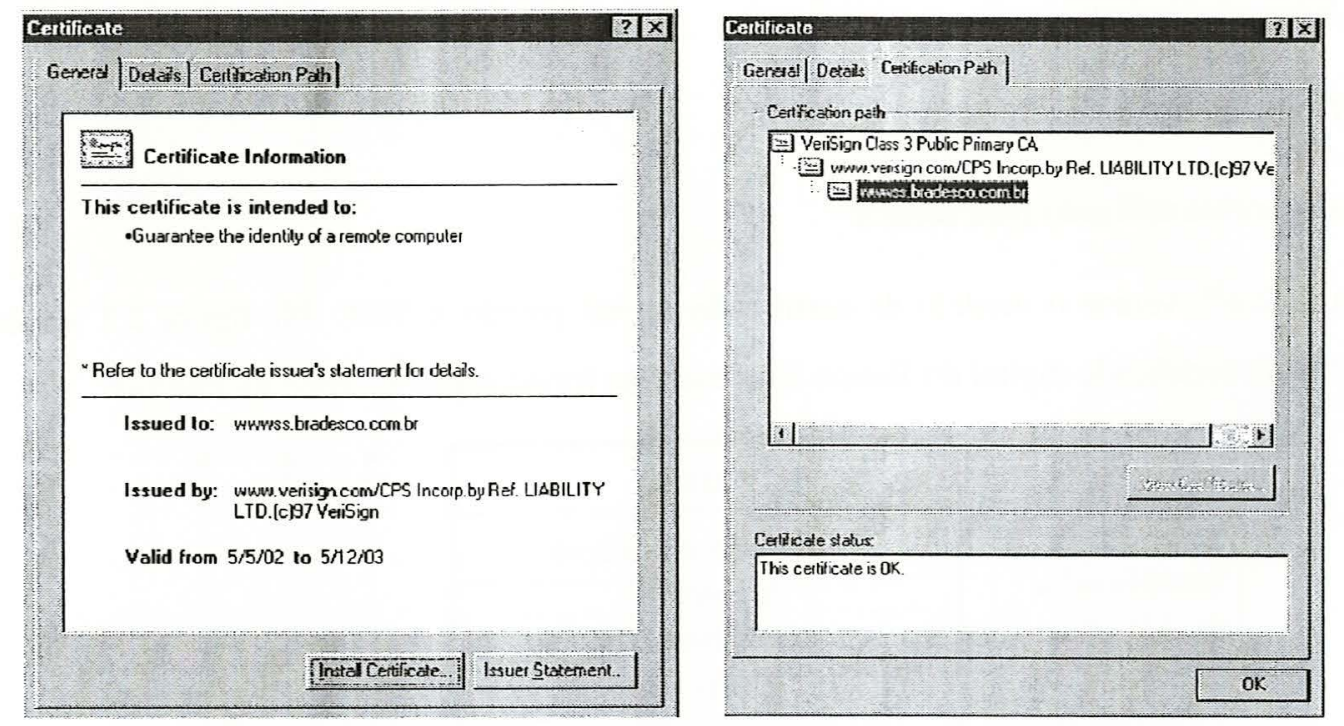

Figura 2.5: Exemplos de certificado digital - Vemos acima exemplos do certificado digital do banco Bradesco, conforme aparece na página http: / / www . bradesco. com . br. Na figura da esquerda vemos a página inicial do certificado, indicando quem emitiu, para quem e qual o período de validade; na figura da direita podemos ver o caminho de certificação e a indicação de que o certificado é válido.

\section{- Autoridade De Registro}

Uma Autoridade de Registro (AR) é uma entidade com as seguintes atribuições, dentre outras:

- Identificação dos usuários;

- Validação da solicitação de certificados;

- Submissão da solicitação de certificado à Autoridade certificadora.

\subsubsection{Obtenção de um certificado digital}

Para obter um certificado digital junto à uma autoridade certificadora, um usuário deve seguir os seguintes passos:

- Cliente gera um par de chaves pública e particular (por exemplo, usando RSA);

- Envia-se um pedido de certificado para a Autoridade de Registro;

- AR retransmite o pedido para a AC após fazer a prova de existência do requisitante e também a prova de posse da chave particular (i.e., pede ao requisitante que comprove a 
posse da chave particular por meio de um protocolo que o force a decriptografar alguma mensagem criptografada com sua chave pública);

- AC assina e envia o certificado;

- Usuário instala seu certificado;

- Usuário divulga o certificado.

PolíticA DE CERTIFICAÇÃo - A autoridade de registro, tendo a delegação de uma AC para tal, faz uma investigação no solicitante e determina se o pedido deve ser atendido e quais as características que deve ter.

\subsubsection{Modelos de certificação}

À medida que o tamanho de um sistema cresce, aumentando o número de usuários a solicitar certificados digitais, pode ser necessário haver mais de uma autoridade de registro e até mesmo mais de uma autoridade certificadora. Chamamos de modelo de certificação a forma como serão estruturadas hierarquicamente estas várias autoridades. Os dois modelos mais comuns são os modelos em árvore e em floresta de árvores.

No modelo em árvore, existe uma única autoridade certificadora, chamada AC raiz e diversas autoridades de registro subordinadas a essa AC. A grande vantagem desse modelo é que existirá um caminho único entre o usuário final e a autoridade que assinou o certificado. A desvantagem é que quando o número de usuários do sistema é muito grande, torna-se inviável existir apenas uma autoridade certificadora. Na figura $2.6^{11}$ vemos um modelo hierárquico em árvore.

No modelo em floresta de árvores, existem duas ou mais autoridades certificadoras, como pode ser visto na figura $2.7^{12}$.

Chamamos de certificação cruzada o processo pelo qual uma AC emite certificados para outras AC. A certificação cruzada pode ser utilizada tanto no mesmo domínio

\footnotetext{
${ }^{11}$ Retirada de [Custodio 2002].

${ }^{12}$ Retirada de [Custodio 2002].
} 


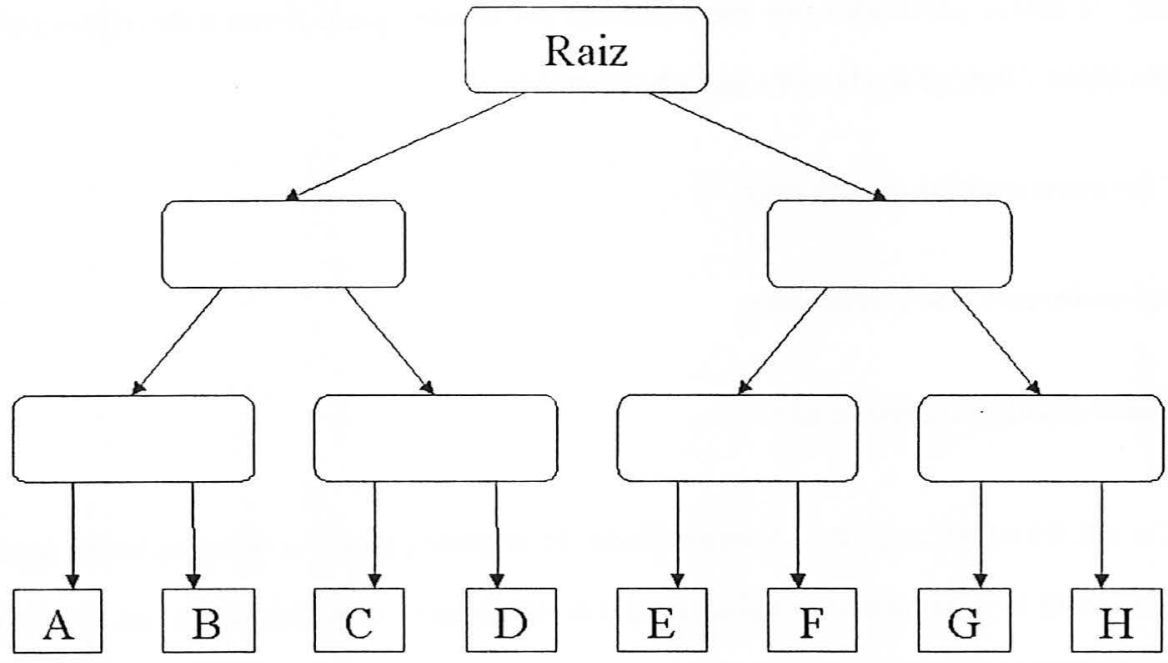

Figura 2.6: Modelo hierárquico em árvore - Neste modelo, existe uma única autoridade certificadora, chamada de $\mathrm{AC}$ raiz e diversas autoridades de registro subordinadas a essa $\mathrm{AC}$.

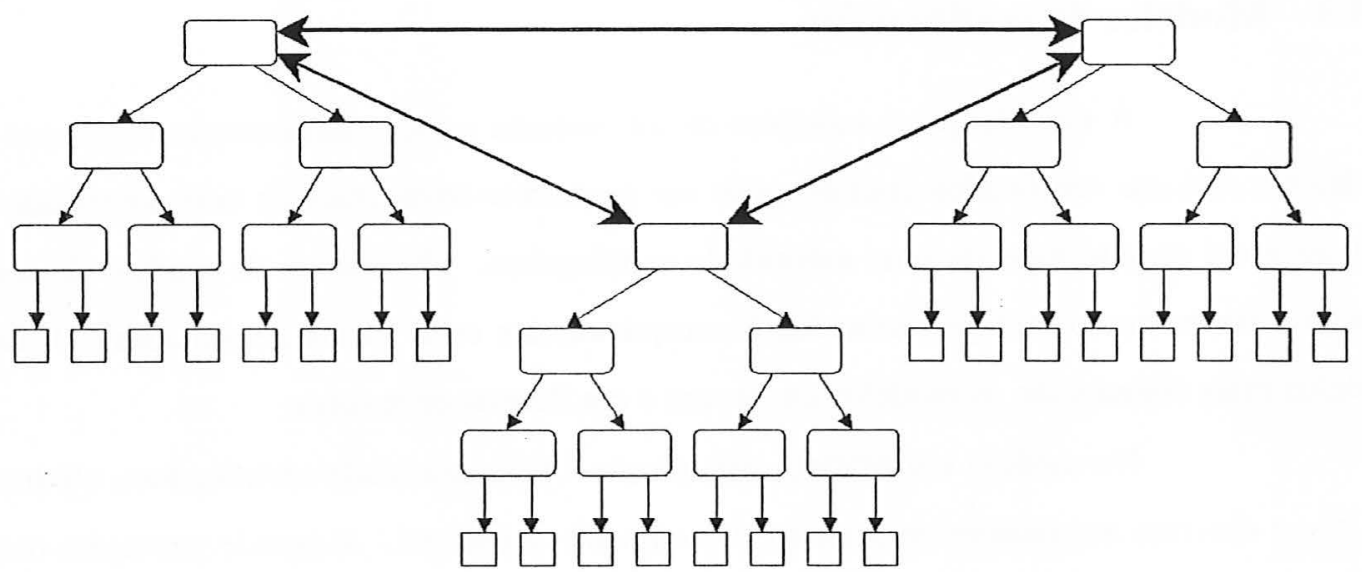

Figura 2.7: Modelo hierárquico em floresta - Neste modelo, existem duas ou mais autoridades certificadoras.

administrativo quanto entre domínios, podendo também ser utilizada em uma única direção ou em ambas.

\subsubsection{Caminhos de certificação}

Vimos que em sistemas com muitos usuários, pode haver mais de uma $\mathrm{AC}$ e, subordinadas a elas, várias AR. Dependendo do sistema, podem ainda existir diversas AR intermediárias entre o usuário e a AC que assinará o certificado. Chamamos caminho de cer- 
tificação à relação das autoridades que participaram do processo de emissão de um certificado digital, desde o usuário final até a autoridade que assinou o certificado.

As aplicações devem reconhecer o caminho de certificação, mesmo que este possua mais de uma AC. Não há confiança na chave pública, caso não seja possível determinar o caminho. Deve-se, portanto, buscar um ponto confiável. A dificuldade desse processo reflete a complexidade da infra-estrutura de chaves públicas.

Hipótese Fundamental DA INFRA-ESTRUTURA DE CHAVES PÚbliCAS - O Certificado da AC raiz é obtido através de um canal confiável e legítimo por todas as partes interessadas. A segurança de toda a hierarquia de certificação depende desta hipótese.

\subsubsection{Verificação de um certificado}

Quando recebemos um certificado digital, antes de usarmos a chave pública que consta nele, temos que fazer uma verificação da validade desse certificado, ou seja, temos que verificar se ele foi realmente assinado por uma autoridade certificadora e também, se não foi alterado durante o caminho de certificação por algum intruso. Descrevemos a seguir o processo de verificação de um certificado, processo esse que está representado na figura 2.8 .

- Ao receber um certificado digital assinado, aplicamos nele (deixando de fora apenas a assinatura) a função de espalhamento que foi utilizada para gerar o código. Essa função consta no corpo do certificado (ex. MD-5). ${ }^{13}$ Geramos, com isso, o código $c_{1}$;

- Usamos então a chave pública da autoridade de confiança que assinou o certificado (essa chave também consta no corpo do certificado) para verificar a assinatura da AC, de acordo com o sistema que foi usado para criptografar (e que também consta no certificado), gerando com isso, o código $c_{2}$;

- Finalmente, aceitamos o certificado como válido se e somente se $c_{1}=c_{2}$, caso contrário, descartamos o certificado;

${ }^{13}$ Sigla que representa Message $\quad$ Digest $\quad 5, \quad$ conforme $\quad$ [Terada 2000,
Menezes, Oorschot e Vanstone 1997, Stallings 2002].


- Tal processo de verificação de certificados é feito automaticamente pelos navegadores (browsers).

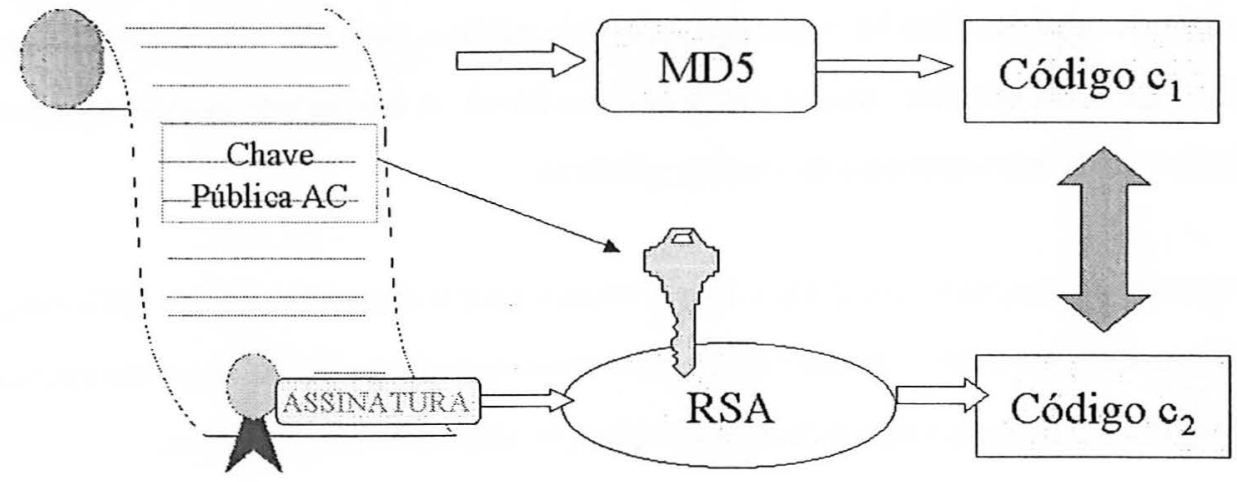

Figura 2.8: Verificação de um certificado - Ao receber um certificado digital assinado, aplicamos nele (deixando de fora apenas a assinatura) a função de espalhamento que foi utilizada para gerar o código. Essa função consta no corpo do certificado (ex. MD-5). Geramos, com isso, o código $c_{1}$. Usamos então a chave pública da autoridade de confiança que assinou o certificado (essa chave também consta no corpo do certificado) para decriptografar a assinatura da $\mathrm{AC}$, usando o mesmo algoritmo que foi usado para criptografar (no exemplo, RSA, que também consta no certificado), gerando com isso, o código $c_{2}$. Finalmente, aceitamos o certificado como válido se e somente se $c_{1}=c_{2}$, caso contrário, descartamos o certificado.

\subsubsection{Revogação de certificados}

Um Certificado pode ser revogado, caso haja comprometimento ${ }^{14}$ da chave particular da AC ou da entidade final (usuário) ou quando houver necessidade de alteração de qualquer informação constante no mesmo. Periodicamente, a AC emite e publica uma Lista de Certificados Revogados (LCR).

Um processo de revogação é constituído das seguintes etapas:

- Ocorrência de algum evento comprometedor (fato gerador da revogação);

- Solicitação de revogaçã̃o, feita pelo usuário à autoridade de registro;

- Revogação propriamente dita do certificado, pela autoridade certificadora;

- Publicação de uma nova lista de certificados revogados.

\footnotetext{
${ }^{14}$ Chamamos de comprometimento a revelação de uma informação a uma pessoa não autorizada.
} 
Podemos perceber que tal processo muitas vezes pode ser demorado, dependendo do tamanho da estrutura hierárquica. Somado a isso, muitas vezes o usuário nem sequer se dá conta de que sua chave foi comprometida, ou quando o faz, já ocorreu um intervalo de tempo muito grande.

Claramente, podemos notar que o intervalo de tempo compreendido entre o instante em que houve o fato gerador (evento comprometedor) e o instante em que é publicada uma nova lista de certificados revogados, representa uma grande brecha na segurança do sistema, pois a chave particular que foi comprometida pode ser usada por terceiros durante todo esse intervalo de tempo. Este é um dos grandes problemas da criptografia assimétrica tradicional e não ocorre na criptografia assimétrica baseada em identidades, tendo em vista que nesta não há certificados a serem revogados (veremos, quando estudarmos as aplicações de sistemas criptográficos baseados em identidades, que existe uma forma de limitarmos o tempo de vida de um par de chaves).

\subsubsection{Principais problemas e vulnerabilidades da ICP}

Resumiremos a seguir os principais problemas e vulnerabilidades da infraestrutura de chaves públicas.

- É NeCESSÁRio MANTER UM diRETório de chaVEs PÚblicas.

Este problema está relacionado com o espaço necessário para o armazenamento dessas chaves, principalmente quando há um grande número de usuários no sistema;

- Dificuldade de gerenciamento da infra-estrutura de Chaves públicas. Vimos que a infra-estrutura de chaves públicas cuida do gerenciamento das chaves públicas de centenas ou milhares de usuários e, para tal, necessita de uma estrutura extremamente complexa, a fim de não ocorrerem falhas de segurança. Tal complexidade é crescente à medida que aumenta o número de usuários do sistema.

- É NeCESSÁRIo QUE SE FAÇA A VERIFICAÇÃo DE UM CERTIFICADo, ANTES DE USAR UMA CHAVE PÚBLICA.

Tal fato envolve um aumento no custo computacional de verificação, que pode se tornar 
muito grande a medida que temos um grande número de certificados a serem verificados, pois a verificação deve ser feita a cada vez que utilizamos uma chave pública;

- Tempo decorrido entre a ReVogaÇão de um Certificado e a publicaÇão de UMA NOVA LCR.

Tal problema já foi comentado anteriormente, pois pode acarretar em uma grave falha na segurança, sendo portanto, uma importante vulnerabilidade apresentada pela infraestrutura de chaves públicas;

- Impossibilidade de RecuperaÇão de uma chave particular, Quando isto SE FIZER NECESSÁRIO.

Esse fato pode levar a perda de informações importantes, como veremos na seção 3.6, no próximo capítulo.

\subsection{Resumo}

Apresentamos neste capítulo uma visão geral de criptografia e infra-estrutura de chaves públicas, com o objetivo de relacionar suas principais características, problemas e possíveis vulnerabilidades.

Vimos que a criptografia simétrica apresenta como principais problemas a necessidade de se estabelecer um canal seguro para negociação das chaves secretas, a dificuldade no gerenciamento dessas chaves, a medida que aumenta o número de participantes na comunicação e também a impossibilidade de irretratabilidade.

Relacionamos também os principais problemas da criptografia assimétrica, como a necessidade de provar a autenticidade do detentor de uma chave pública, a necessidade de um pesada infra-estrutura para gerenciamento das chaves e ainda a revogação de certificados, além de não ser possível a recuperação de chaves particulares, o que às vezes pode ser interessante.

É importante ressaltar que não nos preocupamos em estudar com detalhes toda a criptografia e toda a ICP, pois fugiria do escopo desta dissertação. A seguir, apresentaremos os sistemas criptográficos baseados em identidades, objetivo principal desta pesquisa. 


\section{Capítulo 3}

\section{Sistemas criptográficos baseados em identidades}

\subsection{Histórico e Introdução}

O conceito de sistemas baseados em identidades surgiu em 1984, com A. Shamir [Shamir 1984]. Nesse artigo, o autor propôs um novo modelo criptográfico, que permitiria a qualquer par de usuários se comunicar de forma segura, sem que fosse necessária a troca de chaves secretas, como ocorre na criptografia simétrica, e sem que fosse preciso utilizar certificados digitais para autenticar chaves públicas, que é o caso da criptografia assimétrica tradicional. Nesse novo modelo, segundo Shamir, existe um Gerador de Chaves Particulares (PKG - Private Key Generator), cuja principal função é gerar uma chave particular para um usuário solicitante e transmiti-la ao mesmo por um canal seguro. Naturalmente, antes de gerar e distribuir essa chave, o PKG fará uma cuidadosa investigação com o objetivo de autenticar o solicitante, da mesma forma que ocorre em uma verificação de identidade para emissão de certificados na criptografia assimétrica tradicional, como vimos no capítulo anterior.

Como "canal seguro", poderíamos imaginar que o solicitante compareça pessoalmente ao PKG, onde receberá sua chave particular gravada, por exemplo, em um cartão inteligente (smart card). Nesse caso, antes de receber sua chave particular, esse usuário deverá provar sua identidade. Diferentemente da criptografia assimétrica tradicional, após gerar e distribuir as chaves particulares, o PKG não precisa mais participar da comunicação, permitindo que a rede funcione de forma totalmente descentralizada. Além disso, neste novo modelo não 
é preciso que os centros coordenem suas atividades e nem mantenham lista de seus usuários, como vimos na infra-estrutura de chaves públicas. Ainda de acordo com Shamir, o modelo proposto é ideal para grupos fechados, como por exemplo em uma cadeia de lojas ou de bancos, onde a matriz pode fazer o papel de PKG.

O modelo proposto por Shamir baseia-se no esquema de criptografia assimétrica tradicional, sendo que, em vez de termos um par de chaves representadas por uma sequiência de bits, sendo uma aleatória e a outra calculada em função da primeira, como no caso do RSA, teremos como chave pública um identificador, ou seja, uma característica que identifique o usuário de forma única, de modo que ele não tenha como negar que essa informação diz respeito a ele. Como exemplos de identificador, poderíamos citar o número do CPF ou o endereço eletrônico (e-mail). A grande vantagem deste esquema é que, ao contrário da criptografia assimétrica tradicional, não há necessidade de se fazer um mapeamento entre uma chave pública e seu dono, haja vista que, nesse caso, a chave pública identifica o dono.

Uma outra vantagem é que, por não ser mais um número aleatório, um usuário Beto não precisa reservar espaço adicional para guardar as chaves públicas das pessoas com quem deseja se comunicar, pois pode usar sua própria lista de endereços eletrônicos. Tais características fazem com que a criptografia assimétrica baseada em identidades se assemelhe ao correio físico, ou seja, se você conhece o endereço de uma pessoa, você pode enviar-lhe uma mensagem, de modo que somente ela poderá ler. Com base no mesmo conceito, se Alice deseja enviar uma mensagem sigilosa para Beto, ela necessita apenas do endereço eletrônico de Beto, ou seja, não é preciso nem mesmo ter algum conhecimento sobre chaves ou protocolos de comunicação.

No mesmo artigo em que apresentou o modelo de sistema criptográfico baseado em identidades [Shamir 1984], Shamir propôs um esquema de assinatura, cuja segurança, assim como no RSA, se baseia na dificuldade de fatoração de números inteiros e considerou como um problema em aberto um esquema de criptografia ${ }^{1}$ baseado em identidades. Desde então, vários pesquisadores [Desmedt e Quaisquater 1986, Tanaka 1987, Tsuji e Itoh 1989, Maurer e Yacobi 1991] tentaram, sem sucesso, desenvolver um esquema de

\footnotetext{
'Nesse caso, criptografia é simplesmente a tradução de encryption, ao passo que no modelo criptográfico proposto por Shamir, o termo criptografia é empregado no seu sentido mais amplo.
} 
criptografia baseado em identidades, obedecendo a propriedade de não expor a chave particular do PKG. Algumas soluções propostas exigiam que os usuários não entrassem em conluio, em outras o PKG gastaria um tempo muito grande na geração de cada chave particular solicitada e em outras havia a necessidade de que o hardware fosse resistente a fraudes. Somente com o esquema proposto por D. Boneh e M. Franklin [Boneh e Franklin 2001], baseado em propriedades de curvas elípticas, conseguiu-se uma solução satisfatória para criptografia com chaves baseadas em identidades.

Veremos nas seções seguintes as notações que serão utilizadas ao longo desta dissertação, os conceitos principais de criptografia com curvas elípticas, fundamentais para o entendimento e desenvolvimento do restante desta dissertação, os conceitos de criptografia e assinatura baseados em identidades e, finalmente, comentaremos as principais vantagens e desvantagens de um esquema baseado em identidades. Outros conceitos importantes, porém não fundamentais para o entendimento desta dissertação, são apresentados no anexo A.

\subsection{Definições e notações iniciais}

Um sistema de criptografia baseado em identidades envolve uma série de notações e conceitos matemáticos, que nesta seção serão elucidados, para possibilitar um melhor entendimento do leitor.

\subsubsection{Gerador de chaves particulares $(\mathrm{PKG})$}

Definiremos gerador de chaves particulares, também conhecido como autoridade de confiança (TA) ou ainda como centro gerador de chaves (KGC), como uma entidade idônea que tem como principal objetivo gerar uma chave particular baseada em identidades, a partir do identificador de um usuário solicitante, e transmitir essa chave ao mesmo por um canal seguro. A fim de garantirmos o sucesso dos esquemas baseados em identidades que iremos apresentar, vamos considerar a hipótese de que a idoneidade desse PKG é inquestionável, ou seja, podemos confiar nele incondicionalmente. Vamos então nos referir ao PKG "totalmente idôneo" como autoridade de confiança (TA). 


\subsubsection{Problema do Logaritmo Discreto (PLD)}

Muitos sistemas criptográficos baseiam-se na dificuldade computacional do Problema do Logaritmo Discreto, definido da seguinte forma:

Dados um número primo $p$ e números inteiros $g$, $t$, tais que $0<g, t<p$, calcular um inteiro s tal que

$$
t=g^{s} \bmod p
$$

Para números pequenos, conseguimos calcular $s$ pelo método conhecido como "força bruta", ou seja, atribuímos valores para $s$, até que o resultado desejado seja encontrado. Veja no exemplo ilustrativo a seguir:

Exemplo 1: Para $p=13, g=2$ e $t=12$, calcular $s$ tal que $12=2^{s} \bmod 13$.

\begin{tabular}{|c|c|}
\hline$s$ & $2^{s} \bmod 13$ \\
\hline \hline 0 & 1 \\
\hline 1 & 2 \\
\hline 2 & 4 \\
\hline 3 & 8 \\
\hline 4 & 3 \\
\hline 5 & 6 \\
\hline 6 & $\mathbf{1 2}$ \\
\hline
\end{tabular}

Resposta: O valor de $s$ é 6 .

Entretanto, a medida que o valor de $p$ aumenta, tal método se torna inviável. Ainda não se conhece nenhum algoritmo de tempo polinomial - pelo menos até o momento em que foi escrita esta dissertação - que resolva o problema do logaritmo discreto. Portanto, o PLD se enquadra na classe de problemas computacionalmente difíceis e, devido a isto, é usado em sistemas criptográficos.

\subsubsection{PLD em Curvas Elípticas (PLD - CE)}

O PLD escrito em notação multiplicativa tem aplicação em curvas elípticas e é chamado de "Problema do Logaritmo Discreto em Curvas Elípticas", sendo enunciado da seguinte forma: 
Dados dois pontos $R, P$, de uma curva elíptica definida sobre um corpo finito, achar um inteiro s tal que ${ }^{2}$

$$
R=s P \text {. }
$$

Veremos a seguir a dificuldade no cálculo do logaritmo discreto sobre curvas elípticas:

Dados $R$ e $P$, calcular $s$ tal que $R=s P$.

Solução: testar todos os valores possíveis de $s$ até encontrar $s P=R$.

Pior caso : $\Omega(r)$ tentativas, utilizando busca exaustiva, onde $r$ é o número de pontos que satisfazem à equação da curva. O tempo para encontrar $s$ é exponencial em relação ao número de bits de $r$. Se $k=\lg r$, então teremos, no pior caso, $\Omega\left(2^{k}\right)$ tentativas.

Segundo [Barreto 1999], algoritmos que utilizam busca exaustiva não fazem uso da estrutura do grupo ${ }^{3}$ para calcular o PLD e são essencialmente exponenciais. Nessa classe, o melhor algoritmo que se conhece é o $\rho$ de Pollard [Menezes, Oorschot e Vanstone 1997], que consegue calcular o PLD em $\Omega\left(2^{k / 2}\right)$ tentativas. Ainda assim, para valores suficientemente grandes de $q$ (por exemplo, $q \sim 2^{160}$ ), o PLD-CE é intratável em curvas definidas sobre $\mathbb{F}_{q}$.

Existem algumas técnicas para calcular o PLD que usam a estrutura do grupo e que podem ser calculadas em tempo sub-exponencial. Entretanto, tais técnicas só se aplicam a determinados grupos. Dentre essas técnicas, podemos destacar o cálculo de índices [Menezes, Oorschot e Vanstone 1997] e o ataque de MOV [Menezes, Oorschot e Vanstone 1997]. Este último mapeia o PLD da curva sobre $\mathbb{G}_{1}$ para um PLD da curva sobre $\mathbb{G}_{2}$. Podemos dizer que um sistema é resistente ao ataque MOV se o PLD for intratável em $\mathbb{F}_{q^{k}}$.

Até hoje o PLD-CE é considerado um problema matemático intratável para escolhas apropriadas de $q$ e $k$ (por exemplo, $k \lg q \sim 1024$ ).

No anexo A e em [Silverman 1986] e [Barreto 1999] o leitor encontrará as principais operações utilizadas em curvas elípticas. Para prosseguir com o entendimento deste capítulo, porém, basta apenas ter em mente que, da equação (3.1), o valor $s$ está protegido pelo PLD - CE, ou seja, "para uma escolha apropriada do tamanho do corpo sobre o qual a curva está

\footnotetext{
${ }^{2}$ Podemos interpretar "s $P$ " na equação (3.1) como sendo $\underbrace{P+P+P+\ldots+P}_{S \text { vezes }}$.

${ }^{3}$ A definição algébrica de grupo, subgrupo, ordem e corpo finito encontra-se no anexo A.
} 
definida, é computacionalmente inviável se calcular $s$, dado que conhecemos os pontos $R$ e $P$ ".

\subsubsection{Curvas elípticas}

Seja $\mathbb{Z}_{q}$ o conjunto de inteiros módulo $q$ e $\mathbb{F}_{q}$ um corpo finito de ordem $q$, onde $q>3$ é um número primo (se $q$ é primo, então $\mathbb{Z}_{q}$ coincide com $\mathbb{F}_{q}$ ).

A curva ${ }^{4}$ elíptica $y^{2}=x^{3}+a x+b$ sobre $\mathbb{F}_{q}$ é o conjunto de soluções $(x, y) \in \mathbb{F}_{q} \times \mathbb{F}_{q}$ para a congruência:

$$
y^{2} \equiv x^{3}+a x+b \quad(\bmod q)
$$

onde $a, b \in \mathbb{F}_{q}$ são constantes tais que

$$
4 a^{3}+27 b^{2} \neq 0 \quad(\bmod q)
$$

juntamente com um ponto especial $\mathcal{O}$, chamado de ponto no infinito.

Mais formalmente, temos: $E\left(\mathbb{F}_{q}\right) \equiv\left\{(x, y) \in \mathbb{F}_{q} \times \mathbb{F}_{q} \mid y^{2}=x^{3}+a x+b\right\} \cup\{\mathcal{O}\}$

O termo $4 a^{3}+27 b^{2}$ na equação (3.3) representa o discriminante de uma equação cúbica e, segundo P. Barreto [Barreto 1999], deve ser diferente de zero para garantir que o polinômio $f(x)=x^{3}+a x+b$ não tenha raízes múltiplas, sendo possível, desta forma, traçar a reta tangente a qualquer ponto da curva. Caso tal condição seja satisfeita, os pontos da curva definida sobre $\mathbb{F}_{q}$ definirão uma lei de grupo, onde a identidade é o ponto $\mathcal{O}$ (pois $P+\mathcal{O}=P$ ) e o elemento neutro é o ponto simétrico em relação ao eixo das abscissas, i.e., $-P($ pois $P+(-P)=\mathcal{O})$.

Uma curva elíptica $E$ definida sobre $\mathbb{F}_{q}(q$ primo, $q>3)$ tem aproximadamente $q$ pontos sobre ela. Tal afirmação decorre do teorema de Hasse:

Teorema 3.2.1 (Hasse) O número de pontos sobre E, denotado por \#E, é chamado ordem da curva e satisfaz à seguinte desigualdade:

$$
\# E \leqslant q+1-t
$$

\footnotetext{
${ }^{4}$ Segundo [Barreto 1999], o nome "curva" é um abuso de linguagem. Embora o gráfico da equação $y^{2}=x^{3}+a x+b$ sobre $\mathbb{R}$ tenha realmente o aspecto de uma curva, a mesma equação sobre um outro corpo pode determinar um conjunto discreto de pontos.
} 
Onde $|t| \leqslant 2 \sqrt{q}$ é conhecido na literatura como traço de Frobenius da curva. O valor exato de \#E pode ser calculado pelo algoritmo de R. Schoof [Schoof 1985], eficiente mesmo para primos com várias centenas de dígitos.

Veremos a seguir mais algumas definições, segundo [Barreto 1999, Barreto, Lynn e Scott 2003, Barreto et al. 2002], utilizadas em criptografia com curvas elípticas e que são importantes para o entendimento da implementação de um sistema baseado em identidades.

- ordem de um ponto - é o menor inteiro positivo $z$ tal que $z \cdot P=\mathcal{O}$;

- grau de imersão (embedding degree) - "um subgrupo $\mathbb{G}$ de uma curva elíptica $E\left(\mathbb{F}_{q}\right)$ é dito ter grau de imersão $k$ se sua ordem $r$ divide $q^{k}-1$, mas não divide $q^{i}-1$ para todo $0<i<k$ ". Em outras palavras, $k$ é o menor inteiro tal que $r \mid\left(q^{k}-1\right)$.

O grupo $E\left(\mathbb{F}_{q}\right)$ é isomorfo ao grupo $E\left(\mathbb{F}_{q^{k}}\right)$. Sendo assim, se $P$ é um ponto de ordem $r$ em $E\left(\mathbb{F}_{q}\right), E\left(\mathbb{F}_{q^{k}}\right)$ contém um ponto $Q$ de mesma ordem, linearmente independente a $P$. Um alto grau de imersão é importante para que possamos ter um elevado nível de segurança em sistemas criptográficos baseados em curvas elípticas. Por outro lado, é possível fazer importantes simplificações usando curvas com pequeno grau de imersão.

Desta forma, procuraremos trabalhar com curvas onde o grau de imersão seja grande o bastante para que consigamos um nível de segurança adequado e ao mesmo tempo, pequeno o suficiente para permitir simplificações que significam aumento do desempenho.

\subsubsection{Curvas não adequadas para criptografia}

Vimos que a equação (3.3) deve ser satisfeita, para que seja possível definirmos uma lei de grupos sobre os pontos da curva. As curvas elípticas em que $4 a^{3}+27 b^{2}=0 \quad(\bmod q)$ são conhecidas como singulares ou degeneradas e não podem ser usadas para criptografia.

Além das curvas singulares, existem curvas que são consideradas totalmente impróprias para criptografia, como é o caso das curvas ditas anômalas - cuja ordem é igual ao 
tamanho do corpo sobre o qual está definida. Em outra palavras: $r=\# E=q$. Tais curvas são inadequadas pois nelas o logaritmo discreto pode ser resolvido em tempo polinomial.

Uma outra classe de curvas que merece destaque em criptografia são as curvas ditas supersingulares. Uma curva é dita supersingular se o seu traço de Frobenius $t$ é múltiplo da característica $p$ do corpo sobre a qual a curva está definida, ou seja se $t \mid p$. Um fato importante em curvas supersingulares é que nelas o grau de imersão $k$ é sempre menor ou igual a 6. Isto possibilita um ataque conhecido como MOV [Menezes, Oorschot e Vanstone 1997], onde o logaritmo discreto de um grupo elíptico pode ser mapeado para o grupo multiplicativo de um corpo finito, onde existem algoritmos sub-exponenciais.

Entretanto, se o tamanho de $q$ for escolhido adequadamente, o PLD em E $\left(\mathbb{F}_{q^{k}}\right)$ pode ser tornado intratável mesmo se $k$ for pequeno. Por exemplo, suponha que o tamanho de $q$ é aproximadamente 160 bits, de modo que o PLD em E $\left(\mathbb{F}_{q}\right)$ seja normalmente intratável. Agora suponha que $k=2$, isto é, o tamanho do corpo estendido é de aproximadamente 320 bits. Aqui o PLD é “facilmente” solucionável [Menezes, Vanstone e Okamoto 1991] e a redução MOV permite usar esse fato para resolver o PLD em $\mathrm{E}\left(\mathbb{F}_{q}\right)$. No exemplo acima, se o tamanho do corpo estendido fosse de aproximadamente 512 bits a redução MOV seria inócua. O uso de curvas supersingulares, por esta razão, é desaconselhado em aplicações práticas, por estarem mais sujeitas a ataques.

Por outro lado, as curvas supersingulares são muito eficientes em desempenho. Usando curvas supersingulares, é possível calcular o emparelhamento entre dois pontos usando o algoritmo simplificado de Miller, proposto por Barreto et al. [Barreto, Lynn e Scott 2003]. Essa otimização consegue um ganho de cerca de 125 vezes [Barreto 2003] em relação aos métodos anteriormente conhecidos de cálculo de emparelhamento.

Mais recentemente, I. Duursma e H. Lee [Duursma e Lee 2003] propuseram um algoritmo que pode ser usado com curvas hiper-elípticas supersingulares e que para o caso particular de curvas (elípticas) de característica 3 é mais eficiente que uma verificação ou decriptografia RSA para o mesmo nível de segurança.

As curvas não-supersingulares usadas em criptografia são normalmente chamadas de curvas ordinárias. 


\subsubsection{Emparelhamento}

Sejam $\mathbb{G}_{1}$ e $\mathbb{G}_{2}$ dois grupos de ordem $q$, para algum número primo $q$ muito grande. Definimos emparelhamento (pairing) como um mapeamento ê entre esses grupos, tal que:

$$
\hat{e}: \mathbb{G}_{1} \times \mathbb{G}_{1} \rightarrow \mathbb{G}_{2}
$$

Tal mapeamento, para que possa ser usado em sistemas baseados em identidades, deve satisfazer às seguintes propriedades, segundo D. Boneh e M. Franklin [Boneh e Franklin 2001]:

1. Ser bilinear: dizemos que um mapeamento $\hat{e}: \mathbb{G}_{1} \times \mathbb{G}_{1} \rightarrow \mathbb{G}_{2}$ é bilinear se

$$
\hat{e}(a P, b Q)=\hat{e}(P, Q)^{a b} \quad \forall P, Q \in \mathbb{G}_{1} \mathrm{e} \forall a, b \in \mathbb{Z}
$$

2. Ser não-degenerado: um mapeamento é dito não-degenerado se não mapeia todos os pares $\mathbb{G}_{1} \times \mathbb{G}_{1}$ para a identidade em $\mathbb{G}_{2}$. Observe que como $\mathbb{G}_{1}$ e $\mathbb{G}_{2}$ são grupos de ordem prima, isto implica que se $P$ é um gerador ${ }^{5}$ de $\mathbb{G}_{1}$, então $\hat{e}(P, P)$ é um gerador de $\mathbb{G}_{2}$.

3. Ser computável: dizemos que um mapeamento é computável se existe um algoritmo eficiente (i.e., tempo polinomial) para computar $\hat{e}(P, Q)$ para todo $P, Q \in \mathbb{G}_{1}$.

Um mapeamento que satisfaça tais propriedades é dito um mapeamento admissível. Os emparelhamentos de Weil e Tate são exemplos de mapeamentos admissíveis para os grupos $\mathbb{G}_{1}$ e $\mathbb{G}_{2}$. Estudaremos com mais detalhes o emparelhamento de Tate pois [Galbraith, Harrison e Soldera 2002, Barreto et al. 2002, Barreto, Lynn e Scott 2003] mostram que sua implementação é mais eficiente.

\subsubsection{Emparelhamento de Tate}

Para implementar esquemas baseados em identidades (ou algoritmos relacionados) precisamos de um mapeamento bilinear computável e não degenerado. Podemos conseguir tal mapeamento, dito admissível, com os emparelhamentos de Weil ou de Tate. Consideraremos a seguir o emparelhamento de Tate, por ser mais eficiente que o de Weil:

\footnotetext{
${ }^{5}$ Se $g$ é gerador de $\mathbb{F}_{q}$, então $g^{j} \bmod q$ apresenta $\mathbb{F}_{q}$ como imagem, $\forall j, 0 \leqslant j<p$.
} 
Define-se o emparelhamento de Tate $\left(e_{t}\right)$ entre pontos linearmente independentes $P$ e $Q$ da curva $E\left(\mathbb{F}_{q^{k}}\right)$, sendo $k$ o grau de imersão da curva considerada. O primeiro argumento deve ser de ordem $r$; na prática, costuma-se tomar $P$ sobre a curva $E\left(\mathbb{F}_{q}\right)$. O emparelhamento $e_{t}(P, Q)$ assume valores no corpo finito estendido $\mathbb{F}_{q^{k}}$. Mais formalmente, temos:

$$
e_{t}: E\left(\mathbb{F}_{q}\right)[r] \times E\left(\mathbb{F}_{q^{k}}\right) \rightarrow \mathbb{F}_{q^{k}}^{*}
$$

Dependendo dos parâmetros da curva utilizada, poderemos calcular o emparelhamento através do algoritmo de Miller simplificado, usando como referência o artigo de Barreto et al. [Barreto, Lynn e Scott 2003]. No capítulo 8 descrevemos a algoritmo de Miller simplificado, usado para calcular o emparelhamento de Tate em curvas ordinárias com característica $p>3$ e grau de imersão par ou em curvas supersingulares, sem contudo, entrarmos em detalhes sobre esse algoritmo. Uma definição minuciosa do emparelhamento de Tate envolve álgebra pesada, como por exemplo teoria de divisores e foge ao escopo desta dissertação. Caso o leitor queira obter maiores detalhes, poderá consultar as referências [Barreto et al. 2002, Barreto, Lynn e Scott 2003, Boneh e Franklin 2001, Galbraith, Harrison e Soldera 2002].

A idéia essencial é que o emparelhamento de Tate é uma função racional $e_{t}: E\left(\mathbb{F}_{q}\right)[r] \times E\left(\mathbb{F}_{q^{k}}\right) \rightarrow \mathbb{F}_{q^{k}}^{*}$.

Isto significa que, se $P=(u, v)$ e $Q=(x, y)$, o emparelhamento tem a forma

$$
e(P, Q)=\frac{N(u, v, x, y)}{D(u, v, x, y)}
$$

onde $N$ e $D$ são polinômios primos entre si.

Na prática, não dá para escrever esses polinômios por extenso. Miller descobriu como calcular o valor do emparelhamento mesmo sem uma fórmula explícita. O truque é escrever os polinômios acima como composições de polinômios de grau pequeno (normalmente de grau 1, mas há otimizações que usam grau 2). Grande parte da dificuldade na implementação do algoritmo de Miller está no fato de que sua versão original está em um manuscrito não publicado [Miller 1986] e várias versões posteriores foram publicadas incorretamente.

Especificamente, Miller percebeu que, considerando $P$ como fixo e $Q$ como variável, é possível escrever

$$
e(P, Q)=\frac{f\left(x_{0}, y_{0}\right)}{f\left(x_{1}, y_{1}\right)}
$$


onde $f$ é uma função racional cujos coeficientes só dependem de $u$ e $v$ e os valores $x_{0}, y_{0}, x_{1}, y_{1}$ dependem de $x$ e $y$. Mais ainda, Miller mostrou que $f(x, y)$ tem um aspecto semelhante a:

$$
f(x, y)=\frac{\left[(3 x-y+4)^{a} \cdot(x+5 y-9)^{b} \cdot \ldots \cdot(2 x+6 y+5)^{c}\right]}{\left[(2 x-7)^{a} \cdot(x+8)^{b} \cdot \ldots \cdot(2 x+8)^{c}\right]}
$$

Isso sugere que $f(x, y)$ pode ser calculado com uma fórmula recorrente. Miller fez exatamente isso, percebendo que os coeficientes e os expoentes dos termos acima dependem de $u, v$ e da ordem $r$ de $P$, e que esses valores tornam-se imediatamente disponíveis durante o cálculo de $r P$.

No algoritmo simplificado [Barreto, Lynn e Scott 2003], todos os denominadores acima (os de $f$ e o polinômio $D$ inteiro) são eliminados por conta da exponenciação final do emparelhamento de Tate.

Baseados na definição do emparelhamento de Tate, quando formos implementar um sistema baseado em identidades será necessário calcularmos o emparelhamento entre pontos linearmente independentes $P$ e $Q$.

De acordo com a definição, como o ponto $P \in \mathbb{F}_{q}$, pode ser representado como um par de inteiros $(x, y) \bmod q$. Quanto ao ponto $Q$, como $Q \in \mathbb{F}_{q^{k}}$, deverá ser representado por um par de polinômios $(x(u), y(u))$, onde cada polinômio tem grau maior que $k \mathrm{e}$ coeficientes em $\mathbb{F}_{q}$. Além disso, todas as operações algébricas em $\mathbb{F}_{q^{k}}$ são efetuadas módulo um polinômio irredutível de grau $k$, sendo os coeficientes reduzidos mod $q$.

\subsubsection{Nomenclatura utilizada nesta dissertação}

Para que possamos implementar sistemas criptográficos baseados em identidade, é necessário tomarmos grupos onde o problema do logaritmo discreto é aparentemente difícil (i.e., não se conhece algoritmo eficiente para resolvê-lo) e existe um mapeamento admissível.

Sejam:

$q$ : número primo longo; ${ }^{6}$

$\mathbb{G}_{1}, \mathbb{G}_{2}$ : grupos onde existe um mapeamento admissível e o PLD é supostamente difícil; $e_{t}: \mathbb{G}_{1} \times \mathbb{G}_{2} \rightarrow \mathbb{G}_{3}:$ emparelhamento de Tate.

\footnotetext{
${ }^{6}$ Em termos práticos, $q$ é da ordem de $2^{160}$.
} 
A partir deste ponto, iremos escrever os grupos $\mathbb{G}_{1}$ e $\mathbb{G}_{2}$ em notação aditiva e $\mathbb{G}_{3}$ em notação multiplicativa, e considerar:

- $\mathbb{G}_{1}$ : subgrupo do grupo aditivo de pontos de uma curva elíptica sobre $\mathbb{F}_{q}$, ou simplesmente $\mathrm{E}\left(\mathbb{F}_{q}\right)$;

- $\mathbb{G}_{2}$ : subgrupo do grupo aditivo de pontos de uma curva elíptica sobre $\mathbb{F}_{q^{k}}$, ou simplesmente $\mathrm{E}\left(\mathbb{F}_{q^{k}}\right)$, onde $k \in \mathbb{Z}^{*}$ é o grau de imersão da curva considerada.

- $\mathbb{G}_{3}:$ subgrupo do grupo multiplicativo de um corpo finito $\mathbb{F}_{q^{k}}^{*}$

\subsubsection{Bilinearidade}

Na seção 3.2.4, definimos sucintamente bilinearidade através de uma de suas propriedades. Definiremos agora as demais propriedades de bilinearidade. Uma função $f$ é dita linear se valem as seguintes propriedades:

$$
f(x+y)=f(x)+f(y) \text { e } f(\alpha x)=\alpha f(x) .
$$

Uma função de duas variáveis é dita bilinear se ela for linear em relação a cada uma de suas variáveis, i.e.,

$$
f(x+y, z)=f(x, z)+f(y, z) \text { e } f(\alpha x, y)=\alpha f(x, y)
$$

e também:

$$
f(x, y+z)=f(x, y)+f(x, z) \text { e } f(x, \alpha y)=\alpha f(x, y) .
$$

Note que se $f$ for escrita em notação multiplicativa (como definimos o emparelhamento), reescrevemos as propriedades acima como:

$$
f(x+y, z)=f(x, z) \cdot f(y, z) \text { e } f(\alpha x, y)=f(x, y)^{\alpha} .
$$

Quando trabalhamos com curvas elípticas em criptografia, uma propriedade que utilizamos muito é a bilinearidade. Dizemos que um emparelhamento $e: \mathbb{G}_{1} \times \mathbb{G}_{2} \longrightarrow \mathbb{G}_{3}$ é bilinear se valem as seguintes propriedades (considere que $P \in \mathbb{G}_{1}, Q \in \mathbb{G}_{2}$ e $a, b, c \in \mathbb{Z}_{q}$ ): 
1. Propriedade distributiva em relação ao primeiro argumento

$$
e\left(P_{1}+P_{2}, Q\right)=e\left(P_{1}, Q\right) \cdot e\left(P_{2}, Q\right)
$$

2. Propriedade distributiva em relação ao segundo argumento

$$
e\left(P, Q_{1}+Q_{2}\right)=e\left(P, Q_{1}\right) \cdot e\left(P, Q_{2}\right)
$$

3. Das propriedades 3.5 e 3.6, decorre a terceira propriedade, que já havíamos citado na seção 3.2.4:

$$
e(a P, b Q) \stackrel{(3.6)}{=} e(a P, Q) \stackrel{b c}{\stackrel{(3.5)}{=}} e(P, Q) \cdot{ }^{a b c}
$$

Ressaltamos que a propriedade (3.7), que decorre das duas propriedades anteriores, será muito utilizada em todas as demonstrações de corretude dos protocolos que serão apresentados.

É importante destacar que, em termos computacionais, o cálculo de um emparelhamento tem ordem de grandeza maior do que uma exponenciação em $\mathbb{F}_{q}$ [Cha e Cheon 2002], sendo portanto, a operação de maior custo computacional em sistemas criptográficos baseados em identidades [Barreto et al. 2002].

\subsubsection{Segurança de sistemas baseados em identidades}

Vimos que a escolha do grupo sobre o qual a curva elíptica será definida é de suma importância, para que o PLD-CE se torne um problema intratável — pois caso contrário, seria fácil calcular o valor de $s$ dado que se conhece $P$ e $R=s P$. Entretanto, veremos que mesmo sem conseguir determinar $s$, um adversário conseguiria obter vantagens sobre um sistema baseado em identidades caso conseguisse resolver um problema conhecido como "problema Diffie-Hellman bilinear" (BDHP), que definiremos a seguir.

Antes de definir o BDHP, entretanto, vamos definir outros problemas, conhecidos como "problema Diffie-Hellman de decisão"(DDHP), "problema Diffie-Hellman computacional"(CDHP) e "problema Diffie-Hellman lacunar" (GDHP). As definições que daremos a seguir foram retiradas do artigo "Identity-based encryption from the Weil pairing" [Boneh e Franklin 2001] de D. Boneh e M. Franklin: 
- DDHP (Decision Diffie-Hellman problem) - Sejam $a, b, c, n \in \mathbb{Z}_{q}$ e $P \in \mathbb{G}$. Dados ( $P$, $a P, b P, c P) \subset \mathbb{G}$, decidir se $c=a b \bmod n$.

Observe que, sendo o PLD intratável, temos que o valor $a P$ é conhecido (sem perda de generalidade), mas não se conhece o valor de $a$.

Podemos notar, usando bilinearidade, que:

$$
c=a b \bmod n \Leftrightarrow e(P, c P)=e(a P, b P) .
$$

Portanto o DDHP é considerado um problema fácil em grupos onde exista um emparelhamento admissível.

- CDHP (Computational Diffie-Hellman problem) - Sejam $a, b \in \mathbb{Z}_{q}$ e $P \in \mathbb{G}$. Dados $(P$, $a P, b P) \subset \mathbb{G}$, calcular $a b P$. Claramente, se o PLD for tratável, CDHP pode ser resolvido sem maiores dificuldades.

Para uma escolha apropriada do grupo $\mathbb{G}$, não se conhece nenhum algoritmo subexponencial que resolva o CDHP.

- GDHP (Gap Diffie-Hellman problem)- Seja $\mathbb{G}$ um grupo onde o DDHP é tratável. O problema Diffie-Hellman lacunar (GDHP) consiste em resolver o CDHP em $\mathbb{G}$, dado que o DDHP é tratável em $\mathbb{G}$.

- BDHP (Bilinear Diffie-Hellman problem) - Este problema é uma variante do CDHP e é definido da seguinte forma:

$\operatorname{Dados}(P, a P, b P, c P) \subset \mathbb{G}$ calcular $e(P, P) \cdot{ }^{a b c}$

Além desses, existem também os chamados co-problemas (co-DDHP, coCDHP, co-GDHP, co-BDHP), envolvendo dois grupos em vez de um único grupo. Por simplicidade, definiremos apenas o co-BDHP, os demais são análogos:

- co-BDHP (co-Bilinear Diffie-Hellman problem) - Dados $(P, a P, b P) \subset \mathbb{G}_{1}$ e $Q \in \mathbb{G}_{2}$, calcular $e(P, Q)^{a b}$.

Note que o co-BDHP se reduz ao BDHP quando $\mathbb{G}_{1}=\mathbb{G}_{2}$, bastando para isto, tomar $Q=c P$. 
Podemos notar que se o GDHP é fácil, então o BDHP também é fácil:

Calcule $a b P$ (supondo que o CDHP é fácil);

Calcule $e(a b P, c P)=e(P, P){ }^{a b c}$

Porém, para escolhas apropriadas dos tamanhos de $q$ e $k$, conjectura-se que o GDHP é intratável e portanto o BDHP também é. Nesta hipótese se baseia a segurança da maioria dos esquemas baseados em identidades.

\subsubsection{Funções de Espalhamento}

R. Terada [Terada 2000], entre outros autores, define uma função de espalhamento (Hash) da seguinte forma:

"Dado um valor $x$, de tamanho qualquer, uma função de espalhamento calcula um valor y de tamanho fixo, relativamente menor do que o tamanho de $x$. Por exemplo, x pode ser um texto da ordem de centenas de bytes e y é da ordem de 128 bits. $O$ valor y é chamado de resumo de $x "$.

Para que possa ser empregada com segurança em criptografia, uma função de espalhamento deve satisfazer aos seguintes requisitos básicos:

- A entrada pode ser de qualquer tamanho;

- A saída tem um tamanho fixo;

- Dado $x$, é computacionalmente fácil calcular $H(x)$, onde $H$ é a função de espalhamento;

- Resistência à primeira inversão, ou seja, é computacionalmente fácil calcular $y$ tal que $H(x)=y$. Porém, é computacionalmente inviável, dado $y$, recuperar o valor de $x$;

- Resistência à segunda inversão, isto é, dada um valor $x$, é computacionalmente inviável encontrar um valor $z \neq x$ tal que $H(x)=H(z)$;

- Resistência à colisões, onde é computacionalmente inviável encontrar quaisquer dois valores $x$ e $z$ tais que $H(x)=H(z)$. 
Um ataque básico sobre funções de espalhamento é escolher entradas aleatórias para uma função $H(x)$ até que encontremos alguma entrada cujo valor de saída é o que estamos procurando (contrariando o requisito de ser resistente a inversões) ou então encontrarmos duas entradas que produzem a mesma saída (contrariando o requisito de ser resistente a colisões). Supondo que a função de espalhamento produza uma saída de $n$ bits, se nós tentarmos encontrar alguma entrada que produza a saída desejada, considerando que cada saída é igualmente provável, faremos no pior caso, $2^{n}$ tentativas.

Por outro lado, para encontrarmos uma colisão, o número esperado de tentativas é de $2^{n / 2}$, de acordo com o paradoxo do aniversário [Menezes, Oorschot e Vanstone 1997]. Devido a isto, um ataque de força bruta pode ser implementado para encontrar colisões. Para que possamos evitar um ataque de força bruta, a saída da função de espalhamento deve ser suficientemente grande.

\subsubsection{Funções de espalhamento $\times$ oráculos aleatórios}

Além da possibilidade de um intruso obter vantagens com o paradoxo do aniversário, caso a saída da função de espalhamento não seja suficientemente grande, a maioria da funções de espalhamento usadas — como SHA-1 ou MD-5 apresentam uma estrutura interna transparente, que pode ser aproveitada por intrusos mal-intencionados. Desta forma, podemos considerar que uma construção pode não ser segura com funções de espalhamento comuns.

Portanto, muitos autores propõem o uso de uma estrutura ideal (meramente teórica) onde deixamos de dar importância à estrutura interna das funções de espalhamento, para nos concentrarmos no protocolo propriamente dito. Nessa estrutura ideal, é necessário supor que o que se usa efetivamente são oráculos aleatórios, definidos por M. Bellare e P. Rogaway [Bellare e Rogaway 1993] da seguinte forma:

"Um oráculo aleatório $R$ é um mapeamento de $\{0,1\}^{*}$ para $\{0,1\}^{\infty}$, onde cada bit de $R(x)$ é escolhido de forma uniforme e independente para cada $x \in\{0,1\}^{*}$.

Podemos interpretar o conjunto $\{0,1\}^{\infty}$ como sendo uma saída suficientemente grande para os propósitos a que o oráculo se destina. 
Essencialmente, um oráculo aleatório funciona como uma "caixa-preta" que responde a uma "consulta" (a cadeia de entrada) com uma resposta indistinguível de uma sequiência aleatória. Em outras palavras, um agressor do sistema não tem como analisar a estrutura interna do oráculo (por ser opaca) para saber se o resultado do hash é proveniente de um cálculo sobre a cadeia de entrada ou se foi escolhido ao acaso (com a observação de que, para uma dada cadeia de entrada, a saída é sempre a mesma - algo assim como preencher aleatoriamente uma tabela indexada pela cadeia de entrada).

Nos esquemas de criptografia e assinatura baseados em identidade que iremos ver ao longo desta dissertação são utilizadas algumas funções de espalhamento. Considerando que a segurança só pode ser estabelecida no modelo de oráculos aleatórios, vamos supor que cada função de espalhamento é um oráculo aleatório, definidos da seguinte forma:

$$
\begin{array}{ll}
H_{1}: & \{0,1\}^{*} \longrightarrow \mathbb{G}_{1} \\
H_{2}: & \{0,1\}^{*} \longrightarrow \mathbb{F}_{q} \\
H_{3}: & \mathbb{G}_{2} \longrightarrow\{0,1\}^{*}
\end{array}
$$

Em outras palavras, $H_{1}$ é um oráculo aleatório que tendo como entrada uma sequiência de bits de tamanho arbitrário, responde com um ponto da curva elíptica; $H_{2}$ é um oráculo aleatório que tendo como entrada uma seqüência de bits de tamanho arbitrário, responde com um inteiro menor do que $q$ e $H_{3}$ é um oráculo aleatório que tendo como entrada o resultado de um emparelhamento entre dois pontos da curva, responde com uma seqüência de bits de tamanho arbitrário. ${ }^{7}$ As funções $H_{1}, H_{2}$ e $H_{3}$ que acabamos de definir serão usadas em quase todos os esquemas que apresentaremos nesta dissertação.

\subsubsection{Chaves utilizadas}

Antes de darmos início ao esquema de criptografia baseada em identidades, vamos definir os tipos de chaves que serão utilizadas.

\footnotetext{
${ }^{7}$ Veremos como implementar tais funções de espalhamento quando tratarmos da implementação de um protótipo, no capítulo 8.
} 
- Par de chaves Pública/ Particular Padrão ${ }^{8}(R, s)$

Sejam $R \in E\left(\mathbb{F}_{q^{k}}\right), s \in \mathbb{F}_{q}$ e $P$ um ponto gerador ${ }^{9}$ de $E\left(\mathbb{F}_{q^{k}}\right)$ e de conhecimento público. Temos que:

$$
R=s P \text {. }
$$

- Par de chaves pública/ particular baseadas em identidades $\left(Q_{I D}, S_{I D}\right)$

Sejam $Q_{I D}, S_{I D} \in \mathbb{G}_{1}$ e suponha que exista uma autoridade de confiança com um par de chaves padrão $\left(R_{T A}, s\right)$ de modo que valem as seguintes relações:

$$
\begin{aligned}
& S_{I D}=s Q_{I D} \\
& Q_{I D}=H_{1}(I D),
\end{aligned}
$$

onde $I D$ é o identificador (p. ex. um endereço eletrônico: alice @ime.usp.br).

Note pela equação (3.8), que apesar de os valores $R$ e $P$ serem públicos, o valor de $s$ não pode ser calculado eficientemente, pois está protegido pelo PLD-CE. Da mesma forma, pela equação (3.9), mesmo se Beto possuir um par de chaves válido $\left(Q_{\text {beto }}, S_{\text {beto }}\right)$, ele não consegue recuperar a chave particular $s$ da autoridade de confiança. O leitor mais atento deverá ter notado que nesse tipo de sistema, diferentemente da criptografia assimétrica tradicional, a autoridade de confiança tem conhecimento da chave particular de todos os seus usuários. Tal fato é chamado de custódia de chaves (key escrow) e será discutido mais adiante, ainda neste capítulo.

\subsection{Assinaturas compactas}

Vimos até aqui a nomenclatura e definições básicas necessárias para o entendimento dos sistemas criptográficos baseados em identidades. Nesta seção, veremos o conceito de assinaturas compactas, que apesar de não se enquadrarem em sistemas baseados em identidades, utilizam a propriedade de bilinearidade em emparelhamentos de pontos de uma

\footnotetext{
${ }^{8}$ Esse é um par de chaves assimétricas produzido por um algoritmo baseado em curvas elípticas. Quando nos referirmos a um par de chaves gerado por um algoritmo como o RSA, por exemplo, usaremos a denominação par de chaves tradicional.

${ }^{9} \mathrm{~A}$ definição de gerador encontra-se no anexo A.
} 
curva elíptica e, por isto, são muito utilizadas em conjunto com os sistemas baseados em identidades, como veremos mais adiante, razão pela qual decidimos inclui-las nesta dissertação.

O conceito de assinaturas compactas (short signatures) surgiu em 2001. São assim chamadas pois produzem uma assinatura de comprimento significativamente menor do que o comprimento das assinaturas geradas por algoritmos de criptografia assimétrica tradicional, como por exemplo o RSA, que pode gerar assinaturas de até 1024 bits. Em contraste a isto, D. Boneh, B. Lynn e H. Shacham [Boneh, Lynn e Shacham 2001] propuseram um esquema de assinatura (conhecida como assinatura BLS) cujo comprimento é de aproximadamente 160 bits, com um nível de segurança similar ao de uma assinatura $\operatorname{DSA}^{10}$ de 320 bits. Segundo os autores, para que a assinatura BLS seja considerada segura, é necessário um grupo onde o CDHP seja difícil e o DDHP seja fácil de ser resolvido.

Uma assinatura compacta pode ser desejável, por exemplo, quando um usuário precisa digitar manualmente uma assinatura, como por exemplo, ao fazer o registro de um produto, cuja assinatura se encontra em uma etiqueta do $\mathrm{CD}$ de instalação (obviamente, seria muito incômodo se fosse necessário que ele digitasse uma assinatura de 1024 bits). Mais genericamente, assinaturas compactas são necessárias em ambientes de comunicação de pequena largura de banda. Um outro exemplo de aplicação é quando surge a necessidade de imprimir uma assinatura em selos postais. Vamos ao esquema propriamente dito:

\subsubsection{Assinatura}

Seja $s$ a chave particular padrão de um usuário Beto. Suponha que Beto deseja assinar uma mensagem $m$. Ele então, calcula:

$$
V=s H_{1}(m)
$$

onde $V$ é a assinatura compacta de $m$ gerada por Beto. Note que podemos representar $V$ com apenas 160 bits da abscissa do ponto $x$, considerando que o tamanho do corpo $(q)$ é da ordem de $2^{160}$. Como a curva é simétrica em relação ao eixo das abscissas [Barreto 1999], basta apenas mais um bit para indicar se a ordenada y está acima ou abaixo do eixo das abscissas.

\footnotetext{
${ }^{10}$ Sigla que representa Digital Signature Algorithm, ou algoritmo de assinatura digital.
} 
Observe ainda que, para gerar sua assinatura, Beto utiliza sua chave particular $s$. Observe também que, pela definição de $H_{1}$, temos que $H_{1}(m)$ é um ponto de uma curva elíptica sobre $\mathbb{F}_{q}$, assim como $s H_{1}(m)$.

\subsubsection{Verificação}

Se Alice quiser confirmar se a assinatura $V$ foi, de fato, produzida por Beto, ela faz a seguinte verificação:

$$
e_{t}(V, P)=e_{t}\left(H_{1}(m), R\right)
$$

onde $e_{t}$ representa o emparelhamento de Tate, como vimos na seção anterior. Se o resultado encontrado no cálculo dos emparelhamentos de ambos os membros da equação (3.12) for o mesmo, Alice aceita a assinatura de Beto como válida, caso contrário, ela rejeita. Note que a verificação de uma assinatura utiliza apenas valores públicos e conhecidos.

\subsubsection{Demonstração}

Vamos agora demonstrar que a igualdade da equação (3.12) se verifica, caso a assinatura seja válida.

$$
\begin{aligned}
e_{t}(V, P) & =e_{t}\left(s H_{1}(m), P\right), & & \text { pois } V=s H_{1}(m) \text { de }(3.11) \\
& =e_{t}\left(H_{1}(m), P\right)^{s}, & & \text { por bilinearidade } \\
& =e_{t}\left(H_{1}(m), s P\right), & & \text { por bilinearidade } \\
& =e_{t}\left(H_{1}(m), R\right), & & \text { pois } R=s P \text { de }(3.8) .
\end{aligned}
$$

Note que, se $V \neq s H_{1}(m)$, ou seja, se a assinatura não foi produzida por Beto, a igualdade não será verificada e Alice pode rejeitar a assinatura. Note, também, que para produzir uma assinatura compacta, é necessário que o usuário possua um par de chaves padrão.

Observe ainda que se o GDHP fosse fácil, um intruso - conhecendo $P$, $s P=R_{T A}$ e $h P=H_{1}(m)$ (pois $H_{1}(m)$ é um ponto da curva cujo gerador é $P$ ) conseguiria calcular corretamente $s h P=s H_{1}(m)=V$ e forjar uma assinatura. Portando, a segurança da assinatura BLS se baseia na dificuldade do GDHP. 


\subsection{Criptografia em sistemas baseados em identidades}

Vamos entrar agora nos sistemas criptográficos baseados em identidades propriamente ditos, iniciando com a criptografia ${ }^{11}$ baseada em identidades (IBE - Identity-Based Encryption). Sejam $\left(Q_{\text {beto }}, S_{\text {beto }}\right)$ o par de chaves baseadas em identidades de um usuário Beto; $R_{T A}$ a chave pública padrão da autoridade de confiança que gerou a chave particular de Beto; e $m$ a mensagem que Alice deseja enviar para Beto.

Veremos a seguir o modelo de criptografia baseada em identidades proposto por Boneh \& Franklin [Boneh e Franklin 2001] .

\subsubsection{Criptografia}

Alice escolhe um elemento aleatório $r$, tal que $r \in \mathbb{F}_{q}$ e calcula ${ }^{12}$ :

$$
\left\{\begin{array}{l}
U=r P \\
V=m \oplus H_{3}\left(e_{t}\left(r Q_{b e t o}, R_{T A}\right)\right)
\end{array}\right.
$$

e envia o texto criptografado $(U, V)$ para Beto. Note que os valores $P, Q_{\text {beto }}$ e $R_{T A}$ são valores públicos, assim como a função $H_{3}$. O único valor secreto usado na criptografia é o aleatório $r$.

Boneh \& Franklin, em seu artigo, não destacam a importância na escolha de $r$. É importante que o elemento aleatório $r$ escolhido por Alice seja diferente para cada mensagem a ser criptografada (números com tal característica são conhecidos na literatura específica como "NONCE": Number used ONCE.); caso contrário, haverá uma falha de segurança que veremos mais adiante. Note que Alice utiliza a chave pública baseada em identidades de Beto para criptografar $m$. Para isto, basta que ela conheça o identificador de Beto (p. ex. beto@ime.usp.br).

\subsubsection{Decriptografia}

Beto, recebendo $(U, V)$ de Alice, faz o seguinte cálculo para recuperar o legível $m$ :

$$
m=V \oplus H_{3}\left(e_{t}\left(S_{\text {beto }}, U\right)\right) .
$$

Vemos que Beto utiliza sua chave particular baseada em identidades para recuperar $m$.

\footnotetext{
${ }^{11}$ Novamente aqui no sentido restrito de encryption.

${ }^{12} \mathrm{~A}$ operação $\oplus$ representa o ou-exclusivo bit a bit.
} 


\subsubsection{Demonstração}

Queremos demonstrar que Beto, através do cálculo efetuado na equação (3.14), consegue, de fato, recuperar $m$.

$$
\begin{array}{rlrl}
V \oplus H_{3}\left(e_{t}\left(S_{\text {beto }}, U\right)\right) & =V \oplus H_{3}\left(e_{t}\left(S_{\text {beto }} r P\right)\right), & & \text { pois } U=r P \operatorname{de}(3.13) \\
& =V \oplus H_{3}\left(e_{t}\left(s Q_{b \epsilon t o}, r P\right)\right), & & \text { pois } S_{\text {beto }}=s Q_{\text {beto }} \text { de }(3.9) \\
& =V \oplus H_{3}\left(e_{t}\left(Q_{\text {beto }}, P\right)^{r s}\right), & & \text { por bilinearidade } \\
& =V \oplus H_{3}\left(e_{t}\left(r Q_{b e t o}, s P\right)\right), & & \text { por bilinearidade } \\
& =V \oplus H_{3}\left(e_{t}\left(r Q_{b e t o}, R_{T A}\right)\right), & & \text { pois } R_{T A}=s P \operatorname{de}(3.8) \\
& =m, & & \text { pois pela equação }(3.13) \\
& & V=m \oplus H_{3}\left(e_{t}\left(r Q_{b e t o}, R_{T A}\right)\right) .
\end{array}
$$

Boneh \& Franklin definem o modelo de criptografia baseada em identidades através de quatro algoritmos, chamados de configuração (setup), extração (extract), criptografia (encrypt) e decriptografia (decrypt), que resumiremos a seguir:

\section{Configuração}

- seleção dos parâmetros $q, \mathbb{G}_{1}, \mathbb{G}_{2}, P$ e $e_{t}$;

- escolha da chave particular $s$, tal que $s \in \mathbb{Z}_{q}^{*}$ e cálculo da chave pública $R_{T A}$, conforme equação (3.8);

- escolha das funções de espalhamento $H_{1}$ e $H_{3}$.

Os parâmetros do sistema são os valores públicos $\left(q, \mathbb{G}_{1}, \mathbb{G}_{2}, e_{t}, P, R_{T A}, H_{1}, H_{3}\right)$.

A chave particular $s$, também chamada de chave mestra, é um parâmetro conhecido apenas pela autoridade de confiança.

\section{Extração}

- cálculo de $Q_{I D}$, para um dado $I D$, conforme equação (3.10);

- cálculo da chave particular $S_{I D}$ baseada em identidades, conforme equação (3.9). 


\section{Criptografia}

- cálculo de $(U, V)$, conforme equação (3.13).

\section{Decriptografia}

- recuperação do legível $m$, conforme equação (3.14).

Os algoritmos configuração e extração são executados pela autoridade de confiança (TA) e os algoritmos criptografia e decriptografia pelos participantes da comunicação.

\subsubsection{Importância da escolha do elemento aleatório $r$}

Vimos na seção anterior que Alice deve escolher um elemento aleatório $r$ antes de enviar uma mensagem para Beto. É importante que $r$ seja um elemento estatisticamente único, uniformemente distribuído e independente, para que um intruso não consiga detectar padrões através de um ataque de texto ilegível no valor de $U$.

Primeiramente, vamos supor que Alice selecione $r$ em seqüência (por exemplo, $r, r+d, r+2 d, \ldots$, para algum inteiro $d$ ). Supondo que um adversário conseguisse, de alguma forma, resolver o PLD de algum valor interceptado $U$, descobrindo o valor de $r$, saberia calcular os demais $r$, caso tivesse conhecimento da sequiência utilizada por Alice.

Um caso extremo ocorreria se Alice escolhesse sempre o mesmo valor de $r$ para todas as mensagens que criptografasse. Nesse caso, poderíamos montar um ataque semelhante ao apresentado na seção 3 de [Borisov, Goldberg e Wagner 2001], conforme descrevemos a seguir:

Suponha que Alice enviou as mensagens $m_{1}$ e $m_{2}$ para Beto e não teve a preocupação de selecionar dois $r$ distintos. Pela equações (3.13), vemos que o valor de $U$ será o mesmo, tanto para $m_{1}$ quanto para $m_{2}$, apenas os valores de $V$ serão diferentes para cada mensagem. Sejam então $V_{1}$ e $V_{2}$ os valores calculados por Alice, sobre $m_{1}$ e $m_{2}$, respectivamente. Da mesma forma, como $r$ é o mesmo para $m_{1}$ e $m_{2}$, o valor de $H_{3}\left(e_{t}\left(r Q_{b e t o}, R_{T A}\right)\right)$ permanece constante. Vamos chamar este valor de $x$. Desta forma, podemos reescrever a segunda equação 
de (3.13) como:

$$
\left\{\begin{array}{l}
V_{1}=m_{1} \oplus x \\
V_{2}=m_{2} \oplus x
\end{array}\right.
$$

Se um intruso Carlos interceptar os valores $V_{1}$ e $V_{2}$, ele pode calcular:

$$
\begin{aligned}
V & =V_{1} \oplus V_{2} \\
& =\left(m_{1} \oplus x\right) \oplus\left(m_{2} \oplus x\right) \\
& =m_{1} \oplus m_{2} .
\end{aligned}
$$

Conhecendo o valor de $V$, se o intruso conseguir ter acesso a $m_{1}$ (sem perda de generalidade), pode realizar um ataque de "texto legível conhecido" e recuperar $m_{2}$.

Entretanto, caso Alice escolha sempre um valor diferente para $r$ a cada mensagem a ser transmitida e, além disso, tal escolha não obedeça a padrões que possam ser analisados por um intruso, a operação de ou-exclusivo na equação (3.13) funcionará como uma cifra simétrica conhecida como one-time pad, que segundo R. Terada [Terada 2000], é considerada inquebrável (ou seja, segurança perfeita) caso as chaves utilizadas sejam realmente aleatórias.

Infelizmente, como não se conhece uma maneira de implementar um gerador de números realmente aleatórios, Alice teria que usar valores "pseudo-aleatórios" para $r$, o que abre uma possibilidade de aproveitamento por um intruso. Desta forma, sugerimos a seguir uma pequena variação no esquema B-F, onde a operação de ou-exclusivo é substituída por uma função criptográfica simétrica conhecida. Tal modificação fará com que o esquema de B-F funcione como um protocolo (seguro) de negociação de chaves (robustas).

\subsubsection{Variação no esquema de Boneh \& Franklin}

Podemos observar pela equação (3.13) que o valor de $V$ é calculado fazendose um "ou-exclusivo" $(\oplus)$ da mensagem $m$ com um valor calculado $H_{3}\left(e_{t}\left(r Q_{\text {beto }}, R_{T A}\right)\right)$. Se chamarmos este valor calculado de $k$, vemos que foi demonstrado que Beto calcula esse mesmo valor $k$ através do cálculo de $H_{3}\left(e_{t}\left(S_{\text {beto }}, U\right)\right)$. Em resumo, temos que Alice calcula $V=m \oplus k$ e Beto calcula $m=V \oplus k$.

Considerando que, na prática, a criptografia assimétrica é utilizada apenas como um meio de se obter um canal seguro para transmissão de uma chave e a partir desse momento, as mensagens passam a ser criptografadas com criptografia simétrica - cujos algoritmos são algumas dezenas de vezes mais rápidos —, propomos aqui uma pequena modificação 
no esquema original de Boneh \& Franklin, onde substituímos a operação de "ou-exclusivo" por uma função criptográfica simétrica conhecida (por exemplo, DES, AES), onde a chave simétrica seria $k$. Desta forma, o esquema modificado de Boneh \& Franklin fará o papel de "canal seguro" para a troca de chaves simétricas, desde que a chave $k$ seja assinada pelo remetente (usando, por exemplo, o esquema de assinatura de F. Hess, que veremos na seção 3.5).

Vimos na seção anterior que Alice deve sempre ter o cuidado de escolher um $r$ distinto, pois caso escolha o mesmo valor de $r$ para transmitir duas mensagens distintas, abrirá uma janela para um possível ataque de texto legível conhecido. Isso se dá devido à propriedade de que a função inversa da operação de "ou-exclusivo" é ela própria. No esquema original, como vimos, Alice deve sempre escolher um novo valor de $r$ a cada mensagem e, devido a isto, em cada troca de mensagens há a necessidade de se calcular um emparelhamento (cujo valor depende de $r$ ), para somente então se criptografar a mensagem desejada com uma cifra de blocos ("ou-exclusivo").

Ao substituirmos a operação de "ou-exclusivo" por um algoritmo simétrico, o esquema de Boneh \& Franklin poderia ser encarado como um protocolo (seguro) de negociação de chaves (robustas), pois após Alice e Beto terem chegado ao mesmo valor $k$, todas as mensagens entre eles poderiam ser criptografadas com o algoritmo simétrico escolhido, utilizando $k$ como chave. Obviamente, Alice tem certeza de que somente Beto conseguirá calcular a chave $k$ corretamente, pois usou a chave pública dele na criptografia. Para que Beto tenha certeza de que foi realmente Alice quem gerou a chave $k$, é necessário que esta esteja assinada por Alice. Claramente, sempre que Alice e Beto sentirem necessidade de trocar a chave $k$, basta que reiniciem o protocolo modificado de Boneh \& Franklin (em conjunto com um esquema conhecido de assinatura) e negociem uma nova chave.

Como podemos impor que a saída da função $H_{3}$ seja uma seqüência de tamanho 128 bits (ou até maior), podemos considerar que Alice e Beto vão utilizar uma criptografia simétrica forte, pois estarão usando uma chave considerada robusta. Como o cálculo do emparelhamento (que é a operação de maior custo) só é feito na negociação da chave (incluindo a criptografia e a assinatura) e, após isso, a troca de mensagens se dá por meio de criptografia simétrica, as mensagens entre Alice e Beto podem ser trocadas de forma bem rápida e ao mesmo tempo, de forma segura. 
O esquema modificado ficaria da seguinte forma:

\subsubsection{Negociação de chave - fase I}

Como no esquema de criptografia de Boneh \& Franklin (B-F) [Boneh e Franklin 2001], Alice escolhe um elemento aleatório $r$, tal que $r \in \mathbb{F}_{q}$ e calcula:

$$
\begin{cases}U & =r P \\ k & =H_{3}\left(e_{t}\left(r Q_{b e t o}, R_{T A}\right)\right)\end{cases}
$$

Alice assina $k$ com um algoritmo conhecido de assinatura (por exemplo, o esquema de Hess, que veremos a seguir), produzindo a assinatura $S_{A}[k]$ e envia $\left(U, S_{A}[k]\right)$ para Beto.

\subsubsection{Negociação de chave - fase II}

Beto, recebendo $\left(U, S_{A}[k]\right)$ de Alice, faz o seguinte cálculo para recuperar a chave $k$, como na decriptografia $\mathrm{B}-\mathrm{F}$ :

$$
k=H_{3}\left(e_{t}\left(S_{\text {beto }}, U\right)\right)
$$

em seguida, verifica se $S_{A}[k]$ é uma assinatura válida de Alice.

A partir desse ponto, as mensagens trocadas entre Alice e Beto serão criptografadas por um algoritmo simétrico pré-estabelecido entre eles (por exemplo, AES, DES), onde $k$ é a chave simétrica. Por exemplo, Alice envia $\mathcal{C}=C_{k}(m)$ e Beto recupera $m=D_{k}(\mathcal{C})$, onde $D_{k}$ é a operação inversa de $C_{k}$.

Note que Beto precisa primeiramente usar sua chave particular $S_{\text {beto }}$ para calcular o valor de $k$ e só então pode verificar se a assinatura de Alice sobre $k$ é válida (veremos na equação (3.21) que a verificação de assinatura produzida pelo esquema de Hess depende da mensagem assinada). Qualquer outra pessoa que não conheça a chave particular de Beto não conseguirá recuperar $k$ corretamente.

Caso a opção seja por um esquema de assinatura com recuperação de mensagem, como ocorre na assinatura RSA, de nada adiantaria Alice assinar a chave simétrica $k$, pois qualquer usuário, de posse da chave pública dela, recuperaria $k$. Alice, então, assina $U \mathrm{e}$ envia $S_{A}[U]$ para Beto. 


\subsubsection{Vantagem de um intruso caso o BDHP seja fácil}

Vimos que além da hipótese de que o PLD-CE seja um problema difícil pois, caso contrário, seria fácil determinar a chave da autoridade de confiança e, com isso, todas as chaves particulares geradas por essa TA — precisamos considerar também a hipótese de que o BDHP seja difícil. Felizmente, para uma escolha apropriada do grupo (ou seja, $\lg q \sim 160$ e $k \lg q \sim 1024$ ), conseguimos obter tanto o PLD-CE quanto o BDHP difíceis, garantindo com isso a segurança do sistema. Veremos nesta seção como um adversário conseguiria obter vantagem sobre o esquema de criptografia de Boneh e Franklin caso conseguisse resolver o BDHP, considerando que ele não consegue resolver o PLD-CE.

Suponha que Alice enviou para Beto uma mensagem $m$ criptografada com o esquema de Boneh e Franklin. Como vimos, Beto vai receber de Alice o par $(U, V)$. Para que um intruso, digamos Carlos, possa decriptografar a mensagem de Alice, ele poderia calcular $m$, por exemplo, através da equação (3.14). Entretanto, como não conhece $S_{b e t o}$ e não consegue resolver o PLD-CE, ele não conseguiria calcular corretamente o valor de $e_{t}\left(S_{\text {beto }}, U\right)$ e portanto não conseguiria determinar $m$ dessa forma.

Vamos supor, contudo, que ele consegue resolver o BDHP no grupo escolhido por Alice. Podemos notar que Carlos conhece os seguintes valores:

- $R_{T A}=s P$;

- $Q_{\text {beto }}=H_{1}\left(I D_{\text {beto }}\right)=h P\left(\right.$ pois $Q_{\text {beto }}$ é um ponto da curva);

- $U=r P$, supondo que Carlos interceptou o par $(U, V)$.

Considerando que Carlos consiga resolver o BDHP, se ele conhece $s P, h P$ e $r P$ ele consegue calcular $e(P, P)^{s h r}$.

Analisando o emparelhamento $e\left(S_{\text {beto }}, U\right)$, temos:

$$
\begin{aligned}
e\left(S_{\text {beto }}, U\right) & =e\left(s Q_{\text {beto }}, r P\right) \\
& =e(s h P, r P) \\
& =e(P, P) . s h r
\end{aligned}
$$

Logo, considerando a hipótese de que o BDHP é fácil, o intruso conseguiria calcular corretamente o valor do emparelhamento e determinar $m$, sem para para isso, precisasse conhecer $S_{\text {beto }}$ ou $s$. 


\subsection{Assinatura em sistemas baseados em identidades}

Existem diversos sistemas de assinatura baseados em identidades, como [Paterson 2002, Cha e Cheon 2002, Hess 2002] e outros. Vamos apresentar aqui o esquema de F. Hess, que é mais eficiente que os demais segundo [Chen et al. 2002].

\subsubsection{Assinatura}

Alice, querendo assinar uma mensagem $m$, primeiramente escolhe um ponto aleatório $P_{1} \in \mathbb{G}_{1}^{*}$ e calcula:

$$
r=e_{t}\left(P_{1}, P\right)
$$

Em seguida, calcula ${ }^{13}$

$$
h=H_{2}(m \| r),
$$

e finalmente,

$$
U=h S_{\text {alice }}+P_{1}
$$

onde a assinatura de $m$ é $(U, h)$.

Note em (3.19) que Alice usa sua chave particular $S_{\text {alice }}$ para gerar a assinatura de $m$. Observe também que a "soma" na equação (3.19) representa uma soma de pontos, pois $h S_{\text {alice }}$ e $P_{1}$ são pontos de uma curva elíptica sobre $\mathbb{F}_{q}$.

\subsubsection{Verificação}

Se Beto deseja verificar se a assinatura é realmente de Alice, faz o seguinte cálculo:

$$
r=e_{t}(U, P) \cdot e_{t}\left(Q_{\text {alice }},-R_{T A}\right),^{h}
$$

onde $-R_{T A}$ é o ponto simétrico de $R_{T A}$ em relação ao eixo das abscissas.

Após calcular $r$, Beto aceita a assinatura de Alice como válida se, e somente se:

$$
h=H_{2}(m \| r) .
$$

Note que somente valores públicos são utilizados na verificação de uma assinatura. Observe também que Beto precisa conhecer a mensagem $m$ para que possa verificar a assinatura de

\footnotetext{
${ }^{13}$ O termo || na equação (3.18) significa "concatenar".
} 
Alice. Esquemas de assinatura com essa propriedade são conhecidos como assinatura sem recuperação de mensagem, ou seja, a mensagem clara deve ser transmitida anexa à assinatura.

A título de observação, na fase de assinatura do esquema original de Hess, Alice deveria escolher um aleatório $k \in \mathbb{F}_{q}$ e na equação (3.17), calcular $r=e_{t}\left(P_{1}, P\right)^{k}$. Entretanto, observamos que este aleatório não é necessário, pois se usarmos bilinearidade, podemos reescrever como $r=e_{t}\left(k P_{1}, P\right)$, onde $k P_{1}$ é um outro ponto da curva. Como em nenhum momento o valor $k$ é usado separadamente de $P_{1}$, basta Alice escolher $P_{1}$.

\subsubsection{Demonstração}

Vamos demonstrar que a equação (3.20) é satisfeita para uma assinatura válida. Observe que são empregadas as propriedades de bilinearidade, vistas nas equações (3.5) e (3.6).

$$
\begin{aligned}
e_{t}(U, P) \cdot e_{t}\left(Q_{\text {alice }},-R_{T A}\right)^{h} & =e_{t}\left(h S_{\text {alice }}+P_{1}, P\right) \cdot e_{t}\left(Q_{\text {alice }},-R_{T A}\right)^{h} \\
& =e_{t}\left(h S_{\text {alice }}+P_{1}, P\right) \cdot e_{t}\left(Q_{\text {alice }},-s P\right)^{h} \\
& =e_{t}\left(h S_{\text {alice }}+P_{1}, P\right) \cdot e_{t}\left(Q_{\text {alice }},-P\right)^{s h} \\
& =e_{t}\left(h S_{\text {alice }}+P_{1}, P\right) \cdot e_{t}\left(s Q_{\text {alice }}, P\right)^{-h} \\
& =e_{t}\left(h S_{\text {alice }}+P_{1}, P\right) \cdot e_{t}\left(S_{\text {alice }}, P\right)^{-h} \\
& =e_{t}\left(h S_{\text {alice }}+P_{1}, P\right) \cdot e_{t}\left(-h S_{\text {alice }}, P\right) \\
& =e_{t}\left(h S_{\text {alice }}-h S_{\text {alice }}+P_{1}, P\right) \\
& =e_{t}\left(P_{1}, P\right) \\
& =r \quad \text { (pela equação }(3.17)) .
\end{aligned}
$$

Note que se pelo menos um dos valores $h$ ou $U$ for alterado por um ataque de modificação, Beto calculará um valor $r_{1} \neq r$ pela equação (3.20). Desta forma, ao verificar a condição da equação (3.21), encontrará um valor de $h$ diferente daquele que recebeu como parte da assinatura de Alice e, portanto, rejeitará a assinatura. 


\subsubsection{Segurança na assinatura de Hess}

Veremos nesta seção que a segurança do esquema de assinatura de Hess se baseia na dificuldade do GDHP. O esquema de assinatura de Hess calcula inicialmente $r=e\left(P_{1}, P\right)$, em seguida, $h=H(m \| r)$ e finalmente, $U=h S_{I D}+P_{1}$, onde $P$ é um ponto público em $\mathbb{F}_{q^{k}}$ e $P_{1}$ um ponto escolhido em $\mathbb{F}_{q}$. Para que uma assinatura seja forjada com sucesso - considerando que $r$ depende de valores selecionados pelo assinante e $h$, por sua vez, depende deste $r$ - um intruso precisa "apenas" conhecer a chave particular $S_{I D}$. Se o GDHP fosse tratável, conhecendo $P, R_{T A}=s P$ e $Q_{I D}=H_{1}(I D)=a P$, pois $Q_{I D}$ é um ponto da curva, o intruso conseguiria calcular "facilmente" $s a P=s Q_{I D}=S_{I D}$ e forjar a assinatura com sucesso.

Note que, caso o GDHP seja intratável, mesmo que o BDHP fosse tratável o intruso não conseguiria obter vantagem e calcular a chave $S_{I D}$ para forjar a assinatura. Portanto, a assinatura Hess depende da dificuldade do GDHP.

\subsection{Vantagens e desvantagens}

- VANTAGEnS

\section{- NÃo É NECESSÁRIO UM DIRETóRIO DE CHAVES PÚBLICAS.}

Como vimos, a chave pública baseada em identidades é uma característica que identifica o usuário de forma única, chamada de identificador. Na verdade, vimos que a chave é o resultado de uma função de espalhamento sobre esse identificador, mas como tal função de espalhamento é de conhecimento público, podemos simplificar dizendo que a chave pública é o identificador. Desta forma, se pensarmos que o identificador é o endereço eletrônico de um usuário, uma vez conhecendo esse endereço eletrônico (e, obviamente, precisamos conhecer, se quisermos enviar-lhe um e-mail), podemos enviar-lhe mensagens sigilosas, sem que seja necessário recorrermos a um diretório de chaves públicas.

- Qualquer entidade Que possua um par de chaves padrão pode fazer o PAPEL DE GERADOR DE CHAVES PARTICULARES.

Vimos que o PKG tem conhecimento de todas as chaves particulares de seus usuários. 
Tal fato nem sempre é desejável. Considere, por exemplo, uma empresa que trata de assuntos sensíveis. Se o PKG fosse uma entidade externa à empresa, ele teria acesso a todas as mensagens tramitadas na empresa, o que pode vir a se tornar um problema (Vamos ignorar a hipótese feita na seção 3.2.1 e supor que esse PKG foi subornado pela empresa concorrente). Com sistemas baseados em identidades, basta que uma entidade possua um par de chaves padrão, como vimos na seção 3.2.8, para que possa gerar as chaves baseadas em identidades. Portanto, o Presidente da empresa pode fazer o papel de PKG e, neste caso, seria uma autoridade de confiança.

Essa propriedade também é importante no sentido de que reduz (ou até mesmo elimina) a dificuldade de se obter um canal seguro para distribuição da chave particular, pois podemos considerar que o usuário e o PKG estejam próximos fisicamente.

- O PKG TEM CONHECIMENTO DE TODAS AS CHAVES PARTICULARES DE SEUS USUÁRIOS.

Tal fato é conhecido como custódia de chaves e embora nem sempre seja desejável (e por esta razão, também o incluímos nas desvantagens), em algumas situações, pode ser conveniente a possibilidade de recuperação de chaves particulares.

Vamos aproveitar a situação descrita na vantagem anterior, onde o Presidente da empresa age como autoridade de confiança. Neste caso, o conhecimento das chaves particulares é desejável. Imagine que um diretor da empresa sofreu um grave acidente e não tem condições de acessar seus arquivos nem confiar sua chave para uma terceira pessoa. Como o presidente gerou a chave particular desse diretor, ele conhece essa chave e, portanto, pode recuperar os arquivos de interesse da empresa que tenham sido criptografados com a chave pública baseada em identidades desse diretor.

Uma outra situação em que o conhecimento das chaves particulares pode ser desejável é o assunto "Segurança Nacional", onde órgãos de inteligência do Governo podem desejar ter acesso a informações que possam vir a comprometer a soberania de uma Nação. Mas definirmos até que ponto deve ir a intervenção do Estado nos assuntos privados é um assunto delicado e, portanto, vamos deixar de lado tais discussões por não fazerem parte do escopo desta pesquisa. 
- Alice pode enviar mensagens Criptografadas para Beto mesmo se ele AINDA NÃO OBTEVE SEU PAR DE CHAVES DA AUTORIDADE DE CONFIANÇA.

Diferentemente dos sistemas de chave pública tradicionais, em que a chave pública é uma seqüência aleatória de bits, e portanto deve ser previamente calculada, juntamente com seu par (chave particular), para que uma mensagem possa ser enviada, nos sistemas baseados em identidades Alice pode enviar uma mensagem sigilosa para Beto antes mesmo de ele ter obtido seu par de chaves baseadas em identidades de uma autoridade de confiança.

Alice precisa apenas da chave pública padrão da autoridade de confiança que irá gerar o par de chaves de Beto. Caso Alice tenha conhecimento dessa autoridade de confiança (por exemplo, digamos que a autoridade em questão é o presidente da empresa em que Alice trabalha e que Beto acabou de ser admitido nessa empresa, mas ainda não obteve seu par de chaves baseadas em identidades), ela envia uma mensagem criptografada, utilizando como identificador o endereço eletrônico de Beto. Ele, por sua vez, ao receber a mensagem criptografada, precisará apenas solicitar um par de chaves à autoridade de confiança usando seu $e$-mail como identificador e então, decriptografar a mensagem.

\section{- NÃo é necessário Alice obter o certificado da Chave pública de Beto.}

Diferentemente da criptografia assimétrica tradicional, onde não há nenhuma relação entre o usuário e sua chave pública, nos sistemas baseados em identidades a chave pública é uma característica que identifica o usuário de forma única e que ele não tem como negar que tal característica diz respeito a ele. Portanto, não há a necessidade de certificados digitais para autenticar chaves públicas e, conseqüentemente, não há necessidade de se estabelecer uma infra-estrutura de chaves públicas.

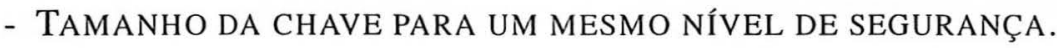

A grande vantagem do uso de sistemas criptográficos baseados em curvas elípticas (ECC Elliptic Curve Cryptosystems) em relação aos sistemas de chaves assimétricas tradicionais — como por exemplo, o RSA — é, segundo J. Hernandez [Hernandez 2000], "que parâmetros significativamente menores podem ser usados nos ECC com o mesmo nível de 
segurança. Tal vantagem é especialmente importante em aplicações em ambientes computacionais limitados, como cartões inteligentes, telefones celulares, computadores de bolso e pagers." Na figura 3.1 podemos ver um gráfico comparativo do tamanho da chave simétrica, assimétrica tradicional (RSA) e assimétrica baseada em curvas elípticas (ECC), necessárias para alcançar um mesmo nível de segurança. Cabe ressaltar que o nível de segurança em sistemas criptográficos é medido usando-se o melhor algoritmo conhecido (estado da arte) para quebrá-los.

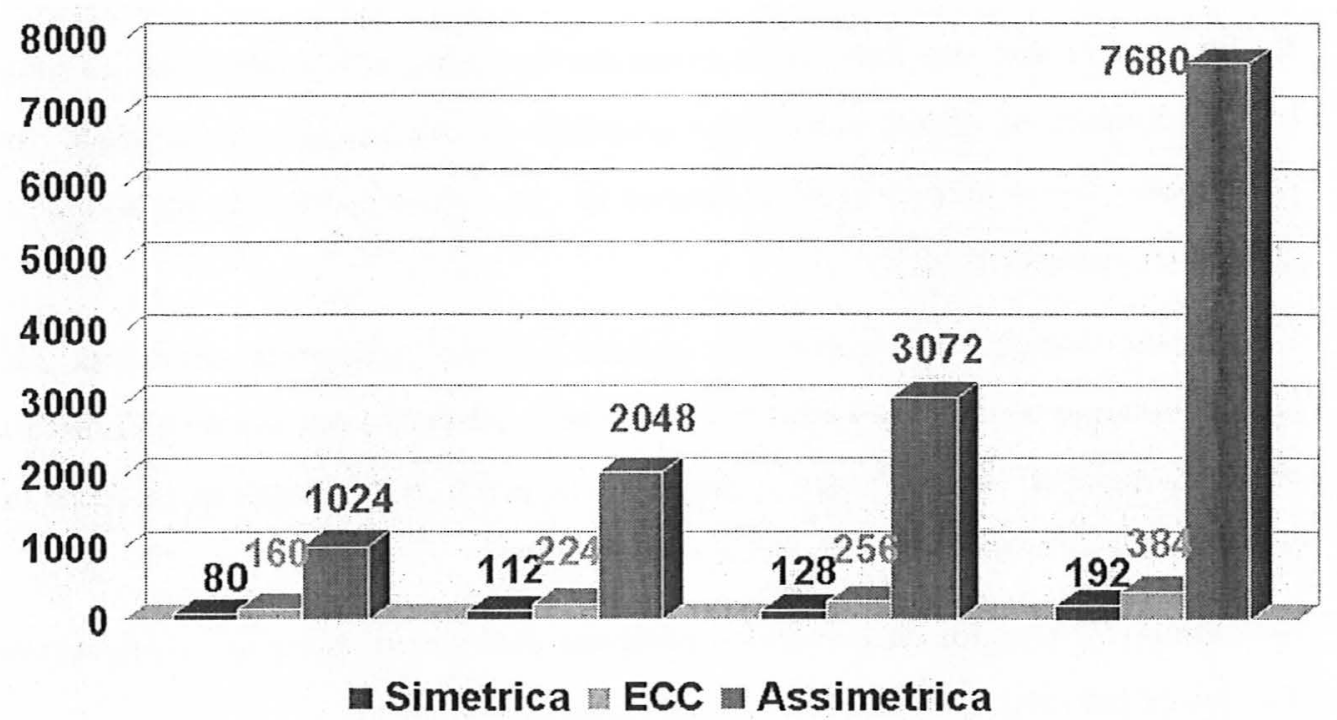

Figura 3.1: Tamanho de chaves para um mesmo nível de segurança - Vemos acima uma comparação entre tamanhos de chaves necessários para se obter um mesmo nível de segurança.

\section{- Desvantagens}

\section{- GRANDE DEPENDÊNCIA NA CHAVE MESTRA DO PKG.}

Vimos que nos sistemas baseados em identidades, todas as chaves particulares são geradas a partir da chave mestra do PKG. Caso essa chave mestra seja comprometida, teremos o comprometimento de todas as chaves particulares que foram geradas com tal chave, comprometendo seriamente a segurança do sistema, não só nas mensagens já transmitidas, como também nas mensagens futuras. Apesar da dificuldade computacional de se obter a chave mestra (pois está protegida pelo PLD-CE), é fundamental que a chave mestra do PKG esteja protegida em um hardware resistente a fraudes. Ainda assim, como há 
outros métodos de se tentar obter essa chave mestra e com isso, conseguir total controle sobre o sistema (como por exemplo, obrigando o PKG a revelar sua chave), veremos no capítulo 7 uma solução usando múltiplos PKG, em que podemos distribuir entre várias entidades a responsabilidade de geração das chaves (nesse caso, a segurança do sistema só estaria comprometida caso todas as chaves mestras fossem descobertas);

\section{- O PKG TEM CONHECIMENTO DE TODAS AS CHAVES PARTICULARES DE SEUS USUÁRIOS.}

Resolvemos repetir este item, agora como desvantagem, pois dependendo da situação, o conhecimento de chaves particulares (custódia de chaves) por uma entidade externa pode causar sérios problemas de segurança (p. ex. como no caso de suborno do PKG, comentado anteriormente).

Uma outra situação indesejável que poderá ocorrer, novamente desconsiderando a hipótese de que o PKG seja incondicionalmente confiável, é que ele pode forjar a assinatura de qualquer um dos usuários para os quais gerou chaves baseadas em identidades, pois conhece as chaves particulares de cada um deles.

No capítulo 7, veremos duas soluções possíveis para situações em que o conhecimento das chaves pelo PKG for considerado como uma desvantagem.

\section{- Dificuldade DE implementaÇão do emparelhamento de TATE.}

Vimos que, em termos computacionais, o cálculo do emparelhamento em curvas elípticas é a operação de maior custo. Dependendo da forma como é implementado, um sistema criptográfico baseado em identidades pode se tornar inviável de ser utilizado em termos práticos, pois pode se tornar muito lento. Alguns pesquisadores [Galbraith, Harrison e Soldera 2002, Barreto et al. 2002, Barreto, Lynn e Scott 2003] já conseguiram uma implementação mais eficiente do emparelhamento de Tate, porém este ainda possui ordem de grandeza superior ao cálculo de exponenciação em um corpo finito. 
- Criptografia E ASSinAtura Mais Lentas do Que um ESQuema COM CHAVE ASSIMÉTRICA TRADICIONAL.

Como comentado no item anterior, mesmo utilizando a implementação mais eficiente que se conhece até hoje do emparelhamento de Tate [Barreto, Lynn e Scott 2003], os sistemas criptográficos baseados em identidades ainda apresentam um desempenho inferior a sistemas que utilizam chaves assimétricas tradicionais, como por exemplo, o RSA, seja em esquemas de assinatura ou de criptografia.

Na tabela 3.1, retirada do artigo "Efficient algorithms for pairing-based cryptosystems" [Barreto et al. 2002], podemos ver um quadro comparativo de desempenho entre uma assinatura RSA com chaves de 1024 bits e um assinatura compacta BLS utilizando uma curva supersingular sobre $\mathbb{F}_{3^{97}}$ e também uma curva não-supersingular sobre $\mathbb{F}_{p}$, onde $p$ é um primo com 157 bits. Os parâmetros foram adotados de modo a se obter um nível de segurança equivalente entre os esquemas comparados. Os tempos estão expressos em milissegundos (ms) e foi utilizado um processador Pentium III $1 \mathrm{GHz}$.

Tabela 3.1: Desempenho de esquemas de assinatura RSA $\times$ BLS

\begin{tabular}{|l|c|c|c|}
\hline Algoritmo & Assinatura & Verificação & Total \\
\hline \hline Assinatura RSA 1024 & 7,90 & 0,40 & 8,30 \\
\hline Assinatura BLS $\mathbb{F}_{3^{97}}$ supersingular & 3,57 & 53,0 & 56,57 \\
\hline Assinatura BLS $\mathbb{F}_{p}$ não-supersingular, $|p|=157$ & 2,75 & 81,0 & 83,75 \\
\hline
\end{tabular}

Nessa tabela, podemos ver que o esquema da assinatura RSA (considerando o processo completo, ou seja, assinar e verificar) é cerca de 7 vezes mais rápido do que um esquema de assinatura BLS utilizando uma curva supersingular e cerca de 10 vezes mais rápido do que um esquema de assinatura BLS utilizando uma curva não-supersingular.

A título de observação, o pequeno tempo de verificação de uma assinatura RSA se dá por conta de uma variante na implementação do RSA conhecida como RSA em lote, onde são usados expoentes públicos extremamente pequenos.

No mesmo artigo [Barreto et al. 2002] também foi feita uma simulação com um esquema de criptografia de D. Boneh e M. Franklin (B-F) baseado em identidades utilizando uma 
curva sobre $\mathbb{F}_{p}$ - onde $p$ é um primo de 512 bits e a ordem da curva é um primo de 160 bits - cujos resultados podemos ver na tabela 3.2.

Tabela 3.2: Desempenho de esquemas de criptografia de Boneh e Franklin

\begin{tabular}{|l|c|c|}
\hline Operação & sem pré-processamento & com pré-processamento \\
\hline \hline Criptografia B-F & 48 & 36 \\
\hline Decriptografia B-F & 30 & 19 \\
\hline Total & 78 & 45 \\
\hline
\end{tabular}

Considerando que um esquema de criptografia como o RSA possui desempenho semelhante à assinatura RSA, podemos notar, analisando a tabela 3.2 que mesmo com um préprocessamento, o esquema de B-F é bem mais lento do que o RSA, seja na criptografia ou na decriptografia.

Entretanto, mais recentemente, I. Duursma e H. Lee [Duursma e Lee 2003] propuseram um algoritmo que também pode ser usado com curvas hiper-elípticas supersingulares sobre $\mathbb{F}_{p^{m}}$ e que, no caso particular de curvas de característica $p=3$, é mais eficiente que uma verificação ou decriptografia RSA para o mesmo nível de segurança.

Apesar desta aparente desvantagem no desempenho, podemos tomar como exemplo as otimizações feitas por Barreto et al. e Duursma \& Lee e o fato de que a busca de uma otimização no cálculo de emparelhamentos é uma preocupação constante dos pesquisadores da área e acreditar que a tendência para o futuro é diminuir cada vez mais tal desvantagem. Independente disso, o fato é que hoje já podemos considerar que as vantagens têm um peso maior sobre as desvantagens e, portanto, sistemas criptográficos baseados em identidades podem ser considerados como o estado da arte em criptografia.

\subsection{Resumo}

Apresentamos neste capítulo os sistemas baseados em identidades, foco principal desta dissertação. Em tais sistemas, a chave pública de um usuário é um identificador que o caracteriza de forma única, como por exemplo, seu endereço eletrônico. Com isso, não é mais necessário o uso de certificados digitais e nem mesmo uma infra-estrutura de gerenciamento, 
como a PKI. Além disso, uma mensagem pode ser transmitida antes mesmo do destinatário da mensagem ter obtido seu par de chaves. Outra característica importante é que as chaves particulares podem ser recuperadas, pois são geradas não pelo usuário, mas por uma terceira parte confiável. Tal característica, como vimos, dependendo da aplicação pode ou não ser desejável, mas caso não o seja, existem meios de a evitarmos, como veremos no capítulo 7.

Mostramos um esquema de assinatura compacta, que apesar de não ser baseado em identidades, utiliza emparelhamentos em curvas elípticas e, por essa razão, também o incluímos nesta dissertação.

Vimos também o esquema de criptografia de Boneh e Franklin, bem como o esquema de assinatura de Hess. Fizemos uma análise da importância da escolha do elemento aleatório nesses esquemas, análise esta que não foi feita pelos autores.

Apresentamos ainda, uma variação no esquema original de Boneh e Franklin, para que possa ser usado - em conjunto com um esquema de assinatura (por exemplo, o esquema de Hess) - como um protocolo de negociação de chaves simétricas robustas.

Finalmente, relacionamos as principais vantagens e desvantagens no uso de sistemas criptográficos baseados em identidades, chegando à conclusão de que os sistemas baseados em identidade podem ser considerados como o estado da arte em Criptografia assimétrica.

Veremos no capítulo a seguir o conceito de criptassinatura (signcryption), onde uma mensagem é assinada e criptografada em um único passo, permitindo a comunicação autenticada e sigilosa entre duas partes de uma forma mais eficiente do que a tradicional "assinar-e-depois-criptografar". Nesse capítulo, serão apresentados dois esquemas de criptassinatura e será feita uma comparação entre esses esquemas e o esquema tradicional. 


\section{Capítulo 4}

\section{Criptassinatura}

\subsection{Definição}

Na seção 2.2.5.2 vimos que, quando desejamos garantir autenticidade em ambos os extremos de uma comunicação, devemos combinar um esquema de assinatura com criptografia. Nos sistemas criptográficos baseados em identidades, também é possível garantir a autenticidade na origem e no destino, que chamaremos de autenticidade mútua.

Podemos conseguir essa autenticidade mútua de duas formas: a primeira delas, mais natural, é empregando esquemas de assinatura (signature) e de criptografia (encryption) de forma combinada, ou seja, em uma primeira fase, criptografamos alguma mensagem com a chave pública do destinatário e na fase 2, usamos nossa chave particular para assinar o texto que acabamos de criptografar. Ao receber a mensagem, o destinatário vai realizar o processo inverso, ou seja, primeiramente usa nossa chave pública para verificar a assinatura e em seguida usa sua chave particular para decriptografar, recuperando o texto legível. Cabe ressaltar que a ordem das fases, dependendo dos esquemas utilizados, pode ser mudada, ou seja, poderemos primeiramente assinar e depois criptografar, sendo que o destinatário, necessariamente, deverá realizar o processo na ordem inversa.

A segunda maneira de garantirmos autenticidade mútua é realizando as duas fases em um único passo, ou seja, assinamos e criptografamos uma mensagem em uma única fase. Tal conceito foi primeiramente proposto por Y. Zheng [Zheng 1997] e é conhecido como signcryption, que nesta dissertação vamos chamar de criptassinatura.

Apresentaremos neste capítulo dois esquemas de criptassinatura (signcryp- 
tion) [Nalla e Reddy 2003, Malone-Lee 2002] e faremos uma comparação em termos de custos computacionais entre esses dois esquemas e o esquema tradicional "assinar-e-depoiscriptografar"1.

No anexo B, o leitor poderá ver as sugestões que foram feitas a um dos autores do artigo "Signcryption scheme for Identity-based Cryptosystems" [Nalla e Reddy 2003], publicado em 28 de março de 2003. Estas sugestões foram todas acatadas pelo autor, que republicou o artigo com as mesmas em 09 de abril do mesmo ano.

\subsection{Utilizando esquemas conhecidos de criptografia e assi- natura}

Quando pensamos em um esquema combinado de assinatura e criptografia, a primeira idéia que nos vem à mente é utilizarmos um esquema conhecido de assinatura, associado a algum esquema conhecido de criptografia. Se usarmos como base os esquemas apresentados no capítulo 3, poderíamos pensar no esquema de criptografia de Boneh \& Franklin [Boneh e Franklin 2001] usado em conjunto com o esquema de Hess [Hess 2002]. Essa combinação de dois esquemas independentes é conhecida na literatura com "assinar-edepois-criptografar". Vejamos na figura 4.1 como garantir a autenticidade na origem e no destino, usando o esquema de Hess para assinar e o de Boneh \& Franklin para criptografar. Suponha que Alice deseja enviar uma mensagem $m$ para Beto, tendo certeza de que somente ele poderá decriptografar tal mensagem. Para isto, Alice pode usar, por exemplo, o esquema de Boneh \& Franklin que vimos na seção 3.4. Sendo assim, Alice usa a chave pública baseada em identidades de Beto $\left(Q_{\text {beto }}\right)$, calcula $(U, V)$ de acordo com as equações (3.13) e envia para Beto. Como somente Beto ${ }^{2}$ possui a chave particular $S_{\text {beto }}$ associada a $Q_{\text {beto }}$, Alice pode ter certeza de que somente ele poderá ter acesso a $m$, garantindo a autenticidade do destino.

Beto, por sua vez, ao receber $(U, V)$ consegue recuperar o legível $m$, mas não tem certeza de que $m$ foi realmente enviado por Alice, pois qualquer pessoa que tenha o endereço eletrônico de Beto poderia ter calculado o mesmo par $(U, V)$ e enviado a Beto, se

\footnotetext{
'Conhecido na literatura específica como "signature-then-encryption".

${ }^{2}$ Sabemos que o PKG de Beto também conhece $S_{\text {beto }}$, mas vamos supor que o PKG é confiável.
} 


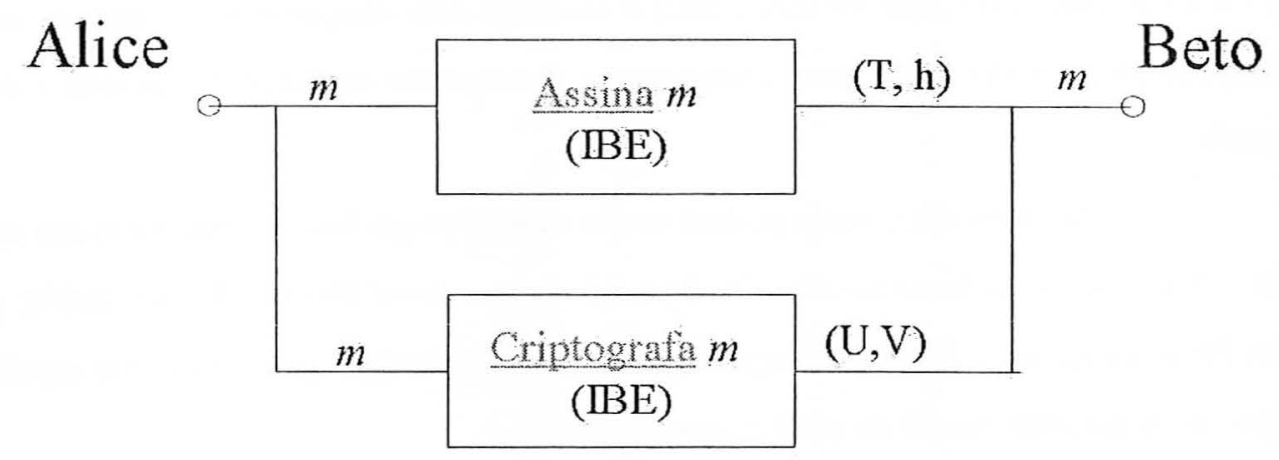

Figura 4.1: Esquema combinado de assinatura e criptografia - Primeiramente Alice assina uma mensagem $m$ e envia para Beto o par $(T, h)$, conforme visto no esquema de Hess. Em seguida, criptografa $m$ e envia o par $(U, V)$, como no esquema de Boneh \& Franklin. Beto, por sua vez, decriptografa $(U, V)$, recuperando $m$ e verifica a assinatura de Alice.

fazendo passar por Alice. Para que Beto possa garantir que foi Alice quem criptografou $m$, é necessário que Alice assine $m$ com sua chave particular baseada em identidades.

Alice então, usando por exemplo, o esquema de Hess que vimos na seção 3.5 pode assinar $m$ com sua chave particular $S_{\text {alice. }}$ Vimos na equação (3.19) que Alice calcula o valor $U$. Vamos utilizar aqui uma notação diferente do autor e renomear o valor desse $U$ para $T$, a fim de não confundir com o par $(U, V)$ enviado na criptografia de $m$. Desta forma, Alice envia $(T, h)$ para Beto.

Beto, ao receber $(T, h)$ faz as verificações necessárias e pode ter certeza de que a mensagem foi realmente enviada por Alice, garantindo a autenticidade da origem. Note que primeiramente, Beto deve decriptografar $(U, V)$ e recuperar $m$, pois o valor de $m$ será usado na verificação da assinatura de Alice (de acordo com a equação (3.21)).

\subsubsection{Contabilização de custo computacional}

Para que possamos fazer uma comparação entre esse esquema e os dois que serão apresentados a seguir, vamos contabilizar as principais operações realizadas, tendo em mente que consomem um tempo computacional na seguinte ordem decrescente:

1. cálculo de um emparelhamento;

2. exponenciação do resultado de um emparelhamento; 
3. multiplicação de pontos de uma curva elíptica por um inteiro.

Vamos simplificar a notação, chamando as três operações acima de TATE, EXP e MULT, respectivamente. É importante notarmos que alguns emparelhamentos podem ser précalculados, pois seus parâmetros não dependem da mensagem a ser transmitida. Isso pode significar um grande ganho em termos de tempo computacional e será levado em conta no cômputo geral. Sempre que nos depararmos com algum emparelhamento que pode ser pré-calculado, indicaremos tal fato ao leitor, durante a contabilização do número de operações realizadas.

Vamos, agora, contabilizar o número de operações TATE, EXP e MULT do esquema combinado de Boneh \& Franklin e Hess que, para simplificar, chamaremos de BFH.

- Criptografia

Primeiramente, vamos analisar o termo $e_{t}\left(r Q_{b e t o}, R_{T A}\right)$ da equação (3.13). Note que se usarmos a propriedade de bilinearidade, podemos reescrever esse termo como $e_{t}\left(Q_{b e t o}, R_{T A}\right)^{r} \mathrm{e}$ observarmos que $e_{t}\left(Q_{\text {beto }}, R_{T A}\right)$ pode ser pré-calculado, pois não depende da mensagem $m$ a ser enviada.

Portanto, vemos que o esquema BFH executa 1 MULT, 1 EXP e 1 TATE (que pode ser précalculado) na criptografia.

- Decriptografia

Pela equação (3.14), vemos que o emparelhamento $e_{t}\left(S_{b e t o}, U\right)$ não pode ser pré-calculado, pois depende de $U$ que, por sua vez, depende de $r$, que é escolhido aleatoriamente por Alice. Sendo assim, na decriptografia, o esquema BFH executa 1 TATE (que não pode ser précalculado) e nenhuma MULT e EXP.

\section{- Assinatura}

Vamos observar as equações (3.17) a (3.19). Observe que o emparelhamento $e_{t}\left(P_{1}, P\right)$ pode ser pré-calculado, pois $P$ é um ponto fixo e $P_{1}$ é escolhido por quem vai assinar a mensagem. Deste modo, o esquema BFH executa na assinatura 2 MULT, 1 EXP e 1 TATE (que pode ser pré-calculado). 
- Verificação da assinatura

Observando a equação (3.20), vemos que o emparelhamento $e_{t}\left(Q_{\text {alice }},-R_{T A}\right)$ pode ser précalculado, pois $Q_{\text {alice }}$ e $R_{T A}$ são valores conhecidos por Beto, independente da mensagem $m$ transmitida por Alice. Já o emparelhamento $e_{t}(T, P)$ não pode ser pré-calculado por Beto, pois depende de $T$ que é enviado por Alice (lembre-se que nesta seção "rebatizamos" o " $U$ " da assinatura para " $T$ ", para não confundir com o " $U$ " da criptografia).

Sendo assim, o esquema BFH executa na verificação da assinatura 1 EXP, nenhuma MULT e 2 TATE (dos quais, 1 pode ser pré-calculado).

Vamos agora, resumir o custo computacional do esquema BFH na tabela 4.1.

Tabela 4.1: Operações realizadas pelo esquema BFH

\begin{tabular}{|l|l|c|c|c|c|c|}
\hline Esquema & Operação & TATE & \multicolumn{2}{|c|}{ Pré-calc. } & EXP & MULT \\
\hline \hline \multirow{2}{*}{ BFH } & Assinar & 1 & 1 & $e_{t}\left(P_{1}, P\right)$ & 1 & 2 \\
\cline { 2 - 7 } & Criptografar & 1 & 1 & $e_{t}\left(Q_{\text {beto }}, R_{T A}\right)$ & 1 & 1 \\
\cline { 2 - 7 } & Decriptografar & 1 & - & - & - & - \\
\cline { 2 - 7 } & Verificar assinatura & 2 & 1 & $e_{t}\left(Q_{\text {alice }},-R_{T A}\right)$ & 1 & - \\
\cline { 2 - 7 } & Total & $\mathbf{5}$ & $\mathbf{3}$ & & $\mathbf{3}$ & $\mathbf{3}$ \\
\hline
\end{tabular}

\subsection{Esquema de Malone-Lee}

Vimos na seção anterior como garantir a autenticidade em ambos os extremos de uma comunicação utilizando criptografia e depois assinatura de uma mesma mensagem. Podemos conseguir essa autenticidade mútua em apenas um passo, com esquemas que são conhecidos na literatura específica como "signcryption", que traduzimos nesta dissertação para "criptassinatura".

Vejamos a seguir o esquema de J. Malone-Lee [Malone-Lee 2002]. Suponha que Alice deseja enviar uma mensagem $m$ para Beto em uma comunicação que exija autenticidade mútua. 


\subsubsection{Assinatura e criptografia}

Primeiramente, Alice escolhe um valor aleatório $z$, tal que $z \in \mathbb{F}_{q}$ e calcula:

$$
\begin{aligned}
U & =z P \\
r & =H_{2}(U \| m) \\
W & =z R_{T A} \\
V & =r S_{\text {alice }}+W \\
y & =e_{t}\left(Q_{\text {beto }}, W\right) \\
k & =H_{3}(y) \\
C & =k \oplus m
\end{aligned}
$$

A mensagem criptassinada a ser enviada para Beto é $(C, U, V)$. Note que Alice utiliza a chave pública de Beto $\left(Q_{\text {beto }}\right)$ e sua chave particular $\left(S_{\text {alice }}\right)$ no processo. A mesma discussão que fizemos na seção 3.4.5 quanto ao uso de uma função criptográfica simétrica em vez da operação de "ou-exclusivo" também se aplica a este esquema.

\subsubsection{Decriptografia e verificação da assinatura}

Beto, tendo recebido $(C, U, V)$ e conhecendo $Q_{\text {alice }}$ e $S_{\text {beto }}$, faz os seguintes cálculos para recuperar $m$ e verificar se a mensagem foi, de fato, criptassinada por Alice:

$$
\begin{aligned}
y & =e_{t}\left(S_{\text {beto }}, U\right) \\
k & =H_{3}(y) \\
m & =k \oplus C \\
r & =H_{2}(U \| m)
\end{aligned}
$$

E verifica se:

$$
e_{t}(V, P)=e_{t}\left(Q_{\text {alice }}, R_{T A}\right)^{r} \cdot e_{t}\left(U, R_{T A}\right)
$$

Note que na verificação, Beto utiliza sua chave particular $\left(S_{\text {beto }}\right)$ e a chave pública de Alice $\left(Q_{\text {alice }}\right)$. 


\subsubsection{Demonstração}

Vamos demonstrar por etapas que este esquema vai garantir autenticidade mútua.

- Prova que Alice e Beto calculam o mesmo $y$.

Vimos que Alice calcula $y=e_{t}\left(Q_{\text {beto }}, W\right)$ (equação (4.5)) e Beto calcula $y=e_{t}\left(S_{\text {beto }}, U\right)$ (equação (4.8)). Vamos provar que estes valores são iguais:

$$
\begin{aligned}
y & =e_{t}\left(S_{\text {beto }}, U\right) & & \operatorname{de}(4.8) \\
& =e_{t}\left(s Q_{\text {beto }}, U\right) & & \text { pois } S_{\text {beto }}=s Q_{\text {beto }} \\
& =e_{t}\left(Q_{\text {beto }}, s U\right) & & \text { por bilinearidade } \\
& =e_{t}\left(Q_{\text {beto }}, s z P\right) & & \operatorname{de}(4.1) \\
& =e_{t}\left(Q_{\text {beto }}, z R_{T A}\right) & & \text { pois } R_{T A}=s P \\
& =e_{t}\left(Q_{\text {beto }}, W\right) & & \operatorname{de}(4.3)
\end{aligned}
$$

- Prova que Alice e Beto calculam o mesmo $k$.

Das equações (4.6) e (4.9) podemos ver que ambos calculam $k=H_{3}(y)$ e como vimos que tanto Alice quanto Beto calculam o mesmo valor de $y$, o resultado segue.

- Prova que Beto consegue recuperar $m$.

Da equação (4.7) vimos que $C=k \oplus m$. Vimos também que Beto recebe $C$ e calcula $k$. Então, aplicando a propriedade da operação "ou-exclusivo", Beto calcula:

$$
C \oplus k=(m \oplus k) \oplus k=m
$$

Note que para executar este passo, Beto utilizou sua chave particular $S_{\text {beto }}$, garantindo a autenticidade no destino. Beto agora precisa ter certeza de que a mensagem foi enviada por Alice. Para tal, ele faz a verificação da equação (4.12). Vamos demonstrar que tal igualdade se satisfaz se, e somente se, a mensagem tiver sido criptassinada por Alice:

$$
\begin{array}{rlrl}
e_{t}\left(Q_{\text {alice }}, R_{T A}\right)^{r} \cdot e_{t}\left(U, R_{T A}\right) & =e_{t}\left(Q_{\text {alice }}, s P\right)^{r} \cdot e_{t}(z P, s P) & \text { de }(3.8) e(4.1) \\
& =e_{t}\left(r s Q_{\text {alice }}, P\right) \cdot e_{t}(s z P, P) & \text { por bilinearidade } \\
& =e_{t}\left(r s Q_{\text {alice }}+z s P, P\right) & & \text { por bilinearidade } \\
& =e_{t}\left(r s Q_{\text {alice }}+z R_{T A}, P\right) & & \text { de }(3.8) \\
& =e_{t}\left(r s Q_{\text {alice }}+W, P\right) & & \text { de }(4.3) \\
& =e_{t}\left(r S_{\text {alice }}+W, P\right) & & \text { pois } s Q_{\text {alice }}=S_{\text {alice }} \\
& =e_{t}(V, P) & & \text { de }(4.12)
\end{array}
$$


Note que nesta verificação, Beto utiliza a chave pública $Q_{\text {alice }}$ de Alice, garantindo a autenticidade na origem. Se um intruso Carlos bloquear a mensagem $(C, U, V)$ enviada de Alice para Beto e fabricar uma mensagem $\left(C^{\prime}, U^{\prime}, V^{\prime}\right)$, tentando se fazer passar por Alice, não terá sucesso, pois na verificação da equação (4.12) a igualdade não será satisfeita:

$$
e_{t}\left(V^{\prime}, P\right) \neq e_{t}\left(Q_{\text {alice }}, R_{T A}\right)^{r} \cdot e_{t}\left(U^{\prime}, R_{T A}\right)
$$

Portanto, este esquema não é suscetível a um ataque de modificação.

\subsubsection{Importância da escolha do elemento aleatório $z$}

Embora o autor [Malone-Lee 2002] não destaque a importância da escolha de $z$, vamos montar um ataque semelhante ao da seção 3 de [Borisov, Goldberg e Wagner 2001] para vermos o que aconteceria se Alice enviasse duas mensagens distintas $m_{1}$ e $m_{2}$ para Beto, sem se preocupar em escolher dois $z$ distintos. Neste caso, pelas equações (4.1) e (4.3), vemos que $U_{1}=U_{2}$ e $W_{1}=W_{2}$. Como conseqüência, teríamos que $y_{1}=y_{2}$ e $k_{1}=k_{2}$. Os demais valores calculados por Alice seriam distintos, pois dependem de $m$. Se um intruso Carlos interceptar as mensagens criptassinadas $\left(C_{1}, U_{1}, V_{1}\right)$ e $\left(C_{2}, U_{2}, V_{2}\right)$, e sabendo que:

$$
\left\{\begin{array}{l}
m_{1}=k_{1} \oplus C_{1} \quad(*) \\
m_{2}=k_{2} \oplus C_{2} \quad(* *)
\end{array}\right.
$$

Ele pode calcular $(*) \oplus(* *)$, encontrando:

$$
m_{1} \oplus m_{2}=C_{1} \oplus C_{2}
$$

Pois $k_{1}=k_{2}$. Deste modo, como ele conhece $C_{1}$ e $C_{2}$ (pois supomos que ele interceptou), basta que ele conheça o valor de $m_{1}$ (sem perda de generalidade), para que ele possa realizar um ataque de "texto legível conhecido" e recuperar $m_{2}$.

Portanto, para a segurança desse esquema, é fundamental que seja escolhido um $z$ distinto para cada mensagem a ser transmitida.

Apenas reforçando o que já foi comentado, mesmo que Alice use sempre o mesmo $z$, um intruso Carlos, apesar de ter a possibilidade de recuperar $m$, não conseguirá se fazer passar por Alice, devido à verificação da equação (4.12). Portanto, em tal situação, um ataque de interceptação poderá ter sucesso, mas um ataque de modificação ou mesmo de fabricação, não o terá. 


\subsubsection{Contabilização de custo computacional}

Vamos agora contabilizar o número de operações TATE, EXP e MULT realizadas pelo esquema de Malone-Lee.

- Assinar e criptografar

Observando as equações (4.1) a (4.7), vemos que o emparelhamento $e_{t}\left(Q_{\text {beto }}, W\right)$ pode ser reescrito como $e_{t}\left(Q_{\text {beto }}, R_{T A}\right)^{z}$ usando a equação (4.3) e bilinearidade. Com isso, o emparelhamento $e_{t}\left(Q_{\text {beto }}, R_{T A}\right)$ pode ser pré-calculado por Beto.

Temos então que o esquema Malone-Lee executa 1 TATE (que pode ser pré-calculado), 1 EXP e 3 MULT. A exponenciação que surgiu no nosso cálculo refere-se à modificação que fizemos ao reescrever o emparelhamento $e_{t}\left(Q_{\text {beto }}, z R_{T A}\right)$ como $e_{t}\left(Q_{\text {beto }}, R_{T A}\right)^{z}$.

- Decriptografar e verificar assinatura

Antes de calcularmos o custo computacional das operações de decriptografia e verificação de assinatura do esquema Malone-Lee, vamos observar que o termo $R_{T A}$ se repete no produto do segundo membro da igualdade da equação (4.12). Desta forma, poderíamos aplicar a propriedade 3.5 de bilinearidade e reescrever a equação (4.12) como:

$$
e_{t}(P, V)=e_{t}\left(r Q_{a l i c e}+U, R_{T A}\right)
$$

Com tal modificação, calcularíamos 1 TATE a menos, porém, em contrapartida, teríamos também a diminuição de 1 TATE no número de emparelhamentos pré-calculáveis, já que, ao passarmos $r$ para dentro do parênteses, o emparelhamento $e_{t}\left(r Q_{\text {alice }}, R_{T A}\right)$ deixa de ser précalculável, pois $r$ depende da mensagem (conforme equação (4.11)). Tendo em vista que tal modificação não traria uma melhoria significativa no cômputo geral do custo computacional do esquema de Malone-Lee — pois o número de emparelhamentos a serem efetivamente calculados (ou seja, descontando os que poderiam ser pré-calculados) não se alteraria — optamos em não fazer essa modificação na equação (4.12), deixando-a na sua forma original, como no artigo de J. Malone-Lee [Malone-Lee 2002].

Portanto, das equações (4.8) a (4.12), vemos que os emparelhamentos $e_{t}\left(S_{\text {beto }}, U\right)$ e $e_{t}\left(U, R_{T A}\right)$ não podem ser pré-calculados, pois dependem de $U$; da mesma forma, 
o emparelhamento $e_{t}(P, V)$ também não pode ser pré-calculado, pois depende de $V$; o emparelhamento $e_{t}\left(Q_{\text {alice }}, R_{T A}\right)$, porém, pode ser pré-calculado por Beto, pois ele conhece os parâmetros $Q_{\text {alice }}, R_{T A}$, que não dependem de $m$.

Com isso, o esquema de Malone-Lee executa 4 TATE (dos quais, 1 pode ser pré-calculado), 1 EXP e nenhuma MULT. Caso optássemos por fazer a modificação na equação (4.12), o esquema de Malone-Lee executaria 3 TATE (dos quais nenhum poderia ser pré-calculado), nenhuma EXP e 1 MULT.

Vamos agora, resumir o custo computacional do esquema Malone-Lee na tabela 4.2.

Tabela 4.2: Operações realizadas pelo esquema Malone-Lee

\begin{tabular}{|c|c|c|c|c|c|c|}
\hline Esquema & Operação & TATE & & Pré-calc. & EXP & MULT \\
\hline \multirow[t]{3}{*}{ Malone-Lee } & Assinar e criptografar & 1 & 1 & $e_{t}\left(Q_{\text {beto }}, R_{T A}\right)$ & 1 & 3 \\
\hline & decriptografar e verificar assinatura & 4 & 1 & $e_{t}\left(Q_{\text {alice }}, R_{T A}\right)$ & 1 & - \\
\hline & Total & 5 & 2 & & 2 & 3 \\
\hline
\end{tabular}

\subsection{Esquema de Nalla \& Reddy}

Veremos agora o esquema de criptassinatura proposto por D. Nalla e K.C. Reddy no artigo Signcryption scheme for Identity-based Cryptosystems [Nalla e Reddy 2003]. Este esquema, como veremos, tem desempenho melhor do que os dois vistos anteriormente e, até o momento em que concluímos esta dissertação, não tivemos conhecimento de falhas em sua segurança.

Cabe ressaltar que esse artigo foi publicado em 28 de março de 2003 e nessa versão havia algumas incorreções. Após estudá-lo, enviei um correio eletrônico a um dos autores (Divya Nalla) apontando os erros e sugerindo mudanças. O artigo foi então, republicado em 09 de abril do mesmo ano com todas as mudanças sugeridas por mim. No anexo B, comentaremos as incorreções que existiam e as mudanças que foram sugeridas. Ainda nesse anexo, o leitor poderá ver o e-mail enviado ao autor e sua respectiva resposta. Vamos ao esquema de Nalla \& Reddy. 


\subsubsection{Assinatura e criptografia}

Primeiramente, Alice escolhe um valor aleatório $a$, tal que $a \in \mathbb{F}_{q}$ e calcula:

$$
\begin{aligned}
R & =a S_{\text {alice }} \\
h & =H_{2}\left(R\left\|H_{3}\left(e_{t}\left(Q_{\text {beto }}, S_{\text {alice }}\right)\right)\right\| m\right) \\
S & =a h Q_{\text {alice }} \\
k_{a} & =H_{3}\left(e_{t}\left(Q_{\text {beto }}, S_{\text {alice }}\right)^{a h}\right) \\
C & =k_{a} \oplus m
\end{aligned}
$$

e envia $(R, S, C)$ para Beto. Veja que Alice usa sua chave particular $S_{\text {alice }}$ e a chave pública de Beto $Q_{b e t o}$, garantindo a autenticidade mútua. Aqui também poderíamos trocar a operação de "ou-exclusivo" por uma função criptográfica simétrica, como fizemos na seção 3.4.5, mas o esquema não poderia ser usado como protocolo de troca de chaves, como veremos mais adiante.

\subsubsection{Decriptografia e verificação da assinatura}

Beto, tendo recebido $(R, S, C)$ e conhecendo $Q_{\text {alice }}$ e $S_{\text {beto }}$, faz os seguintes cálculos para recuperar $m$ e confirmar se a mensagem foi, de fato, criptassinada por Alice:

$$
\begin{aligned}
k_{b} & =H_{3}\left(e_{t}\left(S_{\text {beto }}, S\right)\right) \\
m & =k_{b} \oplus C \\
h & =H_{2}\left(R\left\|H_{3}\left(e_{t}\left(S_{\text {beto }}, Q_{\text {alice }}\right)\right)\right\| m\right)
\end{aligned}
$$

e verifica se:

$$
e_{t}\left(S_{\text {beto }}, S\right)=e_{t}\left(Q_{\text {beto }}, R\right)^{h}
$$

Note que na verificação, Beto utiliza sua chave particular $\left(S_{\text {beto }}\right)$ e a chave pública de Alice (Qalice).

\subsubsection{Demonstração}

Vamos demonstrar por etapas que este esquema vai garantir autenticidade mútua. 
- Prova que Alice e Beto calculam a mesma chave (ou seja $k_{a}=k_{b}$ ).

Vimos nas equações (4.17) e (4.19) que Alice calcula $k_{a}=H_{3}\left(e_{t}\left(Q_{\text {beto }}, S_{\text {alice }}\right)^{a h}\right)$ e Beto calcula $k_{b}=H_{3}\left(e_{t}\left(S_{\text {beto }}, S\right)\right)$. Vamos provar que estes valores são iguais:

$$
\begin{aligned}
k_{b} & =e_{t}\left(S_{\text {beto }}, S\right) & & \text { de }(4.19) \\
& =e_{t}\left(S_{\text {beto }}, a h Q_{\text {alice }}\right) & & \text { de }(4.16) \\
& =e_{t}\left(S_{\text {beto }}, Q_{\text {alice }}\right)^{a h} & & \text { por bilinearidade } \\
& =e_{t}\left(s Q_{\text {beto }}, Q_{\text {alice }}\right)^{a h} & & \text { pois } S_{\text {beto }}=s Q_{\text {beto }} \\
& =e_{t}\left(Q_{\text {beto }}, s Q_{\text {alice }}\right)^{a h} & & \text { por bilinearidade } \\
& =e_{t}\left(Q_{\text {beto }}, S_{\text {alice }}\right)^{a h} & & \text { pois } s Q_{\text {alice }}=S_{\text {alice }} \\
& =k_{a} & & \text { de }(4.17)
\end{aligned}
$$

- Prova que Beto consegue recuperar $m$.

Da equação (4.18) vimos que $C=k_{a} \oplus m$. Vimos também que Beto recebe $C$ e calcula $k_{b}$.

Como provamos que $k_{a}=k_{b}$, Beto, aplicando a propriedade da operação "ou-exclusivo", calcula:

$$
C \oplus k_{b}=\left(m \oplus k_{a}\right) \oplus k_{b}=m
$$

Para ter certeza de que a mensagem foi enviada por Alice, Beto faz a verificação da equação (4.22). Vamos demonstrar que tal igualdade se satisfaz se, e somente se, a mensagem tiver sido criptassinada por Alice:

$$
\begin{aligned}
e_{t}\left(Q_{\text {beto }}, R\right)^{h} & =e_{t}\left(Q_{\text {beto }}, a S_{\text {alice }}\right)^{h} & & \text { de }(4.14) \\
& =e_{t}\left(Q_{\text {beto }}, a h S_{\text {alice }}\right) & & \text { por bilinearidade } \\
& =e_{t}\left(Q_{\text {beto }}, a h s Q_{\text {alice }}\right) & & \text { pois } S_{\text {alice }}=s Q_{\text {alice }} \\
& =e_{t}\left(s Q_{\text {beto }}, a h Q_{\text {alice }}\right) & & \text { por bilinearidade } \\
& =e_{t}\left(S_{\text {beto }}, a h Q_{\text {alice }}\right) & & \text { pois } s Q_{\text {beto }}=S_{\text {beto }} \\
& =e_{t}\left(S_{\text {beto }}, S\right) & & \text { de }(4.16)
\end{aligned}
$$

\subsubsection{Segurança no esquema de Nalla \& Reddy}

Antes de fazermos a contabilização do número de operações executadas no esquema de Nalla \& Reddy, vamos fazer uma análise um pouco mais detalhada de segurança.

- Problema Diffie-Hellman.

Para analisarmos a segurança no esquema de Nalla \& Reddy, devemos considerar dois fatores: 
1. Para obter vantagem em decriptografar uma mensagem, um intruso precisa calcular corretamente a chave $k$, seja calculando $e_{t}\left(Q_{\text {beto }}, S_{\text {alice }}\right)^{\text {ah }}$ (essa opção pode ser descartada, pois $a$ é aleatório e $h$ depende de $m$ ) ou então calculando $e_{t}\left(S_{b e t o}, S\right)$, de acordo com as equações (4.17) e (4.19).

Como $Q_{\text {beto }}$ e $Q_{\text {alice }}$ são pontos da curva, sejam $Q_{\text {beto }}=b P$ e $Q_{\text {alice }}=c P$, para inteiros quaisquer $b$ e $c$. Sabendo que o intruso conhece $b P, s P=R_{T A}$ e considerando que ele tenha interceptado $S=a h Q_{\text {alice }}=a h c P$, basta tomar $x=a h c$ e então o intruso vai calcular $e_{t}(P, P)^{b x s}$, dado que conhece $b P, x P$ e $s P$ e supondo que o BDHP seja tratável. Note porém, que $e_{t}\left(S_{\text {beto }}, S\right)=e_{t}(s b P, a h c P)=e_{t}(P, P)^{s b a h c}$ e sendo $x=a h c$, claramente este resultado é igual a $e_{t}(P, P)^{b x s}$.

Logo, se o BDHP for tratável, o intruso consegue decriptografar a mensagem (mesmo que o GDHP seja intratável). Neste caso, podemos dizer que a segurança do esquema de Nalla \& Reddy "quanto à confidencialidade da mensagem" depende da dificuldade do BDHP;

2. Entretanto, "do outro lado da comunicação" um intruso pode tentar obter vantagem criando sua própria mensagem e tentar forjar uma assinatura de Alice. Para isto, ele precisa tentar "falsificar a assinatura de Alice", ou seja, precisa reproduzir sua chave particular $\left(S_{\text {alice }}\right)$. Considerando que ele conhece $c P=Q_{\text {alice }}$ e $s P=R_{T A}$, se o GDHP for tratável, ele calcula $c s P=s Q_{\text {alice }}=S_{\text {alice }}$ e consegue forjar a assinatura. Note que, assim como na assinatura de Hess, se o GDHP fosse intratável, de nada adiantaria o BDHP ser tratável, pois o cálculo de $e_{t}(P, P)^{b s c}$ não convenceria Beto de que a mensagem foi originada de Alice. Portanto, podemos dizer que a segurança do esquema de Nalla \& Reddy "quanto à autenticidade da origem" depende da dificuldade do GDHP.

Veremos a seguir mais algumas considerações sobre segurança:

- Confidencialidade.

A confidencialidade é alcançada nesse esquema, tendo em vista que as mensagens são criptografadas com a chave pública do destinatário, garantindo que somente ele terá acesso; 
- Autenticidade.

Como vimos, a autenticidade é garantida nos dois extremos da comunicação. Primeiramente, Alice tem certeza de que somente Beto poderá ler a mensagem $m$, pois só ele tem a chave $S_{b e t o}$. Por outro lado, Beto tem certeza de que a mensagem foi enviada por Alice, pois a mesma foi assinada com a chave $S_{\text {alice}}$;

- Segurança contra ataque de "homem-no-meio".

Qualquer alteração no conteúdo de $m$ será percebido por Beto na verificação da equação (4.22). Suponha que um intruso Carlos bloqueou os valores $(R, S, C)$ transmitidos de Alice para Beto e os substituiu por valores $\left(R^{\prime}, S^{\prime}, C^{\prime}\right)$ que ele, Carlos, calculou. Note que na equação (4.21), Beto usa a chave pública $Q_{a l i c e}$ (pois ele pensa que a mensagem foi enviada por Alice). Desta forma, para que Carlos conseguisse produzir o mesmo $h$ que Beto vai calcular usando $Q_{\text {alice}}$, teria que conhecer $S_{\text {alice }}$. Qualquer outro valor que Carlos use, diferente de $S_{\text {alice }}$ em (4.15), vai gerar um valor de $h$ diferente do que Beto calcula e, portanto, Beto perceberá que houve tentativa de modificação. Note que $e_{t}\left(Q_{\text {beto }}, S_{\text {alice }}\right)=e_{t}\left(Q_{\text {beto }}, s Q_{\text {alice }}\right)=e_{t}\left(s Q_{\text {beto }}, Q_{\text {alice }}\right)=e_{t}\left(S_{\text {beto }}, Q_{\text {alice }}\right)$.

Isso significa dizer que este esquema não é suscetível a ataque de modificação;

- Irretratabilidade.

Alice não pode negar a transmissão de qualquer mensagem, pois sua chave $Q_{\text {alice }}$ é usada na decriptografia e verificação de assinatura e portanto, se qualquer outro valor diferente de $S_{\text {alice }}$ tivesse sido usado na criptassinatura, a igualdade da equação (4.22) não seria satisfeita.

- Segurança no futuro.

Suponha que um intruso Carlos interceptou os valores $\left(R_{1}, S_{1}, C_{1}\right)$, resultados de uma mensagem $m_{1}$ criptassinada por Alice para Beto. Mesmo se, mais tarde, $S_{\text {alice }}$ for comprometida, Carlos não conseguirá ter acesso ao conteúdo de $m_{1}$, pois para recuperar $m_{1}$, através da equação (4.18), teria que conhecer $k_{a}$. Porém, pela equação (4.17), $k_{a}$ depende de $a$ e de $h$, que são desconhecidos pelo intruso. Note que $a$ está protegido pelo PLD-CE, como pode ser visto na equação (4.14) e $h$ também não pode ser calculado, pois depende 
de $m_{1}$, como pode ser visto na equação (4.15). Da mesma forma, ele não consegue calcular $k_{b}$ pois não conhece $S_{\text {beto }}$. Portanto, mesmo se a chave particular do remetente da mensagem for comprometida, as mensagens já transmitidas permanecem seguras.

- Importância da escolha do elemento aleatório $a$.

Neste esquema, diferente do que ocorre no esquema de Malone-Lee, mesmo se Alice escolher sempre o mesmo $a$ para criptassinar mensagens distintas $m_{1}$ e $m_{2}$, um intruso Carlos não conseguirá recuperar $m_{2}$ dado que conhece $m_{1}$ (ataque por texto legível conhecido), pois o valor de $k_{a}$ depende de $h$ que, por sua vez, depende da mensagem a ser transmitida. Ainda assim, é recomendável que Alice sempre use um a distinto para cada mensagem, pois desse modo, mesmo que criptassine mensagens iguais para Beto duas vezes (em ocasiões distintas), gerará textos diferentes, aumentando ainda mais a segurança.

\subsubsection{Contabilização de custo computacional}

Vamos agora contabilizar o número de operações TATE, EXP e MULT realizadas pelo esquema de Nalla \& Reddy.

- Assinar e criptografar

Analisando as equações (4.14) a (4.18), vemos que o emparelhamento $e_{t}\left(Q_{\text {beto }}, S_{\text {alice }}\right)$ pode ser pré-calculado por Alice.

Desta forma, o esquema Nalla \& Reddy executa 1 TATE (que pode ser pré-calculado), 1 EXP e 2 MULT para assinar e criptografar.

- Decriptografar e verificar assinatura

Das equações (4.19) a (4.22), vemos que os emparelhamentos $e_{t}\left(S_{\text {beto }}, S\right)$ e $e_{t}\left(Q_{\text {beto }}, R\right)$ não podem ser calculados, pois dependem respectivamente de $S$ e $R$, que são enviados por Alice. Já o emparelhamento $e_{t}\left(S_{\text {beto }}, Q_{\text {alice }}\right)$ pode ser pré-calculado por Beto.

Isto nos leva a concluir que o esquema Nalla \& Reddy executa 3 TATE (dos quais, 1 pode ser pré-calculado), 1 EXP e nenhuma MULT para decriptografar e verificar assinatura. 
Vamos agora, resumir o custo computacional do esquema Nalla \& Reddy na tabela 4.3.

Tabela 4.3: Operações realizadas pelo esquema Nalla \& Reddy

\begin{tabular}{|c|c|c|c|c|c|c|}
\hline Esquema & Operação & TATE & & Pré-calc. & EXP & MULT \\
\hline \multirow[t]{3}{*}{ Nalla \& Reddy } & Assinar e criptografar & 1 & 1 & $e_{t}\left(Q_{\text {beto }}, S_{\text {alice }}\right)$ & 1 & 2 \\
\hline & decriptografar e verificar assinatura & 3 & 1 & $e_{t}\left(Q_{\text {alice }}, S_{\text {beto }}\right)$ & 1 & - \\
\hline & Total & 4 & 2 & & 2 & 2 \\
\hline
\end{tabular}

\subsection{Comparação entre os esquemas BFH, MALONE-LEE e NALLA \& REDDY}

Para que possamos fazer uma comparação em termos de desempenho entre os esquemas BFH, MALONE-LEE e NALLA \& REDDY, vamos primeiramente, observar a tabela (4.4), construída com a linha "Total" das tabelas (4.1), (4.2) e (4.3). Para efeito de com-

Tabela 4.4: Comparação entre os esquemas BFH, MALONE-LEE e NALLA \& REDDY

\begin{tabular}{|l|c|c|c|c|}
\hline Esquema & TATE & Pré-calc. & EXP & MULT \\
\hline \hline BFH & 5 & 3 & 3 & 3 \\
\hline Malone-Lee & 5 & 2 & 2 & 3 \\
\hline Nalla \& Reddy & 4 & 2 & 2 & 2 \\
\hline
\end{tabular}

paração, vamos supor que Alice deseja enviar uma mensagem para Beto em que a autenticidade mútua é um requisito dessa comunicação. Vamos considerar também que todos os emparelhamentos que podem ser pré-calculados já o foram antes de iniciar a comunicação. Vemos pela tabela (4.4) que o esquema de Nalla \& Reddy executa um total de 4 TATE, dos quais 2 podem ser pré-calculados. Considerando a hipótese de que já houve a pré-computação, podemos dizer que o esquema de Nalla \& Reddy executará 2 TATE, mesmo número de TATE que o esquema de BFH e 1 a menos do que o de Malone-Lee. Sabendo que o cálculo do emparelhamento é a operação de maior custo computacional, podemos dizer que os esquemas BFH e Nalla \& Reddy têm desempenho melhor do que o de Malone-Lee. 
Para compararmos os esquemas BFH e Nalla \& Reddy, devemos observar na tabela (4.4) a segunda operação de maior custo computacional, que é a operação EXP. Vemos então que o esquema Nalla \& Reddy realiza uma operação EXP a menos do que o esquema BFH e portanto, podemos concluir que o esquema Nalla \& Reddy é o mais eficiente dos três.

Uma outra vantagem que o esquema Nalla \& Reddy leva sobre os outros dois apresentados é o fato de não ser suscetível a um ataque por texto legível conhecido, caso não se tenha o cuidado de escolher sempre um valor diferente ("NONCE") para cada mensagem a ser enviada.

Como podemos observar nas equações (4.14) a (4.22), o esquema de Nalla \& Reddy não utiliza o valor de $R_{T A}$ em nenhum passo (nem na criptografia e assinatura e nem na decriptografia e verificação). Tal fato pode se tornar em mais uma vantagem, a medida que os usuários que participem de um sistema onde existam diversas Autoridades de confiança, não precisarão armazenar as chaves públicas padrão destas Autoridades.

Entretanto, se formos pensar na implementação do esquema de Nalla e Reddy, se o uso de curvas supersingulares for aceitável e, com elas, o emparelhamento simétrico $e: E\left(\mathbb{F}_{q}\right)[r] \times E\left(\mathbb{F}_{q}\right)[r] \rightarrow \mathbb{F}_{q^{*}}^{*}$ definido por $e(P, Q)=e(P, \phi(Q))$ [Boneh e Franklin 2001], então há chances do esquema de Nalla e Reddy ser competitivo. Se, ao contrário, apenas curvas não-supersingulares (chamadas ordinárias) forem desejáveis por considerações de segurança ${ }^{3}$ podemos notar que quando Alice é a origem da mensagem para Beto, suas chaves $\left(S_{\text {alice }}\right.$ na etapa em que Alice criptassina a mensagem e $Q_{\text {alice }}$ quando Beto vai decriptografar e verificar) aparecem no segundo argumento do emparelhamento de Tate. Quanto a Beto, suas chaves $\left(Q_{b e t o}\right.$ quando Alice criptassina e $S_{\text {beto }}$ quando ele decriptografa e verifica) aparecem sempre como o primeiro argumento do emparelhamento de Tate.

Como pode ser visto na seção 3.2.4.1, o primeiro argumento do emparelhamento de Tate é um ponto em $E\left(\mathbb{F}_{q}\right)$ e o segundo argumento é um ponto em $E\left(\mathbb{F}_{q^{k}}\right)$. Com isso, vemos que as chaves do remetente da mensagem devem ser pontos em $E\left(\mathbb{F}_{q^{k}}\right)$ enquanto que as chaves do destinatário devem ser pontos em $E\left(\mathbb{F}_{q}\right)$. Tal fato pode ser inconveniente, pois além do desconforto de o PKG ter que gerar dois pares de chaves para cada usuário (um par em

\footnotetext{
${ }^{3}$ Segundo S. Galbraith [Galbraith 2001], o uso de curvas supersingulares deve ser evitado em criptografia, pois nestas curvas, o PLD-CE pode ser tratável.
} 
$E\left(\mathbb{F}_{q}\right)$ e o outro em $E\left(\mathbb{F}_{q^{k}}\right)$ ), existirá um custo maior de implementação, pois deverá ser criada uma nova função de espalhamento, que vai mapear uma sequiência de bits em um ponto de $E\left(\mathbb{F}_{q^{k}}\right)$. Neste caso, o custo acima parece inevitável (no sentido de que evitá-lo é um problema em aberto).

Apesar de tudo, tal alteração é transparente para o usuário, pois ele continua só precisando digitar o identificador da origem e do destino e a mensagem que deseja transmitir, deixando que o protocolo decida quando usar uma chave em $E\left(\mathbb{F}_{q^{k}}\right)$ ou quando usar uma chave em $E\left(\mathbb{F}_{q}\right)$. O mesmo ocorre para o destino da mensagem.

Considerando que o esquema de Nalla e Reddy, comparado com o tradicional “assinar-e-depois-criptografar", possui um desempenho superior, porém não muito significativo - já que ambos calculam o mesmo número de emparelhamentos - e levando-se em conta a inconveniência para o PKG gerar sempre o dobro do número de chaves e o maior custo na implementação, concluímos, ao contrário do que os autores afirmam [Nalla e Reddy 2003] que o esquema de Nalla e Reddy não é muito superior ao tradicional "assinar-e-depois-criptografar" e portanto, a relação custo-benefício de implementar o esquema de Nalla e Reddy é pequena e com isso, o esquema tradicional, em nossa opinião, continua sendo a melhor opção de se conseguir autenticidade mútua.

Vimos na seção 3.4 .5 que o esquema tradicional, combinando criptografia com assinatura (por exemplo, Boneh \& Franklin [Boneh e Franklin 2001] e Hess [Hess 2002]) pode ser usado como um protocolo de negociação de chaves simétricas. É importante observar que o esquema de Nalla \& Reddy [Nalla e Reddy 2003] não pode ser usado dessa forma, pois a chave calculada depende da mensagem (pela equação (4.17), $k_{a}$ depende de $h$ que, por sua vez, de acordo com a equação (4.15), depende de $m$ ). Já com o esquema de Malone-Lee, tal situação é possível, bastando na equação (4.2) substituir $m$ pelo $k$ calculado na equação (4.6). Entretanto, como vimos que o esquema tradicional é mais eficiente do que o esquema de Malone-Lee, mantemos nossa opção pelo primeiro.

Mais recentemente, foi publicado um novo artigo sobre um outro protocolo de criptassinatura [Boyen 2003]. Este esquema, entretanto, também é menos eficiente do que o de Nalla e Reddy, pois calcula 5 emparelhamentos, dos quais somente 2 podem ser préprocessados. Por esta razão, resolvemos não estudar este esquema mais a fundo. 


\subsection{Resumo}

Vimos neste capítulo que podemos conseguir autenticidade em ambos os extremos de uma comunicação empregando um esquema combinado de assinatura e criptografia (que chamamos de "assinar-e-depois-criptografar") ou empregando um esquema de assinatura $\&$ criptografia em um único passo, que batizamos de criptassinatura (signcryption).

Estudamos com detalhes um esquema combinado e dois de criptassinatura, contabilizando o custo computacional em cada um deles e concluímos que o esquema de Nalla \& Reddy [Nalla e Reddy 2003] é mais eficiente para garantir a autenticidade mútua. Essa superioridade, porém, não é muito significativa e, por outro lado, existe a inconveniência de o PKG ter que gerar sempre dois pares de chaves para cada usuário, caso não seja conveniente a adoção de curvas supersingulares por questões de segurança. Desta forma, concluímos que o esquema tradicional ainda é a melhor opção para se garantir autenticidade em ambos os extremos da comunicação.

Também neste capítulo (assim como no capítulo anterior), fizemos uma análise da importância na escolha do elemento aleatório nos esquemas de Nalla \& Reddy e Malone-Lee, análise essa que não foi feita pelos autores.

Destacamos ainda que foram feitas várias sugestões de alteração ao esquema original proposto por Nalla \& Reddy e que todas as sugestões propostas foram implementadas pelos autores. Tais alterações podem ser vistas com detalhes no anexo B.

Veremos no próximo capítulo as principais aplicações realizadas com sistemas criptográficos baseados em identidades. 


\section{Capítulo 5}

\section{Aplicações e hierarquia de sistemas baseados em identidades}

Neste capítulo, vamos apresentar as principais aplicações de sistemas criptográficos baseados em identidades e também como podemos certificar chaves públicas baseadas em identidades, através de uma hierarquia de certificação. É importante ressaltar que a maioria das aplicações que serão vistas aqui também são possíveis em sistemas criptográficos baseados em chaves assimétricas tradicionais. Portanto, nosso objetivo aqui não é mostrar que certa aplicação é uma exclusividade dos sistemas baseados em identidades e, sim, mostrar que determinada aplicação também pode ser realizada em tais sistemas e muitas vezes, de forma mais eficiente.

\subsection{Aplicações}

Vimos no capítulo 3 que, para gerar um par de chaves baseadas em identidades, é necessário apenas possuir um par de chaves padrão. Tal propriedade vai proporcionar uma grande flexibilidade nos sistemas baseados em identidades, pois permite uma descentralização do papel de gerador de chaves (PKG), como veremos a seguir.

Suponha que os usuários de um sistema sejam empregados de uma corporação. É natural se esperar que cada corporação seja capaz de gerar as chaves particulares para seus empregados, ou seja, cada corporação age como uma autoridade de confiança ${ }^{1}(\mathrm{TA})$. Pode-

\footnotetext{
${ }^{1}$ Como vimos no capítulo 2, autoridade de confiança (TA) é um gerador de chaves particulares (PKG) considerado "totalmente idôneo".
} 
mos descer ainda mais na hierarquia e supor que um usuário seja sua própria TA. Isto é possível dentro de um esquema baseado em identidades e permite uma série de aplicações, que veremos a seguir.

\subsubsection{Revogação de chaves públicas}

Vimos no capítulo 2 que o processo de revogação de um certificado digital pode ser demorado, levando a uma brecha na segurança do sistema e, por sua vez, representando uma grande vulnerabilidade nos sistemas criptográficos de chaves assimétricas tradicionais, que seguem o padrão PKI. Nos sistemas baseados em identidades, como vimos, não há a necessidade de certificados digitais para garantir a autenticidade das chaves públicas mas, por outro lado, sabemos que se uma mesma chave é usada por muito tempo, ela pode se tornar vulnerável a criptanálise e, portanto, quanto maior o nível de segurança exigido, menor será o tempo de vida recomendado para o uso de uma chave.

Sistemas baseados em identidades permitem que sejam utilizadas chaves públicas (e seu correspondente par particular) com prazo de validade pré-estabelecido. Basta que seja acrescentado o período de validade no identificador, como por exemplo:

$$
\begin{gathered}
\text { alice@ime.usp.br II } 2003 \text { ou } \\
\text { alice@ime.usp.br II novembro2003 }
\end{gathered}
$$

conforme o nível de segurança exigido.

Em ambientes que exijam um nível muito elevado de segurança, uma chave pode ter, por exemplo, a validade de 1 dia ou até mesmo de algumas horas. Naturalmente, seria muito incômodo se diariamente Alice solicitasse ao PKG uma nova chave particular associada ao seu identificador (por exemplo, seu e-mail concatenado com a data). Se Alice possuir um par de chaves padrão, ela pode gerar suas próprias chaves particulares diariamente e tudo que tem a fazer, é comunicar ao seu círculo de amigos que caso queiram lhe enviar uma mensagem criptografada, o deverão fazer usando como chave pública seu $e$-mail concatenado com a data da mensagem (vale lembrar que, na verdade, a chave pública é uma função desse identificador, mas como tal função é de domínio público, simplificamos dizendo que a chave pública é o identificador). 


\subsubsection{Delegação para um notebook}

Suponha que Beto possua um par de chaves pública/ particular padrão e ele precisa fazer uma viagem. Em vez de colocar sua chave particular padrão no notebook e correr o risco de haver comprometimento em caso de roubo, ele pode gerar chaves particulares baseadas em identidades, correspondentes aos dias de viagem, e instalá-las em seu notebook, da seguinte forma:

$$
\text { Seja }\left(s, R_{\text {beto }}=s P\right) \text { o par de chaves padrão de Beto. }
$$

Beto, agindo como TA, gera:

$$
\begin{aligned}
& S_{1}=s H_{1}\left(\left(\text { ID }_{\text {beto }} \| \text { data }_{1}\right)\right) \\
& S_{2}=s H_{1}\left(\left(\text { ID }_{\text {beto }} \| \text { data }_{2}\right)\right) \\
& \cdots \\
& S_{n}=s H_{1}\left(\left(\text { ID }_{\text {beto }} \| \text { data }_{n}\right)\right)
\end{aligned}
$$

onde $I D_{\text {beto }}$ é por exemplo, seu e-mail: beto@ime.usp.br.

Agora, mesmo que o notebook de Beto seja roubado, somente as chaves correspondentes aos dias de viagem serão comprometidas e a chave particular padrão de Beto continua segura, podendo ele gerar novas chaves baseadas em identidades.

Vamos supor, então, que Alice deseja enviar uma mensagem $m$ criptografada para Beto na data: data $_{j}$. Ela pode, por exemplo, usar o esquema de criptografia de Boneh \& Franklin [Boneh e Franklin 2001] que vimos no capítulo 3 para criptografar a mensagem para Beto. Vamos relembrar o esquema de Boneh \& Franklin, descrevendo os passos executados por Alice para criptografar e em seguida, por Beto para decriptografar $m$.

Alice calcula:

$$
\left\{\begin{array}{l}
U=r P \\
V=m \oplus H_{3}\left(e_{t}\left(r Q_{\text {beto }}, R_{\text {beto }}\right)\right)
\end{array}\right.
$$

E envia $(U, V)$ para Beto.

Beto então, utiliza sua chave $S_{\text {beto }}$, que ele gerou usando como identificador beto@ime.usp.br $\|$ data $_{1}$ e calcula:

$$
m=V \oplus H_{3}\left(e_{t}\left(S_{\text {beto }}, U\right)\right)
$$

recuperando $m$.

Relembrando o que vimos no capítulo 3, temos: 
1. $r$ é um elemento sorteado por Alice aleatoriamente em $\mathbb{F}_{q}$;

2. P é um ponto conhecido de uma curva elíptica (também conhecida);

3. $R_{\text {beto }}$ é a chave pública padrão da autoridade que gerou o par de chaves baseadas em identidades de Beto, no caso, o próprio Beto;

4. $Q_{b e t o}$ é o e-mail de Beto concatenado com a data $d a t a_{j}$ e mapeado em um ponto da curva pela função de espalhamento $H_{1}$; e

5. $H_{3}$ é uma função de espalhamento que mapeia o valor de um emparelhamento em uma seqüência de bits.

\subsubsection{Delegação de serviços}

Suponha que Alice envia uma mensagem para Beto usando o campo "assunto" concatenado com o ID dele. Beto, agindo como PKG, pode, através de sua chave particular padrão, gerar a chave particular baseada em identidades correspondente e decriptografar essa mensagem.

Ex. Alice criptografa uma mensagem usando como identificador de Beto:

$$
Q_{\text {beto }}=H_{1}\left(I D_{\text {beto }} \| \text { assunto }\right)
$$

Beto gera a chave particular $S_{\text {beto }}$ correspondente e consegue ler a mensagem enviada por Alice.

Tal aplicação pode ser muito útil se por exemplo, Beto for o presidente de uma empresa e o "assunto" for cada um dos departamentos. Desta forma, Beto, agindo como PKG, poderá ter acesso a todas as mensagens de sua empresa (pois ele gerou as chaves particulares de cada departamento), sendo que um departamento não conseguirá decriptografar as mensagens de um outro.

Para ilustrarmos melhor esta aplicação, digamos que Beto seja o Diretor do IME. Ele pode então gerar uma chave particular baseada em identidades correspondente a cada um dos três Departamentos (Computação, Matemática e Estatística), da seguinte forma:

$$
\begin{array}{ll}
S_{\text {computação }} & =s H_{1}\left(\left(I D_{\text {beto }} \| \text { computação }\right)\right) \\
S_{\text {matemática }} & =s H_{1}\left(\left(I D_{\text {beto }} \| \text { matemática }\right)\right) \\
S_{\text {estatística }} & =s H_{1}\left(\left(I D_{\text {beto }} \| \text { estatística }\right)\right)
\end{array}
$$


de modo que cada um possa decriptografar as mensagens de sua responsabilidade, sem contudo, conseguir decriptografar as mensagens dos demais. Beto, por sua vez, tem acesso a todas as mensagens do IME.

Note que Alice só precisa obter os parâmetros de uma única chave pública (Beto), ou seja, se o IME tivesse 30 departamentos, Alice não precisaria conhecer o identificador de cada um deles.

Podemos ampliar ainda mais se pensarmos que Beto é (o presidente da) matriz de uma grande rede de bancos e cada um dos departamentos é uma filial. O identificador desse banco (vamos batizá-lo de "Banco XXX") poderia ser:

www.bancoXXX.com.br

Deste modo, se quiséssemos enviar uma mensagem criptografada (por exemplo, uma solicitação de extrato, contendo nossos dados pessoais) para uma de suas milhares de agências (digamos, agência “ABC”), poderíamos simplesmente, usar como identificador:

www.bancoXXX.com.br||agenciaABC

\subsubsection{Criação de grupos}

Suponha que Beto acabou de chegar à cidade para um congresso, mas não conhece ninguém além de Alice. Beto deseja que Alice o pegue no aeroporto, mas como Alice não pode ir, algum amigo dela o fará. Mas como Beto vai disseminar uma mensagem para os amigos de Alice, se ele não os conhece?

Naturalmente, ele não poderia simplesmente disseminar uma mensagem legível do tipo: "Oi, aqui é o Beto. Estou no Aeroporto. Será que algum dos amigos da Alice poderia vir me buscar ?”, pois alguém mal-intencionado poderia aparecer no aeroporto dizendo ser amigo de Alice e Beto estaria "em maus lençóis".

Uma solução não muito prática seria Alice dar a Beto uma lista contendo o e-mail de cada um de seus amigos, e desta forma, Beto poderia enviar uma mensagem criptografada com a chave pública baseada em identidades de um desses amigos de Alice. Mas como Beto não sabe, de antemão, qual deles vai estar disponível, ele teria que enviar a mensagem para cada um deles e, caso fossem muitos, não seria uma solução muito prática. 
Um modo mais razoável de Alice resolver o problema de Beto seria ela criar um grupo "amigosAlice" e gerar ${ }^{2}$ um par de chaves baseadas em identidades ( $S_{\text {amigos Alice, }}, Q_{\text {amigosAlice }}$ ), entregando a chave particular $S_{\text {amigosAlice }}$ a cada um de seus amigos (obviamente, utilizando um canal seguro). Assim, chegando ao aeroporto, Beto pode enviar uma mensagem criptografada, usando como chave pública $Q_{\text {amigos Alice }}$ (que ele sabe calcular, pois conhece a função de espalhamento $H_{1}$ e conhece o identificador amigosAlice), tendo a certeza de que somente os amigos de Alice poderão decriptografar essa mensagem, pois possuem o par correspondente $S_{\text {amigos Alice }}$.

\subsubsection{Adição de assinaturas}

Considere três usuários, Alice, Beto e Carlos e seus respectivos pares de chaves pública/ particular padrão:

$$
\begin{aligned}
& R_{\text {alice }}=a P \\
& R_{\text {beto }}=b P \\
& R_{\text {carlos }}=c P
\end{aligned}
$$

Como os três poderão assinar eletronicamente um documento que contém um único campo para assinatura, como por exemplo, um Tratado Internacional ou um testamento ?

Seja $D$ o documento a ser assinado. Inicialmente, cada um deles, usando o modelo de assinatura compacta de Boneh, Lynn \& Shacham [Boneh, Lynn e Shacham 2001], que vimos no capítulo 2, gera sua assinatura do documento $D$ :

$$
\begin{array}{ll}
V_{\text {alice }} & =a H_{1}(D) \\
V_{\text {beto }} & =b H_{1}(D) \\
V_{\text {carlos }} & =c H_{1}(D)
\end{array}
$$

A assinatura que será colocada no documento é:

$$
V=V_{\text {alice }}+V_{\text {beto }}+V_{\text {carlos }}
$$

Note que a assinatura $V$ é uma soma de pontos de uma curva elíptica e, portanto, pode ser facilmente calculada.

Para verificarmos a assinatura $V$, teremos que usar a seguinte chave pública:

$$
R=R_{\text {alice }}+R_{\text {beto }}+R_{\text {carlos }}
$$

\footnotetext{
${ }^{2}$ Partindo da suposição que Alice possui um par de chaves padrão.
} 
Que também é uma soma de pontos de uma curva elíptica.

Vamos agora, demonstrar que a chave $R$ realmente verifica a assinatura $V$ :

Primeiramente, expressamos $V$ em função de $a, b, c$ :

$$
\begin{aligned}
V & =V_{\text {alice }}+V_{\text {beto }}+V_{\text {carlos }} \\
V & =a H_{1}(D)+b H_{1}(D)+c H_{1}(D) \\
V & =(a+b+c) H_{1}(D)
\end{aligned}
$$

E agora $R$ :

$$
\begin{aligned}
& R=R_{\text {alice }}+R_{\text {beto }}+R_{\text {carlos }} \\
& R=a P+b P+c P \\
& R=(a+b+c) P
\end{aligned}
$$

Queremos mostrar que $e_{t}(P, V)=e_{t}\left(R, H_{1}(d)\right)$ :

$$
\begin{aligned}
e_{t}(P, V) & =e_{t}\left(P,(a+b+c) H_{1}(D)\right) & & \text { pois } V=(a+b+c) H_{1}(D) \\
& =e_{t}\left(P, H_{1}(D)\right)^{(a+b+c)} & & \text { por bilinearidade } \\
& =e_{t}\left((a+b+c) P, H_{1}(D)\right) & & \text { por bilinearidade } \\
& =e_{t}\left(R, H_{1}(D)\right) & & \text { pois } R=(a+b+c) P
\end{aligned}
$$

Veremos nas próximas seções como podemos certificar chaves públicas baseadas em identidades, através de uma hierarquia de certificação.

\subsection{Hierarquia}

Vimos que, em sistemas baseados em identidades, a chave particular de um usuário é gerada por um centro gerador de chaves (PKG). Em uma rede com muitos usuários, tal fato poderia se tornar um problema, caso houvesse apenas um PKG, pois este teria um trabalho árduo para gerar todas as chaves. Assim como ocorre na infra-estrutura de chaves públicas, podemos obter uma hierarquia de certificação em sistemas baseados em identidades, onde os PKG emitem chaves somente para entidades imediatamente abaixo deles na hierarquia.

Vimos nas aplicações de sistemas baseados em identidades (seção 5.1), que o PKG pode ser, por exemplo, o Presidente de uma empresa. Vimos também, que a chave pública padrão da autoridade que gerou a chave particular baseada em identidades é usada na maioria dos esquemas de criptografia e assinatura, como por exemplo, na equações (3.13), (3.20) e (7.8). Um intruso mal-intencionado poderia realizar com sucesso um ataque de bloqueio caso conseguisse modificar a chave pública do PKG, pois neste caso, os resultados das equações citadas seriam alterados. Para que isto seja evitado em sistemas baseados em identidades, podemos 
certificar as chaves públicas, como veremos mais adiante. É importante notar que nos métodos de certificação que apresentaremos a seguir, utilizamos assinaturas compactas e a propriedade de bilinearidade de um emparelhamento, não sendo, portanto, necessários certificados digitais como na tradicional PKI.

\subsubsection{Modelo híbrido PKI / IBE}

J. Horwitz e B. Lynn [Horwitz e Lynn 2002] apresentaram uma maneira de lidar com hierarquias de geração de chaves, em que cada PKG gera chaves para outros PKG, descendo ao longo da hierarquia. Há somente um par de chaves particular / pública padrão em todo o sistema, que pertence ao PKG raiz. As demais chaves são pares de chaves baseadas em identidades, e desta forma, a hierarquia produzida podia ser considerada como puramente baseada em identidades.

Entretanto, havia uma desvantagem, pois o sistema proposto operava com somente dois níveis de chaves e, caso houvesse uma determinada quantidade de PKG malintencionados, o sistema todo poderia ser quebrado. Como solução para tal desvantagem, L. Chen, K. Harrison, A. Moss, D. Soldera e N. Smart [Chen et al. 2002] propuseram um sistema híbrido, que combina soluções da tradicional PKI com soluções baseadas em identidades. Essa solução proposta se mostrou mais escalável do que a anterior, tendo em vista que, se por um lado a tradicional PKI se mostra fraca quando existe a necessidade de autenticar um grande número de usuários, devido ao grande custo envolvido na verificação de certificados, por outro, temos que sistemas baseados em identidades são eficientes para autenticar indivíduos, tendo em vista que as chaves públicas, por si só, identificam seus donos.

Veremos nas seções seguintes as soluções propostas por Chen et al., iniciando com uma forma de certificar chaves públicas usando assinaturas compactas.

\subsubsection{Certificados usando assinaturas compactas}

Será considerado o seguinte endereço de e-mail como exemplo:

$$
\text { alice@ime.usp.br }
$$

Suponha que Beto deseja enviar uma mensagem para Alice, através de crip- 
tografia baseada em identidades. Seja $\left(S_{\text {alice }}, Q_{\text {alice }}\right)$ o par de chaves baseadas em identidades de Alice e seja ime o PKG que gerou o par de chaves para Alice. Na tabela 5.1 vemos o par de chaves de cada entidade.

Tabela 5.1: Certificados usando assinaturas compactas

\begin{tabular}{|c|c|c|}
\hline Entidade & Chave particular & Chave pública \\
\hline \hline $\mathrm{br}$ & $s_{1}$ & $R_{b r}=s_{1} P$ \\
\hline $\mathrm{usp}$ & $s_{2}$ & $R_{\text {usp }}=s_{2} P$ \\
\hline ime & $s_{3}$ & $R_{\text {ime }}=s_{3} P$ \\
\hline
\end{tabular}

$$
S_{\text {alice }}=s_{3} Q_{\text {alice }}, \text { onde } Q_{\text {alice }}=H_{1}(\text { alice })
$$

Suponhamos que a chave pública de br é confiável. Para que possamos certificar a chave pública de ime, procedemos da seguinte forma:

Certificado de usp produzido por br:

$$
\left(u s p, b r, R_{u s p}, V\right) \text { onde } V=s_{1} H_{1}\left(R_{u s p} \| u s p\right)
$$

Para comprovar a autenticidade do certificado, Beto precisa apenas fazer a verificação vista na equação (3.12), ou seja, confirmar se

$$
e_{t}(P, V)=e_{t}\left(R_{b r}, H_{1}\left(R_{u s p} \| u s p\right)\right)
$$

Tendo provado a autenticidade de usp, prossegue de forma análoga e verifica autenticidade de ime. Desta forma, tendo certeza da autenticidade da chave pública de ime, pode usá-la para criptografar uma mensagem para Alice.

\subsubsection{Hierarquia de PKG relacionados com chaves baseadas em identi- dades}

Na seção anterior, consideramos que os PKG possuem um par de chaves padrão, porém, tais PKG não estão relacionados por meio de suas identidades. Nesta seção, vamos examinar o que ocorre quando os PKG possuem chaves baseadas em identidades. Na tabela 5.2, vemos os pares de chaves padrão $(s, R)$ e baseadas em identidades $\left(S_{i d}, Q_{i d}\right)$ de cada entidade. Desta forma, se um usuário confia na chave pública padrão de qualquer das enti- 
Tabela 5.2: Hierarquia de PKG com chaves ID

\begin{tabular}{|c|c|c|c|c|}
\hline Entidade & $s$ & $R$ & $S_{\text {id }}$ & $Q_{\text {id }}$ \\
\hline \hline $\mathrm{br}$ & $s_{1}$ & $R_{\text {br }}=s_{1} P$ & - & - \\
\hline $\mathrm{usp}$ & $s_{2}$ & $R_{\text {usp }}=s_{2} P$ & $S_{\text {usp }}=s_{1} Q_{\text {usp }}$ & $Q_{\text {usp }}=H_{1}($ usp $)$ \\
\hline ime & $s_{3}$ & $R_{\text {ime }}=s_{3} P$ & $S_{\text {ime }}=s_{2} Q_{\text {ime }}$ & $Q_{\text {ime }}=H_{1}($ ime $)$ \\
\hline alice & - & - & $S_{\text {alice }}=s_{3} Q_{\text {alice }}$ & $Q_{\text {alice }}=H_{1}($ alice $)$ \\
\hline
\end{tabular}

dades dessa tabela, tal entidade se torna a raiz de confiança para o usuário e, portanto, sua chave particular padrão correspondente se torna a chave mestra. Veremos a seguir como transferir confiança ao longo da tabela 5.2.

\subsubsection{Transferindo confiança}

Suponha que Beto confia no PKG usp. A autenticidade da chave pública baseada em identidades de Alice pode ser verificada de três formas:

1. usp assina a chave pública padrão de ime, usando assinatura compacta - como visto na seção 5.2.2;

2. ime assina sua própria chave pública padrão, usando esquema de assinatura baseado em identidades - como a chave pública padrão de usp é confiável, um verificador pode utilizar a chave pública baseada em identidades de ime para verificar a assinatura e, portanto, confiar na chave pública padrão de ime.

3. A terceira maneira de verificação é mais natural que as duas anteriores, e pode ser desenvolvida por ime ou por usp, sendo transparente para Beto quem realmente produziu a autenticação de ime.

(a) se ime for autenticar, gera um valor aleatório $r \in \mathbb{F}_{q}$ e publica:

$$
\begin{aligned}
& C_{1}=r S_{\text {ime }}=r s_{2} Q_{i m e} \\
& C_{2}=r Q_{i m e} \\
& C_{3}=r R_{i m e}
\end{aligned}
$$


(b) se usp for autenticar, gera um valor aleatório $r \in \mathbb{F}_{q}$ e publica:

$$
\begin{aligned}
C_{1} & =r s_{2} Q_{i m e} \\
C_{2} & =r Q_{i m e} \\
C_{3} & =r R_{i m e}
\end{aligned}
$$

Beto, querendo verificar se o encadeamento é como foi declarado, confirma se as seguintes equações são verdadeiras:

$$
\begin{array}{r}
e_{t}\left(C_{2}, R_{\text {ime }}\right)=e_{t}\left(Q_{\text {ime }}, C_{3}\right) \\
e_{t}\left(P, C_{1}\right)=e_{t}\left(R_{\text {usp }}, C_{2}\right)
\end{array}
$$

E pode confiar na chave pública $R_{\text {ime }}$ e, com isso, usar a chave pública $Q_{\text {alice }}$ para se comunicar com Alice.

Vamos demonstrar agora a consistência na verificação feita por Beto:

$$
\begin{array}{rlrl}
e_{t}\left(C_{2}, R_{\text {ime }}\right) & =e_{t}\left(r Q_{i m e}, R_{\text {ime }}\right) & \text { pois } C_{2}=r Q_{i m e} \\
& =e_{t}\left(Q_{i m e}, r R_{\text {ime }}\right) & \text { por bilinearidade } \\
& =e_{t}\left(Q_{i m e}, C_{3}\right) & & \text { pois } r R_{\text {ime }}=C_{3} \\
e_{t}\left(P, C_{1}\right) & =e_{t}\left(P, r s_{2} Q_{i m e}\right) & & \text { pois } C_{1}=r s_{2} Q_{i m e} \\
& =e_{t}\left(s_{2} P, r Q_{i m e}\right) & & \text { por bilinearidade } \\
& =e_{t}\left(R_{u s p}, r Q_{i m e}\right) & & \text { pois } R_{u s p}=s_{2} P \\
& =e_{t}\left(R_{u s p}, C_{2}\right) & & \text { pois } r Q_{i m e}=C_{2}
\end{array}
$$

\subsubsection{Delegação de direitos}

Suponha que Alice tem controle sobre algum recurso. Seja $\left(R_{\text {alice }}, s\right)$ o par de chaves pública / particular padrão de Alice. Considere a seguinte 5-tupla: (Emissor, Sujeito, Delegação, Autorização, Validade), onde Emissor é quem está autorizando o uso de um recurso, Sujeito é quem recebe a autorização, Delegação indica se o recurso pode ou não ser delegado ("sim" ou "não"), Autorização é o nome do recurso a ser delegado e Validade é o período em que o sujeito está autorizado a usar o recurso. Seja $M_{\text {Beto }}$ a chave pública de Beto (aqui, tanto faz se é padrão ou baseada em identidades). Se Alice deseja dar a Beto autorização de uso do recurso que controla, ela forma a seguinte expressão:

$$
\sigma=H_{1}\left(R_{\text {alice }}\right)\left\|H_{1}\left(M_{\text {Beto }}\right)\right\| \text { Delegacao } \| \text { Autorizacao } \| \text { Validade }
$$


Em seguida, gera o par de chaves pública / particular abaixo:

$$
S_{\sigma}=s Q_{\sigma}, \text { onde } Q_{\sigma}=H_{1}(\sigma)
$$

e dá a chave $S_{\sigma}$ para Beto que, para usar o recurso, basta provar que possui a chave $S_{\sigma}$ (ou seja, provar que ele recebeu a autorização de Alice) e a chave particular associada a $M_{\text {Beto }}$ (ou seja, provar que ele é, de fato, Beto). Note que, para demonstrar esses dois fatos, não é necessário que Beto revele as chaves particulares, bastando apenas que ele assine alguma mensagem com cada uma dessas chaves.

Se o campo Delegação for "Sim", Beto pode delegar parte ou toda a autorização de Alice para Carlos. Seja $\left(R_{\text {beto }}, t\right)$ o par de chaves pública / particular padrão de Beto. A delegação de Beto para Carlos tem a seguinte forma:

$$
\tau=H_{1}\left(R_{\text {beto }}\right)\left\|H_{1}\left(M_{\text {carlos }}\right)\right\| \text { Delegacao }{ }^{\prime} \| \text { Autorizacao }^{\prime} \| \text { Validade }^{\prime}
$$

e Beto dá a Carlos a chave $S_{\tau}$, onde $S_{\tau}=t Q_{\tau}$ e $Q_{\tau}=H_{1}(\tau)$.

Para usar o recurso, Carlos precisa apresentar $\sigma$ e $\tau$ e provar que conhece a chave particular correspondente a $M_{\text {carlos }}$ (ou seja, provar que é, de fato, Carlos) e também que conhece a chave particular correspondente a $Q_{\tau}$ (ou seja, que Beto deu a ele autorização de uso do recurso). Novamente, basta que Carlos assine uma mensagem usando cada uma dessas duas chaves, que terá provado que tem conhecimento delas, sem que seja necessário revelá-las.

Note que Beto poderia ter enviado a Carlos a delegação $\tau$ mesmo se Alice não tivesse lhe conferido poder para delegar (i.e., se o campo Delegação de $\sigma$ fosse "Não"). Bastaria para isto, que Beto alterasse o valor de $\sigma$, que é transmitida em aberto (ou seja, texto legível). Por isso, é necessário que $\sigma$ seja autenticada. Como, então, Beto pode autenticar $\sigma$ ?

1. Como visto anteriormente, Beto gera $r$ aleatório e publica:

$$
\begin{aligned}
& C_{1}=r S_{\sigma} \\
& C_{2}=r Q_{\sigma} \\
& C_{3}=r R_{\text {beto }}
\end{aligned}
$$

$$
\text { Se } e_{t}\left(C_{2}, R_{\text {beto }}\right)=e_{t}\left(Q_{\sigma}, C_{3}\right) \text { e se } Q_{\sigma}=H_{1}(\sigma) \text {, então } Q_{\sigma} \text { é válida }^{3} \text {. }
$$

\footnotetext{
${ }^{3}$ Conforme já demonstrado na seção 5.2.4.
} 
2. Beto assina $Q_{\tau} \operatorname{com} S_{\sigma}$, como visto nas equaçōes (3.17), (3.18) e (3.19) da seção 3.5.1:

$$
\begin{aligned}
r & =e_{t}\left(P_{1}, P\right)^{k} \\
h & =H_{2}\left(Q_{\tau} \| r\right) \\
U & =h S_{\sigma}+k P
\end{aligned}
$$

Se $r=e_{t}(U, P) \cdot e_{t}\left(Q_{\sigma},-R_{\text {beto }}\right)$ e $h=H_{2}\left(Q_{\tau} \| r\right)$, então $Q_{\sigma}$ é válida.

\subsection{Resumo}

Vimos neste capítulo uma pequena amostra das inúmeras aplicações de sistemas criptográficos baseados em identidades. Novamente, reforçaremos o que foi dito no início deste capítulo, que nosso objetivo aqui não foi mostrar que certa aplicação é uma exclusividade dos sistemas baseados em identidades, e sim, mostrar que determinada aplicação também pode ser realizada em tais sistemas, muitas das vezes com vantagens.

Dentre a aplicações, mostramos como é possível revogar chaves públicas, acrescentando o prazo de validade de uma chave pública ao identificador, garantindo a validade daquela chave apenas durante o período desejado; como um usuário pode delegar chaves para um notebook, gravando nele as chaves particulares baseadas em identidade correspondentes apenas aos dias de uma viagem, a fim de não haver risco de comprometimento de sua chave particular padrão; como é possível delegar serviços, onde cada departamento de uma empresa pode decriptografar as mensagens de sua responsabilidade, sem contudo, conseguir decriptografar as mensagens dos outros departamentos, mas o Presidente da empresa consegue decriptografar todas as mensagens.

Vimos ainda como criar grupos, onde é possível enviar uma mensagem para um determinado grupo sem saber quem são os componentes desse grupo e como conseguir que um grupo de pessoas possa assinar um mesmo documento, como por exemplo, um Tratado Internacional, usando adição de assinaturas.

Ainda neste capítulo, mostramos que nos sistemas baseados em identidades — assim como ocorre na tradicional PKI — também pode ser necessária a certificação de chaves públicas, principalmente nas situações em que o PKG desce na hierarquia e deixa de ser uma entidade de conhecimento público. 
Embora uma não-certificação não acarrete problemas tão sérios como na tradicional PKI, onde pode haver personificação, nos sistemas baseados em identidades um intruso mal-intencionado pode realizar com sucesso um ataque de bloqueio, pois caso modifique a chave pública padrão do PKG, conseguirá impedir que uma mensagem seja decriptografada com êxito ou que uma assinatura seja verificada com sucesso.

Vimos, então, como é possível certificar chaves públicas dentro de uma hierarquia baseada em identidades, onde assinaturas compactas ou a propriedade de bilinearidade de um emparelhamento são utilizadas na certificação, não necessitando, com isso, de certificados digitais como na tradicional PKI.

Veremos a seguir algumas variações de esquemas de assinaturas, que apesar de serem menos eficientes que o esquema de F. Hess [Hess 2002], são utilizadas para aplicações específicas. 


\section{Capítulo 6}

\section{Variações em esquemas de assinaturas}

Veremos neste capítulo esquemas de assinatura diferentes do que vimos na seção 3.5. Tais esquemas, embora sejam menos eficientes em termos computacionais do que o visto anteriormente, são utilizados para fins específicos, não atendidos pelo esquema de Hess [Hess 2002].

Inicialmente, veremos o conceito de assinatura em anel, em que é possível garantir que o assinante de uma dada mensagem pertence a um determinado grupo de pessoas, mas não é possível identificar esse assinante, ou seja, o anonimato do assinante é preservado. Dentro desse conceito, veremos o esquema proposto por C. Lin e T. Wu [Lin e Wu 2003].

Em seguida, veremos o conceito de assinatura cega, em que o assinante de uma mensagem não tem qualquer conhecimento sobre o conteúdo da mesma (daí o nome "assinatura cega") e nem sobre a assinatura que produziu. Devido a essas características, é preservado o anonimato do usuário. Dentro desse conceito, veremos o esquema proposto por F. Zhang e K. Kim [Zhang e Kim 2002].

A título de observação, Zhang e Kim, no mesmo artigo em que apresentaram um esquema de assinatura cega [Zhang e Kim 2002], também propuseram um esquema de assinatura em anel, mas optamos por apresentar nesta dissertação o esquema de Lin-Wu pois este requer o cálculo de um número menor de emparelhamentos, sendo portanto, mais eficiente do que aquele.

Cabe ainda ressaltar que não descreveremos aqui as análises de segurança dos dois esquemas apresentados, por não fazer parte do escopo desta dissertação, mas os leitores mais interessados podem consultar essas análises nos respectivos artigos. 


\subsection{Assinatura em anel (ring signature)}

Nesta seção, veremos o conceito de assinatura em anel, em que preservamos o anonimato do assinante. Este conceito foi primeiramente proposto por R. Rivest et al. [Rivest, Shamir e Tauman 2001], e consiste de uma assinatura digital que especifica um conjunto de possíveis assinantes, de forma que um verificador não consegue identificar quem do grupo é o autor da assinatura, apesar de ter certeza de que a assinatura foi gerada por algum membro do grupo.

Como um exemplo de aplicação, imagine que diretores de uma empresa fazem parte de um anel e um deles descobre que o presidente está desviando dinheiro da empresa. Esse diretor, através de uma assinatura em anel, pode revelar tal informação, sem que o presidente (nem qualquer outra pessoa) saiba que ele é o autor da revelação. Por outro lado, qualquer pessoa saberá que a mensagem veio de um dos diretores da empresa e, portanto, é de uma fonte confiável.

Cabe ainda destacar que em uma assinatura em anel, o assinante não precisa obter o conhecimento, consentimento ou mesmo a ajuda dos demais membros do anel para gerar a assinatura, bastando apenas conhecer suas respectivas chaves públicas.

Veremos, a seguir, o esquema de assinatura em anel baseado em identidades, proposto por C. Lin e T. Wu [Lin e Wu 2003].

Consideramos, inicialmente, que cada membro $u_{i}$ do anel possui um par de chaves baseadas em identidades $\left(S_{I D_{i}}, Q_{I D_{i}}\right)$, geradas por uma autoridade de confiança (TA), tal que $S_{I D_{i}}=s Q_{I D_{i}}$, onde $s$ é a chave particular padrão da autoridade de confiança e $I D_{i}$ é a identidade de cada membro do anel.

\subsubsection{Geração da assinatura em anel}

Vamos supor, sem perda de generalidade, que há $n$ membros em um anel, que serão chamados de $u_{1}, u_{2}, u_{3}, \ldots, u_{n}$. Seja $u_{a}, 1 \leqslant a \leqslant n$ o usuário que escolhemos para assinar uma mensagem $m$.

Primeiramente, $u_{a}$ prepara um conjunto $L$ com as identidades de cada um dos membros do anel (inclusive a sua), isto é, $L=I D_{1}, I D_{2}, \ldots, I D_{n}$. Em seguida, $u_{a}$ escolhe um 
ponto aleatório $A \in \mathbb{G}_{1}$ e calcula $c_{a+1}$ da seguinte forma:

$$
c_{(a+1) \bmod n}=e_{t}(A, P)
$$

onde $P \in \mathbb{F}_{q^{k}}$ é um ponto de conhecimento público, tal que $R_{T A}=s P$, sendo $R_{T A}$ a chave pública padrão da autoridade de confiança e $s$ sua chave particular padrão.

Para cada $i=a+1, a+2, \ldots, n-1,0,1, \ldots, a-1$ (i.e., todos os valores de $i \bmod n$, exceto $i=a), u_{a}$ seleciona um ponto aleatório $R_{i} \in \mathbb{G}_{1}$ e calcula:

$$
c_{(i+1) \bmod n}=e_{t}\left(c_{i} H_{1}\left(I D_{i}\right), R_{T A}\right)^{H_{2}(m \| L)} \cdot e_{t}\left(R_{i}, P\right)
$$

Faça $R_{n}=R_{0}$.

Após calcular cada um dos $c_{i}, u_{a}$ calcula:

$$
\begin{aligned}
R_{a} & =A-H_{2}(m \| L) \cdot c_{a} \cdot S_{I D_{a}} \\
R & =\sum_{i=1}^{n} R_{i}
\end{aligned}
$$

Finalmente, faça $c_{n}=c_{0}$.

A assinatura em anel da mensagem $m$ é $\left(c_{1}, c_{2}, c_{3}, \ldots, c_{n}, R\right)$.

\subsubsection{Verificação da assinatura}

Dada uma mensagem $m$, sua assinatura em anel $\left(c_{1}, c_{2}, \ldots, c_{n}, R\right)$ e um conjunto das identidades de todos os membros $L=I D_{1}, I D_{2}, \ldots, I D_{n}$, um verificador pode testar a validade da assinatura através da seguinte igualdade:

$$
\prod_{i=1}^{n} c_{i}=e_{t}\left(\sum_{i=1}^{n} c_{i} H_{1}\left(I D_{i}\right), R_{T A}\right)^{H_{2}(m \| L)} \cdot e_{t}(R, P)
$$

\subsubsection{Demonstração}

Para demonstrarmos que a igualdade da equação (6.5) se verifica caso a assinatura gerada seja válida, vamos supor, sem perda de generalidade, que nosso anel é formado por 03 usuários, $u_{1}, u_{2}, u_{3}$ e que o usuário $u_{1}$ deseja assinar a mensagem $m$ usando uma assinatura em anel. 
De acordo com a equação (6.1), $u_{1}$ vai escolher um ponto aleatório A e calcular $c_{2}=e_{t}(A, P)$. Em seguida vai usar a equação (6.2) para cada um $\operatorname{dos} i \bmod n, i \neq a$, ou seja, $i=0$ e $i=2$.

Primeiramente para $i=2$, escolhe $R_{2}$ e calcula:

$$
c_{0}=e_{t}\left(c_{2} H_{1}\left(I D_{2}\right), R_{T A}\right)^{H_{2}(m \| L)} \cdot e_{t}\left(R_{2}, P\right)
$$

Agora para $i=0$, escolhe $R_{0}$ e calcula:

$$
c_{1}=e_{t}\left(c_{0} H_{1}\left(I D_{0}\right), R_{T A}\right)^{H_{2}(m \| L)} \cdot e_{t}\left(R_{0}, P\right)
$$

Em seguida, faz $R_{0}=R_{3}$.

Agora, vai calcular $R_{1}$ e $R$, usando as equações (6.3) e (6.4):

$$
\begin{aligned}
& R_{1}=A-H_{2}(m \| L) \cdot c_{1} \cdot S_{I D_{1}} \\
& R=\sum_{i=1}^{n} R_{i}=R_{1}+R_{2}+R_{3}
\end{aligned}
$$

Finalmente, faz $c_{3}=c_{0}$ e a assinatura de $m$ será $\left(c_{1}, c_{2}, c_{3}, R\right)$.

Se um verificador desejar testar se essa assinatura é de fato válida, deverá usar a equação (6.5), da seguinte forma:

$$
\begin{aligned}
& \prod_{i=1}^{n} c_{i}=e_{t}\left(\sum_{i=1}^{n} c_{i} H_{1}\left(I D_{i}\right), R_{T A}\right)^{H_{2}(m \| L)} \cdot e_{t}(R, P) \\
& c_{1} \cdot c_{2} \cdot c_{3}=e_{t}\left(c_{1} H_{1}\left(I D_{1}\right)+c_{2} H_{1}\left(I D_{2}\right)+c_{3} H_{1}\left(I D_{3}\right), R_{T A}\right)^{H_{2}(m \| L)} \cdot e_{t}(R, P)
\end{aligned}
$$

Substituindo os valores de $c_{1}, c_{2}$ e $c_{3}$, temos:

$$
\underbrace{e_{t}\left(c_{0} H_{1}\left(I D_{0}\right), R_{T A}\right)^{H_{2}(m \| L)} \cdot e_{t}\left(R_{0}, P\right)}_{c_{1}} \cdot \underbrace{e_{t}(A, P)}_{c_{2}} \cdot \underbrace{e_{t}\left(c_{2} H_{1}\left(I D_{2}\right), R_{T A}\right)^{H_{2}(m \| L)} \cdot e_{t}\left(R_{2}, P\right)}_{c_{3}}
$$

Usando as propriedades 3.5 e 3.6 de bilinearidade, temos:

$$
e_{t}\left(c_{0} H_{1}\left(I D_{0}\right)+c_{2} H_{1}\left(I D_{2}\right), R_{T A}\right)^{H_{2}(m \| L)} \cdot e_{t}\left(R_{0}+A+R_{2}, P\right)
$$

Substituindo a valor de $A$ de acordo com a equação (6.3), temos:

$$
e_{t}\left(c_{0} H_{1}\left(I D_{0}\right)+c_{2} H_{1}\left(I D_{2}\right), R_{T A}\right)^{H_{2}(m \| L)} \cdot e_{t}(R_{0}+\underbrace{R_{1}+H_{2}(m \| L) c_{1} S_{I D_{1}}}_{A}+R_{2}, P)
$$

Rearrumando, temos:

$$
e_{t}\left(c_{0} H_{1}\left(I D_{0}\right)+c_{2} H_{1}\left(I D_{2}\right), R_{T A}\right)^{H_{2}(m \| L)} \cdot e_{t}\left(R_{0}+R_{1}+R_{2}+H_{2}(m \| L) c_{1} s Q_{I D_{1}}, P\right)
$$


Como $Q_{I D_{1}}=H_{1}\left(I D_{1}\right)$, temos:

$$
e_{t}\left(c_{0} H_{1}\left(I D_{0}\right)+c_{2} H_{1}\left(I D_{2}\right), R_{T A}\right)^{H_{2}(m \| L)} \cdot e_{t}\left(R_{0}+R_{1}+R_{2}+H_{2}(m \| L) c_{1} s H_{1}\left(I D_{1}\right), P\right)
$$

Novamente, aplicando a propriedade 3.5 de bilinearidade, temos:

$e_{t}\left(c_{0} H_{1}\left(I D_{0}\right)+c_{2} H_{1}\left(I D_{2}\right), R_{T A}\right)^{H_{2}(m \| L)} \cdot e_{t}\left(R_{0}+R_{1}+R_{2}, P\right) \cdot e_{t}\left(H_{2}(m \| L) c_{1} s H_{1}\left(I D_{1}\right), P\right)$

E como $s P=R_{T A}$, podemos escrever, usando bilinearidade:

$e_{t}\left(c_{0} H_{1}\left(I D_{0}\right)+c_{2} H_{1}\left(I D_{2}\right), R_{T A}\right)^{H_{2}(m \| L)} \cdot e_{t}\left(R_{0}+R_{1}+R_{2}, P\right) \cdot e_{t}\left(H_{2}(m \| L) c_{1} H_{1}\left(I D_{1}\right), R_{T A}\right)$

Podemos agora, passar o termo $\mathrm{H}_{2}(m \| L)$ para fora do parênteses, por bilinearidade:

$e_{t}\left(c_{0} H_{1}\left(I D_{0}\right)+c_{2} H_{1}\left(I D_{2}\right), R_{T A}\right)^{H_{2}(m \| L)} \cdot e_{t}\left(R_{0}+R_{1}+R_{2}, P\right) \cdot e_{t}\left(c_{1} H_{1}\left(I D_{1}\right), R_{T A}\right)^{H_{2}(m \| L)}$

E novamente, usando a propriedade 3.5, temos:

$$
e_{t}\left(c_{0} H_{1}\left(I D_{0}\right)+c_{1} H_{1}\left(I D_{1}\right)+c_{2} H_{1}\left(I D_{2}\right), R_{T A}\right)^{H_{2}(m \| L)} \cdot e_{t}\left(R_{0}+R_{1}+R_{2}, P\right)
$$

E finalmente, como $R=\sum_{i=1}^{n} R_{i}$, temos:

$$
e_{t}\left(\sum_{i=1}^{n} c_{i} H_{1}\left(I D_{i}\right), R_{T A}\right)^{H_{2}(m \| L)} \cdot e_{t}(R, P)
$$

Ou seja,

$$
\prod_{i=1}^{n} c_{i}=e_{t}\left(\sum_{i=1}^{n} c_{i} H_{1}\left(I D_{i}\right), R_{T A}\right)^{H_{2}(m \| L)} \cdot e_{t}(R, P)
$$

E portanto, vale a equação (6.5).

\subsubsection{Comparação com o esquema de Hess}

Claramente, podemos ver que um esquema de assinatura em anel tem desempenho bem inferior ao esquema de Hess, pois, observando as equações (6.1) e (6.2), vemos que para um grupo de $n$ pessoas, são calculados $2 n-1$ emparelhamentos, além de mais 2 emparelhamentos na verificação, de acordo com a equação (6.5). Desse total de $2 n+1$ emparelhamentos, pelo menos $n+1$ deles não podem ser pré-calculados, pois além dos 2 da verificação, que dependem de $c_{1}, c_{2}, \ldots, c_{n}$ e de $R$, temos também os $n-1$ emparelhamentos $\left(e_{t}\left(c_{i} H_{1}\left(I D_{i}\right), R_{T A}\right)\right.$ da equação (6.2), que dependem dos valores calculados $c_{i}$. Entretanto, caso seja desejado o anonimato do assinante, devemos utilizar um esquema de assinatura em anel. 


\subsection{Assinatura cega (blind signature)}

Nesta seção, veremos o conceito de assinatura cega, proposto primeiramente por D. Chaum [Chaum 1983]. Em uma assinatura cega, um usuário $A$ envia alguma informação para o assinante $B$, que assina e devolve para $A$. A partir desta assinatura, $A$ pode calcular a assinatura de $B$ sobre uma mensagem escolhida por $A$, sem que $B$ tenha conhecimento do conteúdo da mensagem (daí o nome "assinatura cega") ou da assinatura produzida por $A$. Aqui, diferentemente da assinatura em anel, todos sabem quem assinou a mensagem, porém, o anonimato do usuário é garantido. Devido a essas características, uma assinatura cega tem um importante papel em votações eletrônicas — onde o órgão responsável assina o voto de um usuário, garantindo ser um voto legítimo, porém não tem conhecimento do conteúdo do voto ou em sistemas de pagamento eletrônico — onde um usuário gera uma assinatura cega do banco sobre uma moeda eletrônica, garantindo com isso que a moeda é válida, sendo que o banco não tem como identificar a moeda que acabou de assinar.

Um protocolo de assinatura cega ocorre da seguinte forma: primeiramente, um usuário oculta uma mensagem (através de uma transformação matemática) e envia essa mensagem oculta ao assinante, solicitando sua assinatura. Este, então, assina a mensagem oculta com sua chave particular e envia o resultado dessa operação para o usuário solicitante. Finalmente, o usuário remove a ocultação da mensagem, obtendo a mensagem original com a assinatura do assinante. Poderíamos fazer uma analogia usando um envelope com um carbono em seu interior. O usuário coloca a mensagem dentro desse envelope e, após fechá-lo, envia para o assinante. Este assina o envelope fechado e devolve ao usuário que, então, abre e obtém a mensagem assinada devido ao carbono.

Estudaremos o esquema de assinatura cega com chaves baseadas em identidades proposto por F. Zhang e K. Kim [Zhang e Kim 2002]. Neste esquema, temos três participantes envolvidos:

- Assinante - entidade que vai utilizar sua chave particular baseada em identidades para assinar uma determinada mensagem $m$ (que ele desconhece). O assinante possui um par de chaves baseadas em identidades, que chamaremos de $\left(S_{I D}, Q_{I D}\right)$; 
- Usuário - entidade que vai gerar a assinatura cega a partir de informações produzidas pelo assinante (e que somente ele poderia ter produzido);

- Verificador - entidade que recebe a assinatura de uma mensagem $m$ e vai tentar provar, utilizando a chave pública baseada em identidades do assinante, que essa mensagem foi, de fato, assinada por ele.

Vamos dar dois exemplos para que o leitor entenda melhor o conceito: Suponha que o usuário do esquema é Alice, que deseja fazer uma compra on-line na loja de Beto que, no caso, será o verificador. Alice precisa garantir a Beto que a moeda eletrônica que ela está transferindo para ele tem valor e, para tal, Alice precisa que o banco (que no nosso exemplo fará o papel de assinante) assine essa moeda. Beto, ao receber o pagamento de Alice, poderá verificar que a moeda está assinada pelo banco, sendo portanto, um pagamento válido. O banco, por sua vez, ao receber de Beto a moeda eletrônica a fim de concluir a transação, verá que se trata de sua assinatura e, portanto, pode creditar o valor correspondente na conta de Beto. Como realizou diversas operações semelhantes no decorrer do dia, o banco não tem como associar a venda de Beto a Alice e, portanto, o anonimato de Alice está preservado, ou seja, o banco não tem idéia do que Alice fez com seu dinheiro.

Não pretendemos entrar em detalhes sobre pagamentos eletrônicos, pois tal assunto certamente tem conteúdo para uma dissertação completa, mas apenas para elucidar alguns detalhes, vamos supor que Alice, ao gerar uma moeda eletrônica, tem o valor correspondente sacado de sua conta corrente. Mais tarde, ao receber a moeda assinada, o banco verifica a validade da moeda e sua assinatura, fazendo então o depósito na conta de Beto. Note que o banco não tem como associar o saque na conta de Alice com o depósito na conta de Beto. Por outro lado, caso Alice tentasse enganar Beto (e o banco) com uma moeda falsa, quando o banco recebesse de Beto a moeda assinada, verificaria que a moeda era falsa e desta forma não concluiria a operação (vamos supor que Beto só entrega o produto a Alice após essa verificação do banco).

Usando a analogia com envelopes, vamos supor que Alice coloca uma cédula em um envelope com carbono em seu interior e envia para o banco. Do lado de fora do envelope há informações sobre o valor da cédula e a conta corrente a ser debitada e, dentro do envelope, 
está a cédula com seu respectivo número de série (oculto). O banco debita o valor da conta de Alice e coloca um selo no envelope, contendo o valor declarado e a assinatura do banco. Quando Alice abre o envelope, terá sua cédula com o selo do banco e pode realizar sua compra. Mais tarde, ao receber a cédula de Beto, o banco só precisa verificar se o número de série é válido e fazer o depósito correspondente na conta de Beto. Note que o banco não tem como associar esse número de série ao saque de Alice, pois quando assinou a cédula de Alice, tal número estava oculto. Na figura ${ }^{1} 6.1$ poderemos ver um esquema desta analogia.

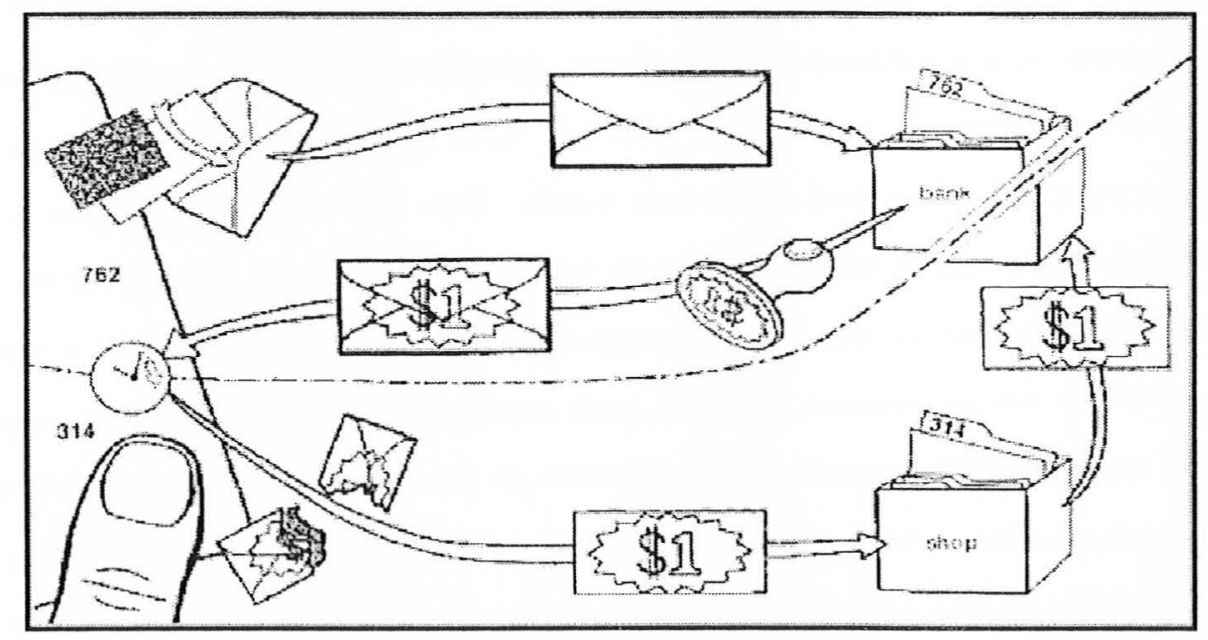

Figura 6.1: Analogia de assinatura cega com envelope - Nesta figura, Alice coloca uma cédula em um envelope e envia para o banco, que insere seu selo no envelope. Alice então, pode fazer o pagamento à loja de Beto. Ao receber a nota com seu selo, o banco não tem como associar esta a Alice.

Um outro exemplo de aplicação de assinatura cega é em votações eletrônicas. Alice é uma eleitora (usuária) que vota em determinado candidato. Para o voto ter validade, é necessário que seja assinado por uma autoridade. Essa autoridade assina o voto de Alice, mas não faz a menor idéia de quem é o candidato que ela escolheu. Beto, por sua vez, fazendo o papel de um representante de partido, pode verificar que se trata de um voto válido, pois contém a assinatura da autoridade. Durante as apurações, nem Beto, nem a autoridade nem qualquer pessoa pode associar um voto com o seu respectivo eleitor, preservando o anonimato dos eleitores.

Vejamos agora o esquema propriamente dito:

\footnotetext{
${ }^{\text {I}}$ Retirada de [Godoy e Curti 2002].
} 


\subsubsection{Assinatura}

1. O banco escolhe um número aleatório $r \in \mathbb{F}_{q}^{*}$, calcula $R=r P$ e publica $R$. Exatamente como no capítulo $3, P \in \mathbb{F}_{q^{k}}$ é um ponto de conhecimento público e $R_{T A}$ é a chave pública padrão da autoridade de confiança (que em nosso exemplo, é Beto);

2. Alice escolhe dois valores aleatórios, $a, b \in \mathbb{F}_{q}^{*}$, calcula ${ }^{2}$

$$
\begin{aligned}
t & =e_{t}\left(b Q_{\text {banco }}+R+a P, R_{T A}\right) \\
c & =\left(H_{2}(m, t)+b\right) \bmod q
\end{aligned}
$$

e envia $c$ para o banco;

3. O banco calcula:

$$
S=c S_{\text {banco }}+r R_{T A}
$$

e envia $S$ para Alice;

4. Alice calcula:

$$
\begin{aligned}
S^{\prime} & =S+a R_{T A} \\
c^{\prime} & =c-b
\end{aligned}
$$

A assinatura cega de $m$ é $\left(S^{\prime}, c^{\prime}\right)$

\subsubsection{Verificação}

Se Beto deseja verificar se $m$ foi realmente assinado pelo banco, verifica se a seguinte igualdade se satisfaz:

$$
c^{\prime}=H_{2}\left(m, e_{t}\left(S^{\prime}, P\right) \cdot e_{t}\left(Q_{\text {banco }}, R_{T A}\right)^{-c^{\prime}}\right)
$$

Caso contrário, rejeita a assinatura.

\footnotetext{
${ }^{2}$ Podemos considerar que o resultado do emparelhamento $e_{t}\left(b Q_{b a n c o}+R+a P, R_{T A}\right)$ é usado como chave na função de espalhamento $\mathrm{H}_{2}$.
} 


\subsubsection{Demonstração}

Vamos demonstrar a seguir a corretude da verificação de Beto, ou seja, vamos provar que a igualdade se satisfaz caso $m$ tenha sido assinada pelo banco:

Beto calcula:

$$
H_{2}\left(m, e_{t}\left(S^{\prime}, P\right) \cdot e_{t}\left(Q_{b a n c o}, R_{T A}\right)^{-c^{\prime}}\right)
$$

Como $S^{\prime}=S+a R_{T A}$, temos:

$$
H_{2}\left(m, e_{t}\left(S+a R_{T A}, P\right) \cdot e_{t}\left(Q_{b a n c o}, R_{T A}\right)^{-c^{\prime}}\right)
$$

Substituindo $S=c S_{\text {banco }}+r R_{T A}$ temos:

$$
H_{2}\left(m, e_{t}\left(c S_{\text {banco }}+r R_{T A}+a R_{T A}, P\right) \cdot e_{t}\left(Q_{\text {banco }}, R_{T A}\right)^{-c^{\prime}}\right)
$$

Aplicando a propriedade (3.5) de bilinearidade:

$$
H_{2}\left(m, e_{t}\left(c S_{\text {banco }}, P\right) \cdot e_{t}\left(r R_{T A}+a R_{T A}, P\right) \cdot e_{t}\left(Q_{\text {banco }}, R_{T A}\right)^{-c^{\prime}}\right)
$$

Novamente por bilinearidade, temos:

$$
H_{2}\left(m, e_{t}\left(S_{\text {banco }}, P\right)^{c} \cdot e_{t}\left(r R_{T A}+a R_{T A}, P\right) \cdot e_{t}\left(Q_{\text {banco }}, R_{T A}\right)^{-c^{\prime}}\right)
$$

Colocando em evidência o termo $R_{T A}$ :

$$
H_{2}\left(m, e_{t}\left(S_{\text {banco }}, P\right)^{c} \cdot e_{t}\left((r+a) R_{T A}, P\right) \cdot e_{t}\left(Q_{\text {banco }}, R_{T A}\right)^{-c^{\prime}}\right)
$$

Substituindo $S_{\text {banco }}=s Q_{\text {banco }}$ e aplicando bilinearidade:

$$
H_{2}\left(m, e_{t}\left(Q_{\text {banco }}, s P\right)^{c} \cdot e_{t}\left((r+a) R_{T A}, P\right) \cdot e_{t}\left(Q_{\text {banco }}, R_{T A}\right)^{-c^{\prime}}\right)
$$

Como $s P=R_{T A}$ :

$$
H_{2}\left(m, e_{t}\left(Q_{\text {banco }}, R_{T A}\right)^{c} \cdot e_{t}((r+a) s P, P) \cdot e_{t}\left(Q_{\text {banco }}, R_{T A}\right)^{-c^{\prime}}\right)
$$

Por bilinearidade em " $s$ " no emparelhamento do meio:

$$
H_{2}\left(m, e_{t}\left(Q_{\text {banco }}, R_{T A}\right)^{c} \cdot e_{t}\left((r+a) P, R_{T A}\right) \cdot e_{t}\left(Q_{\text {banco }}, R_{T A}\right)^{-c^{\prime}}\right)
$$


Agrupando termos $e_{t}\left(Q_{\text {banco }}, R_{T A}\right)$ :

$$
H_{2}\left(m, e_{t}\left(Q_{\text {bunco }}, R_{T A}\right)^{c-c^{\prime}} \cdot e_{t}\left((r+a) P, R_{T A}\right)\right)
$$

Substituindo $c-c^{\prime}=b$ :

$$
H_{2}\left(m, e_{t}\left(Q_{\text {banco }}, R_{T A}\right)^{b} \cdot e_{t}\left(r P+a P, R_{T A}\right)\right)
$$

Substituindo $r P=R$ :

$$
H_{2}\left(m, e_{t}\left(Q_{\text {banco }}, R_{T A}\right)^{b} \cdot e_{t}\left(R+a P, R_{T A}\right)\right)
$$

Usando bilinearidade:

$$
H_{2}\left(m, e_{t}\left(b Q_{\text {banco }}, R_{T A}\right) \cdot e_{t}\left(R+a P, R_{T A}\right)\right)
$$

Pela propriedade (3.6) de bilinearidade:

$$
H_{2}\left(m, e_{t}\left(b Q_{\text {banco }}+R+a P, R_{T A}\right)\right)
$$

Substituindo $t=e_{t}\left(b Q_{\text {banco }}+R+a P, R_{T A}\right)$ :

$$
H_{2}(m, t)
$$

Como $c=H_{2}(m, t)+b$, podemos substituir $H_{2}(m, t)$ por $c-b$ e finalmente, como $c^{\prime}=c-b$, temos como resultado $c^{\prime}$, que é o que queríamos demonstrar.

Note que no esquema que acabamos de apresentar, o banco usa sua chave particular $S_{\text {banco }}$ para assinar a mensagem $m$. Essa mensagem, porém, foi ocultada por Alice através dos fatores $a$ e $b$, que são conhecidos na literatura específica como fatores de ocultação (blinding factors). Desta forma, o banco não tem conhecimento do conteúdo de $m$. Beto, para verificar a assinatura, usa a chave pública do banco $\left(Q_{\text {banco }}\right)$, garantindo, com isso, que somente o banco poderia ter assinado $m$. Ao verificar uma mensagem qualquer com sua assinatura, o banco não tem como associar tal mensagem com o usuário que solicitou a assinatura (note que o valor de $c$, usado pelo banco para gerar a assinatura, não depende da identidade de Alice). 


\subsubsection{Comparação com o esquema de Hess}

Vamos medir o custo computacional em função do cálculo do emparelhamento, que é a operação de maior custo.

Já sabemos que o esquema de Hess calcula 1 emparelhamento na assinatura, que pode ser pré-calculado e 2 na verificação, dos quais um deles $\left(e_{t}\left(Q_{\text {alice }},-R_{T A}\right)\right)$ pode ser pré-calculado. Desta forma, temos um total de 3 cálculos de emparelhamento, onde 2 podem ser pré-calculados.

$\mathrm{O}$ esquema de assinatura cega de F. Zhang e K. Kim calcula 1 emparelhamento na assinatura, que não pode ser pré-calculado (pois depende de $\mathrm{R}$, que é informado pelo assinante) e 2 emparelhamentos na verificação, dos quais 1 pode ser pré-calculado $\left(e_{t}\left(Q_{\text {banco }}, R_{T A}\right)\right)$. Desta forma, temos um total de 03 emparelhamentos, onde 1 pode ser précalculado. Podemos concluir então que o esquema de Hess de assinatura é mais eficiente do que o esquema de assinatura cega de Zhang e Kim. Entretanto, caso seja necessário preservar o anonimato do usuário, devemos usar este último.

\subsection{Resumo}

Vimos neste capítulo esquemas de assinaturas que, embora sejam menos eficientes em termos computacionais do que o esquema de Hess, visto na seção 3.5, são utilizados para fins específicos, como assinaturas cegas, que permitem a um usuário obter uma assinatura legítima de uma mensagem sem que o assinante tenha conhecimento do conteúdo da mesma e assinaturas em anel, em que é possível ter certeza de que determinada mensagem foi assinada por um grupo, mas não há como saber quem do grupo assinou.

Veremos no capítulo a seguir esquemas de assinatura e criptografia que podem ser utilizados quando a custódia das chaves por parte do PKG não for uma vantagem, especialmente quando essa entidade não for confiável. 


\section{Capítulo 7}

\section{Esquemas com PKG não confiável}

Neste capítulo, consideraremos a hipótese de o PKG não ser uma entidade totalmente idônea. Vamos recordar que na seção 3.2.1, consideramos a hipótese de que a idoneidade do PKG é inquestionável, a fim de garantirmos o sucesso dos esquemas de criptografia e assinatura baseados em identidades que apresentamos. Passamos então, a nos referir a esse PKG "totalmente idôneo" como autoridade de confiança (TA).

Sabemos, entretanto, que é muito difícil garantirmos que uma determinada entidade seja incondicionalmente idônea, e como vimos nas vantagens e desvantagens de sistemas baseados em identidades, apresentadas na seção 3.6, o conhecimento das chaves particulares pelo PKG pode ser uma desvantagem, se desconsiderarmos essa hipótese, pois além dele ter acesso a todas as mensagens criptografadas com as chaves particulares que gerou, pode também forjar a assinatura de qualquer um dos usuários para os quais gerou chaves particulares, o que representa um ponto fraco tanto no esquema de criptografia quanto no esquema de assinatura que apresentamos.

Veremos neste capítulo esquemas de assinatura e criptografia que podem ser utilizados quando a idoneidade do PKG é questionável. O esquema de assinatura que apresentaremos foi proposto por X. Chen, F. Zhang e K. Kim [Chen, Zhang e Kim 2003]. Este esquema poderia perfeitamente fazer parte do capítulo anterior, pois não deixa de ser uma variação em esquemas de assinaturas, assim como os esquemas de assinatura cega e assinatura em anel que mostramos, mas decidimos colocá-lo em um capítulo a parte - juntamente com uma solução para criptografia proposta por D. Boneh e M. Franklin [Boneh e Franklin 2001] — por considerarmos que a idoneidade do PKG é um ponto de grande vulnerabilidade nos sistemas 
baseados em identidades.

Por esta razão, as formas de contornar a total dependência da segurança do sistema à confiança irrestrita no PKG mereceram o devido destaque. Vale ressaltar que as variações aqui propostas acarretam um custo adicional, mas como dissemos, tal custo pode ser justificável se não confiarmos integralmente no PKG.

\subsection{Assinatura com PKG não-confiável}

Chen, Zhang e Kim [Chen, Zhang e Kim 2003] propuseram um esquema de assinatura onde um usuário pode provar que sua assinatura foi forjada pelo PKG, considerando que esse PKG não seja uma entidade totalmente idônea. Chamaremos tal esquema de assinatura CZK. Nesse esquema, até o momento em que escrevemos esta dissertação, não foi feita uma prova formal de segurança, apenas uma breve análise feita pelos próprios autores.

\subsubsection{Geração de chaves}

A geração das chaves baseadas em identidades no esquema de assinatura CZK é ligeiramente diferente da que vimos na seção 3.2.8. Aqui, a chave pública baseada em identidades $\left(Q_{I D}\right)$ será função não apenas do identificador, mas também de um ponto público calculado pelo usuário a partir de um inteiro aleatório que será mantido em segredo. Vamos relembrar os passos de uma geração de chaves, apontando as modificações efetuadas:

1. PKG escolhe um $s \in \mathbb{Z}_{q}^{*}$ e calcula

$$
R_{P K G}=s P
$$

onde $P$ é um ponto público. A chave-mestra $s$ é mantida em segredo pelo PKG;

2. Um usuário (digamos, Alice) submete seu ID (por exemplo, seu e-mail) ao PKG e prova sua identidade;

3. Alice escolhe um aleatório $r \in \mathbb{Z}_{q}^{*}$ e envia o ponto $r P$ ao PKG. O aleatório $r$ é mantido em segredo por Alice; 
4. O PKG calcula a chave pública de Alice da seguinte forma:

$$
Q_{\text {alice }}=H_{1}\left(I D_{\text {alice }} \| T, r P\right)
$$

Onde $H_{1}$, da mesma forma como foi definida na seção 3.2.7.1, mapeia uma seqüência de bits de tamanho arbitrário em um ponto da curva elíptica. O valor $T$, que é concatenado com $I D_{\text {alice }}$ na equação (7.2), representa o prazo de validade da chave gerada, como vimos na seção 5.1.1. Embora nada seja dito pelos autores a respeito de como o valor $r P$ seja tratado na função de espalhamento $H_{1}$, podemos interpretar, para fins de implementação, que $H_{1}$ seja uma função de espalhamento com chave e nesse caso, $r P$ seria a chave. Vamos considerar que a cada $I D$ está associado um único $r P$ durante o período $T$;

5. Após calcular $Q_{\text {alice }}$, o PKG calcula

$$
S_{\text {alice }}=s Q_{\text {alice }}
$$

e envia $S_{\text {alice }}$ para Alice através de um canal seguro;

6. A chave particular de Alice será $\left(S_{\text {alice }}, r\right)$, onde somente Alice conhece $r$.

\subsubsection{Assinatura}

Alice escolhe um aleatório $a \in \mathbb{Z}_{q}^{*}$ e calcula

$$
\begin{aligned}
U & =a Q_{\text {alice }} \\
V & =r H_{1}(m, U) \\
h & =H_{2}(m, U+V) \\
W & =(a+h) S_{\text {alice }}
\end{aligned}
$$

onde $m$ é a mensagem a ser assinada, $U$ é usado como chave da função $H_{1}$ e o ponto $U+V$ é usado como chave na função $H_{2}$ e $r$ é conhecido somente por Alice.

A assinatura de Alice sobre $m$ é $(U, V, W, T, r P)$. 


\subsubsection{Verificação}

Se Beto quiser verificar se a assinatura foi realmente produzida por Alice, ele primeiro calcula $Q_{\text {alice }}$ usando a equação (7.2), $H_{1}(m, U)$ e $h$ através da equação (7.6). Note que Beto consegue calcular tais valores, pois só utiliza valores públicos.

Após calcular esses valores, Beto aceita a assinatura de Alice como válida se:

$$
\begin{gathered}
e_{t}(W, P)=e_{t}\left(U+h Q_{\text {alice }}, R_{P K G}\right) \\
e_{t}(V, P)=e_{t}\left(H_{1}(m, U), r P\right)
\end{gathered}
$$

Pela equação (7.8) Beto tem certeza de que Alice conhece $S_{\text {alice }}$, pois somente assim poderia ter calculado $W$ corretamente e pela equação (7.9) Beto garante que Alice conhece $r$, pois somente assim poderia ter calculado $V$ corretamente. Note que Alice não precisou revelar para Beto $S_{\text {alice }}$ e nem $r$ para que ele chegasse a tal conclusão.

\subsubsection{Demonstração}

Vamos demonstrar que as equações (7.8) e (7.9) serão verdadeiras se a assinatura de Alice for válida.

Primeiramente, vamos mostrar que $e_{t}(W, P)=e_{t}\left(U+h Q_{\text {alice }}, R_{P K G}\right)$, garantindo que a chave $S_{\text {alice }}$ foi usada na assinatura:

$$
\begin{aligned}
e_{t}(W, P) & =e_{t}\left((a+h) s Q_{\text {alice }}, P\right) & & \text { pela equação (7.7) } \\
& =e_{t}\left((a+h) Q_{\text {alice }}, s P\right) & & \text { por bilinearidade } \\
& =e_{t}\left(\left(a Q_{\text {alice }}+h Q_{\text {alice }}, s P\right)\right. & & \text { prop. distributiva } \\
& =e_{t}\left(\left(U+h Q_{\text {alice }}, s P\right)\right. & & \text { pela equação (7.4) } \\
& =e_{t}\left(\left(U+h Q_{\text {alice }}, R_{P K G}\right)\right. & & \text { pela equação (7.1) }
\end{aligned}
$$

Agora vamos mostrar que $e_{t}(V, P)=e_{t}\left(H_{1}(m, U), r P\right)$, garantindo que $r$, que só é conhecido por Alice, foi usado na assinatura:

$$
\begin{aligned}
& e_{t}(V, P)=e_{t}\left(r H_{1}(m, U), P\right) \quad \text { pela equação (7.5) } \\
& =e_{t}\left(H_{1}(m, U), r P\right) \text { por bilinearidade }
\end{aligned}
$$

\subsubsection{Personificação}

Vamos supor agora, que o PKG não é uma entidade idônea e deseja forjar a assinatura de Alice sobre uma mensagem $m^{\prime}$. O PKG age da seguinte forma: 
1. Escolhe um $r^{\prime} \in \mathbb{Z}_{q}^{*}$ e calcula

$$
Q_{\text {alice }}^{\prime}=H_{1}\left(I D_{\text {alice }} \| T, r^{\prime} P\right)
$$

2. Calcula $\left(U^{\prime}, V^{\prime}, W^{\prime}, T, r^{\prime} P\right)$ como no protocolo da seção 7.1.2.

Como $S_{\text {alice }}^{\prime}$ foi calculada pela PKG, a verificação feita na seção 7.1.3 indicará que a assinatura $\left(U^{\prime}, V^{\prime}, W^{\prime}, T, r^{\prime} P\right)$ sobre $m^{\prime}$ é uma assinatura válida de Alice.

Porém, o leitor deve ter notado que o PKG teve que escolher um valor $r^{\prime}$, pois não conhece o $r$ escolhido por Alice (e como o valor do parâmetro $q$ deve ser muito grande, a probabilidade de o PKG escolher $r^{\prime}=r$ é próxima de zero). Embora conheça o valor $r P$, pois este lhe foi enviado por Alice, o PKG não consegue calcular $r$, que está protegido pelo PLD-CE e também não pode simplesmente usar $r P$, pois precisa de $r$ para calcular $V$ na equação (7.5).

Tal fato permitirá que Alice possa provar a um árbitro que a assinatura $\left(U^{\prime}, V^{\prime}, W^{\prime}, T, r^{\prime} P\right)$ sobre $m^{\prime}$ foi forjada pelo PKG e, conseqüentemente, desacreditar esse PKG publicamente. Para isso, Alice procede da seguinte forma:

1. Envia $Q_{\text {alice }}=H_{1}\left(I D_{\text {alice }} \| T, r P\right)$ e o ponto $r P$ para o árbitro;

2. O árbitro consegue verificar que o $r P$ enviado por Alice de fato está associado ao identificador dela no período $T$, calculando $Q_{\text {alice }}$ como na equação (7.2) e comparando com o $Q_{\text {alice }}$ enviado por ela;

3. O árbitro então, verificará que o $r P$ enviado por Alice não confere com o $r^{\prime} P$ que consta na assinatura;

4. Alice agora, só precisa provar que possui a chave particular associada a $Q_{\text {alice }}$, pois dessa forma, fará o árbitro concluir que existem dois $r P$ diferentes associados a um mesmo ID em um único período, ou seja, concluirá que o PKG gerou duas chaves particulares distintas para um mesmo identificador (dentro de um único período) e portanto esse PKG é desonesto;

5. Considerando que o PKG não é idôneo, Alice não utilizará mais sua chave $S_{\text {alice }}$ e portanto, pode revelá-la ao árbitro, que verificará a validade da seguinte equação:

$$
e_{t}\left(S_{\text {alice }}, P\right)=e_{t}\left(Q_{\text {alice }}, R_{P K G}\right)
$$


e assim concluirá que o PKG é desonesto e forjou a assinatura de Alice sobre $m^{\prime}$.

Note que o árbitro terá certeza de que $S_{\text {alice }}$ foi gerada pelo PKG pois:

$$
\begin{aligned}
e_{t}\left(S_{\text {alice }}, P\right) & =e_{t}\left(s Q_{\text {alice }}, P\right) & & \text { pela equação (7.3) } \\
& =e_{t}\left(Q_{\text {alice }}, s P\right) & & \text { por bilinearidade } \\
& =e_{t}\left(Q_{\text {alice }}, R_{P K G}\right) & & \text { pela equação (7.1) }
\end{aligned}
$$

\subsubsection{Comparação com o esquema de Hess}

Como dissemos na introdução deste capítulo, este esquema de assinatura com PKG não confiável nada mais é do que uma variação em esquemas de assinaturas. Assim como fizemos no capítulo 6, vamos medir o custo computacional em função do cálculo do emparelhamento, que é a operação de maior custo.

Em termos computacionais, o esquema de Hess, que vimos na seção 3.5 calcula 1 emparelhamento na assinatura, que pode ser pré-calculado e 2 na verificação, dos quais um deles $\left(e_{t}\left(Q_{\text {alice }},-R_{T A}\right)\right)$ pode ser pré-calculado. Desta forma, temos um total de 3 cálculos de emparelhamento, onde 2 podem ser pré-calculados.

O esquema CZK não calcula nenhum emparelhamento na assinatura, porém calcula 4 emparelhamentos na verificação, nenhum deles pré-calculáveis. Considerando que a maioria das aplicações exige várias verificações para uma mesma assinatura, vemos claramente que o esquema de Hess é muito mais eficiente do que o CZK.

Entretanto, se houver qualquer dúvida a respeito da idoneidade do PKG, devemos utilizar o esquema CZK de assinatura, mesmo sendo mais lento, para garantirmos que nossa assinatura não será forjada.

\subsection{Criptografia com múltiplos $\mathrm{PKG}$}

No mesmo artigo em que propuseram um esquema de criptografia baseado em identidades, D. Boneh e M. Franklin [Boneh e Franklin 2001] apresentaram uma solução onde a chave particular de um usuário é gerada por mais de um PKG. Desta forma, a menos que todos os PKG entrem em conluio, essa chave não pode ser recuperada. Tal solução traz consigo um questionamento, pois se por um lado, um grande número de PKG aumenta a probabilidade de 
pelo menos um deles ser confiável, garantindo a segurança da chave, por outro, para cada PKG existe a necessidade de o usuário provar sua identidade e também a necessidade de se estabelecer um canal seguro entre o usuário e o PKG para distribuição da chave particular, gerando com isso, um custo adicional proporcional ao número de PKG. A solução proposta é bem simples:

Suponha que existam $n$ PKG, que chamaremos de $p k g_{1}, p k g_{2}, \ldots, p k g_{n}$. Cada PKG possui sua chave particular padrão $s_{1}, s_{2}, \ldots, s_{n}$ e calcula sua chave pública $R_{P K G_{1}}, R_{P K G_{2}}, \ldots, R_{P K G_{n}}$, tal que $R_{P K G_{i}}=s_{i} P$, onde $1 \leqslant i \leqslant n$.

Um usuário Beto, cujo identificador é $I D_{\text {beto }}$ solicita um par de chaves a cada PKG. A chave pública de Beto baseada em identidades, exatamente como vimos no capítulo 3 será $Q_{\text {beto }}=H_{1}\left(I D_{\text {beto }}\right)$. Cada um dos $i$ PKG $(1 \leqslant i \leqslant n)$, por sua vez, vai gerar as correspondentes chaves particulares:

$$
S_{\text {beto }}^{(i)}=s_{i} Q_{\text {beto }}
$$

Após receber todas as $n$ chaves particulares, Beto calcula sua chave particular, que chamaremos de chave particular global, da seguinte forma:

$$
S_{\text {beto }}=\sum_{i=1}^{n} S_{\text {beto }}^{(i)}
$$

Da mesma forma, a chave pública global dos PKG, que será usada no esquema, será:

$$
R_{P K G}=\sum_{i=1}^{n} R_{P K G_{i}}
$$

Vejamos agora porque tal solução pode ser utilizada, analisando o esquema de Boneh e Franklin visto nas equações (3.13) e (3.14):

\subsubsection{Criptografia}

Alice escolhe um elemento aleatório $r$, tal que $r \in \mathbb{F}_{q}$ e calcula:

$$
\left\{\begin{array}{l}
U=r P \\
V=m \oplus H_{3}\left(e_{t}\left(r Q_{\text {beto }}, R_{P K G}\right)\right)
\end{array}\right.
$$

Onde $R_{P K G}$ é o que chamamos de chave pública global dos PKG.

Alice, então, envia o texto criptografado $(U, V)$ para Beto. 


\subsubsection{Decriptografia}

Beto, recebendo $(U, V)$ de Alice, faz o seguinte cálculo para recuperar $m$ :

$$
m=V \oplus H_{3}\left(e_{t}\left(S_{\text {beto }}, U\right)\right)
$$

Vemos que Beto utiliza sua chave particular global baseada em identidades para recuperar $m$.

\subsubsection{Demonstração}

Vamos agora demonstrar que o uso das chaves que chamamos de "global" não interfere na corretude do esquema:

Beto, recebendo $(U, V)$ de Alice, vai calcular:

$$
V \oplus H_{3}\left(e_{t}\left(S_{\text {beto }}, U\right)\right)
$$

substituindo a chave particular global de Beto de acordo com a equação 7.12, temos:

$$
V \oplus H_{3}\left(e_{t}\left(S_{\text {beto }}^{(1)}+S_{\text {beto }}^{(2)}+\ldots+S_{\text {beto }}^{(n)}, U\right)\right)
$$

como $S_{\text {beto }}^{(i)}=s_{i} Q_{\text {beto }}$, temos:

$$
V \oplus H_{3}\left(e_{t}\left(s_{1} Q_{\text {beto }}+s_{2} Q_{\text {beto }}+\ldots+s_{n} Q_{\text {beto }}, U\right)\right)
$$

aplicando a propriedade (3.5) de bilinearidade e substituindo $U=r P$, temos:

$$
V \oplus H_{3}\left(e_{t}\left(s_{1} Q_{\text {beto }}, r P\right) \cdot e_{t}\left(s_{2} Q_{\text {beto }}, r P\right) \ldots \cdot e_{t}\left(s_{n} Q_{b e t o}, r P\right)\right)
$$

aplicando bilinearidade nos multiplicadores:

$$
V \oplus H_{3}\left(e_{t}\left(r Q_{b e t o}, s_{1} P\right) \cdot e_{t}\left(r Q_{b e t o}, s_{2} P\right) \ldots \cdot e_{t}\left(r Q_{b e t o}, s_{n} P\right)\right)
$$

agora aplicando a propriedade (3.6) de bilinearidade, temos:

$$
V \oplus H_{3}\left(e_{t}\left(r Q_{b e t o}, s_{1} P+s_{2} P+\ldots+s_{n} P\right)\right)
$$

substituindo $R_{P K G_{i}}=S_{i} P$ para $i$ de 1 a $n$, temos:

$$
V \oplus H_{3}\left(e_{t}\left(r Q_{b e t o}, R_{P K G_{1}}+R_{P K G_{2}}+\ldots+R_{P K G_{n}}\right)\right)
$$


e de acordo com a equação (7.13), temos:

$$
V \oplus H_{3}\left(e_{t}\left(r Q_{b e t o}, R_{P K G}\right)\right)
$$

Finalmente, como $V=m \oplus H_{3}\left(e_{t}\left(r Q_{b e t o}, R_{P K G}\right)\right)$, aplicando a propriedade de ou-exclusivo, vemos que Beto consegue recuperar $m$.

Com o artifício de utilizar múltiplos PKG, garantimos que somente Beto conhece sua chave particular "global", a não ser que todos os PKG entrem em conluio. Caso isto aconteça, eles conseguirão calcular a chave particular global de Beto, da mesma forma como Beto faria, ou seja, através da equação (7.12). Podemos diminuir a probabilidade de ocorrer um conluio total aumentando o número de PKG no sistema, o que trará como conseqüência um aumento do número de comunicações necessárias na geração das chaves (e conseqüentemente, a necessidade de um canal seguro entre o usuário e cada PKG), mas que dependendo do nível de segurança desejado e da confiança no(s) PKG, poderá ser uma solução muito interessante.

\subsection{Trabalhos relacionados}

A título de informação aos leitores desta dissertação que queiram ampliar seus conhecimentos sobre esquemas criptográficos que utilizam mapeamentos bilineares, existe um artigo chamado "Certificateless Public Key Cryptography", publicado por S. Al-Riyami e K. G. Paterson [Al-Riyami e Paterson 2003], onde é apresentado um novo esquema, também baseado em mapeamentos bilineares, em que o PKG não tem conhecimento da chave particular dos usuários, haja vista que gera apenas uma parte da chave, que será usada pelo usuário, juntamente com um fator secreto que somente ele (o usuário) conhece para gerar a chave particular definitiva.

Tal esquema, entretanto, não pode ser considerado como sistema baseado em identidades, como os próprios autores afirmam - e por esta razão não será discutido com detalhes nesta dissertação - pois a chave pública deixa de ser função do identificador do usuário e, com isso, volta a existir a necessidade de um diretório público de chaves. Na verdade, o identificador continua sendo usado pelo PKG para gerar a chave particular parcial, mas depois disto, o usuário deve gerar sua própria chave pública a partir do segredo que ele possui. 
As chaves públicas, como afirmam os autores, não necessitam de um certificado, pois mesmo que um intruso mal-intencionado as modificasse, não conseguiria decriptografar mensagens que fossem criptografadas com essas chaves falsas. Entretanto, existe um custo adicional de verificação das chaves públicas, através da consistência de uma igualdade de emparelhamentos, e isto poderia ser até encarado como uma verificação de certificados, como ocorre na tradicional estrutura PKI.

\subsection{Resumo}

Vimos neste capítulo esquemas de assinatura e criptografia em que a hipótese de que o PKG é incondicionalmente confiável é descartada e apresentamos esquemas onde a segurança pode se manter mesmo que a idoneidade do PKG seja questionável.

No esquema de assinatura com PKG não confiável, um usuário pode provar que sua assinatura foi forjada pelo PKG, considerando que esse PKG não seja uma entidade totalmente idônea.

No esquema de criptografia com múltiplos PKG, a chave particular de um usuário é gerada por mais de um PKG e, desta forma, só pode ser revelada caso todos os PKG entrem em conluio. Obviamente, este esquema apresenta o inconveniente de se estabelecer um canal seguro entre o usuário e cada PKG, mas dependendo da aplicação, é uma solução interessante, pois garante o sigilo da chave particular.

Apesar de os esquemas propostos apresentarem um custo adicional em relação aos esquemas apresentados no capítulo 3, em muitas situações podem ser desejáveis, especialmente quando não se tem certeza absoluta da idoneidade do PKG.

No próximo capítulo, descreveremos os principais passos e dificuldades na implementação de um protótipo de sistema baseado em identidades. 


\section{Capítulo 8}

\section{Implementação: principais passos e dificuldades}

Descreveremos neste capítulo os principais passos executados e as dificuldades mais significativas na implementação em ANSI-C dos seguintes esquemas:

- Assinatura compacta BLS (Boneh, Lynn e Shacham);

- Assinatura baseada em identidades (Hess);

- Criptografia baseada em identidades IBE (Boneh e Franklin);

- Criptassinatura (Nalla e Reddy).

Novamente, expressamos nosso agradecimento a Paulo S. L. M. Barreto, pelas valorosas dicas que tornaram possível essa implementação.

\subsection{Componentes e programas utilizados}

Utilizamos, na implementação, um micro-computador tipo Intel, com processador Pentium III 700 MHz e 248 Mb de memória RAM, equipado com sistema operacional Windows Me. Para compilar o programa em ANSI-C utilizamos o compilador Icc-win32. 


\subsection{Escolha de parâmetros}

Como dissemos na Introdução desta dissertação, decidimos fazer uma implementação utilizando parâmetros com valores bem pequenos, com o objetivo didático de mostrar que o esquema realmente funciona e, principalmente, mostrar como implementar um mapeamento bilinear, operação de maior custo computacional. A escolha de parâmetros pequenos possibilitou que fizéssemos a maioria dos cálculos no papel (como por exemplo, operações com polinômios), permitindo uma comparação entre os valores computados e os calculados manualmente, para verificação da corretude dos valores computados. Seguem abaixo os principais parâmetros escolhidos:

1. número primo - adotamos o número primo $q=17$. Na prática, o número primo escolhido deveria ser da ordem de $2^{160}$, de modo a tornar intratável o PLD-CE.

2. curva adotada - adotamos a curva elíptica

$$
y^{2}=x^{3}+6 x+8 \text { sobre } \mathbb{F}_{17}
$$

Tal curva é uma curva ordinária com grau de imersão par, o que nos possibilitará utilizar o algoritmo de Miller simplificado [Barreto, Lynn e Scott 2003]. Essa curva foi escolhida da seguinte forma: desejávamos uma curva com grau de imersão par (para que pudéssemos usar o algoritmo simplificado de Miller) e com ordem prima (para que todos os pontos tivessem a ordem da curva). Variamos então os parâmetros $a$ e $b$ da curva e para cada par $(a, b)$, variamos $x$ de 0 a $q-1$ e calculamos o respectivo $y$ usando a equação da curva, caso tal $y$ existisse. Contamos o número de pares $(x, y)$ de pontos da curva e a esse valor somamos mais 1 , correspondente ao ponto $\mathcal{O}$, obtendo a ordem da curva. Com a ordem $r$ da curva, calculamos o menor $k$ tal que $r \mid q^{k}-1$, obtendo o grau de imersão. Na figura 8.1 o leitor pode ver a execução desse algoritmo de seleção, onde, para facilitar os cálculos, usamos apenas valores inteiros e positivos para $a$ e $b$ e imprimimos na tela apenas as curvas com grau de imersão par e menor ou igual a 6 (escolhemos 6 apenas para que o polinômio que representasse as coordenadas de um ponto em $E\left(\mathbb{F}_{q^{k}}\right)$ não tivesse um grau muito alto) e $r$ ímpar. Finalmente, dentre as curvas impressas, escolhemos a primeira cujo $r$ fosse primo, obtendo $y^{2}=x^{3}+6 x+8$. 


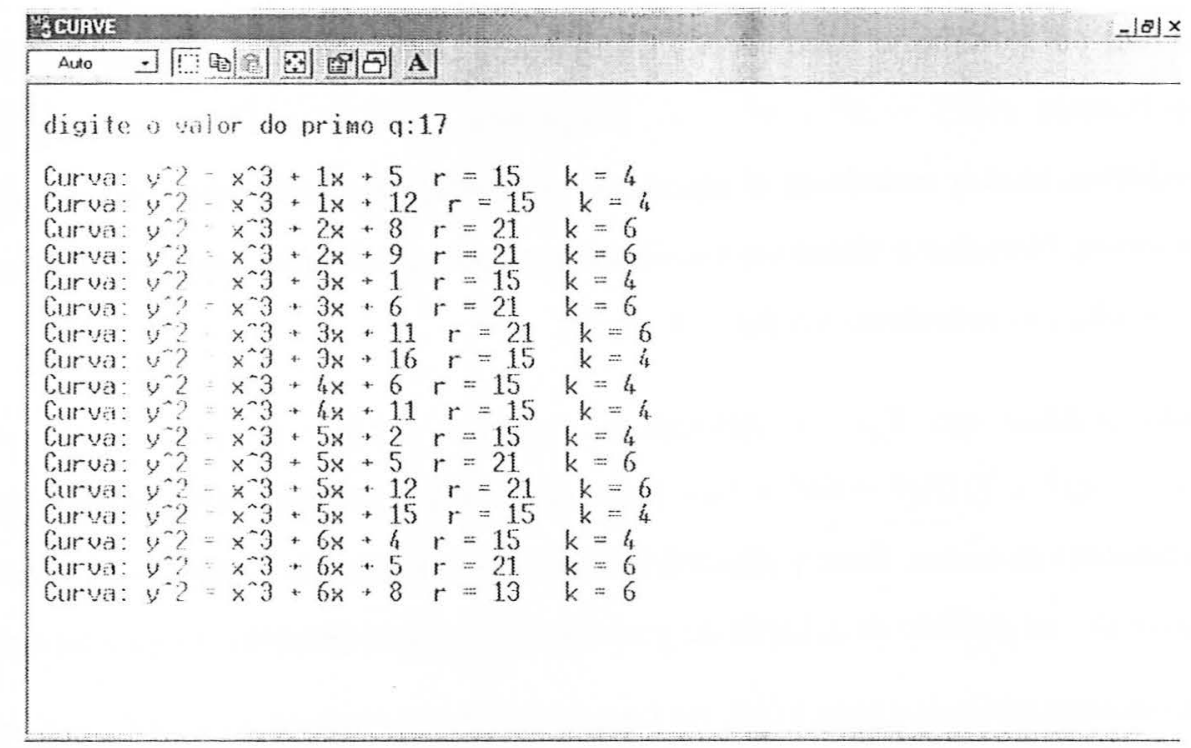

Figura 8.1: Seleção da curva - dentre as curvas com grau de imersão par menor ou igual a 6 e ordem ímpar, selecionamos a primeira de ordem prima.

Mais uma vez, reforçamos a idéia de que tais parâmetros foram escolhidos com a finalidade de se obter uma implementação mais didática, pois na prática seriam necessários milhares de pontos, a fim de tornar o PLD-CE intratável, garantindo, com isto, a segurança do esquema.

3. ordem da curva - a curva adotada tem 13 pontos sobre $\mathbb{F}_{17}$ :

$$
(0,5),(0,12),(1,7),(1,10),(3,6),(3,11),(7,6),(7,11),(9,3),(9,14),(16,1),(16,16)
$$

e mais o ponto $\mathcal{O}$ no infinito. Portanto a ordem dessa curva é $r=13$. Este é um dado importante, pois se a curva tem ordem prima $r$, todos os pontos dessa curva sobre $\mathbb{F}_{17}$ também têm ordem $r$.

4. grau de imersão - a curva considerada tem grau de imersão $k=6$, pois é o menor inteiro tal que $r \mid\left(q^{k}-1\right)$ (ou seja, o quociente $\frac{\left(17^{6}-1\right)}{13}=\frac{24137568}{13}$ é exato).

5. chave particular padrão do PKG - escolhemos, aleatoriamente, o valor de $s=7$ como chave particular padrão do PKG (poderia ser qualquer valor entre 1 e $r-1$ ).

6. polinômio irredutível mod $q$ - todas as operações algébricas em $\mathbb{F}_{q^{k}}$ são realizadas 
módulo um polinômio irredutível. Escolhemos como polinômio irredutível de grau $k$ o polinômio $m(x)=x^{6}+x^{2}+3$. Na prática, pode-se verificar se um polinômio é irredutível mod $q$ usando-se o algoritmo de Berlekamp para fatoração de polinômios [Menezes, Oorschot e Vanstone 1997], alimentando polinômios para o algoritmo até que se obtenha um polinômio irredutível mod $q$.

7. ponto público em $\mathbb{F}_{q^{k}}$ - Adotamos o ponto público $Q$ como sendo o ponto $\left(13 x^{4}+4 x^{2}+1,13 x^{5}+6 x^{3}+5 x\right)$, linearmente independente a qualquer um dos 12 pontos (finitos) da curva. Esse ponto foi calculado e gentilmente cedido por Paulo Barreto, através de seu método de seleção de geradores de grupos [Barreto, Lynn e Scott 2003].

Para mostrarmos que o ponto $Q$ é, de fato, um ponto da curva $y^{2}=x^{3}+6 x+8$ sobre $\mathbb{F}_{17}$, faremos a seguinte verificação:

$$
\left(13 x^{5}+6 x^{3}+5 x\right)^{2} \stackrel{\bmod m(x)}{=}\left[\left(13 x^{4}+4 x^{2}+1\right)^{3}+6\left(13 x^{4}+4 x^{2}+1\right)+8\right]
$$

Primeiramente, calculamos $\left(13 x^{5}+6 x^{3}+5 x\right)^{2}=169 x^{10}+156 x^{8}+166 x^{6}+60 x^{4}+25 x^{2}$. Reduzindo mod 17, temos: $16 x^{10}+3 x^{8}+13 x^{6}+9 x^{4}+8 x^{2}$.

Finalmente, reduzimos mod $m(x)$ (i.e., dividimos por $m(x)$ e pegamos o resto), obtendo: $9 x^{4}+2 x^{2}+9$.

Em seguida, calculamos:

$\left(13 x^{4}+4 x^{2}+1\right)^{3}=2197 x^{12}+2028 x^{10}+1131 x^{8}+376 x^{6}+87 x^{4}+12 x^{2}+1 ;$

Reduzindo mod 17, temos: $4 x^{12}+5 x^{10}+9 x^{8}+2 x^{6}+2 x^{4}+1$

Reduzindo mod $m(x)$, temos: $16 x^{4}+12 x^{2}+12(*)$

$6\left(13 x^{4}+4 x^{2}+1\right)=78 x^{4}+24 x^{2}+6 ;$

Reduzindo mod 17, temos: $10 x^{4}+7 x^{2}+6 x(* *)$

Finalmente, somando $\left({ }^{*}\right)+(* *)+8$, temos $9 x^{4}+2 x^{2}+9$, o que comprova que $Q$ é um ponto da curva.

Pelas escolhas feitas, conseguimos obter uma curva ordinária com grau de imersão par $k=6$. Tal fato nos permite calcular o emparelhamento de Tate usando o algoritmo de Miller simplificado, segundo Barreto et al. [Barreto, Lynn e Scott 2003]. Descreveremos o algoritmo de Miller simplificado na seção 8.8.3. 


\subsection{Escolha da estrutura de dados}

Representamos um ponto em $\mathbb{F}_{q}$ como uma struct Ponto com parâmetros $x$ e $y$ inteiros. O ponto em $\mathbb{F}_{q^{k}}$ foi representado por uma struct PontoFqk com parâmetros $x$ e $y$ sendo vetores de $k$ posições de inteiros. Cada elemento no corpo estendido $\mathbb{F}_{q^{k}}$ - representado por um polinômio de grau menor do que $k$ e coeficientes em $\mathbb{F}_{17}$ - foi tratado como um vetor de $k$ posições de inteiros, correspondendo aos coeficientes dos termos de grau 0 a $k-1$.

\subsection{Função de espalhamento}

Vimos que nos esquemas que descrevemos no capítulo 3 utilizamos oráculos aleatórios no lugar de funções de espalhamento. Como oráculos aleatórios pertencem ao campo meramente teórico, temos que implementar funções de espalhamento de acordo com suas definições.

A fim de evitar que o produto de um valor de hash por um ponto da curva desse como resultado o ponto no infinito $\mathcal{O}$, (caso indesejado, pois o emparelhamento degenera para 1) tomamos o cuidado de evitar que o resultado da função de espalhamento fosse a ordem da curva.

\subsubsection{Função de espalhamento $H_{1}$}

Temos que implementar uma função que mapeie uma seqüência arbitrária de bits (identificador) em um ponto da curva sobre $\mathbb{F}_{q}$. O correto seria utilizarmos uma função de hash conhecida, como por exemplo o SHA-1 ou MD-5. Entretanto, como estamos fazendo uma implementação didática, consideramos que o importante é como transformar o valor do hash em um ponto da curva. Desta forma, implementamos o mapeamento (função MapToPoint) desejado simplesmente acumulando a soma dos valores inteiros dos caracteres digitados. Em uma situação prática, bastaria calcular tal valor usando uma função de hash conhecida.

A primeira idéia para mapearmos o valor de hash em um ponto da curva, foi reduzi-lo módulo $r$ (garantindo que este valor estaria entre 0 e $r-1$ ) e então multiplicar este valor por um gerador da curva, gerando um novo ponto na curva, isto é, sendo $h$ o valor do hash 
sobre o identificador ID, o ponto mapeado seria $h P$. Tal procedimento, porém, acarretaria em uma séria falha de segurança, pois o PLD do identificador na curva estaria resolvido. Em outras palavras, se $H(I D)=h$ e $Q_{I D}=h P$, a chave particular seria $S_{I D}=s Q_{I D}=s h P$. Entretanto, como $s P=R_{T A}$, podemos reescrever a chave particular como $S_{I D}=h R_{T A}$. Sabendo que o valor de $h$ é conhecido, pois $H$ é uma função de domínio público, qualquer pessoa poderia calcular $S_{I D}$

Baseados nisto, descartamos tal idéia e passamos a utilizar o valor do hash reduzido módulo $q$ como sendo a abscissa do ponto da curva. Basta então, verificarmos se existe $y$ tal que $y^{2} \bmod q$ é igual ao valor calculado de $\left(x^{3}+a x+b\right) \bmod q$. Esta verificação pode ser feita utilizando-se um algoritmo de extração de raízes quadradas módulo $q$ [Menezes, Oorschot e Vanstone 1997] ou então por busca exaustiva, se o valor de $q$ permitir. No nosso exemplo, como estamos utilizando $q=17$, simplesmente variamos $y$ de 0 até $17 \mathrm{e}$ calculamos $y^{2} \bmod q$ até encontrarmos o valor calculado $x^{3}+a x+b \bmod q$. Caso não exista tal $y$, incrementamos o contador até que obtenhamos o valor de $y$. Na figura 8.2 pode ser visto o pseudo-código da função de espalhamento $H_{1}$.

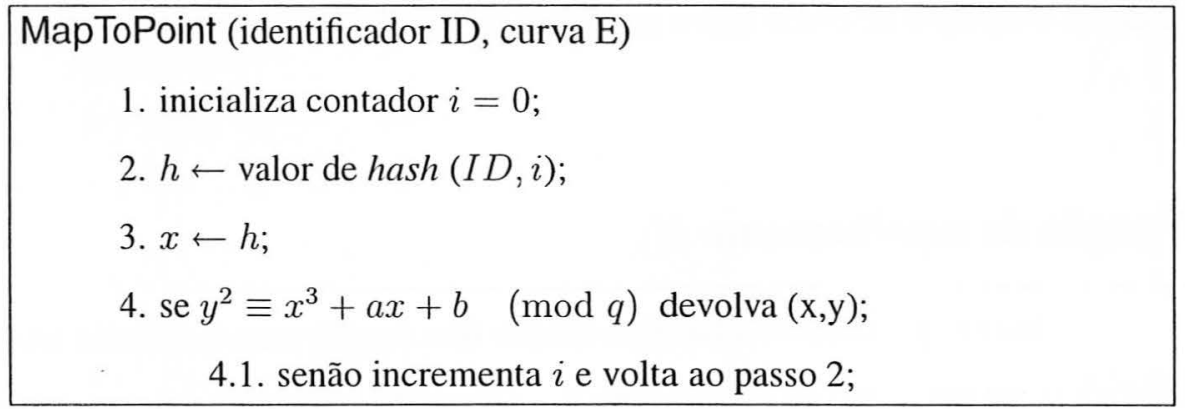

Figura 8.2: Função MapToPoint - recebe como entrada uma seqüência de bits e devolve na saída um ponto da curva $E\left(\mathbb{F}_{q}\right)$.

Um questionamento que surgiu durante a implementação dessa função de hash, é que estaríamos desprezando metade dos pontos em $E\left(\mathbb{F}_{q}\right)$ onde a seqüência de bits pudesse ser mapeada, pois existem sempre duas ordenadas para cada abscissa, e na implementação tínhamos que escolher a menor ou a maior ordenada. Pensamos então em colocar alguma condição que permitisse mapear a seqüência em cada um dos $r$ pontos da curva (e não em apenas $r / 2$ pontos). Uma idéia foi mapear na ordenada maior se o valor de hash fosse ímpar e 
mapear na ordenada menor se o valor de hash fosse par. Outra idéia seria reduzir o valor de hash módulo $2 q$ em vez de reduzir módulo $q$ e usar o último bit desse valor de hash para decidir se a ordenada seria a maior ou a menor. Nesse último caso, o valor inicial da abscissa seria $h / 2$, onde $h$ é o valor de hash.

Entretanto, na prática tal preciosismo não é necessário, tendo em vista que, se considerarmos $q \sim 2^{160}$, teremos um universo de cerca de $2^{80}$ pontos possíveis de se mapear uma mensagem (ou um identificador), que é um valor onde o PLD-CE ainda pode ser considerado intratável. Corroborando com esse fato, verificamos que muitos autores - por exemplo, Boneh, Lynn e Shacham [Boneh, Lynn e Shacham 2001] — já utilizam somente o valor da abscissa do ponto e não o ponto completo. Desta forma, para esses autores o resumo da mensagem é na verdade um par de pontos e não apenas um ponto.

\subsubsection{Função de espalhamento $H_{2}$}

Como precisamos de uma função que mapeia uma seqüência de bits de tamanho arbitrário em um inteiro módulo $q$, aproveitamos a mesma função de espalhamento usada para mapear uma seqüência na abscissa da curva, que vimos na seção anterior.

Mais uma vez, vale lembrar que na prática deveria ser usada uma função de hash conhecida, como por exemplo SHA-1 ou MD-5.

\subsubsection{Função de espalhamento $H_{3}$}

Como vimos no capítulo 3 , a função $H_{3}$ deve mapear o valor de um emparelhamento entre dois pontos em uma seqüência de bits de tamanho pré-definido arbitrariamente. Devido a todos os problemas inerentes ao uso de funções de hash, que discutimos na seção 3.2.7.1, verificamos que a única finalidade da função $H_{3}$ seria colocar o valor do emparelhamento em um formato adequado para que se possa fazer o "ou-exclusivo" com a mensagem.

Em face a isso, concluímos que a função $H_{3}$ pode ser descartada sem prejuízo de conteúdo, pois se utilizarmos, por exemplo, o esquema original de Boneh \& Franklin, podemos simplesmente fazer o "ou-exclusivo" da mensagem com o valor do emparelhamento (i.e., um vetor de inteiros mod $q$, onde cada posição do vetor é um dos coeficientes do em- 
parelhamento). No nosso caso, como $q=17$, cada posição do vetor tem no máximo 4 bits e o vetor inteiro tem no máximo 24 bits (polinômio com grau menor que 6). Para fazer o "ouexclusivo" da mensagem com este valor, basta repetirmos o mesmo até que tenha o tamanho da mensagem, conforme figura 8.3, onde tam é o tamanho da mensagem, mens[tam] é a mensagem clara, C[tam] é o texto criptografado e $e[k]$ é o valor do emparelhamento entre dois pontos $P$ e $Q$.

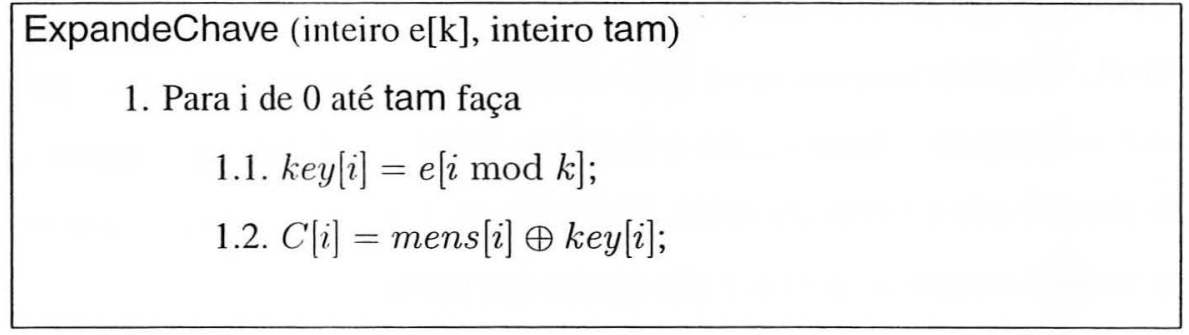

Figura 8.3: Função ExpandeChave - recebe como entrada um polinômio resultante de um emparelhamento e expande esse valor para o tamanho desejado (no caso, o tamanho da mensagem), devolvendo na saída um vetor do tamanho da mensagem.

Caso optemos por usar o esquema modificado, de acordo com a seção 3.4.5, podemos usar o valor do emparelhamento diretamente como chave, apenas colocando-o no tamanho adequado (por exemplo, 128 bits).

\subsubsection{Função de espalhamento $H_{4}$}

Vimos no capítulo 4 que, uma vez que utilizemos uma curva ordinária, faz-se necessário uma função de espalhamento que mapeie uma seqüência de bits de tamanho arbitrário em um ponto em $E\left(\mathbb{F}_{q^{k}}\right)$, na implementação do esquema de Nalla e Reddy.

O mais correto seria calcularmos o valor de hash de um identificador e fazer com que esse valor fosse o coeficiente do termo de grau zero do polinômio que representa a abscissa $x$ em $E\left(\mathbb{F}_{q^{k}}\right)$. Em seguida, colocaríamos um contador nos coeficientes dos demais termos do polinômio-abscissa $x$ e teríamos que calcular a raiz quadrada de $x^{3}+6 x+8$, lembrando sempre que " $x$ " é um polinômio. Essa operação, claramente, seria muito complexa para o modelo simplificado a que nos propusemos implementar.

A idéia de multiplicar o valor de hash por um ponto gerador em $E\left(\mathbb{F}_{q^{k}}\right)$ também foi descartada, pois assim como explicamos na função $H_{1}$, revelaria o valor da chave 
particular.

Finalmente, conseguimos chegar a uma implementação eficiente e não menos segura, baseados na definição de oráculo aleatório da seção 3.2.7.2. Como vimos, podemos "simular" um oráculo preenchendo aleatoriamente uma tabela. Desta forma, fazendo o papel de autoridade certificadora, selecionamos valores inteiros ao acaso (com o devido cuidado de escolhermos valores estatisticamente únicos, uniformemente distribuídos e independentes), multiplicando esses valores por um gerador em $E\left(\mathbb{F}_{q^{k}}\right)$ e inserindo o ponto resultante do produto na tabela. A tabela, após preenchida, seria publicada pela TA, que manteria em segredo os valores inteiros escolhidos (podendo, inclusive, apagá-los).

Um usuário, ao calcular o valor de hash de um identificador, usa esse valor como índice da tabela. Apesar de conhecer o ponto gerador e o ponto resultante (busca na tabela), considerando que o PLD é intratável, ele não consegue descobrir o valor do inteiro escolhido ao acaso pela TA e portanto, não consegue calcular uma chave secreta.

Em nossa implementação, geramos apenas 30 pontos em $E\left(\mathbb{F}_{q^{k}}\right)$, mas poderíamos ter gerado cerca de $17^{6}=24137569$ pontos (considerando que uma curva tem aproximadamente $q$ pontos), que ainda assim, a geração desses pontos seria tratável, já que esse valor é da ordem de grandeza de $10^{7} \simeq 2^{24}$.

\subsection{Aritmética em curvas elípticas}

Antes de calcularmos as chaves baseadas em identidades, teríamos, primeiramente, que implementar a aritmética em curvas elípticas (soma de pontos e produto de um ponto por um inteiro), usando as fórmulas que se encontram no anexo A. Implementamos então, as funções Lambda_1, Lambda_2, soma, duplica e produto.

No cálculo dos valores lambda $(\lambda)$, que são utilizados na soma de pontos e na duplicação de um ponto, de acordo com as fórmulas que podem ser vistas na seção A.4.1, temos um quociente $\bmod q$. Sabemos que um quociente $\frac{N}{D} \bmod q$ equivale a calcular o produto $A \cdot B^{-1}$, onde $B^{-1}$ é a inversa de $B \bmod q$. Tal inversa pode ser calculada pelo algoritmo estendido de Euclides [Terada 2000], que descrevemos na figura 8.4.

As funções soma e duplica foram implementadas sem dificuldades, pois 


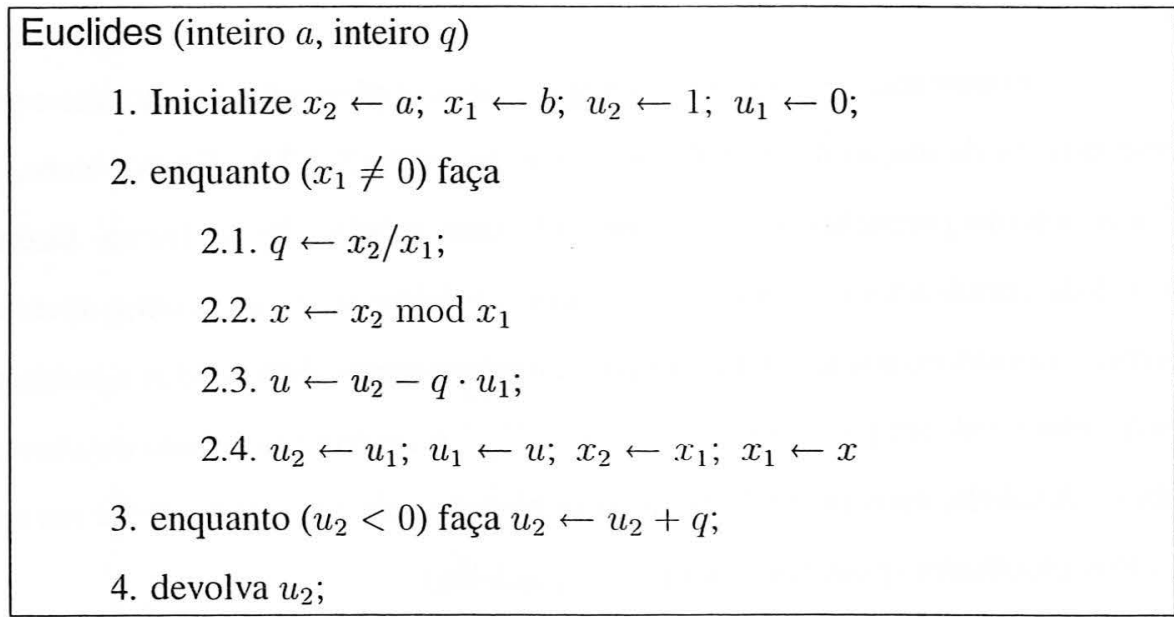

Figura 8.4: Algoritmo de Euclides estendido - recebe como entrada dois inteiros ( $a$ e $q$, onde $q$ é primo) e devolve na saída a inversa de $a \bmod q$.

são mera aplicação de fórmulas. A função produto deu um pouco mais de trabalho, pois queríamos uma operação feita de forma eficiente. Usamos então, o algoritmo "duplica e soma", conforme descrito em pseudo código na figura 8.5.

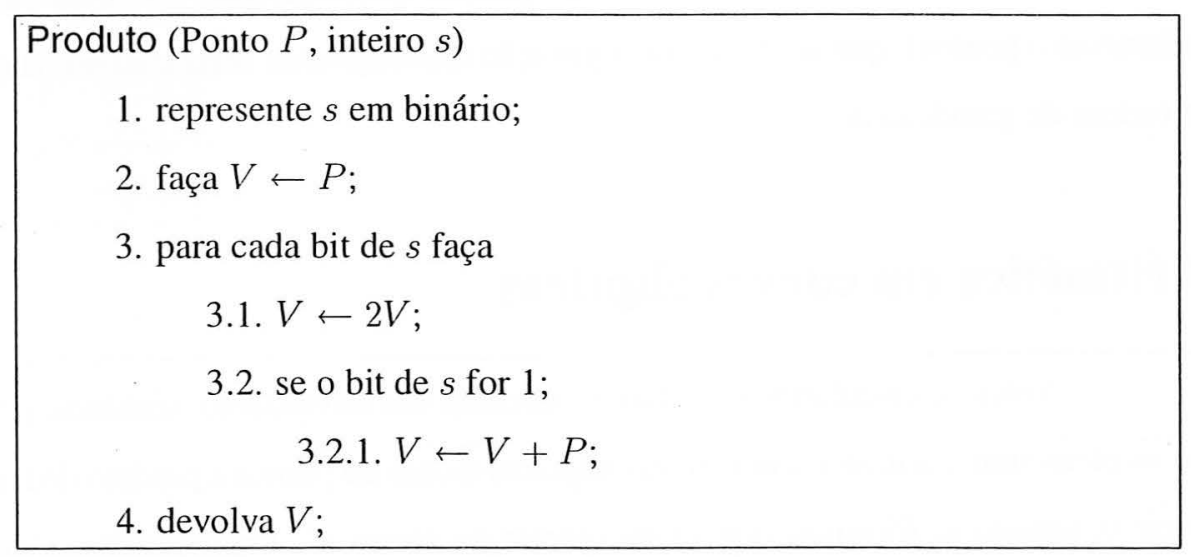

Figura 8.5: Algoritmo duplica-e-soma - recebe na entrada um inteiro $s$ e um ponto $P$ em $E\left(\mathbb{F}_{q}\right)$ e devolve na saída o ponto $V=s \cdot P$.

\subsection{Cálculo do par de chaves baseadas em identidades}

Após termos implementado a função de espalhamento $H_{1}$ e a aritmética em curvas elípticas, ficou fácil implementarmos a geração do par de chaves baseadas em identi- 
dades. Como vimos no capítulo 3, a chave pública baseada em identidades é calculada através da aplicação de uma função de espalhamento sobre o identificador. Portanto, ao digitar um identificador, o usuário obtém como chave pública baseada em identidades o ponto resultante da função de espalhamento $H_{1}$ que implementamos. Para obtermos a chave particular do usuário — chave essa que seria calculada pelo PKG — , basta calcularmos o produto entre o ponto gerado pela função MapToPoint e a chave particular $s$ do PKG.

\subsection{Aritmética no corpo estendido}

Para trabalharmos com pontos em $\mathbb{F}_{q^{k}}$, precisaríamos implementar todas as funções anteriores tendo como entrada polinômios (ou seja, um vetor de $k$ inteiros). Sendo assim, além das funções ditas básicas, como soma, produto e divisão de polinômios, tivemos que implementar as seguintes funções:

- redução de um polinômio módulo $m(x)$, onde $m(x)$ é um polinômio irredutível em $\mathbb{F}_{q^{k}}$, que escolhemos como sendo $x^{6}+x^{2}+3$ - esta operação é feita dividindo-se o polinômio de entrada por $m(x)$ e tomando-se como saída o resto da divisão. Na figura 8.6 descrevemos a multiplicação de polinômios e na figura 8.7 descrevemos a redução módulo $m(x)$, que é o mesmo algoritmo usado para divisão de polinômios, sendo que o segundo argumento é o polinômio $m(x)$;

- cálculo da soma e duplicação de pontos em $E\left(\mathbb{F}_{q^{k}}\right)$ - modificamos as funções soma e duplica para pontos em $E\left(\mathbb{F}_{q^{k}}\right)$, onde $\lambda, x_{1}, y_{1}, x_{2}, y_{2}, x_{3}$ e $y_{3}$ são polinômios de grau menor do que $k$ e coeficientes em $\mathbb{F}_{q}$;

- cálculo da inversa multiplicativa de um polinômio $f(x) \bmod m(x)$ - na soma e na duplicação de pontos em $E\left(\mathbb{F}_{q^{k}}\right)$, temos que calcular, assim como fizemos em $\mathbb{F}_{q}$, os valores de lambda. Tal cálculo envolve uma divisão modular, sendo então necessário o cálculo da inversa multiplicativa mod $m(x)$. Para tal, implementamos o algoritmo de Euclides estendido tendo como entrada polinômios (vetor de inteiros), que é basicamente o mesmo descrito na figura 8.4, sendo que os inteiros são substituídos por vetores de inteiros e as operações básicas de soma, produto e divisão de inteiros são 


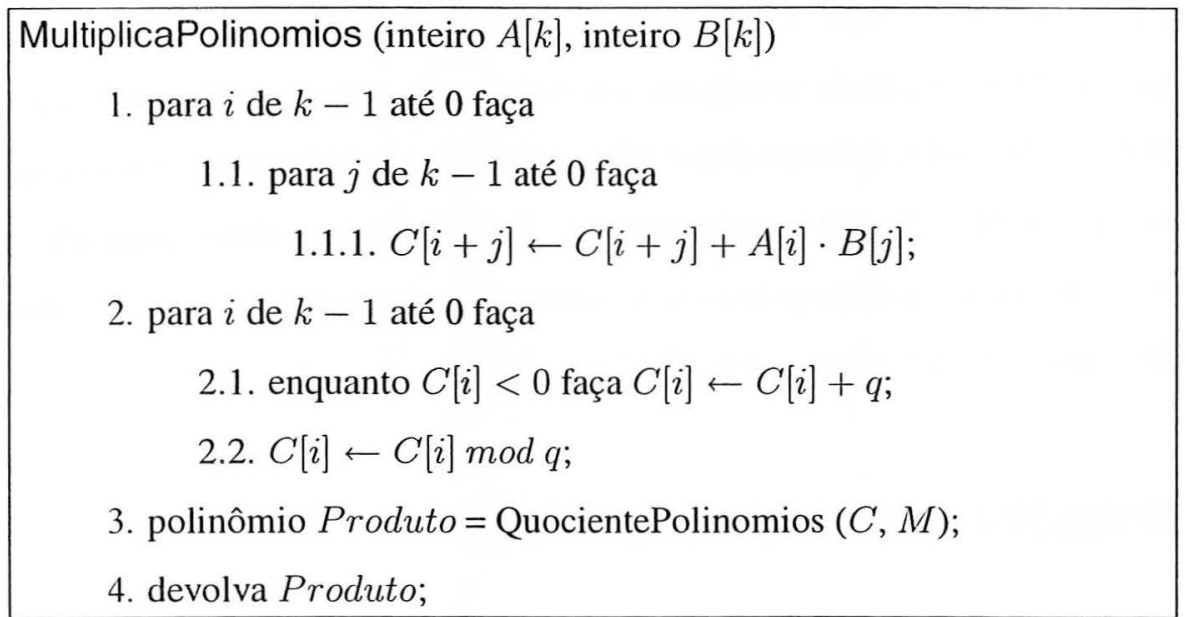

Figura 8.6: Algoritmo multiplicação de polinômios - recebe na entrada dois polinômios e devolve na saída o produto entre esses polinômios reduzido módulo $m(x)$.

substituídas pelas correspondentes SomaPolinomios, MultiplicaPolinomios e QuocientePolinomios. Não descrevemos aqui a função SomaPolinomios, mas esta é calculada simplesmente somando-se os coeficientes dos termos mesmo grau (i.e., mesmo índice no vetor de inteiros que representa o polinômio) e ao final reduz-se todos os coeficientes módulo $q$.

Um fato importante que observamos com o algoritmo de Euclides estendido para valores em $\mathbb{F}_{q^{k}}$ e que custou algumas horas de testes e simulações, foi o fato de que o polinômio resultante do algoritmo de Euclides multiplicado pelo polinômio de entrada não dá como resultado, necessariamente, 1 e sim um polinômio qualquer de grau zero, ou seja, se queremos calcular a inversa mod $m(x)$ do polinômio $A(x)$, obtemos como saída do algoritmo de Euclides estendido um polinômio $B(x)$, tal que $A(x) \cdot B(x) \equiv t \bmod m(x)$, onde $t$ é um polinômio de grau zero, ou seja, um inteiro. Para obtermos, então, a inversa de $A(x) \bmod m(x)$, temos primeiramente que encontrar a $t^{-1}$ (a inversa de $t \bmod q$ ) e multiplicar o polinômio $B(x)$ pelo valor de $t^{-1}$, obtendo finalmente $A^{-1}$.

Segue um exemplo numérico para ilustrar o que foi dito:

\section{Exemplo 1:}

Seja $A=13 x^{4}+4 x^{2}+1$. A saída do algoritmo de Euclides é $B=8 x^{4}+13 x^{2}+6$. Se multiplicarmos os polinômios $A \cdot B$ e reduzirmos módulo $m(x)$, obtemos 15 . 


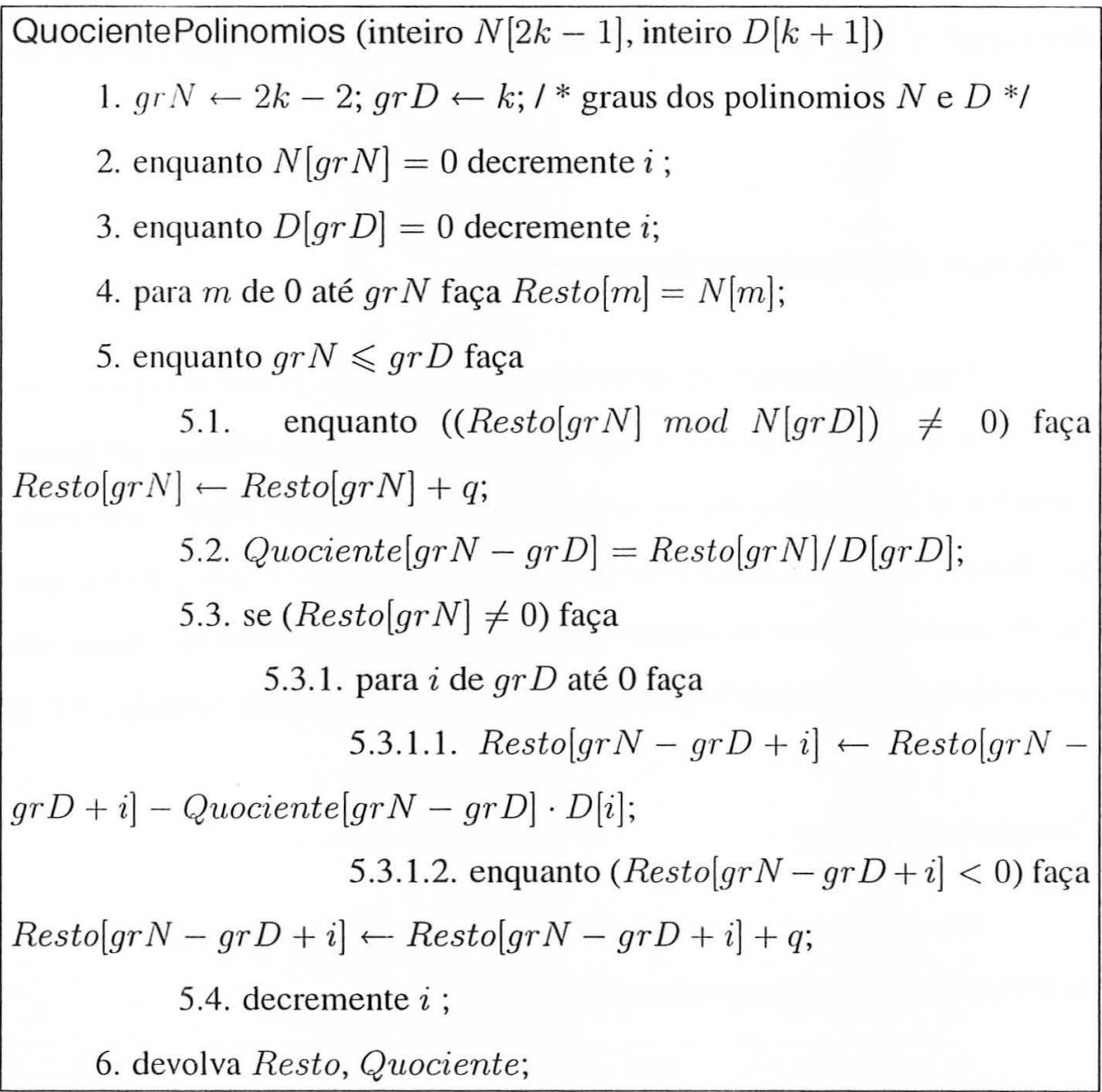

Figura 8.7: Algoritmo divisão de polinômios - recebe na entrada dois polinômios e devolve na saída o quociente entre esses polinômios e o resto da divisão. Se o segundo argumento for o polinômio $m(x)$, este algoritmo serve para reduzir um polinômio módulo $m(x)$.

A inversa de $15 \bmod 17$ é 8 , pois $15 \times 8=120 \bmod 17=1$.

Multiplicando o polinômio $B$ por 8 , temos: $C=64 x^{4}+104 x^{2}+48$, que reduzido mod 17 é igual a $13 x^{4}+2 x^{2}+14$.

Finalmente, multiplicando-se os polinômios $A \cdot C$ e reduzindo módulo $m(x)$, obtemos 1 .

Logo, a inversa de $A=13 x^{4}+4 x^{2}+1 \bmod x^{6}+x^{2}+3$ é $A^{-1}=13 x^{4}+2 x^{2}+14$.

O fato acima se justifica da seguinte forma:

Se existe um polinômio $R$ tal que $Q \cdot R \equiv t \bmod m(x)$, com $t \neq 1$, seja $S=Q \cdot R$. Se $S \equiv t \bmod m$, então seja $S^{\prime}$ é um polinômio tal que os coeficientes de $S^{\prime}$ são os coeficientes de $S$ divididos por $t$. Deste modo, $S^{\prime} \equiv 1 \bmod m$. Logo, $S \cdot t^{-1} \equiv 1 \bmod m$ 
e substituindo $S=Q \cdot R$, temos $Q \cdot R \cdot t^{-1} \equiv 1 \bmod m$ e segue que a inversa de $Q \bmod m$ é $Q^{-1}=R \cdot t^{-1}$.

\subsection{Cálculo do emparelhamento}

Para calcularmos o emparelhamento de Tate $\left(e_{t}\right)$ entre dois pontos linearmente independentes $P$ e $Q$, vamos utilizar o algoritmo de Miller simplificado, proposto primeiramente em [Barreto et al. 2002] e depois em [Barreto, Lynn e Scott 2003], tendo em vista que estamos trabalhando com uma curva cujo grau de imersão é par, o que permite que seja feita a eliminação de denominadores na versão determinística do algoritmo de Miller. Caso $P$ e $Q$ sejam linearmente dependentes, ou seja se $Q \in\langle P\rangle^{1}$, teremos como resultado $e_{t}(P, Q)=1$.

\subsubsection{Funções de linha}

No cálculo do algoritmo de Miller são usadas funções conhecidas como funções de linha, definidas da seguinte forma:

$$
g_{U, V}: E\left(\mathbb{F}_{q^{k}}\right) \rightarrow \mathbb{F}_{q^{k}}
$$

onde $g_{U, V}$ representa a equação da reta que passa pelos pontos $U$ e $V$ (se $U=V$, então $g_{U, U}$ é a equação da reta tangente ao ponto $U$; se $V$ - sem perda de generalidade — for o ponto $\mathcal{O}$ no infinito, então $g_{U, \mathcal{O}}$ é a reta vertical que passa pelo ponto $U$ ). Representamos $g_{U,-U}$ simplesmente por $g_{U}$.

Seja $g_{U, V}(Q)$ o valor da equação da reta entre os pontos $U$ e $V$ no ponto $Q$. Se $U=\left(x_{U}, y_{U}\right), V=\left(x_{V}, y_{V}\right)$ e $Q=(x, y)$, temos:

$$
\begin{aligned}
& g_{U, V}(Q)=1, \quad Q \in\{\mathcal{O}, P\} . \\
& g_{U, U}(Q)=\lambda_{1}\left(x-x_{U}\right)+y_{U}-y, \quad Q \notin\{\mathcal{O}, P\} \text {. } \\
& g_{U, V}(Q)=\lambda_{2}\left(x-x_{U}\right)+y_{U}-y, \quad Q \notin\{\mathcal{O}, P\}, U \neq V . \\
& g_{U}(Q)=x-x_{U}, \quad Q \notin\{\mathcal{O}, P\} .
\end{aligned}
$$

onde $\lambda_{1}=\frac{3 x_{U}^{2}+a}{2 y_{U}}$ e $\lambda_{2}=\frac{y_{V}-y_{U}}{x_{V}-x_{U}}$.

\footnotetext{
${ }^{1}$ Leia-se $Q$ pertence ao subgrupo gerado por $P$.
} 
Implementamos as funções de linha (fig. 8.8) segundo as equações acima, observando que as coordenadas $x, y$ do ponto $Q$ são representadas por polinômios de grau menor do que $k$ e portanto, $g_{U, V}$ também será um polinômio de grau menor do que $k$.

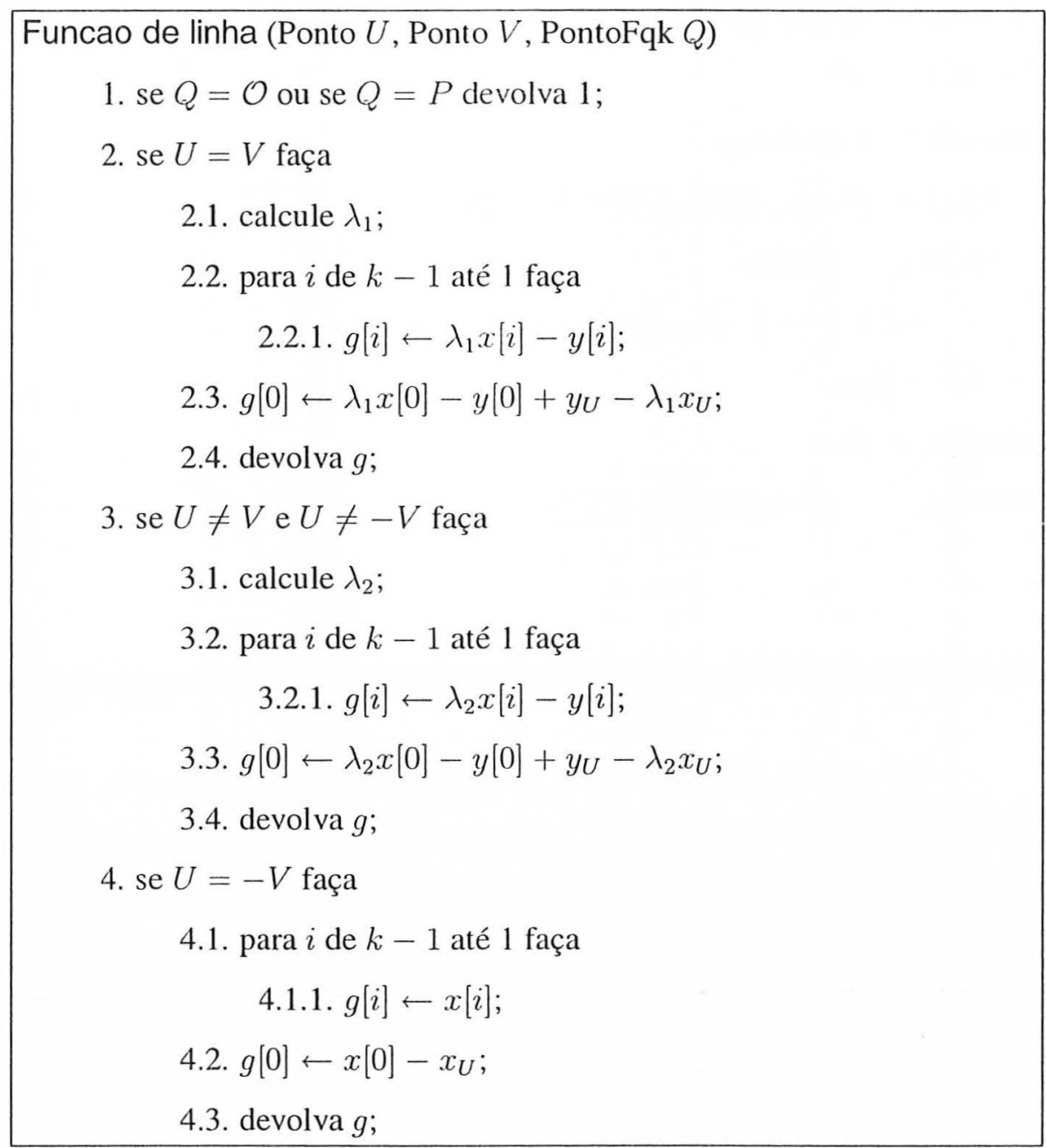

Figura 8.8: Algoritmo Função de linha - recebe na entrada os pontos $U$ e $V$ em $E\left(\mathbb{F}_{q}\right)$ e o ponto $Q$ em $E\left(\mathbb{F}_{q^{k}}\right)$ e devolve na saída o valor da equação da reta entre os pontos $U$ e $V$ no ponto $Q$.

\subsubsection{Versão determinística do algoritmo de Miller}

O algoritmo de Miller original [Miller 1986] é não-determinístico ${ }^{2}$ e encontra-se em um manuscrito não-publicado. Uma versão simplificada e determinística do

\footnotetext{
${ }^{2}$ Dizemos que um algoritmo é não-determinístico quando sua saída depende de algum parâmetro aleatório.
} 
algoritmo de Miller, que pode ser vista abaixo, foi publicada em [Barreto et al. 2002]:

Miller (Ponto $P$, PontoFqk $Q$ )

1. Seja $r=\left(r_{t}, r_{t-1}, \ldots, r_{1}, r_{0}\right)_{2}$ a representação binária da ordem $r$ da curva, tal que $r \geqslant 0, r_{t} \neq 0, r \mid q^{k}-1, Q \notin\{O, P\}$.

2. $f \leftarrow 1, V \leftarrow P$;

3. para $i$ de $t-1$ até 0 faça

3.1. $f \leftarrow f^{2} \cdot g_{V, V}(Q) / g_{2 V}(Q), V \leftarrow 2 V$

3.2. se $r_{i}=1$ então

3.2.1. $f \leftarrow f \cdot g_{V, P}(Q) / g_{V+P}(Q), V \leftarrow V+P$

4. $z \leftarrow\left(q^{k}-1\right) / r$;

5. calcule $e_{t}=f^{z}$;

6. devolva $e_{t} \quad / * e_{t}(P, Q) \in F_{q^{k}} *$.

\subsubsection{Algoritmo de Miller simplificado: eliminação de denominadores}

Para curvas supersingulares e curvas ordinárias com grau de imersão par e $Q$ escolhido adequadamente (por exemplo, segundo o algoritmo de seleção de geradores de [Barreto, Lynn e Scott 2003]), os denominadores $g_{2 V}(Q)$ e $g_{V+P}(Q)$ podem ser eliminados sem que o valor final de $e_{t}(P, Q)$ seja alterado. Esta simplificação, proposta e demonstrada por Barreto et al. em [Barreto et al. 2002, Barreto, Lynn e Scott 2003] possibilitou uma otimização em cerca de 125 vezes [Barreto 2003] no algoritmo de Miller original .

Na figura 8.9 o leitor pode ver nosso pseudo-código para a implementação do algoritmo de Miller simplificado, observando que $f$ e $g$ são polinômios de grau menor do que $k$.

\subsubsection{Exponenciação final}

A exponenciação final (fig. 8.10) de $f$ é calculada por um algoritmo muito semelhante ao algoritmo produto, sendo que o argumento de entrada é o polinômio $f$. 


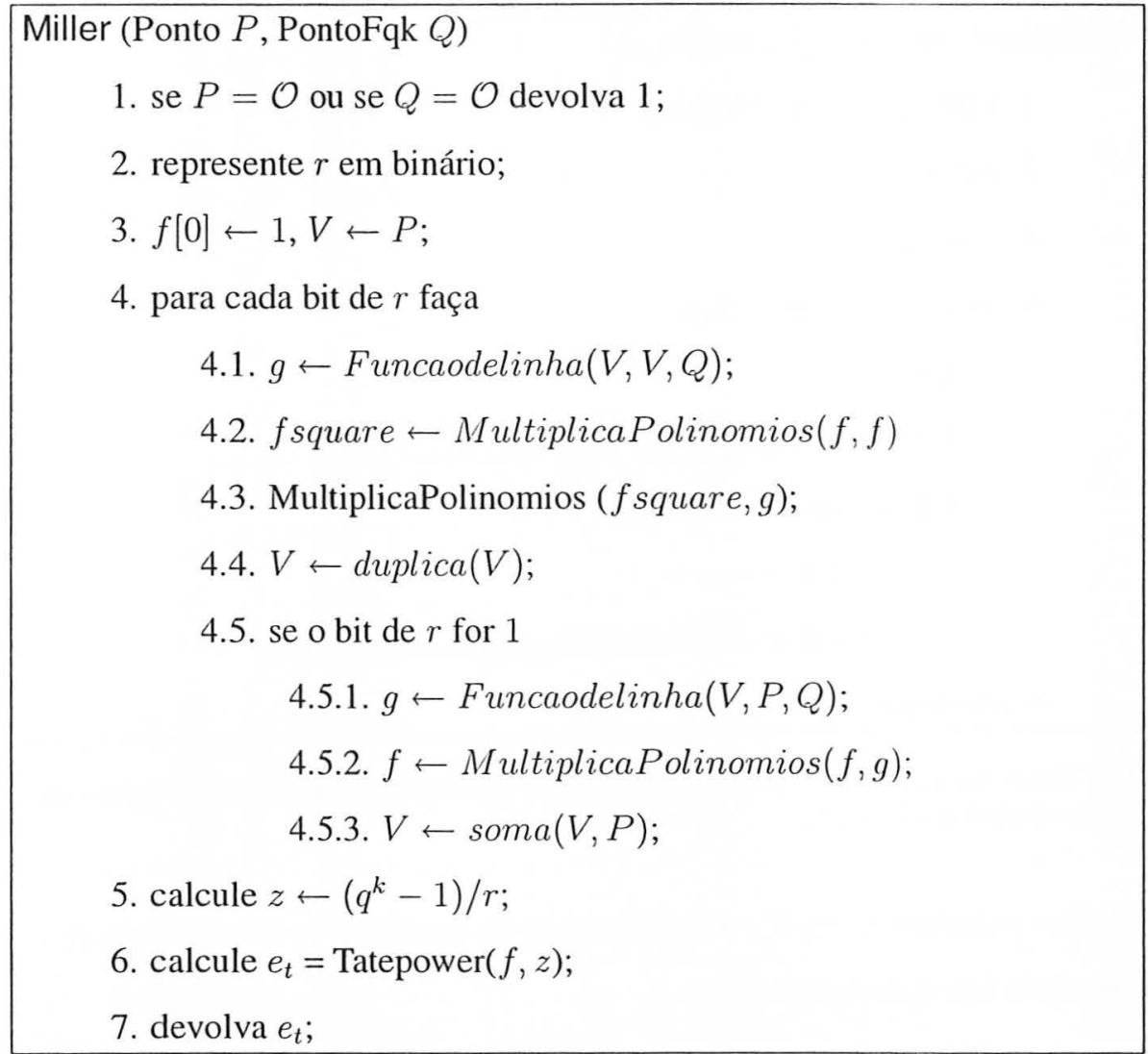

Figura 8.9: Miller simplificado com eliminação de denominadores - recebe como entrada os pontos $P$ em $E\left(\mathbb{F}_{q}\right)$ e $Q$ em $E\left(\mathbb{F}_{q^{k}}\right)$ e devolve na saída o valor do emparelhamento de Tate entre os pontos $P$ e $Q$.

\subsubsection{Verificação do valor do emparelhamento}

Após calcularmos o emparelhamento entre dois pontos $P$ e $Q$, precisávamos ter certeza de que havíamos calculado o valor correto, i.e., se nossa implementação do algoritmo de Miller simplificado estava correta. Uma boa forma de testarmos se o valor calculado estava correto era verificarmos se ele atendia às propriedades de bilinearidade que vimos na seção 3.2.6.

Para tal, fizemos os seguintes testes:

1. $\forall x$ inteiro, $0<x<r$, onde $r$ é a ordem da curva, verificamos se $e_{t}(x \cdot P, Q)=e_{t}(P, x \cdot Q)$, satisfazendo à propriedade 3.7 ;

2. para cada $P_{i} \in E\left(\mathbb{F}_{q}\right), P_{i} \neq P$, dado que $e_{t}(P, Q)=g$, calculamos $e_{t}\left(P_{i}, Q\right)=g_{i}$, onde 


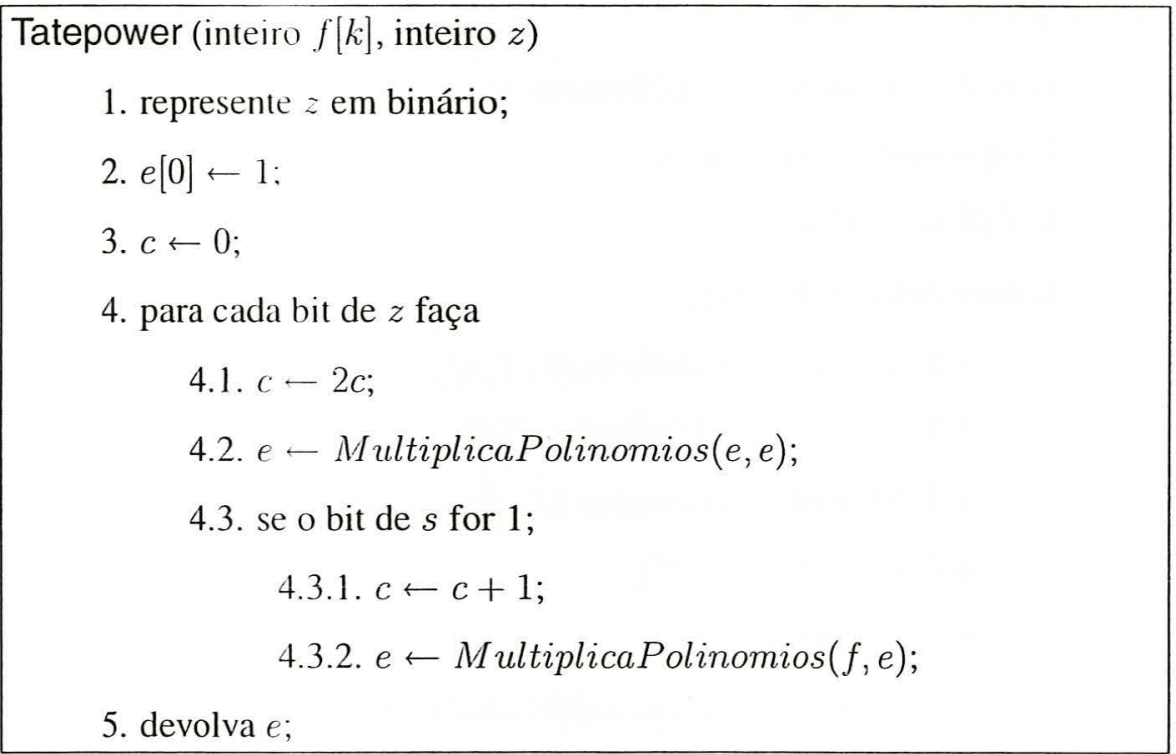

Figura 8.10: Algoritmo Tatepower - recebe na entrada o polinômio $f$ calculado pelo algoritmo de Miller e devolve na saída o polinômio $e_{t}=f^{z}$.

$g$ e $g_{i}$ são polinômios em $\mathbb{F}_{q^{k}}$ e verificamos se $e_{t}(R, Q)=g \cdot g_{i}$, onde $R=P_{i}+P$, satisfazendo à propriedade 3.5;

3. verificamos, finalmente, se $e_{t}(P, Q)^{r}=1$, onde $r$ é a ordem da curva, pois $e_{t}(P, Q)^{r}=$ $e_{t}(r P, Q)=e_{t}(\mathcal{O}, Q)=1$.

Efetuados os testes descritos acima, pudemos comprovar que nossa implementação, de fato, calculava corretamente o valor de $e_{t}(P, Q)$.

\subsection{Entrada de dados}

Adotamos como entrada de dados o teclado, onde o usuário digita os valores solicitados pelo programa, como por exemplo, seu identificador, o identificador do destinatário, a mensagem a ser processada (assinada e/ ou criptografada) e demais valores, como inteiros aleatórios e coordenadas de pontos. Acreditamos que o leitor não encontrará problemas em modificar o programa, caso necessite de outra fonte de entrada, como por exemplo, arquivos com mensagens a serem processadas. 


\subsection{Simulação}

Apresentaremos nesta seção uma simulação do funcionamento dos algoritmos que implementamos, mostrando as principais telas apresentadas.

\subsubsection{Tela inicial - parâmetros do sistema}

Ao ser iniciado, o programa (id_based.exe) apresenta uma tela em que mostra os parâmetros que foram utilizados, como pode ser visto na figura 8.11.

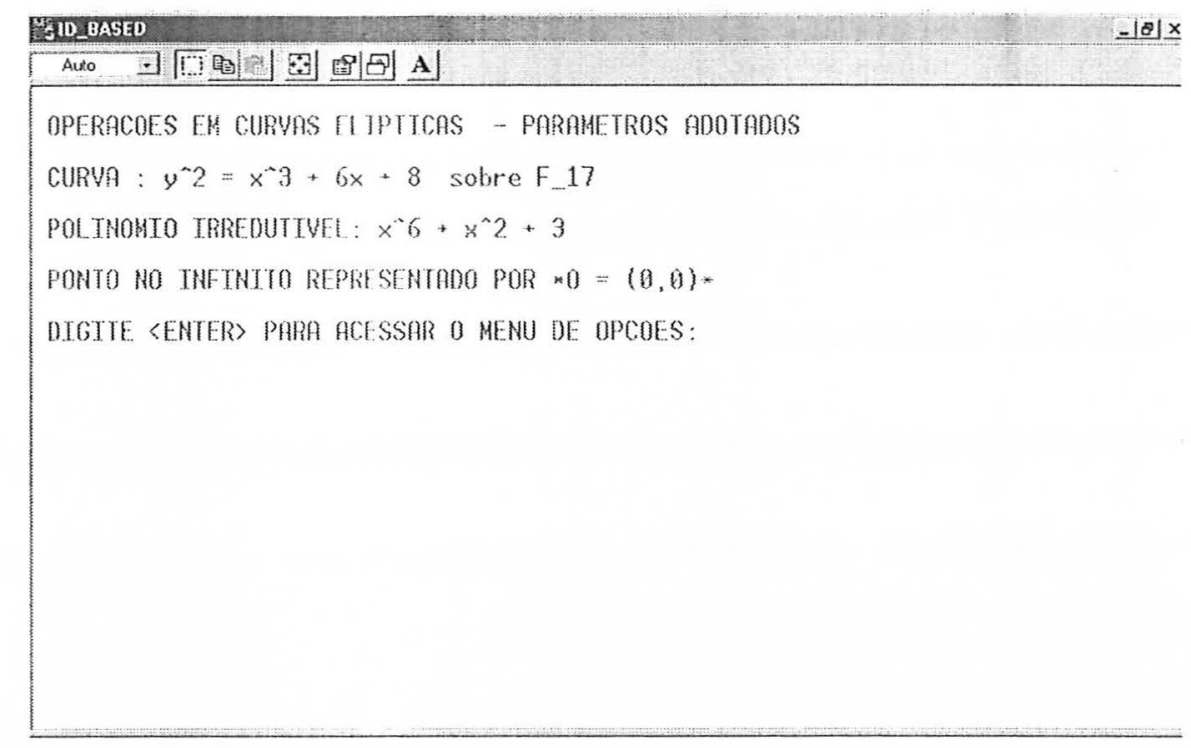

Figura 8.11: Tela inicial - ao iniciar, o programa mostra ao usuário os parâmetros adotados.

\subsubsection{Menu de opções}

Em seguida, é apresentado ao usuário um menu de opções (figura 8.12), onde ele pode escolher um dentre os seguintes esquemas:

- assinatura compacta (BLS): assinatura de uma mensagem utilizando o esquema de Boneh, Lynn e Shacham [Boneh, Lynn e Shacham 2001];

- verificação da assinatura (BLS): verificação da assinatura produzida pelo esquema BLS; 


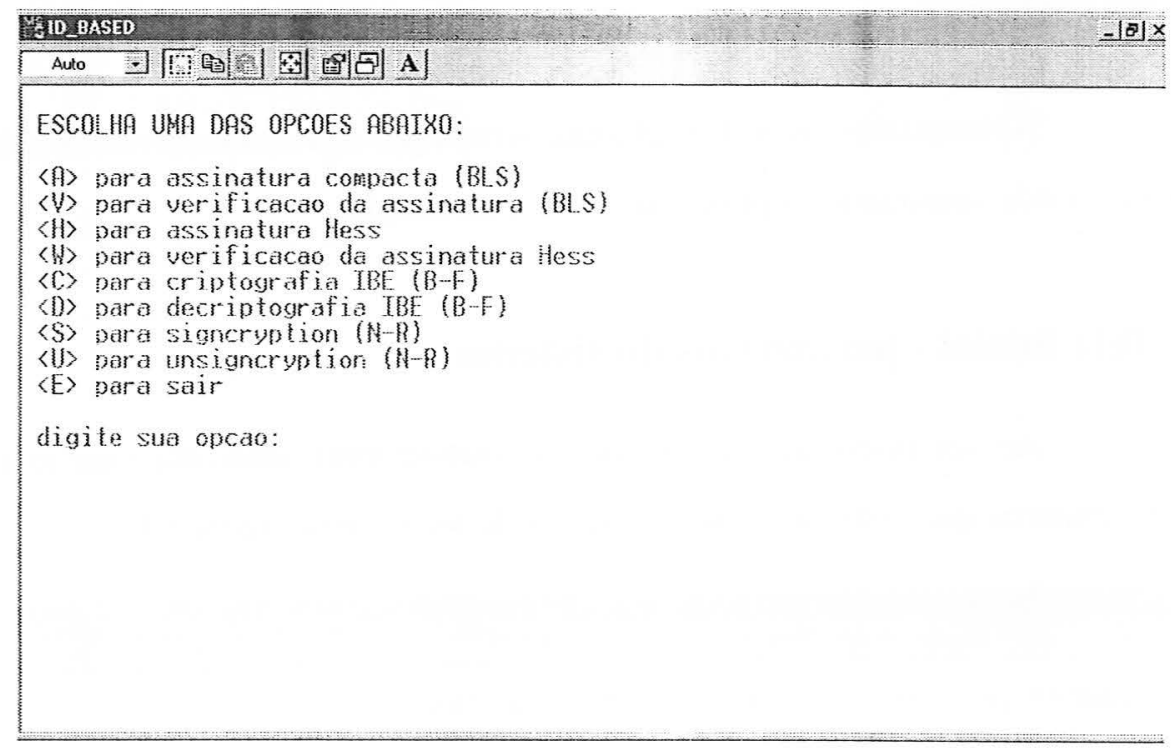

Figura 8.12: Menu de opções - tela que mostra ao usuário as opções do programa.

- assinatura Hess: assinatura de uma mensagem utilizando o esquema de Hess [Hess 2002];

- verificação da assinatura Hess: verificação da assinatura produzida pelo esquema de Hess;

- criptografia IBE (B-F): criptografia de uma mensagem com o esquema de Boneh e Franklin [Boneh e Franklin 2001];

- decriptografia IBE (B-F): decriptografia da mensagem que foi criptografada com o esquema B-F;

- signcryption (N-R): criptassinatura de uma mensagem com o esquema de Nalla e Reddy [Nalla e Reddy 2003];

- unsigncryption (N-R): decriptografar e verificar assinatura de mensagem que foi criptassinada com esquema de Nalla e Reddy.

\subsubsection{Assinatura compacta Boneh, Lynn e Shacham}

Quando o usuário escolhe a opção <A> no menu de opções, é direcionado para o algoritmo que calcula sua assinatura sobre a mensagem digitada (conforme 
equação (3.11)), como pode ser visto na figura 8.13. Adotamos sem perda de generalidade o valor $s=7$ como chave particular padrão do usuário. Embora não fosse necessário, decidimos também imprimir o valor do hash da mensagem, calculado pela função $H_{1}$.

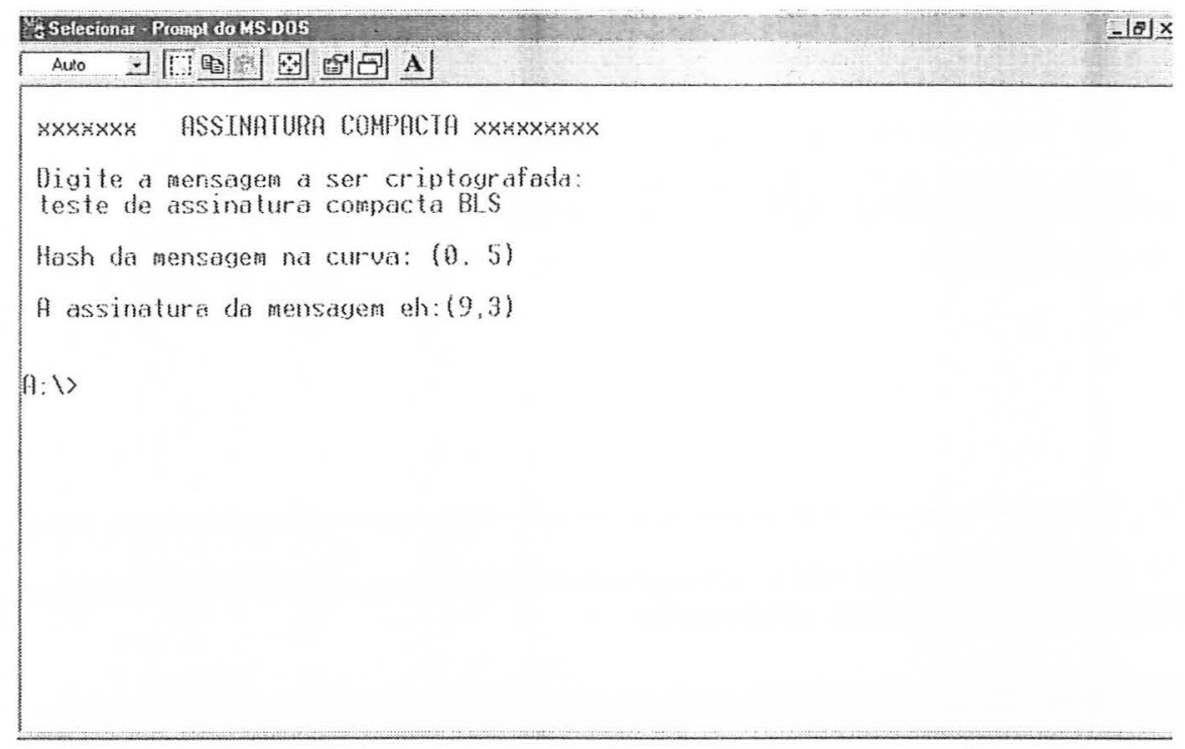

Figura 8.13: Assinatura compacta BLS - ao digitar a mensagem, o usuário obtém a assinatura BLS sobre a mensagem digitada.

\subsubsection{Verificação da assinatura BLS}

Ao digitar $<\mathrm{V}>$ no menu de opções, o usuário é direcionado para o algoritmo de verificação da assinatura BLS (figura 8.14). O programa, então, solicita ao usuário que digite a mensagem e as coordenadas da assinatura. Após isso, verifica se os valores $e_{t}(V, Q)$ e $e_{t}\left(H_{1}(m), R_{T A}\right)$ são iguais (de acordo com equação (3.12)). Caso afirmativo, aceita a assinatura como válida e caso contrário, rejeita a assinatura. Embora não fosse necessário por ser transparente para o usuário, optamos por deixar impresso na tela os valores dos emparelhamentos calculados, para confirmação do leitor.

Na figura 8.15 , podemos ver que os valores dos emparelhamentos calculados são diferentes e a assinatura é rejeitada. Note que, como a mensagem é diferente da que foi assinada (trocamos um "S" por um "s"), a função $H_{1}$ mapeia esta mensagem em um outro ponto da curva. 


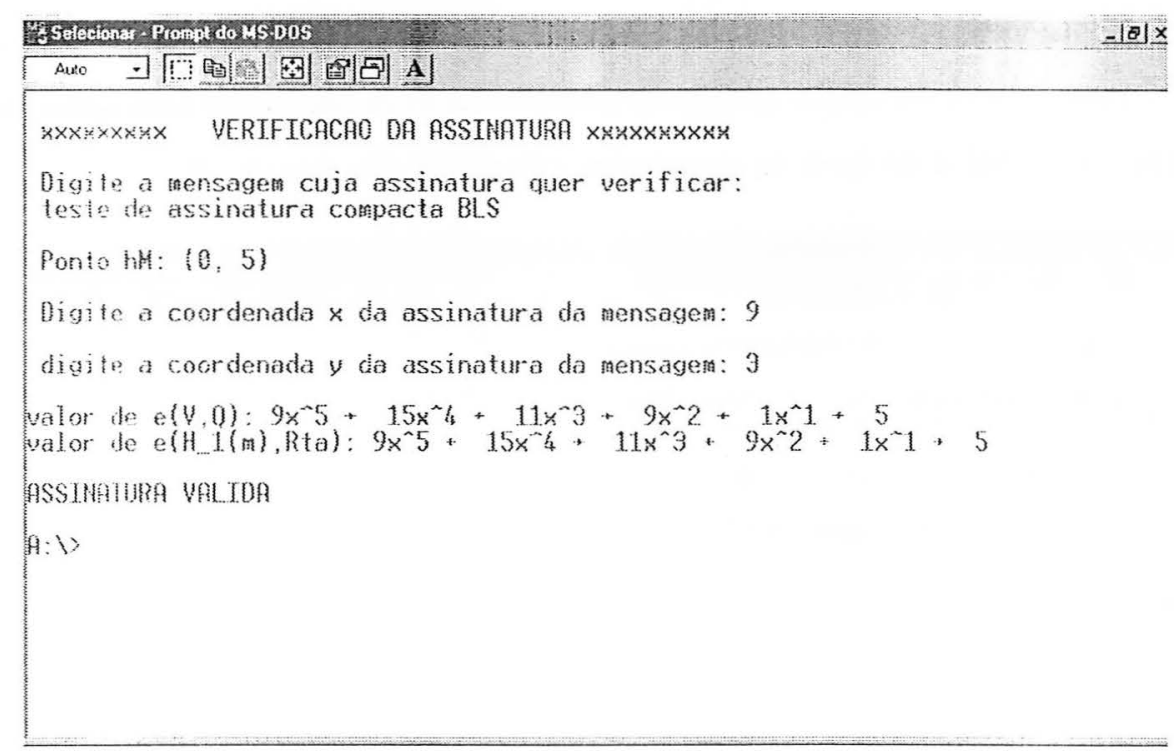

Figura 8.14: Verificação assinatura BLS - ao digitar a mensagem e as coordenadas da assinatura, o usuário obtém a verificação se é uma assinatura válida ou não.

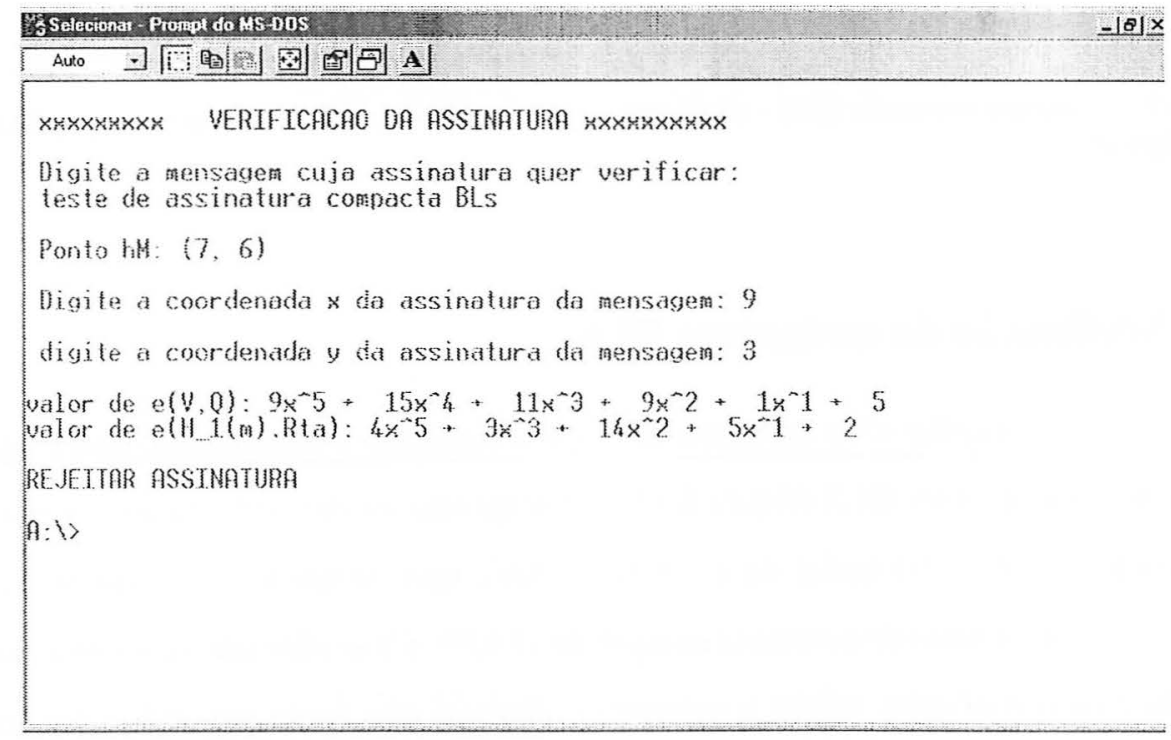

Figura 8.15: Assinatura BLS rejeitada - ao trocarmos o último dígito da mensagem assinada, o valor de $H_{1}(m)$ é alterado e com isso os resultados dos emparelhamentos calculados são diferentes, e a assinatura é rejeitada.

\subsubsection{Assinatura Hess}

Quando o usuário escolhe a opção $<\mathrm{H}>$ no menu de opções, é direcionado para o algoritmo que calcula a assinatura da mensagem digitada, bastando para isso que o 
usuário também digite seu identificador, um ponto qualquer da curva adotada e um inteiro entre 1 e $r-1$, como pode ser visto na figura 8.16. Deixamos impresso na tela o valor do polinômio $r$ - calculado de acordo com a equação (3.17) - para comparação com o valor calculado na verificação da assinatura.

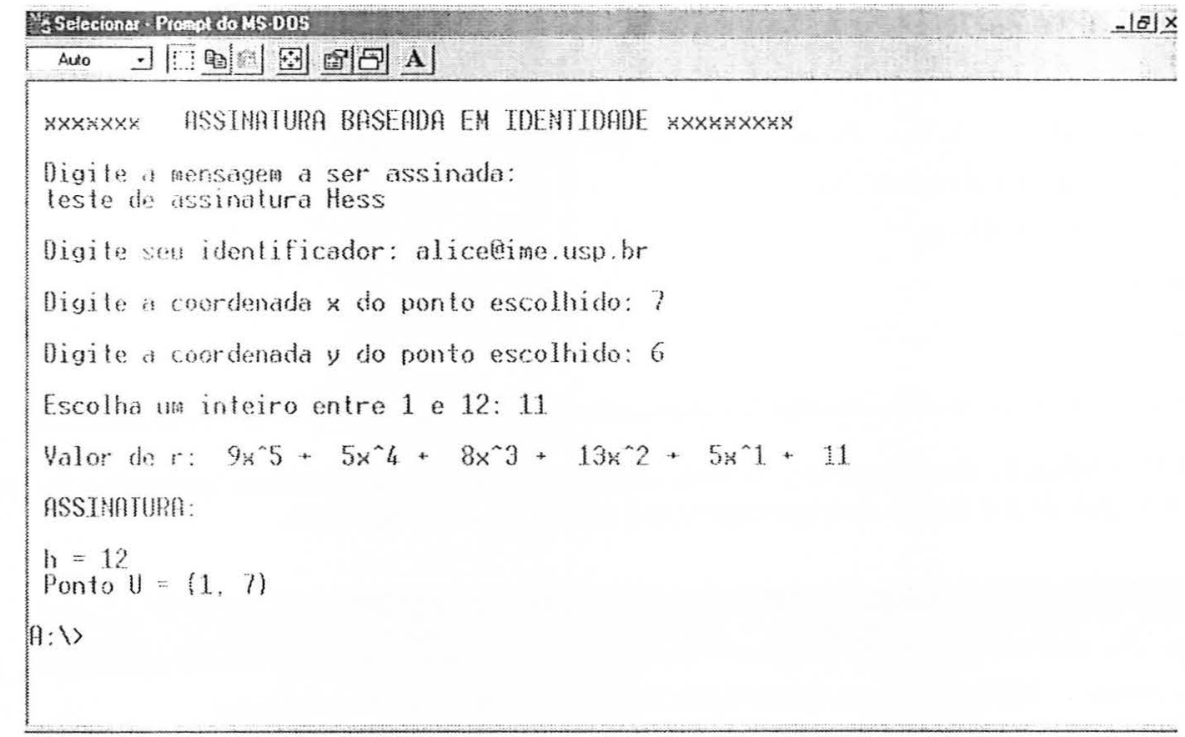

Figura 8.16: Assinatura Hess - o usuário digita seu identificador, escolhe um ponto em $E\left(\mathbb{F}_{q}\right)$ e um inteiro entre 1 e $r-1$, obtendo a assinatura sobre a mensagem digitada.

\subsubsection{Verificação da assinatura Hess}

A opção $<\mathrm{W}>$ direciona o usuário para o algoritmo de verificação da assinatura Hess (figura 8.17). O programa, então, solicita ao usuário que digite a mensagem, o valor de $h$ e as coordenadas do ponto $U$ da assinatura. Após isso, calcula o valor de $r-$ de acordo com equação (3.20) - e também o valor de $h$. Caso o $h$ calculado seja igual ao valor de $h$ que recebeu como parte da assinatura, aceita a assinatura como válida e caso contrário, rejeita a assinatura. Deixamos impresso na tela os valores de $r$ e $h$, para confirmação do leitor.

Na figura 8.18, vemos que o usuário digitou incorretamente o identificador de Alice (esqueceu o ". $b r$ ”), fazendo com que a assinatura fosse rejeitada. 


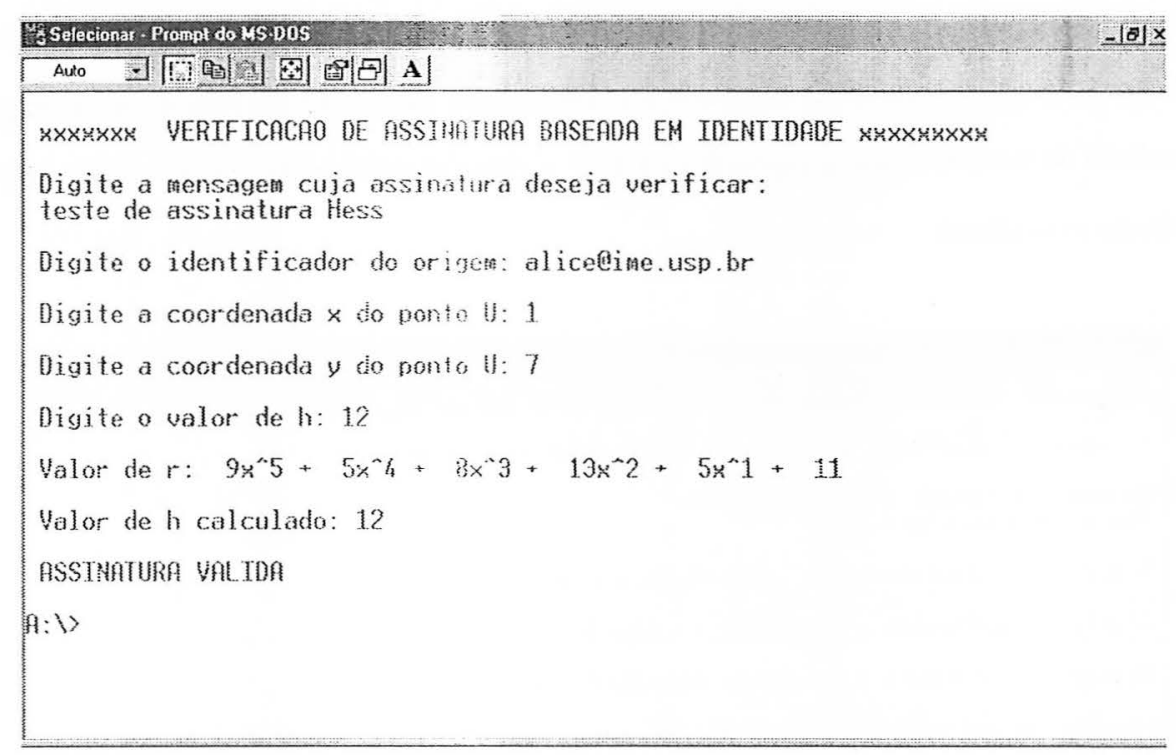

Figura 8.17: Verificação assinatura Hess - o usuário digita o identificador da origem (assinante), as coordenadas do ponto $U$ e o valor de $h$ e recebe uma mensagem se a assinatura é ou não válida.

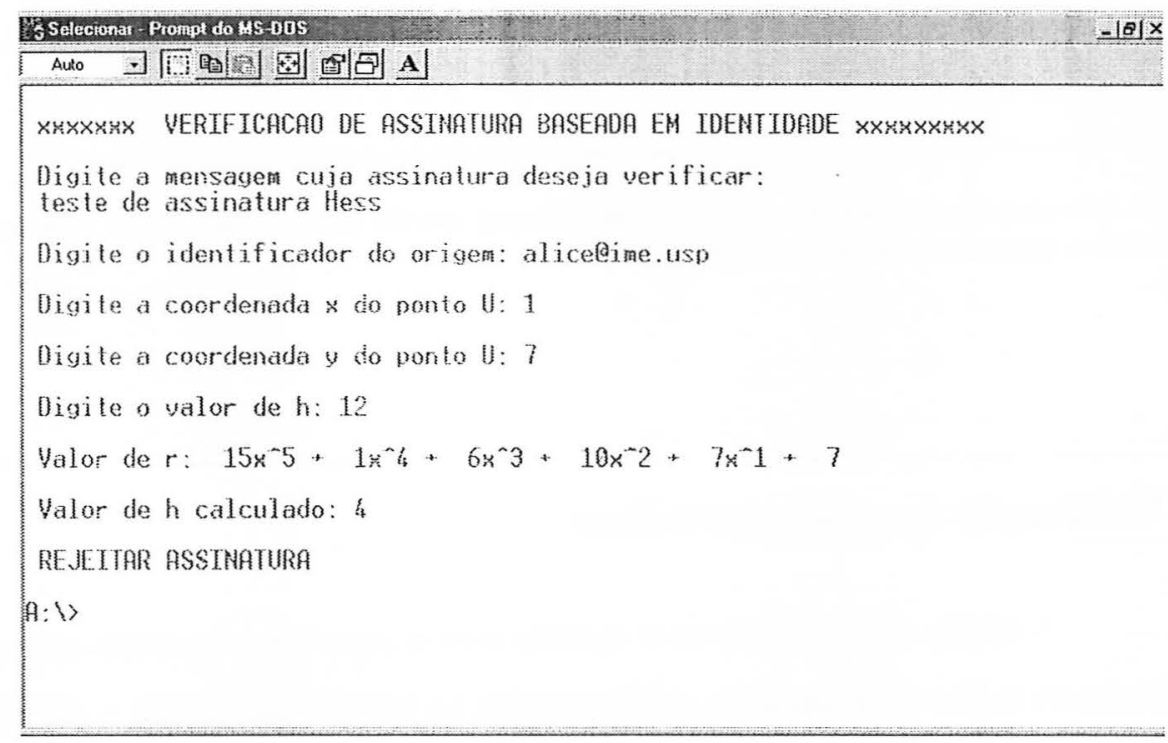

Figura 8.18: Assinatura Hess rejeitada - o usuário digita incorretamente o identificador da origem (assinante), obtendo como resposta que a assinatura deve ser rejeitada.

\subsubsection{Criptografia Boneh e Franklin}

A opção $<$ C $>$ no menu leva o usuário ao algoritmo que criptografa uma mensagem usando o esquema de Boneh e Franklin (figura 8.19). O usuário deve digitar a mensagem 
a ser criptografada, o identificador do destinatário e escolher um inteiro entre 1 e $r$ - 1, obtendo como saída o ponto $U$ em $E\left(\mathbb{F}_{q^{k}}\right)$ e a mensagem criptografada. Optamos por deixar impresso na tela o valor da chave pública do destinatário e o valor da chave simétrica que é calculada, e que em nossa implementação será usada na operação de "ou-exclusivo" com a mensagem, mas que segundo o esquema modificado que propusemos (seção 3.4.5), poderia ser usada como chave em algum algoritmo simétrico escolhido.

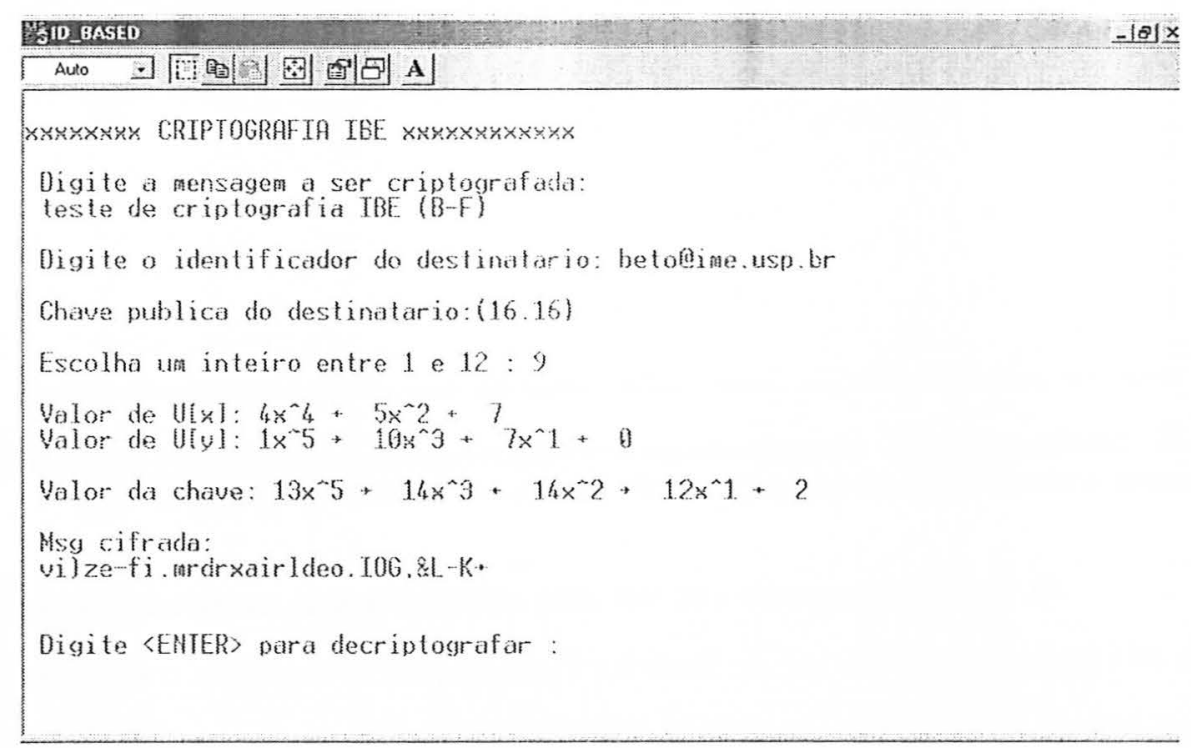

Figura 8.19: Criptografia B-F - o usuário digita a mensagem, o identificador do destinatário e um número escolhido aleatoriamente entre 1 e $r-1$, obtendo como resposta que a mensagem criptografada.

\subsubsection{Decriptografia B-F}

O algoritmo de decriptografia (opção $<\mathrm{D}>$ ) que implementamos recebe como entrada o valor do ponto $U$ calculado na criptografia e também o texto criptografado, para evitar que o usuário precise digitar esses valores. Em uma situação real, esses dados poderiam ser lidos de um arquivo.

Desta forma, para decriptografar uma mensagem com o esquema de Boneh e Franklin, basta que o usuário digite seu identificador, como pode ser visto na figura 8.20.

Note que o valor da chave calculada na figura 8.20 é o mesmo da figura 8.19, comprovando que Alice e Beto geram a mesma chave, que pode ser usada como chave simétrica. 


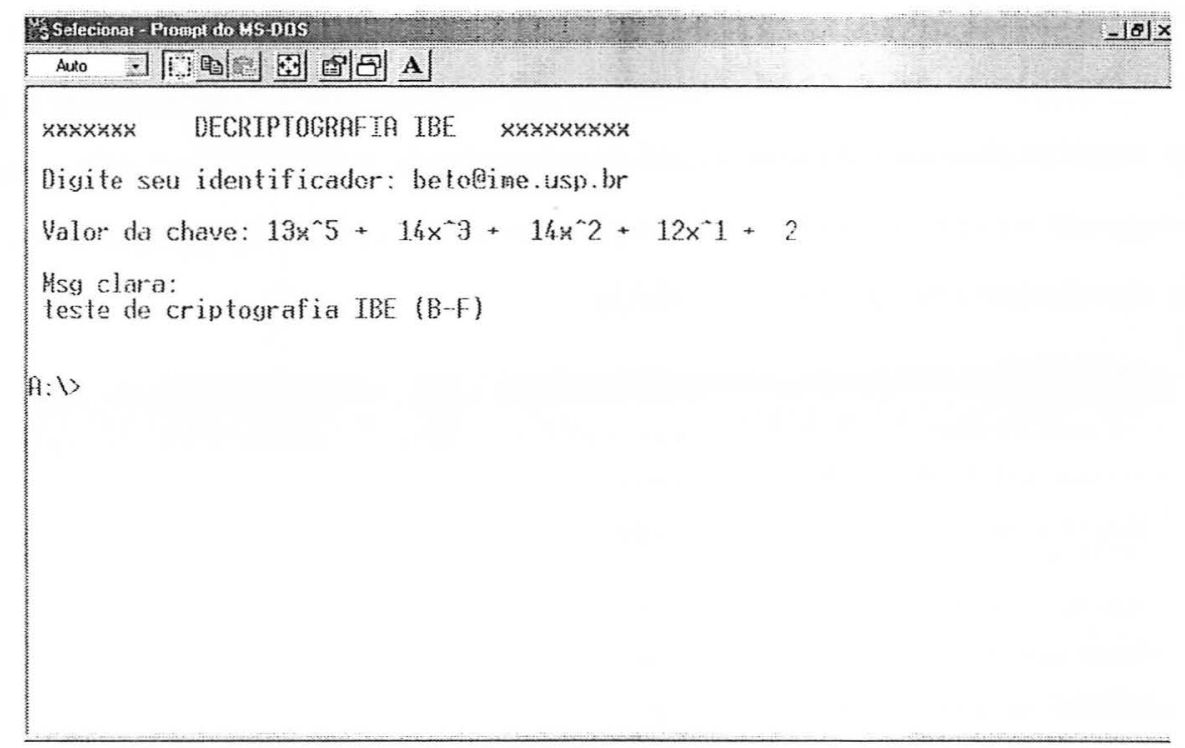

Figura 8.20: Decriptografia B-F - considerando que a mensagem criptografada e o ponto $U$ já foram alimentados para o algoritmo, o usuário digita seu identificador, obtendo como resposta que a mensagem clara.

O leitor interessado em ver uma implementação comercial de um correio eletrônico utilizando o esquema IBE de Boneh e Franklin poderá consultar o seguinte endereço na Internet: http://crypto.stanford.edu/ibe/.

\subsubsection{Criptassinatura Nalla e Reddy}

A opção $<$ S $>$ leva o usuário ao algoritmo que criptassina uma mensagem com o esquema de Nalla e Reddy.

Primeiramente, o usuário digita a mensagem que deseja criptassinar; em seguida, digita seu identificador e o identificador do destinatário da mensagem; o algoritmo calcula os valores de $R, h, S$ e a chave $k$, e finalmente criptassina a mensagem digitada com a chave $k$ calculada. A simulação pode ser vista na figura 8.21.

\subsubsection{Decriptografia e verificação da assinatura N-R}

O algoritmo de decriptografia e verificação da assinatura N-R (opção $<U>$ ) que implementamos recebe como entrada o valor do ponto $R$ e $S$ calculados na criptassinatura 


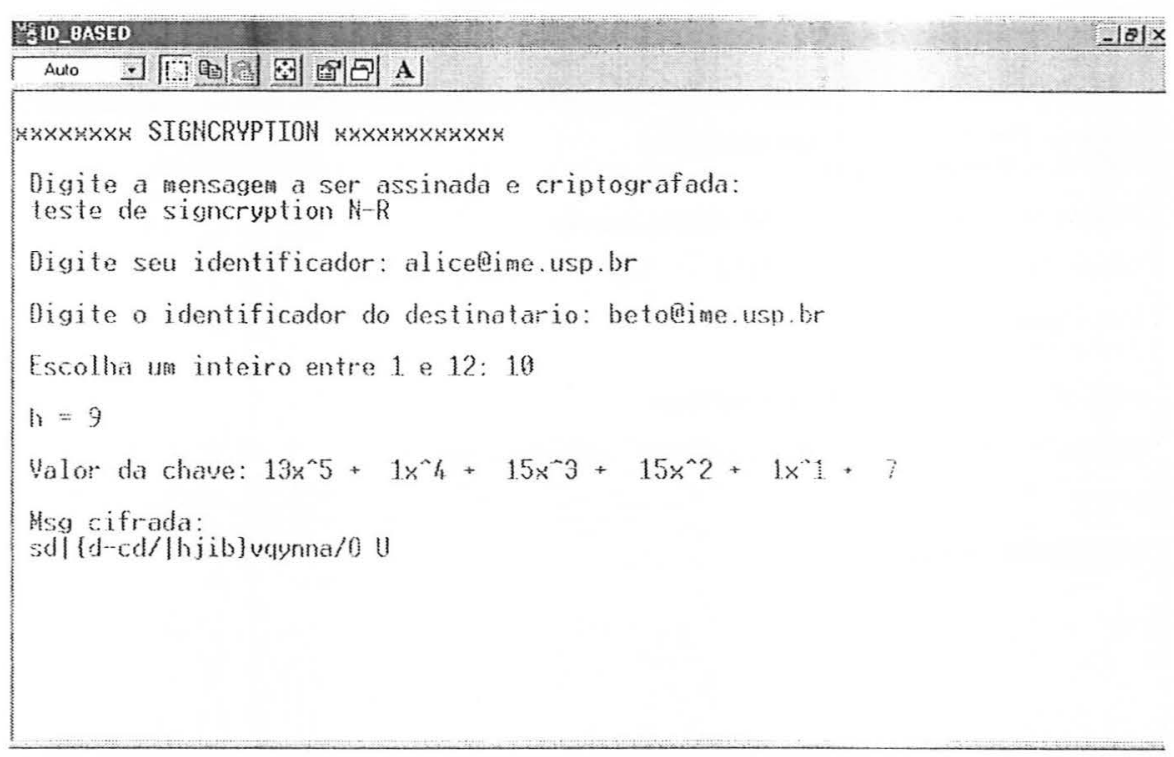

Figura 8.21: Criptassinatura N-R - o usuário digita a mensagem, seu identificador e o identificador do destinatário e obtém a mensagem criptassinada.

e também o texto criptassinado, para evitar que o usuário precise digitar esses valores. Em uma situação real, esses dados poderiam ser lidos de um arquivo.

Desta forma, para decriptografar a mensagem o usuário precisa apenas digitar seu identificador (primeira fase da figura 8.22). Note que o valor da chave calculada nessa primeira fase é o mesmo da figura 8.21.

A simulação deste passo pode ser vista na figura 8.22. Após decriptografar a mensagem, Beto precisa verificar se foi realmente Alice quem criptassinou. Para tal, Beto digita o identificador de Alice e obtém como resposta se é ou não uma assinatura válida. Note que o valor de $h$ é o mesmo calculado na criptassinatura.

Caso Beto não obtenha um texto legível na primeira fase (decriptografia), não é necessário que faça a verificação da assinatura, pois pode descartar a mensagem recebida (figura 8.23). Nesse caso, se o resultado da decriptografia for um texto ilegível, Beto pode abandonar o programa.

Na figura 8.24, simulamos que Carlos vai tentar se fazer passar por Alice perante Beto. Supomos que Carlos usou seu identificador (carlos@ime.usp.br) na criptassinatura, pois não conhece a chave particular de Alice. Note que a chave calculada foi diferente 


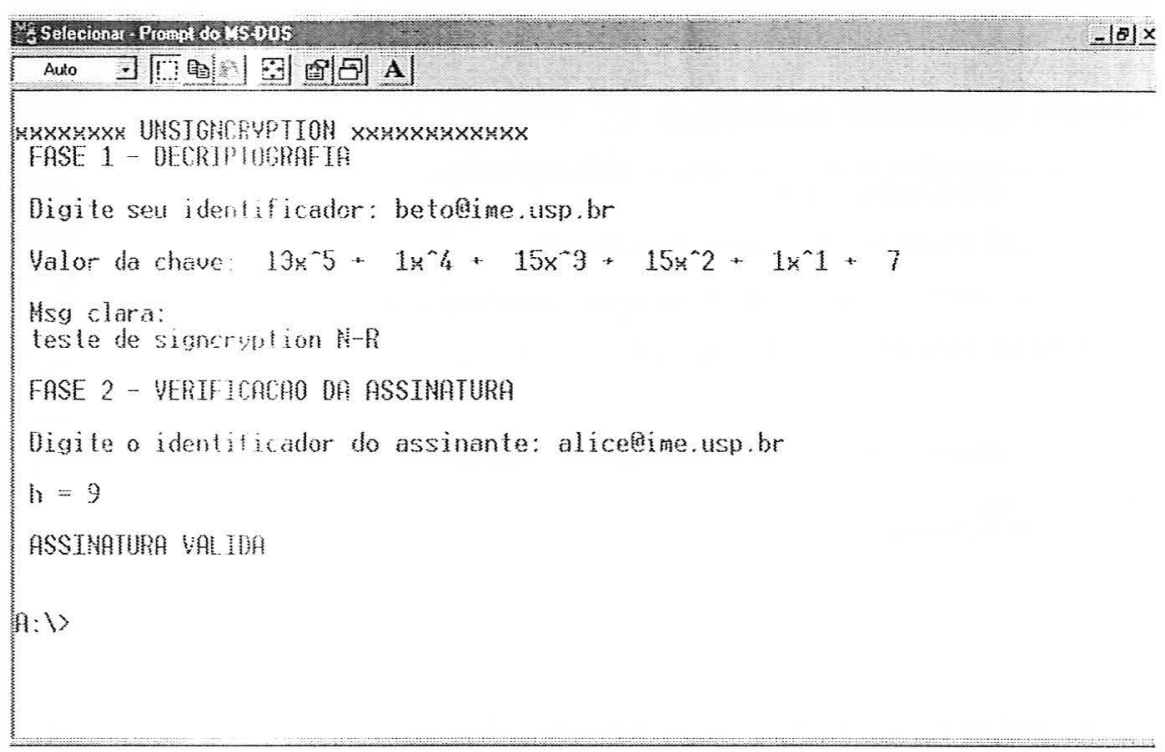

Figura 8.22: Decriptografia e verificação da assinatura N-R - para decriptografar a mensagem, o usuário digita seu identificador e após isso, pode verificar a assinatura digitando o identificador do remetente da mensagem.

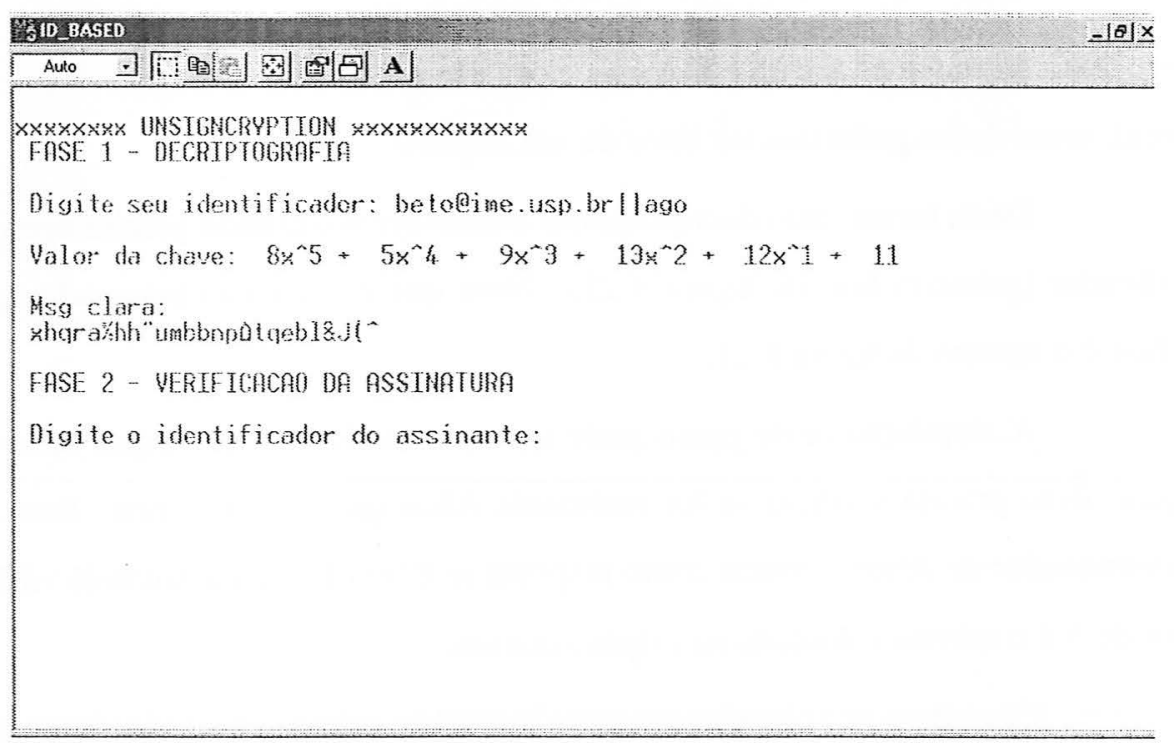

Figura 8.23: Decriptografia incorreta N-R - neste exemplo, Alice criptassinou uma mensagem usando beto@ime.usp.br como identificador de Beto. Como o identificador correto de Beto é beto@ ime.usp.brllago, Beto não obtém um texto legível na decriptografia e pode abandonar o programa, descartando a mensagem recebida.

daquela entre Alice e Beto, na figura 8.22. Ao receber a mensagem que supostamente é de Alice, Beto consegue decriptografar corretamente (pois Carlos conhece a chave pública de Beto e o valor de $S$, que vai ser usado por Beto no cálculo de $k_{a}$, é igual a $a h Q_{c a r l o s}$ ), mas como ele pensa 
que a mensagem foi enviada por Alice, ao digitar o identificador dela (alice @ime.usp.br), obtém como resposta que a assinatura não é válida e rejeita a mensagem. Portanto, Carlos não obtém sucesso ao tentar se fazer passar por Alice perante Beto.

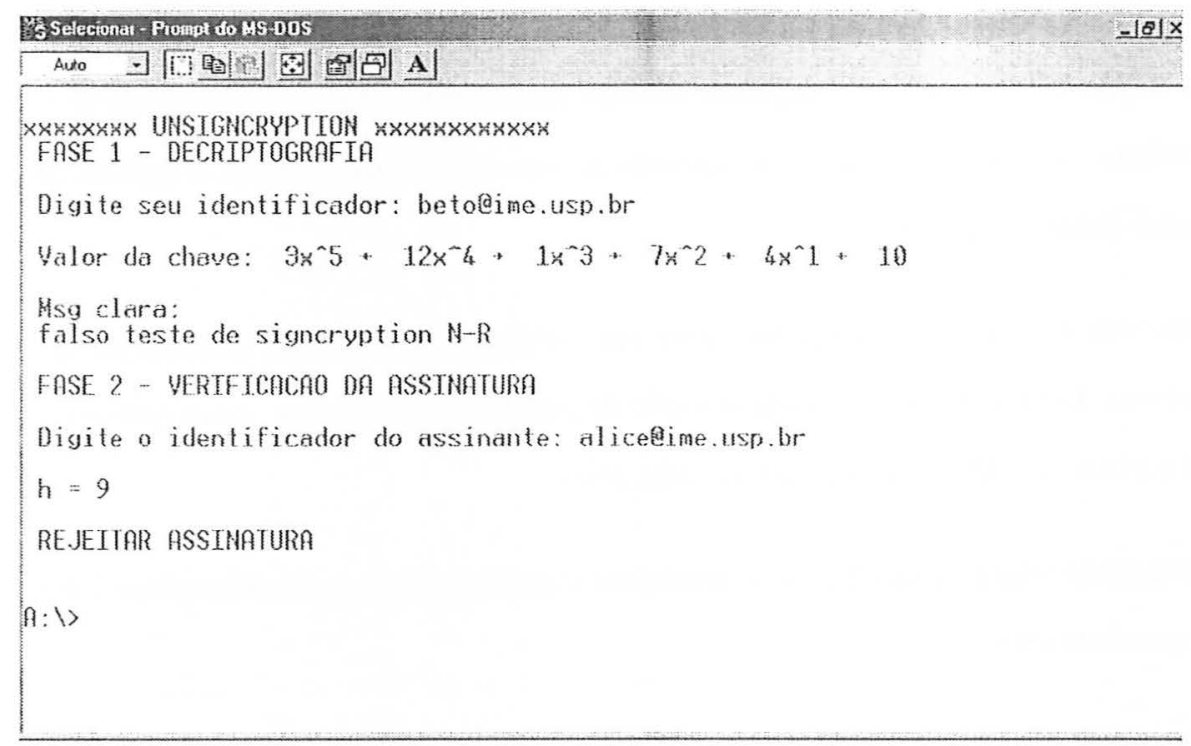

Figura 8.24: Assinatura N-R rejeitada - neste exemplo, Supomos que Carlos vai tentar se fazer passar por Alice perante Beto. Como Carlos conhece o identificador de Beto, a mensagem é criptografada corretamente e Beto obtém um texto legível na decriptografia. Porém, ao fazer a verificação da assinatura, Beto vai digitar o identificador de Alice e receberá como resposta que deve rejeitar a assinatura (e conseqüentemente, a mensagem).

\subsection{Mudança de parâmetros}

Os valores utilizados em nossa implementação foram definidos como constantes no início do programa (função define), o que permite que uma mudança para outros valores seja relativamente simples.

É importante frisar, porém, que implementamos o algoritmo de Miller simplificado para cálculo do emparelhamento entre dois pontos, e que, conseqüentemente, caso haja alteração de algum parâmetro, o programa só irá funcionar corretamente caso os requisitos para se usar o algoritmo simplificado de Miller sejam atendidos. Descreveremos a seguir como deveriam ser processadas as mudanças nos parâmetros adotados:

- parâmetros $a, b$ e $q$ da curva - podem ser modificados desde que a nova curva seja 
ordinária com grau de imersão par ou supersingular, para que possamos utilizar o algoritmo de Miller simplificado. Se $q$ for um número muito grande (da ordem de $2^{160}$, por exemplo), deverá ser modificada a estrutura de dados para suportar números deste tamanho. Caso a curva seja modificada, é necessário ainda que se escolha um novo ponto em $E\left(\mathbb{F}_{q^{k}}\right)$ linearmente independente aos pontos em $E\left(\mathbb{F}_{q}\right)$. Vale ainda lembrar que se a ordem $r$ da curva não for um número primo, não teremos mais o fato de que todos os pontos possuem ordem $r$;

- ponto em $E\left(\mathbb{F}_{q^{k}}\right)$ - esse ponto deve ser escolhido segundo o método de Barreto et al. [Barreto, Lynn e Scott 2003] de seleção de geradores de grupos , para que se possa utilizar o algoritmo de Miller com curvas ordinárias;

- chave particular padrão da TA — pode ser escolhido qualquer valor entre 1 e $r$ - 1 , onde $r$ é a ordem da curva;

- polinômio irredutível em $\mathbb{F}_{q^{k}}$ - pode ser escolhido qualquer polinômio, desde que seja irredutível em $\mathbb{F}_{q^{k}}$. Recomenda-se que seja um polinômio esparso e com a maioria de seus coeficientes não-nulos iguais a 1, para facilitar os cálculos.

Uma outra modificação interessante é alterar a fonte dos dados de entrada. Nesse caso, em vez de digitar a mensagem a ser criptografada e/ou assinada, o usuário digitaria apenas o nome do arquivo onde se encontra essa mensagem e o programa leria o arquivo correspondente. O mesmo ocorreria no processo inverso (decriptografia e/ou verificação da assinatura). Essa modificação é bem simples, basta alterar a forma como os dados serão lidos.

\subsection{Resumo}

Descrevemos neste capítulo os principais passos e dificuldades na implementação de sistemas baseados em identidades. Optamos por fazer uma implementação para fins didáticos, usando parâmetros com valores pequenos, o que nos possibilitou fazer uma comparação dos cálculos feitos pelo algoritmo implementado com cálculos feitos em "lápis-e-papel", sendo possível, com isso, verificar a corretude dos valores calculados. 
Apresentamos a descrição das principais rotinas em linguagem de alto-nível e também mostramos as telas de execução do programa, através de simulações com os esquemas implementados: geração e verificação de assinatura compacta, criptografia e decriptografia de Boneh e Franklin, geração e verificação de assinatura de Hess e criptassinatura de Nalla e Reddy (juntamente com decriptografia e verificação de assinatura nesse mesmo esquema).

Vimos que alterações nos parâmetros adotados podem ser conduzidas, de modo a se obter parâmetros usados na prática, respeitando-se apenas o fato de que implementamos o algoritmo simplificado de Miller para cálculo do emparelhamento entre dois pontos e que, devido a isso, algumas restrições devem ser observadas.

No anexo C o leitor poderá ver a listagem do código-fonte da implementação que descrevemos neste capítulo.

Encerrando esta dissertação, temos a seguir a conclusão de nossa pesquisa, onde destacamos os itens mais relevantes de nosso estudo e sugerimos algumas idéias de trabalhos futuros. 


\section{Capítulo 9}

\section{Conclusões e trabalhos futuros}

\subsection{Conclusões}

Nesta dissertação, apresentamos o conceito de sistemas criptográficos baseados em identidades, que permitem a qualquer par de usuários se comunicar de forma segura, sem que seja necessária a troca de chaves secretas, como ocorre na criptografia simétrica, e sem que seja preciso utilizar certificados digitais para autenticar chaves públicas, que é o caso da criptografia assimétrica tradicional.

O modelo, proposto por A. Shamir [Shamir 1984] em 1984, baseia-se no esquema de criptografia assimétrica tradicional, sendo que, em vez de termos um par de chaves representadas por uma seqüência de bits, sendo uma aleatória e a outra calculada em função da primeira, como no caso do RSA, teremos como chave pública um identificador, ou seja, uma característica que identifique o usuário de forma única, de modo que ele não tenha como negar que tal informação diz respeito a ele. Como exemplos de identificador, poderíamos citar o número do $\mathrm{CPF}$ ou o endereço eletrônico (e-mail). A chave particular é então calculada por uma autoridade de confiança e entregue ao usuário por um canal seguro.

A grande vantagem deste esquema é que, ao contrário da criptografia assimétrica tradicional, não há necessidade de se fazer um mapeamento entre uma chave pública e seu dono, haja vista que, neste caso, a chave pública identifica o dono. Uma outra vantagem é que, por não ser mais um número aleatório, um usuário Beto não precisa reservar espaço adicional para guardar as chaves públicas das pessoas com quem deseja se comunicar, pois pode usar sua própria lista de endereços eletrônicos. Além disso, uma mensagem pode ser envi- 
ada para um destinatário antes mesmo que esse destinatário obtenha seu par de chaves junto a um centro gerador de chaves. Essas características fazem com que a criptografia assimétrica baseada em identidades se assemelhe ao correio físico, ou seja, se você conhece o endereço de uma pessoa, você pode enviar-lhe uma mensagem, de modo que somente ela poderá ler. Com base no mesmo conceito, se Alice deseja enviar uma mensagem sigilosa para Beto, ela necessita apenas do endereço eletrônico de Beto, ou seja, não é preciso nem mesmo ter algum conhecimento sobre chaves ou protocolos de comunicação.

Vimos também que foram propostos diversos esquemas de criptografia e assinatura que utilizavam tal conceito, mas que somente em 2001, com o esquema de Boneh \& Franklin [Boneh e Franklin 2001], foi encontrada uma solução satisfatória, baseada em propriedades de curvas elípticas.

Estes sistemas são ideais para grupos fechados, como por exemplo em uma cadeia de lojas ou de bancos, onde a matriz pode fazer o papel de uma autoridade de confiança.

A grande motivação para estudarmos os sistemas criptográficos baseados em identidades surgiu do levantamento dos principais problemas encontrados na infra-estrutura de chaves públicas (PKI) e suas possíveis vulnerabilidades, que apresentamos no capítulo 2 desta dissertação. Somado a este fato, ao fazermos o levantamento bibliográfico, descobrimos que até o momento em que esta dissertação foi concluída, só tivemos conhecimento de literatura sobre o assunto em língua estrangeira.

Vimos o conceito de assinatura compacta, que embora não seja um sistema baseado em identidades, utiliza o cálculo do emparelhamento entre dois pontos, sendo utilizada por exemplo, na certificação de chaves.

Vimos o esquema de criptografia baseada em identidades proposto por Boneh \& Franklin [Boneh e Franklin 2001] e sugerimos uma pequena modificação nesse esquema, a fim de permitir que ele funcione, em conjunto com um esquema de assinatura, como um protocolo (seguro) de negociação de chaves simétricas (robustas). Fizemos também um estudo da importância na escolha do elemento aleatório utilizado nesse esquema. Mostramos ainda, o esquema de assinatura baseada em identidades de F. Hess [Hess 2002]. Ao final do capítulo sobre sistemas baseados em identidades (capítulo 3), descrevemos as principais vantagens e desvantagens desses esquemas, concluindo que os sistemas baseados em identidades representam hoje 
o estado da arte em criptografia assimétrica.

Estudamos também um esquema de criptassinatura baseado em identidades, proposto em 2002 por J. Malone-Lee [Malone-Lee 2002] e uma outra versão, mais eficiente, proposta por D. Nalla e K.C. Reddy [Nalla e Reddy 2003] em 2003. Esses esquemas têm como principal característica garantir uma comunicação autenticada e sigilosa tanto na origem quanto no destino da comunicação, característica essa que um esquema de criptografia baseado em identidades por si só não consegue prover, a menos que opere em conjunto com um esquema de assinatura baseado em identidades (sendo, neste caso, conhecido como "assinar-e-depoiscriptografar”). Tal solução, porém, é menos eficiente do que a proposta por Nalla \& Reddy.

Estudamos o esquema de criptassinatura detalhadamente, procurando fazer uma comparação em termos de consumo de tempo computacional entre os esquemas de Nalla \& Reddy, Malone-Lee e o esquema tradicional "assinar-e-depois-criptografar". Esse estudo detalhado possibilitou o envio de algumas sugestões de modificações no artigo original, que foram acatadas e alteradas pelos autores. Descrevemos cada uma dessas sugestões no anexo B.

Vimos também as principais aplicações envolvendo sistemas criptográficos baseados em identidades. A maioria das aplicações que vimos também são possíveis em sistemas criptográficos que seguem o padrão PKI (e que, neste trabalho, batizamos de criptografia assimétrica tradicional), mas nosso objetivo foi mostrar que tais aplicações são perfeitamente viáveis de serem realizadas com sistemas baseados em identidades. As principais aplicações que vimos foram:

- REVOGAÇÃO DE CHAVES PÚbliCAS - onde o prazo de validade de uma chave pública é acrescentado ao identificador, garantindo a validade daquela chave apenas durante o período desejado;

- DELEGAÇÃO PARA UM NOTEBOOK - onde um usuário pode gravar em seu notebook as chaves particulares baseadas em identidades correspondentes apenas aos dias de uma viagem, a fim de não haver risco de comprometimento de sua chave particular padrão;

- DELEgAÇÃo DE SERVIÇOS - em que cada Departamento de uma empresa pode decriptografar as mensagens de sua responsabilidade, sem contudo, conseguir decriptografar 
as mensagens dos outros Departamentos, sendo que o Presidente da empresa consegue decriptografar todas as mensagens;

- CRIAÇÃO DE GRUPOS - onde você pode enviar uma mensagem para um determinado grupo sem que saiba quem são os componentes desse grupo;

- ADIÇÃO DE ASSINATURAS - onde um grupo de pessoas pode assinar um mesmo documento, como por exemplo, um Tratado Internacional;

- ASSINATURA COM PKG NÃO-CONFIÁVEL - onde um usuário pode provar que sua assinatura foi forjada pelo PKG, considerando que esse PKG não seja uma entidade totalmente idônea;

- ASSINATURAS CEGAS - que permitem a um usuário obter um assinatura legítima de uma mensagem sem que o assinante tenha conhecimento do conteúdo da mesma, o que pode ser importante, como por exemplo, em votações eletrônicas;

- ASSINATURA EM ANEL - em que você pode ter certeza de que determinada mensagem foi assinada por um grupo, mas não tem como saber quem do grupo assinou.

Além disso, exibimos a hierarquia e certificação de sistemas baseados em identidades, apresentando um modelo híbrido de certificação PKI-IBE. Descrevemos como assinaturas compactas podem ser utilizadas para certificar autoridades de confiança e também como conseguir uma hierarquia de autoridades de confiança relacionadas com chaves baseadas em identidades. Vimos também como transferir confiança e delegar direitos dentro da hierarquia baseada em identidades.

Finalmente, utilizando a linguagem de programação ANSI-C, implementamos protótipos de sistemas baseados em identidades, optando por uma implementação com fins didáticos, onde destacamos os principais passos e dificuldades. Nessa implementação, adotamos o algoritmo simplificado de Miller, de acordo com o modelo proposto por Barreto et al. em [Barreto et al. 2002, Barreto, Lynn e Scott 2003]. 


\subsection{Trabalhos futuros}

Baseados nos resultados obtidos nesta dissertação, apresentamos como sugestão alguns trabalhos de pesquisa:

- reestruturação da implementação de forma a receber como parâmetros valores efetivamente utilizados na prática;

- realização de testes a fim de verificar se os esquemas apresentados são suscetíveis aos ataques de segurança conhecidos;

- realização de uma prova formal de segurança nos esquemas apresentados, tendo em vista que até o momento em que concluímos esta dissertação, não tivemos conhecimento de análises formais de segurança realizadas por terceiros sobre os esquemas aqui propostos;

- otimização da implementação apresentada, de modo a torná-la mais segura e seu desempenho mais eficiente;

- implementação do cálculo da raiz quadrada em $\mathbb{F}_{q^{k}}$, para uso na função de espalhamento $\mathrm{H}_{4}$ usada no signcryption (em nossa implementação, simulamos o comportamento de um oráculo aleatório);

- implementação da geração do ponto em $E\left(\mathbb{F}_{q^{k}}\right)$ e do polinômio irredutível em $\mathbb{F}_{q^{k}}$;

- implementação do cálculo da ordem da curva de forma eficiente (em nossa implementação, como trabalhamos com um valor pequeno de tamanho do corpo $(q=17)$, foi possível calcular todos os pontos da curva).

Naturalmente, as sugestões não se esgotam na lista acima, tendo em vista que $\mathrm{o}$ assunto tem potencial para ser amplamente explorado.

Encerrando esta dissertação, o leitor poderá consultar os anexos, onde podem ser vistos conceitos fundamentais de álgebra e principais operações em curvas elípticas (anexo A), as modificações sugeridas ao artigo de Nalla e Reddy [Nalla e Reddy 2003], juntamente com a íntegra do $e$-mail enviado com as sugestões propostas e aceitas (anexo B) e o código-fonte da implementação (anexo C). 


\section{Anexo A}

\section{Curvas elípticas}

Neste anexo, veremos os principais conceitos relacionados a curvas elípticas e seu emprego na Criptografia. Antes de tratarmos das curvas elípticas propriamente ditas, enunciaremos alguns conceitos fundamentais como complexidade de algoritmos, aritmética modular e álgebra de corpos finitos, para familiarizar o entendimento do leitor com a terminologia empregada.

\section{A.1 Complexidade de algoritmos}

Seja $n$ o tamanho da entrada para um algoritmo $\mathcal{A}$ e seja $f(n)$ a função que representa o tempo de execução no pior caso de $\mathcal{A}$.

Dizemos que $f(n)=O(g(n))$ se existe uma constante $c>0$ e um inteiro $n_{0}$, tais que $0 \leqslant f(n) \leqslant c g(n)$ para todo $n>n_{0}$.

Por outro lado, dizemos que $f(n)=\Omega(g(n))$ se existe uma constante $c>0$ e um inteiro $n_{0}$, tais que $0 \leqslant c g(n) \leqslant f(n)$ para todo $n>n_{0}$.

Baseados nas definições de $O$ e $\Omega$, podemos definir algumas classes de algoritmos, de acordo com o seu tempo de execução no pior caso.

Os algoritmos de tempo polinomial são comumente denominados fáceis ou tratáveis. Os problemas de tempo sub-exponencial (ou super-polinomial) são considerados difíceis, mas não tão difíceis quanto os algoritmos de tempo meramente exponencial , que são 
comumente denominados intratáveis. Na tabela A.1, vemos as três classificações mais comuns e suas respectivas definições.

Tabela A.1: Complexidade de algoritmos

\begin{tabular}{|l|l|}
\hline Classificação & Propriedade \\
\hline \hline polinomial & $\exists k \mid f(n) \in O\left(n^{k}\right)$ \\
\hline sub-exponencial ou super-polinomial & $\forall k, f(n) \in \Omega\left(n^{k}\right)$ e \\
& $\forall a>1, f(n) \in O\left(a^{n}\right)$ \\
\hline exponencial & $\exists a>1 \mid f(n) \in \Omega\left(a^{n}\right)$ e \\
& $\exists b>1 \mid f(n) \in O\left(b^{n}\right)$ \\
\hline
\end{tabular}

\section{A.2 Aritmética modular}

Seja $a$ um inteiro e $n$ um inteiro positivo. Denota-se por $a \bmod n$ o resto que é obtido quando a é dividido por $n$.

Segue desta definição que $a \bmod n$ é o inteiro $r$ tal que $a=q \cdot n+r$ e $0 \leqslant r<n$.

Exemplos:

$$
\begin{array}{rcc}
17 \bmod 5 & =2 & (17=3 \times 5+2) \\
-133 \bmod 9 & =2 & (-133=-15 \times 9+2) \\
2001 \bmod 101 & =82 & (2001=19 \times 101+82)
\end{array}
$$

\section{A.3 Álgebra de grupos}

Seguem os conceitos fundamentais de Álgebra que são usados ao longo desta dissertação.

R. Terada [Terada 2000] define grupo, anel e corpo como:

\section{A.3.1 Grupo}

“Um grupo $(\mathbb{G}$, o $)$ é um conjunto $\mathbb{G}$ com uma operação binária o definida sobre $\mathbb{G}$, tal que: 
1. A operação o é associativa, i.e., $\forall a, b, c \in \mathbb{G}: a \circ(b \circ c)=(a \circ b) \circ c$.

2. Existe um elemento $n \in \mathbb{G}$, chamado identidade ou elemento neutro, tal que $\forall a \in \mathbb{G}: a \circ n=n \circ a=a$.

3. Para cada elemento $a \in \mathbb{G}$ existe um elemento $\bar{a} \in \mathbb{G}$, o inverso de $a$, tal que $a \circ \bar{a}=\bar{a} \circ a=n$.

Dizemos que $\mathbb{G}$ é comutativo (ou abeliano) se $\forall a, b \in \mathbb{G}: a \circ b=b \circ a$. Se a operação o for uma multiplicação (*), o grupo é chamado grupo multiplicativo, a identidade é representada por 1 e o inverso de $a$ é representado por $a^{-1}$. Se a operação o for uma soma (+), o grupo é chamado grupo aditivo, a identidade é representada por 0 e o inverso de $a$ é representado por $-a$.

Se o número de elementos de $\mathbb{G}$ for finito, tal número é chamado de ordem de $\mathbb{G}$. Se existe um elemento $P \in \mathbb{G}$ tal que qualquer elemento $G \in \mathbb{G}$ possa ser escrito como um múltiplo escalar de G, i.e., $G=\alpha P$ para algum inteiro $\alpha$, então dizemos que $G$ é cíclico. Neste caso, o ponto $P$ é chamado de gerador de $\mathbb{G}$.

Um subconjunto não vazio $\mathbb{H}$ de $\mathbb{G}$ é subgrupo se $\mathbb{H}$ é um grupo com a mesma operação de $\mathbb{G}$. "

\section{A.3.2 Anel}

"Um anel $(\mathbb{A},+, *)$ é um conjunto $\mathbb{A}$ com duas operações binárias: soma $(+)$ e multiplicação $(*)$ definidas sobre $\mathbb{G}$, tais que:

1. $(\mathbb{A},+)$ é um grupo aditivo comutativo com identidade 0 .

2. A operação $*$ é associativa, i.e., $\forall a, b, c \in \mathbb{A}: a *(b * c)=(a * b) * c$.

3. Existe um elemento identidade $1 \in \mathbb{A}, 1 \neq 0$, tal que $\forall a \in \mathbb{A}: a * 1=$ $1 * a=a$.

4. A operação $*$ é distributiva sobre + , i.e., $\forall a, b, c \in \mathbb{A}: a *(b+c)=(a * b)+$ $(a * c)$ e $(b+c) * a=(b * a)+(c * a)$.

Dizemos que $\mathbb{A}$ é comutativo se $\forall a, b \in \mathbb{G}: a * b=b * a$. Um exemplo de anel comutativo é o conjunto $\mathbb{Z}$ dos inteiros com as operações de soma e multiplicação 
usuais. Outro exemplo é $\mathbb{Z}_{n}$ com a soma e multiplicação $\bmod n$."

\section{A.3.3 Corpo}

"Um corpo $\mathbb{C}$ é um anel comutativo no qual todos os elementos não nulos possuem inverso multiplicativo.” Ou seja:

$$
\forall a \in \mathbb{C}, a \neq 0 \Longrightarrow \exists b \in \mathbb{C} \mid a b=1
$$

A característica de um corpo é zero se $\overbrace{1+1+1+\ldots+1}^{m \text { vezes }}$ é diferente de zero para qualquer $m \geqslant 1$. Caso contrário, a característica do corpo é o menor $m$ para o qual esta soma é zero.

$\mathbb{Z}_{n}$ é um corpo se e só se $n$ é primo. Se o número de elementos do corpo é finito, ele é chamado de corpo finito (finite field).

O número de elementos de um corpo finito $\left(\mathbb{F}_{q}\right)$ é sempre da forma $p^{m}$. O valor $p$ é definido como sendo a característica desse corpo, pois $\overbrace{1+1+\ldots 1}^{p \text { vezes }}=p$ e $p=0 \bmod p$. O inteiro $m$ é chamado grau de extensão. Se $q$ é primo, então $p=q$.

Caso o leitor queira se aprofundar mais no assunto, poderá consultar as seguintes referências: [Terada 2000, Boneh e Franklin 2001, Galbraith 2001, Barreto 1999, Menezes, Oorschot e Vanstone 1997, Silverman 1986, Domingues e Iezzi 1979].

\section{A.4 Criptografia com curvas elípticas}

O uso de curvas elípticas em criptografia está ligado à possibilidade de se tomar 2 pontos sobre uma curva específica, adicioná-los de acordo com regras especiais e obter um outro ponto sobre a mesma curva [Custodio 2000].

Mais importante para a Criptografia é a dificuldade de descobrir quais 2 pontos foram adicionados na obtenção de um terceiro: para uma escolha adequada de parâmetros, o problema é intratável. 


\section{A.4.1 Soma de pontos - método algébrico}

Esta operação é escrita aditivamente e é definida como segue (com todas as operações aritméticas realizadas em $\mathbb{Z}_{q}$ ):

Sejam $P=\left(x_{P}, y_{P}\right)$ e $Q=\left(x_{Q}, y_{Q}\right)$ dois pontos sobre uma curva elíptica

$$
E: y^{2}=x^{3}+a x+b
$$

- se $x_{Q}=x_{P}$ e $y_{Q}=-y_{P}$, então $P+Q=\mathcal{O}$, sendo $\mathcal{O}$ o ponto no infinito.

- senão

$$
P+Q=\left(x_{R}, y_{R}\right), \text { onde }\left\{\begin{aligned}
x_{R} & =\lambda^{2}-x_{P}-x_{Q} \\
y_{R} & =\lambda\left(x_{P}-x_{R}\right)-y_{P} \\
\lambda & =\left\{\begin{array}{l}
\frac{y_{Q}-y_{P}}{x_{Q}-x_{P}}, \text { se } P \neq Q \\
\frac{3 x_{P}^{2}+a}{2 y_{P}}, \text { se } P=Q
\end{array}\right.
\end{aligned}\right.
$$

\section{A.4.2 Soma de pontos - método geométrico}

Para calcularmos geometricamente a soma dos pontos $P$ e $Q$, primeiramente, traçamos uma reta entre $P$ e $Q$, interceptando a curva em um terceiro ponto, que chamaremos de $-R$. O resultado de $P+Q$ é o ponto simétrico de $-R$ em relação ao eixo das abscissas, ou seja, $P+Q=R$.

Pode-se provar (segundo N. Koblitz [Koblitz 1994], cap.6) que essa reta traçada entre dois pontos da curva sempre intercepta a curva em um terceiro ponto $(-R)$.

Na figura A.1 podemos ver um exemplo de como calcular geometricamente a soma de pontos na curva elíptica $y^{2}=x^{3}-7 x+5$. Consideramos que os pontos da curva são números reais.

\section{A.4.3 Exemplos de cálculos com curvas elípticas}

Veremos a seguir alguns exemplos numéricos com curvas elípticas.

Exemplo 1: Seja $E$ a curva elíptica $y^{2}=x^{3}+x+6$ sobre $\mathbb{Z}_{11}$.

Determinando os pontos sobre $E$ : 


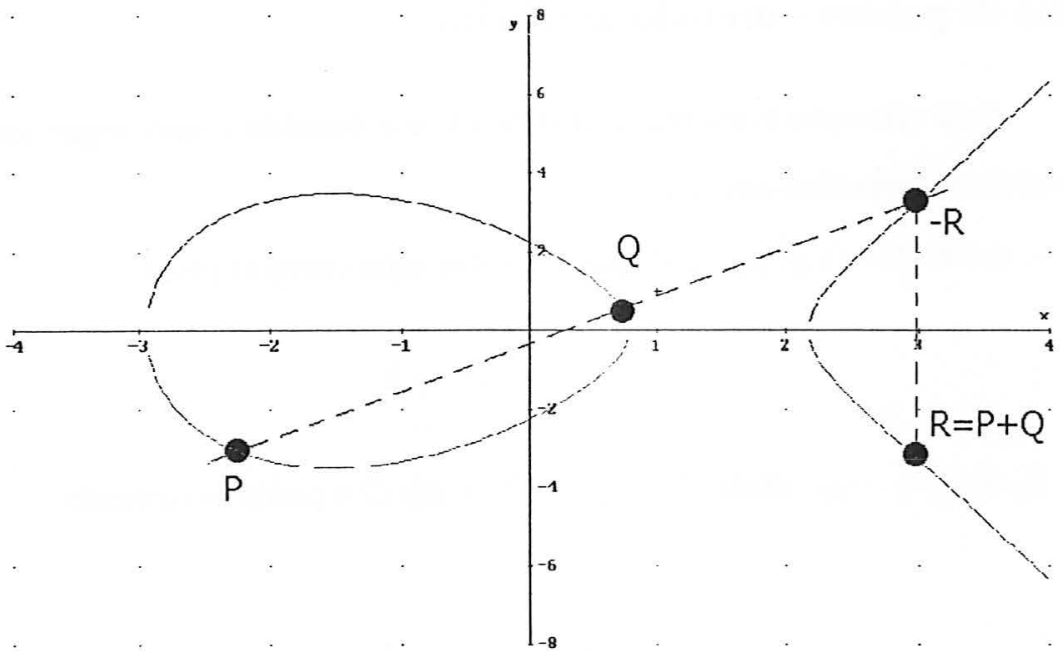

Figura A.1: Soma de pontos reais em uma curva elíptica - Para calcularmos geometricamente a soma dos pontos $P$ e $Q$, primeiramente, traçamos uma reta entre $P$ e $Q$, interceptando a curva em um terceiro ponto, que chamaremos de $-R$. O resultado de $P+Q$ é o ponto simétrico de $-R$ em relação ao eixo das abscissas, ou seja, $P+Q=R$.

\begin{tabular}{|c|c|c|}
\hline$x$ & $x^{3}+x+6 \bmod 11$ & $y$ \\
\hline \hline 0 & 6 & - \\
\hline 1 & 8 & - \\
\hline 2 & 5 & 4,7 \\
\hline 3 & 3 & 5,6 \\
\hline 4 & 8 & - \\
\hline 5 & 4 & 2,9 \\
\hline 6 & 8 & - \\
\hline 7 & 4 & 2,9 \\
\hline 8 & 9 & 3,8 \\
\hline 9 & 7 & - \\
\hline 10 & 4 & 2,9 \\
\hline
\end{tabular}

Onde a segunda coluna representa o valor de $x^{3}+x+6$ reduzido ao módulo 11 , ou seja, o resto da divisão de $x^{3}+x+6$ por 11 e a terceira coluna representa o valor de $y$ tal que $y^{2} \bmod 11$ dá como resultado o valor correspondente na segunda coluna. Deste modo, temos que:

Se $y=4$, então $y^{2} \bmod 11=16 \bmod 11=5$;

Se $y=7$, então $y^{2} \bmod 11=49 \bmod 11=5$;

Se $y=5$, então $y^{2} \bmod 11=25 \bmod 11=3$;

Se $y=6$, então $y^{2} \bmod 11=36 \bmod 11=3$;

Se $y=2$, então $y^{2} \bmod 11=4 \bmod 11=4$; 
Se $y=9$, então $y^{2} \bmod 11=81 \bmod 11=4$;

Se $y=3$, então $y^{2} \bmod 11=9 \bmod 11=9$;

Se $y=8$, então $y^{2} \bmod 11=64 \bmod 11=9$;

Os demais valores de $y^{2}$ não possuem um correspondente $y$ tal que $y^{2} \bmod 11$ dê como resultado o valor na segunda coluna da tabela.

Deste modo, a curva elíptica $y^{2}=x^{3}+x+6$ sobre $\mathbb{Z}_{11}$ tem 13 pontos, que são:

$(2,4),(2,7),(3,5),(3,6),(5,2),(5,9),(7,2),(7,9),(8,3),(8,8),(10,2),(10,9)$ e o ponto $\mathcal{O}$.

Exemplo 2: Vamos agora, utilizando as equações do método algébrico, calcular o ponto $R=P+Q$, sendo $P=(2,4)$ e $Q=(7,2)$ pontos da curva $y^{2}=x^{3}+x+6$ sobre $\mathbb{Z}_{11}$ :

$y_{Q}-y_{P}=2-4=-2 \bmod 11=9$

$\left(x_{Q}-x_{P}\right)^{-1}=(7-2)^{-1}=5^{-1} \bmod 11=\frac{1}{5} \bmod 11=\frac{1 \bmod 11}{5 \bmod 11}=\frac{45 \bmod 11}{5 \bmod 11}=\frac{45}{5}=9$

$\lambda=\left(y_{Q}-y_{P}\right) \cdot\left(x_{Q}-x_{P}\right)^{-1}=9 \times 9=81 \bmod 11=4$

$x_{R}=\lambda^{2}-x_{P}-x_{Q}=4^{2}-2-7=7 \bmod 11=7$

$y_{R}=\lambda\left(x_{P}-x_{R}\right)-y_{P}=4(2-7)-4=-24 \bmod 11=9$

Resposta: $R=(7,9)$, que é também um ponto da curva $y^{2}=x^{3}+x+6$ sobre $\mathbb{Z}_{11}$.

Exemplo 3: Vamos agora, calcular o ponto $S=2 P$, sendo $P=(2,4)$ :

$3 x_{P}^{2}+a=3 \times 2^{2}+1=3 \times 4+1=13$

$\left(2 y_{P}\right)^{-1}=(2 \times 4)^{-1}=8^{-1}=\frac{1}{8} \bmod 11=\frac{1 \bmod 11}{8 \bmod 11}=\frac{56 \bmod 11}{8 \bmod 11}=\frac{56}{8}=7$

$\lambda=\left(3 x_{P}^{2}+a\right) \cdot\left(2 y_{P}\right)^{-1}=13 \times 7=91 \bmod 11=3$

$x_{S}=\lambda^{2}-2 x_{P}=3^{2}-2 \times 2=5 \bmod 11=5$

$y_{S}=\lambda\left(x_{P}-x_{R}\right)-y_{P}=3(2-5)-4=-13 \bmod 11=9$

Resposta: $S=(5,9)$, que é também um ponto da curva $y^{2}=x^{3}+x+6$ sobre $\mathbb{Z}_{11}$.

Se quiséssemos, agora, calcular o ponto $3 P$, bastaria somarmos o ponto $S=2 P$ com o ponto $P$ que obteríamos o resultado desejado.

Exemplo 4: Calculando o ponto $T=3 P=S+P$

$y_{S}-y_{P}=9-4=5 \bmod 11=5$

$\left(x_{S}-x_{P}\right)^{-1}=(5-2)^{-1}=3^{-1} \bmod 11=\frac{1}{3} \bmod 11=\frac{1 \bmod 11}{3 \bmod 11}=\frac{12 \bmod 11}{3 \bmod 11}=\frac{12}{3}=4$ 
$\lambda=\left(y_{S}-y_{P}\right) \cdot\left(x_{S}-x_{P}\right)^{-1}=5 \times 4=20 \bmod 11=9$

$x_{T}=\lambda^{2}-x_{P}-x_{S}=9^{2}-2-5=8 \bmod 11=8$

$y_{T}=\lambda\left(x_{P}-x_{T}\right)-y_{P}=9(2-8)-4=-58 \bmod 11=8$

Resposta: $T=(8,8)$, que é também um ponto da curva $y^{2}=x^{3}+x+6$ sobre $\mathbb{Z}_{11}$.

Prosseguindo analogamente, podemos calcular todos os múltiplos do ponto $P$, que, como demonstrado em [Koblitz 1994], serão todos pontos da curva $y^{2}=x^{3}+x+6$ sobre $\mathbb{Z}_{11}$.

Vimos, nos exemplos, que para pequenos valores de $q$ (no exemplo, $q=11$ ) conseguimos calcular todos os pontos de uma dada curva sobre $\mathbb{Z}_{q}$. Desta forma, uma simples busca na tabela resolveria o problema do logaritmo discreto. Porém, para valores de $q$ muito grandes (por exemplo, na prática, usamos $q=2^{160}$ ), tal problema passa a ser intratável, residindo aí a segurança da criptografia com curvas elípticas. A título de ilustração, como uma curva definida sobre $\mathbb{Z}_{q}(q$ primo, $q>3$ ) tem aproximadamente $q$ pontos, o tempo necessário para que um computador que, hipoteticamente, fosse capaz de executar $10^{24}$ instruções por segundo conseguisse calcular todos os $2^{160} \simeq 10^{48}$ (aproximadamente) pontos seria cerca de $10^{24}$ segundos ou $10^{17}$ anos.

Neste anexo, vimos o suporte matemático necessário a um melhor entendimento dos conceitos apresentados nesta dissertação, com destaque para álgebra de corpos finitos e curvas elípticas em criptografia. Veremos no próximo anexo, as sugestões que foram feitas pelo autor desta dissertação ao artigo Signcryption scheme for Identity-based Cryptosystems [Nalla e Reddy 2003], através de um e-mail cujo conteúdo reproduzimos na íntegra. 


\section{Anexo B}

\section{Sugestões feitas ao artigo Signcryption scheme for Identity-based Cryptosystems [Nalla e Reddy 2003]}

\section{B.1 Problemas no artigo publicado em 28/ 03/ 2003}

Destacaremos a seguir os problemas encontrados no artigo publicado em 28 de março de 2003.

1. Valor de $R^{\prime}$ no esquema Nalla \& Reddy.

No artigo de 28 de março, os autores definiam $R^{\prime}$ como:

$$
R^{\prime}=\left(R\left\|H_{3}\left(\hat{e}\left(S_{A}, Q_{B}\right)\right)\right\| M\right)
$$

Onde $M$ é a mensagem a ser enviada e ê é o emparelhamento de Weil.

Em seguida, no cálculo de $k_{A}$, utilizavam o emparelhamento

$$
\hat{e}\left(Q_{B}, S_{A}\right)
$$

Sabemos [Silverman 1986] que para o emparelhamento de Weil,

$$
\hat{e}(P, Q)=\hat{e}(Q, P)^{-1}
$$

Desta forma, o esquema estaria calculando um emparelhamento a mais, desnecessariamente, pois $\hat{e}\left(S_{A}, Q_{B}\right) \neq \hat{e}\left(Q_{B}, S_{A}\right)$.

Foi sugerido que o emparelhamento da equação (B.1) fosse trocado para $\hat{e}\left(Q_{B}, S_{A}\right)$. 
2. Emparelhamento $\hat{e}\left(W, Q_{B}\right)$ no esquema Malone-Lee.

Os autores, ao apresentarem o esquema de Malone-Lee, calculavam y como

$$
y=\hat{e}\left(W, Q_{B}\right)
$$

Porém, na verificação, chegavam ao valor $\hat{e}\left(Q_{B}, W\right)$.

Foi sugerido que se trocasse o valor da equação (B.3) de $\hat{e}\left(W, Q_{B}\right)$ para $\hat{e}\left(Q_{B}, W\right)$, tendo em vista que tais valores são diferentes (a propriedade comutativa não vale para o emparelhamento de Weil).

Ainda no mesmo item, os autores não contabilizavam o emparelhamento $\hat{e}\left(W, Q_{B}\right)$ (ou $\hat{e}\left(Q_{B}, W\right)$, como foi sugerido) como um emparelhamento pré-calculável. Foi mostrado aos autores que

$$
\hat{e}\left(Q_{B}, W\right)=\hat{e}\left(Q_{B}, z P_{K G C}\right)=\hat{e}\left(Q_{B}, P_{K G C}\right)^{z}
$$

onde $P_{K G C}$ é o que nesta dissertação chamamos de $R_{T A}$ e sugerido que fosse atualizada a contabilização dos emparelhamentos pré-calculáveis do esquema Malone-Lee.

\section{Uso do esquema de assinatura de Hess.}

Os autores usavam o esquema de assinatura Cha \& Cheon [Cha e Cheon 2002] para efeito de cálculo do número de operações realizadas no esquema "assinar-e-depois-criptografar". Utilizando o esquema de Cha \& Cheon, o esquema combinado executava um total de 4 emparelhamentos, sendo que 1 deles poderia ser pré-calculado, o que dava um "saldo" de 3 durante a comunicação (considerando que os pré-calculáveis foram computados antes da comunicação). Foi sugerido aos autores usarem o esquema de assinatura de Hess [Hess 2002], que como vimos, leva o esquema combinado a calcular 5 emparelhamentos, dos quais 3 podem ser pré-calculados, chegando a um "saldo" de 2, melhor do que o apresentado pelos autores.

\section{Alteração da Tabela-Resumo.}

Por fim, foi sugerido aos autores a alteração da Tabela-Resumo, com base nas modificações sugeridas.

Desta forma, a tabela deveria ser alterada no cômputo das operações do esquema com- 
binado, e no cômputo do número de emparelhamentos pré-calculáveis do esquema de Malone-Lee.

Todas as alterações sugeridas foram efetuadas e o artigo foi republicado em 9 de abril de 2003.

\section{B.2 Íntegra do correio eletrônico enviado a um dos autores do artigo}

Segue abaixo o texto na íntegra do correio eletrônico enviado a Divya Nalla, sugerindo algumas modificações no artigo publicado em 28 de março de 2003. Algumas notações matemáticas foram alteradas para o formato $\mathrm{LT}_{\mathrm{E}} \mathrm{X} 2 \varepsilon$ para permitir melhor visualização do leitor.

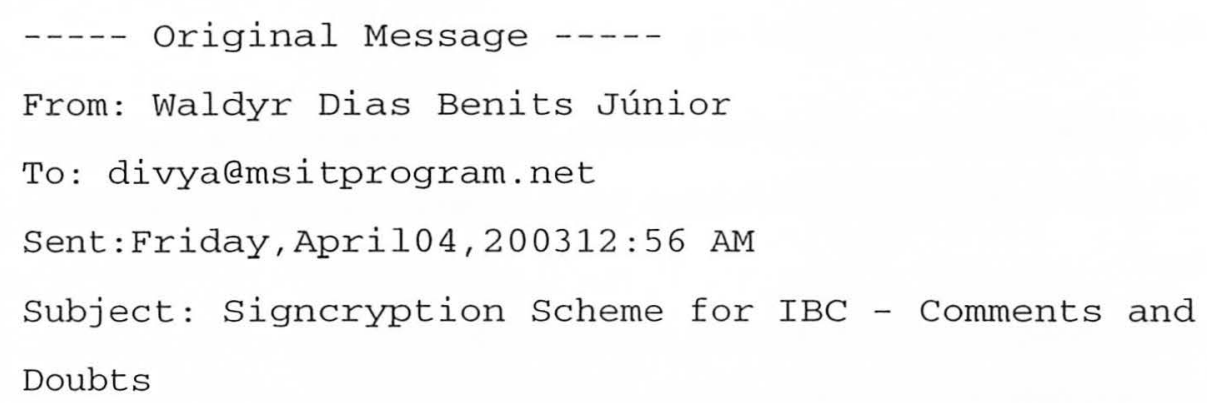

Hi, Mr Nallla, D. My name is Waldyr Benits, I'm a Master Student of Computer Science at Institute of Mathematics and Statistics - University of São Paulo (Brazil) and I've been studying your's and Mr. Reddy's paper "Signcryption scheme for Identity-based Cryptosystems". May I ask you some questions, and do some comments, based on your last version (published on March, 28th)?

1 - On page 5, when you present yours and Mr. Reddy's signcryption scheme, you mention that "A" must calculate some values, and among these values is R'. I noticed that you included the pairing $e\left(S_{a}, Q_{b}\right)$,so as to avoid the "man-in-the-middle" attack. But two lines below, when you show how to calculate $k_{a}$, you use the pairing $e\left(Q_{b}, S_{a}\right)$. I suppose you have committed a little mistake, because in this case, "A" would have to calculate 2 pairings, instead of only one, as you have proposed, since the pairing doesn't have the commutative property (I mean: $e(A, B)$ 
is different from $e(B, A)$ ). If you use the pairing $e\left(Q_{b}, S_{a}\right)$ when calculating $\mathrm{R}$ ', the result will follow, if $\mathrm{B}$, during verification, use the corresponding pairing $e\left(S_{b}, Q_{a}\right)$.

2 - When you present the table on page 7, You say that Malone-Lee's scheme can precompute only one pairing, that is, $e\left(Q_{a}, P_{K G C}\right)$,during unsigncryption step. I agree, that this pairing can be precomputed, but I think another pairing can also be precomputed in that scheme: the pairing $e\left(W, Q_{b}\right)$ in the signcryption step. Look:

$W=x P_{K G C}$

Then, $e\left(W, Q_{b}\right)=e\left(x P_{K G C}, Q_{b}\right)=e\left(P_{K G C}, Q_{b}\right)^{x}$ - due to bilinearity - So, the pairing $e\left(P_{K G C}, Q_{b}\right)$ can also be precomputed. Still in the same pairing, I think the order is changed again, because $y=e\left(W, Q_{b}\right)=e\left(S_{b}, U\right)=e\left(s Q_{b}, U\right)=e\left(Q_{b}, s U\right)=e\left(Q_{b}, s x P\right)=$ $e\left(Q_{b}, x P_{K G C}\right) \neq e\left(Q_{b}, W\right)$.

Since the pairing doesn't have the commutative property, I think would be better to use $y=e\left(Q_{b}, W\right)$ in the signcryption step, instead of $y=e\left(W, Q_{b}\right)$.

3 - Why do you use Cha \& Cheon's Signature Scheme in the "signature-then-encryption" scheme? I think if you use Hess' Signature Scheme (your reference 5) would be better, because you would have :

a) sign step : 1 pairing (where $e(P, P)$ - that can be precomputed)

b) verify step : 2 pairings (where $e\left(Q_{a},-P_{K G C}\right)$ - can be precomputed)

c) encryption and decryption steps stay the same (BF)

In this situation above, the total of pairings calculated on "signature-thenencryption" scheme (BF-Hess) would be 5, where 3 can be precomputed. This lead us to 2 pairings to be computated during communications, just equal to your scheme (4 to 2 ). Although the number of pairings to be calculated on (BF-Hess') is equal to your scheme (and better than Malone's), yours is still the best, because your scheme needs less exponentiation than BF-Hess' (2 versus 3).

I apologize if I wasted your time, and I sincerely hope to have contributed for improving your paper.

Yours Sincerely, Waldyr. 


\section{B.3 Resposta de Divya Nalla ao $e$-mail enviado}

Segue abaixo a resposta de Divya Nalla ao $e$-mail enviado. Cabe ressaltar que todas as alterações sugeridas foram feitas e o artigo foi republicado em 09 de abril de 2003.

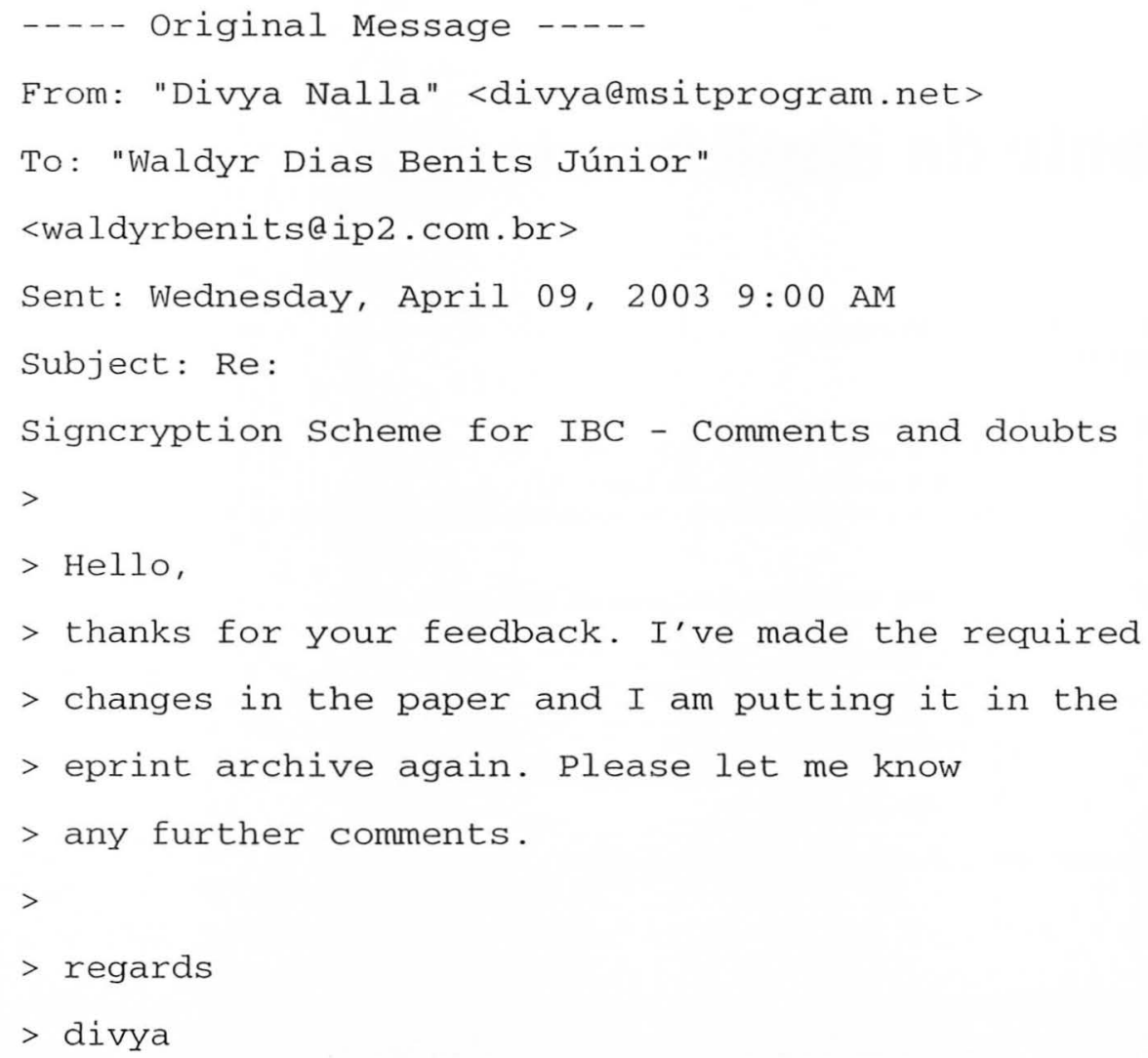




\section{Anexo C}

\section{Código fonte da implementação}

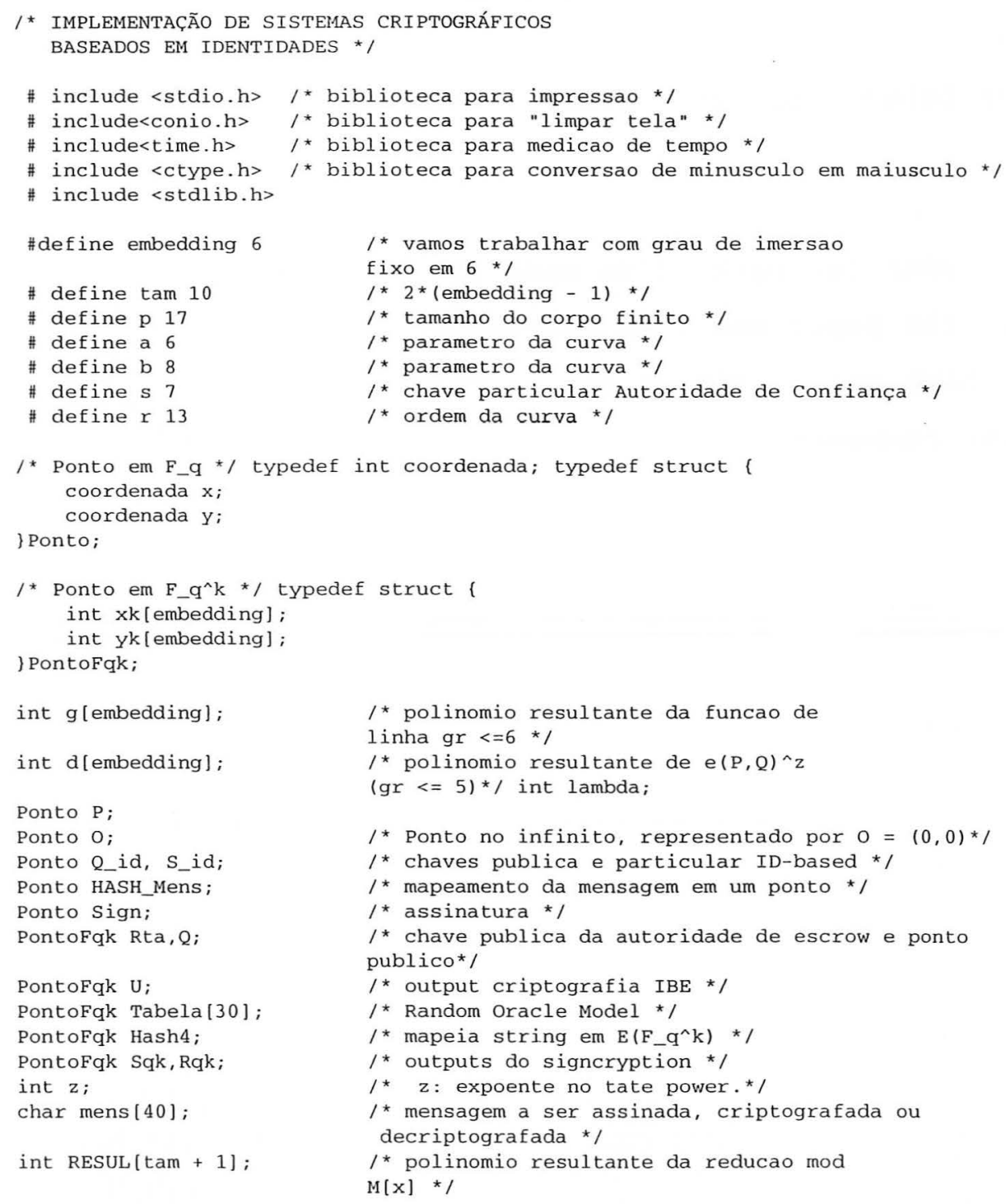

int g [embedding] ;

int $d$ [embedding];

Ponto P;

Ponto $\mathrm{O}$;

Ponto Q_id, S_id;

Ponto HASH_Mens;

Ponto Sign;

PontoFqk Rta, Q;

PontoFqk U;

PontoFqk Tabela[30];

PontoFqk Hash4;

PontoFqk Sqk, Rqk;

int $\mathrm{z}$;

char mens [40];

int RESUL [tam +1$]$;

$I^{*}$ polinomio resultante da funcao de linha gr $<=6$ * $/$

$I^{\star}$ polinomio resultante de $e(P, Q)^{\wedge} z$ (gr $<=5)$ */ int lambda;

$1 *$ Ponto no infinito, representado por $0=(0,0) * /$

1 * chaves publica e particular ID-based */

1 * mapeamento da mensagem em um ponto */

1 * assinatura * 1

1 * chave publica da autoridade de escrow e ponto publico* $/$

/* output criptografia IBE */

/* Random Oracle Model */

/* mapeia string em $E\left(F_{-} q^{\wedge} k\right)$ */

1 * outputs do signcryption */

$l^{*} \mathrm{z}$ : expoente no tate power. */

1 * mensagem a ser assinada, criptografada ou decriptografada */

/* polinomio resultante da reducao mod $H[x] * /$ 


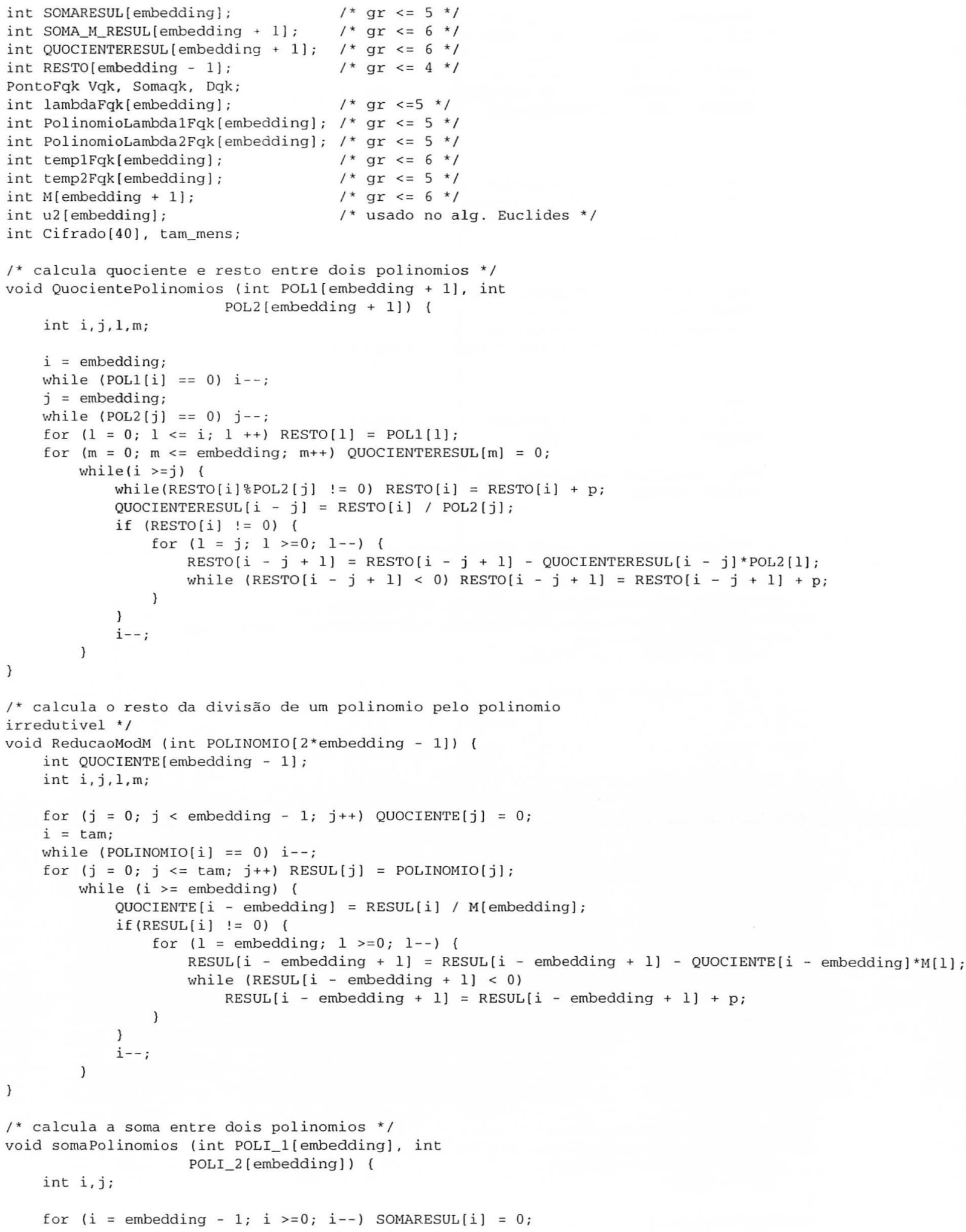




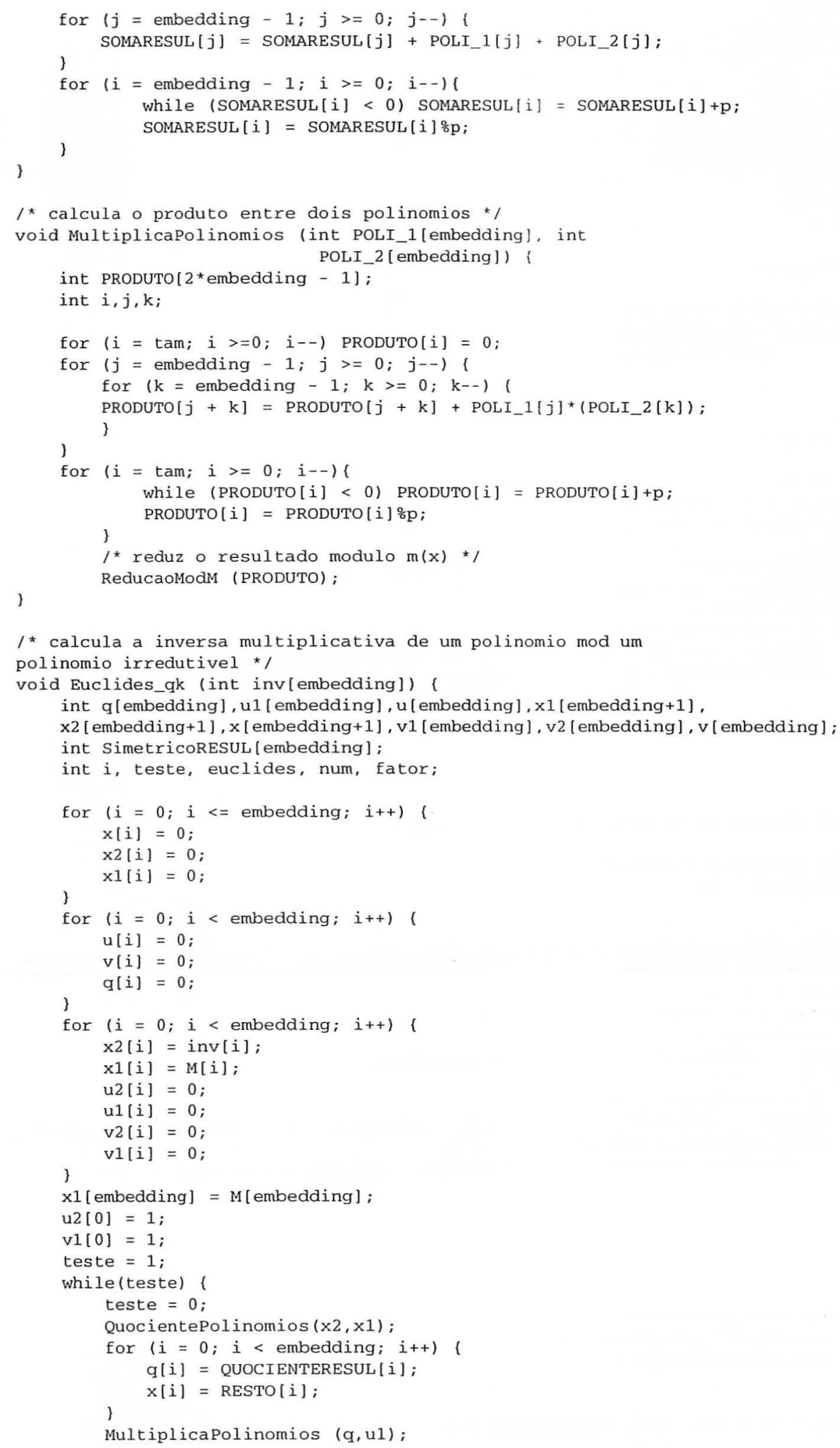




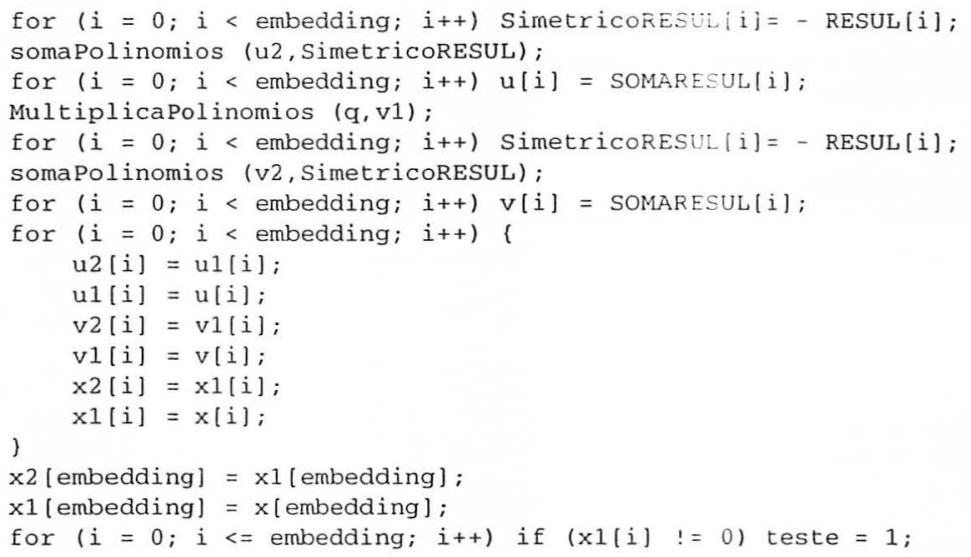




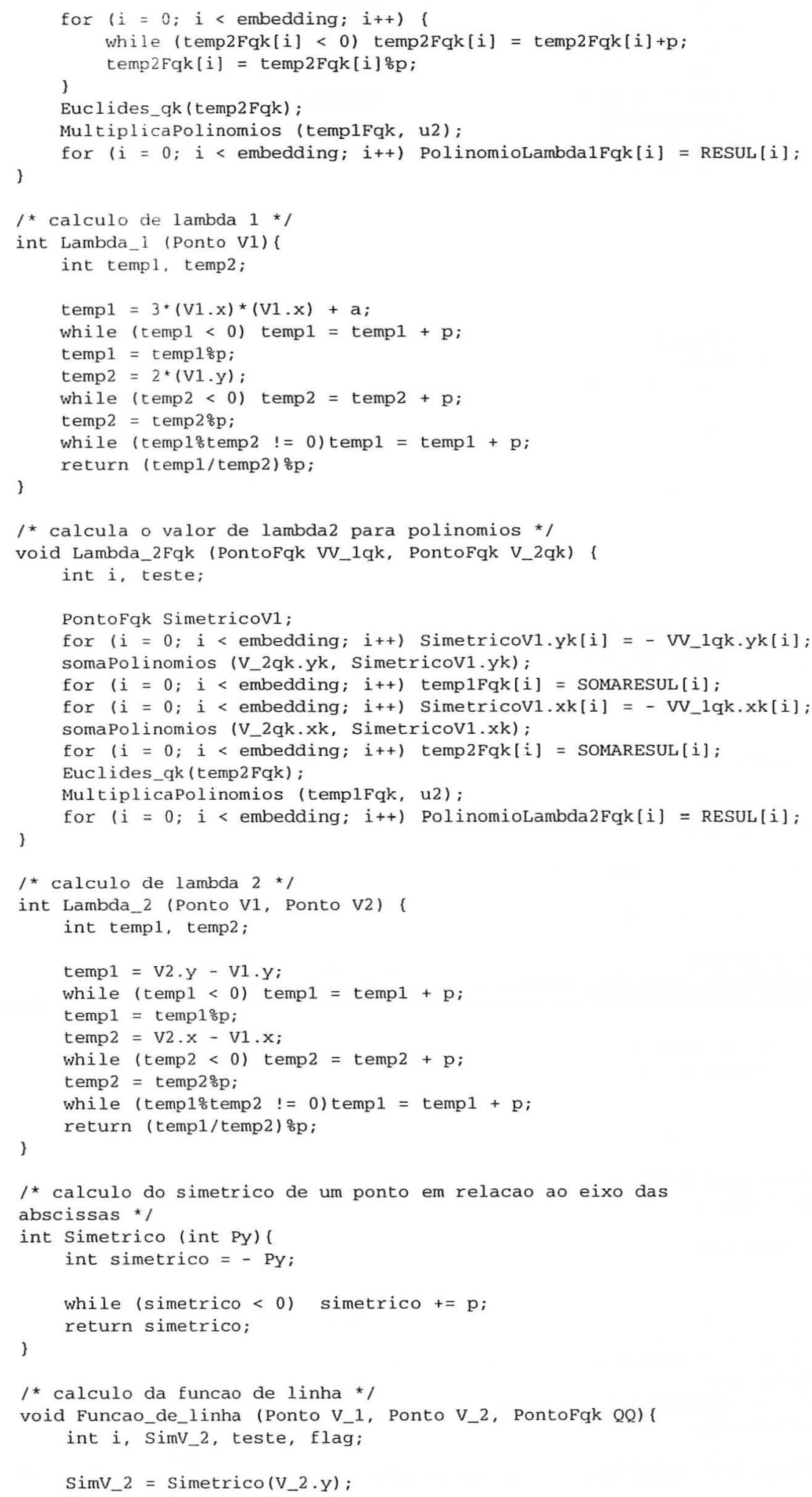




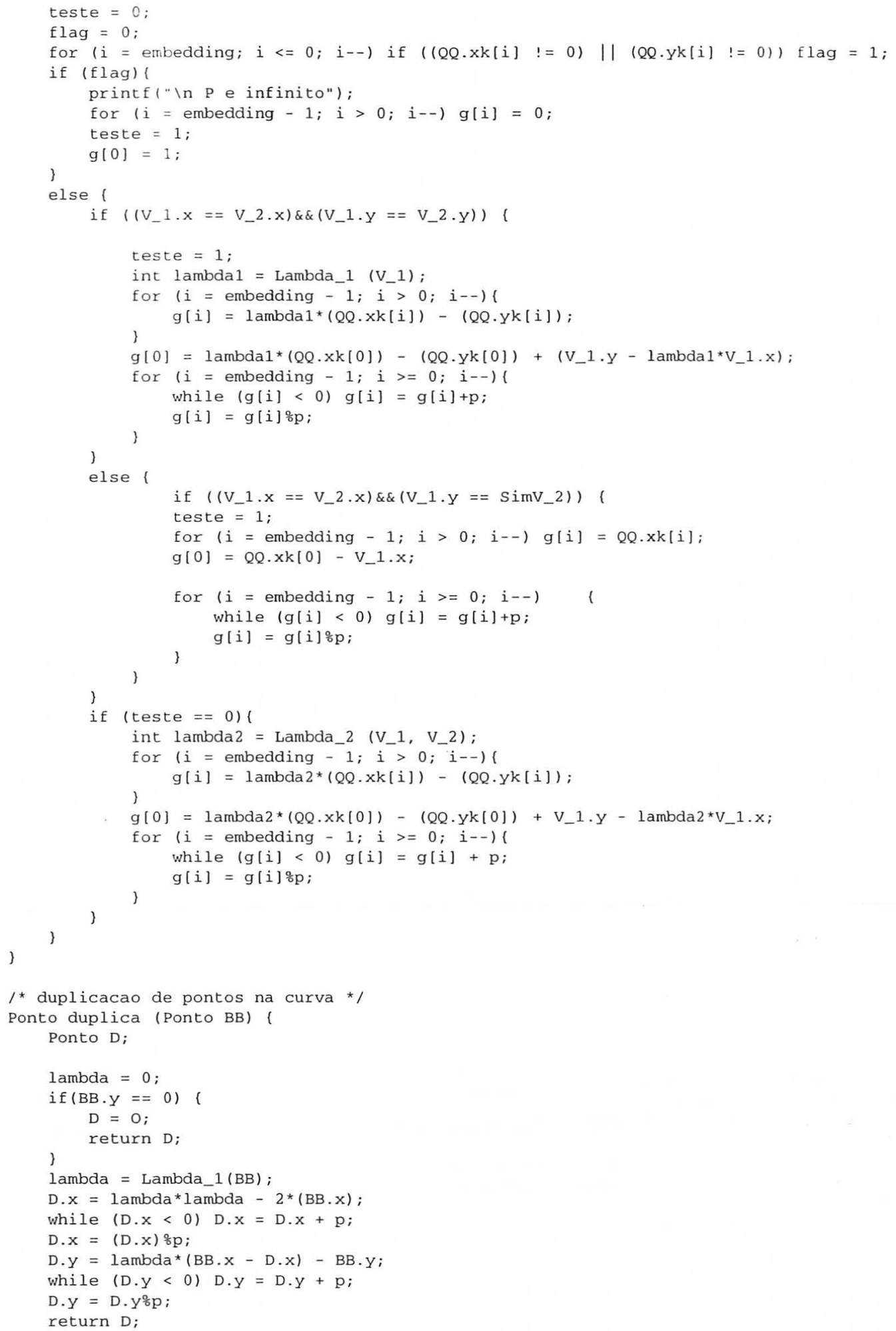




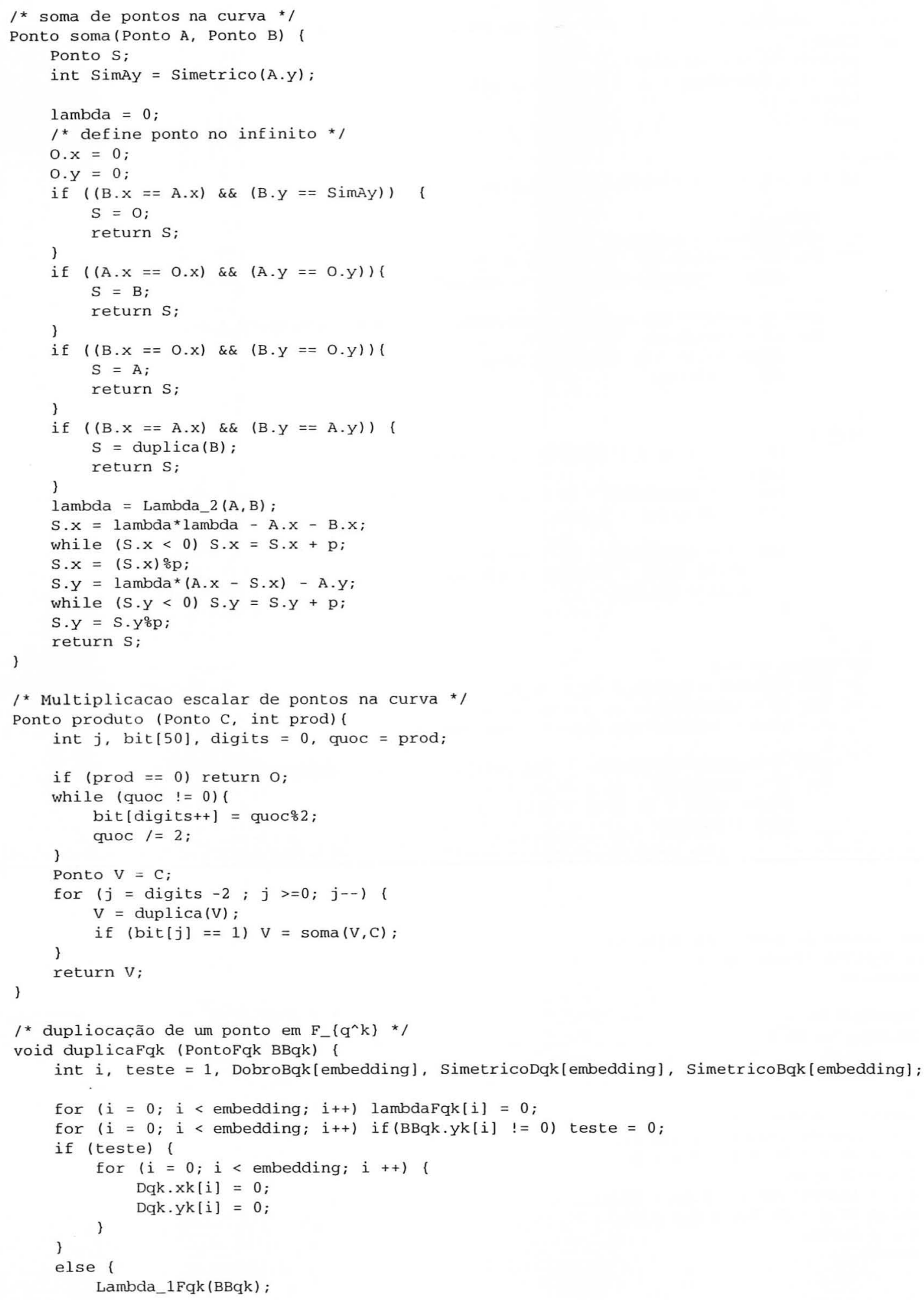


for $(i=0 ; i<$ embedding; $i++$ ) lambdaFqk[i] = PolinomioLambda1Fqk[i]; MultiplicaPol inomios (lambdaFqk, lambdaFqk);

for $(i=0 ; i<$ embedding; $i++)$ DobroBqk[i] = BBqk.xk[i]*(-2);

somaPolinomios (RESUL, DobroBqk):

for $(i=0 ; i<$ embedding; $i++)$ Dgk.xk[i] = SOMARESUL[i];

for $(i=0 ; i<$ embedding; $i++)$ SimetricoDqk[i] $=-\operatorname{Dqk} \cdot x k[i]$;

somaPolinomios (BBqk. xk, SimetricoDqk);

MultiplicaPolinomios (lambdaFqk, SOMARESUL);

for $(i=0 ; i<$ embedding; $i++)$ SimetricoBqk[i] = - BBqk.yk[i] ;

somaPolinomios (RESUL, SimetricoBgk):

for $(i=0 ; i<$ embedding; $i++)$ Dqk.yk $[i]=$ SOMARESul $[i] ;$

)

I* soma de pontos em $F_{-}\left\{q^{\wedge} k\right\}$ */

void somaFqk (PontoFqk Aqk, PontoFqk Bqk) \{

int $i$, teste $=1$, flag $=1$;

int Simetricosqk[embedding], Somaparcial[embedding];

PontoFqk SimetricoAqk, SimetricoBqk:

for $(i=0 ; i<$ embedding; $i++$ ) lambdaFqk[i] $=0$

for $(i=0 ; i<$ embedding; $i++$ ) if (Bqk.xk[i] $!=0)$ flag $=0$;

if (flag) ( // B é o ponto no infinito

teste $=0$.

for $(i=0 ; i<$ embedding; $i++)\{$

Somaqk.xk[i] $=A q k \cdot x k[i] ;$

Somaqk $\cdot y k[i]=A q k \cdot y k[i]$ :

flag $=1$;

for $(i=0 ; i<$ embedding; $i++)$ if (Aqk.xk[i] $!=0$ ) flag $=0$;

if ( $f(a g)(/ / A$ é o ponto no infinito

teste $=0$;

for $(i=0 ; i<$ embedding; $i++)\{$

Somaqk. $x k[i]=$ Bqk. $x k[i]$;

Somaqk.yk $[i]=B q k \cdot y k[i]$

$\mathrm{flag}=1 ;$

for $(i=0 ; i<$ embedding; $i++)$

if ((Bqk.xk[i] != Aqk.xk[i]) || (Bqk.yk[i] != (p-Aqk.yk[i])\%p)) flag = 0;

if (flag) $\{/ /$ é o simetrico

teste $=0$ :

for $(i=0 ; i<$ embedding; $i++)($

Somaqk. $x k[i]=0$;

Somaqk.yk $[i]=0$;

$\mathrm{flag}=1 ;$

for $(i=0 ; i<$ embedding; $i++)$

if ((Bqk.xk[i] !=Aqk.xk[i]) || (Bqk.yk[i] !=Aqk.yk[i])) flag =0;

if (flag) \{ // é o mesmo ponto

teste $=0$.

duplicaFqk (Bqk);

for $(i=0 ; i<$ embedding; $i++)$ (

Somaqk. $x k[i]=D q k \cdot x k[i] ;$

Somaqk. $y k[i]=D q k \cdot y k[i]$;

if (teste) \{

Lambda_2Fqk (Aqk, Bqk);

for $(i=0 ; i<$ embedding; $i++)$ lambdaFqk[i] = PolinomioLambda2Fqk[i];

for $(i=0 ; i<$ embedding; $i++)\{$

SimetricoAqk.xk[i] $=-$ Aqk.xk[i];

SimetricoAqk.yk[i] = -Aqk.yk[i];

SimetricoBqk.xk[i] = - Bqk.xk[i];

SimetricoBqk.yk[i] $=-$ Bqk.yk[i] 


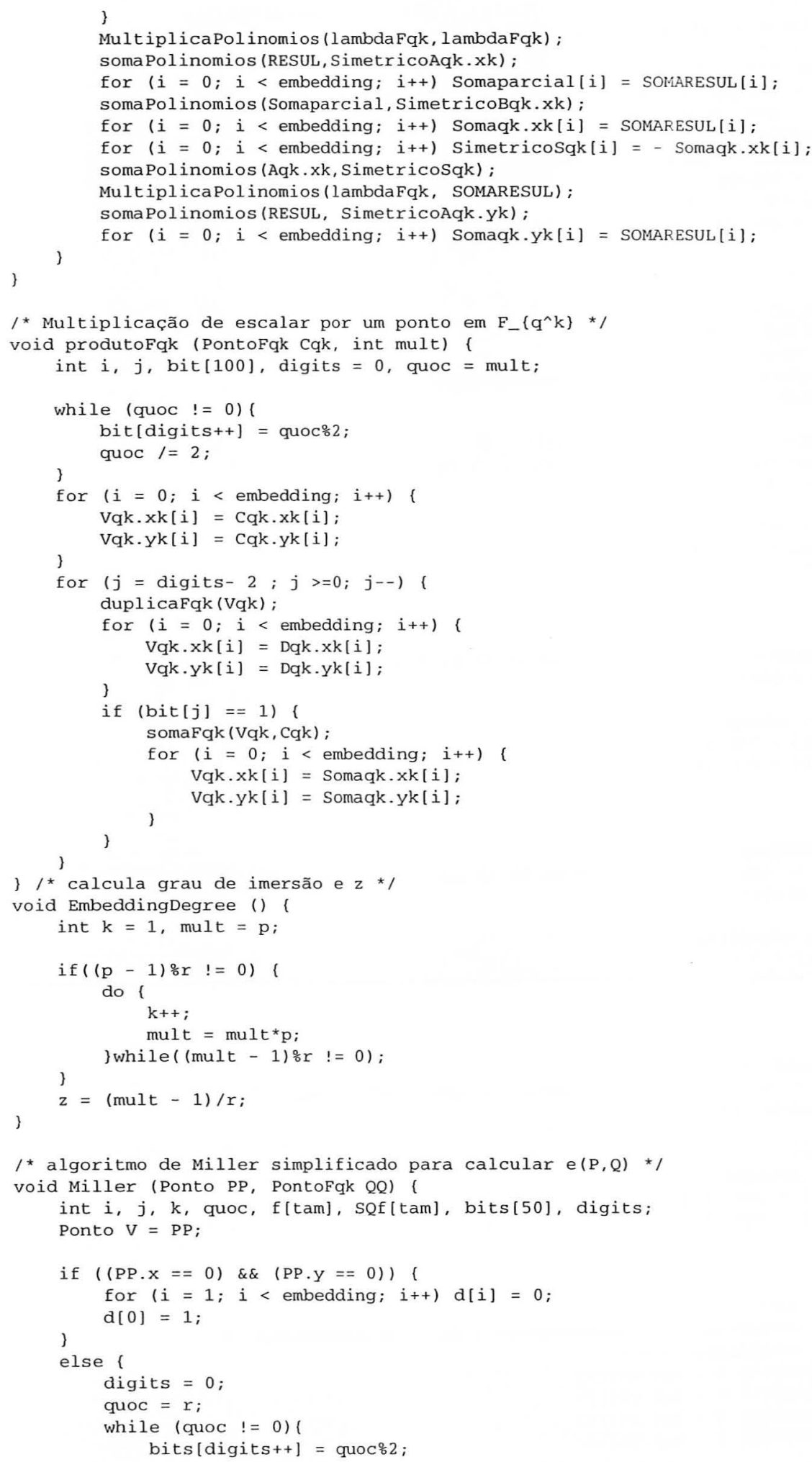




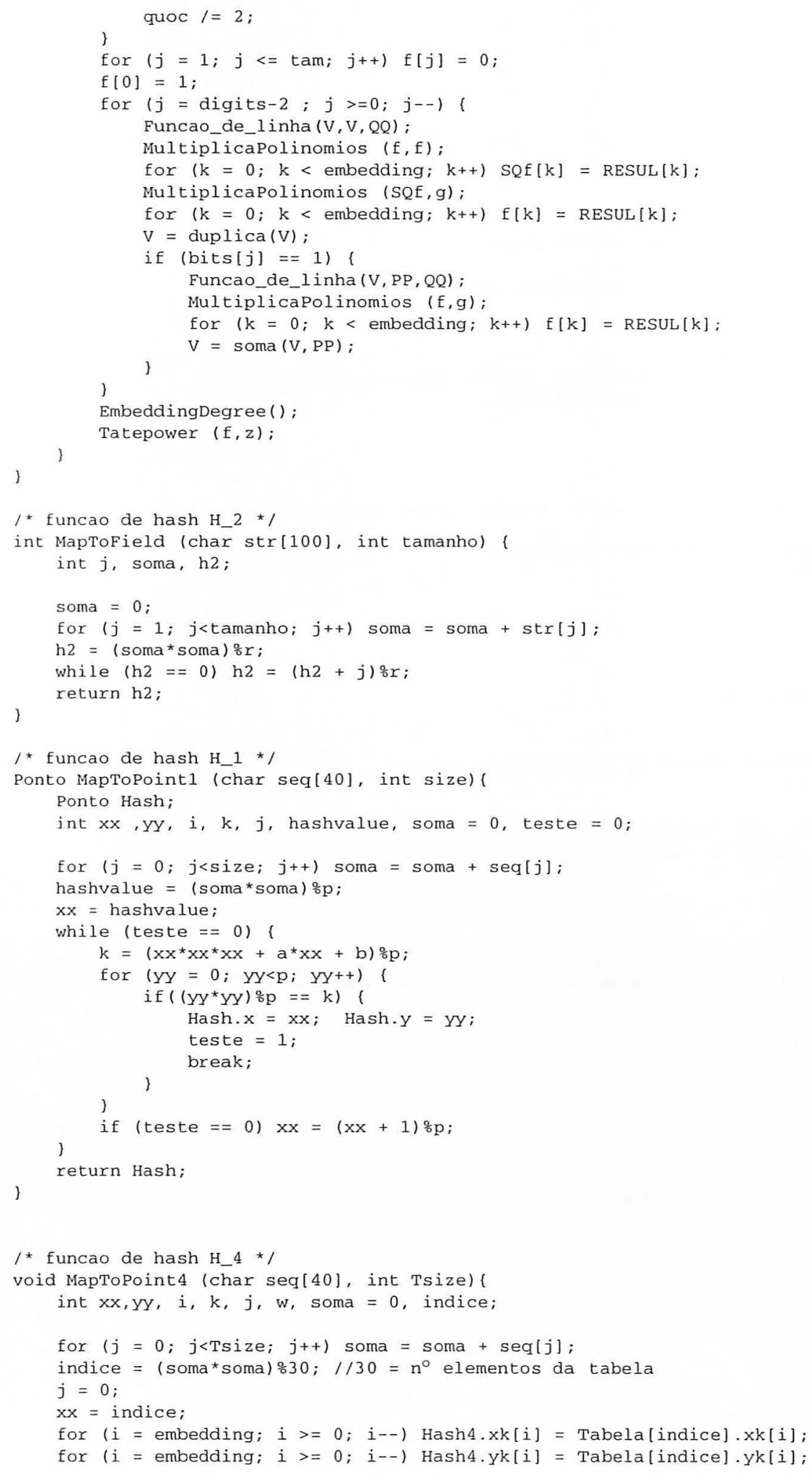




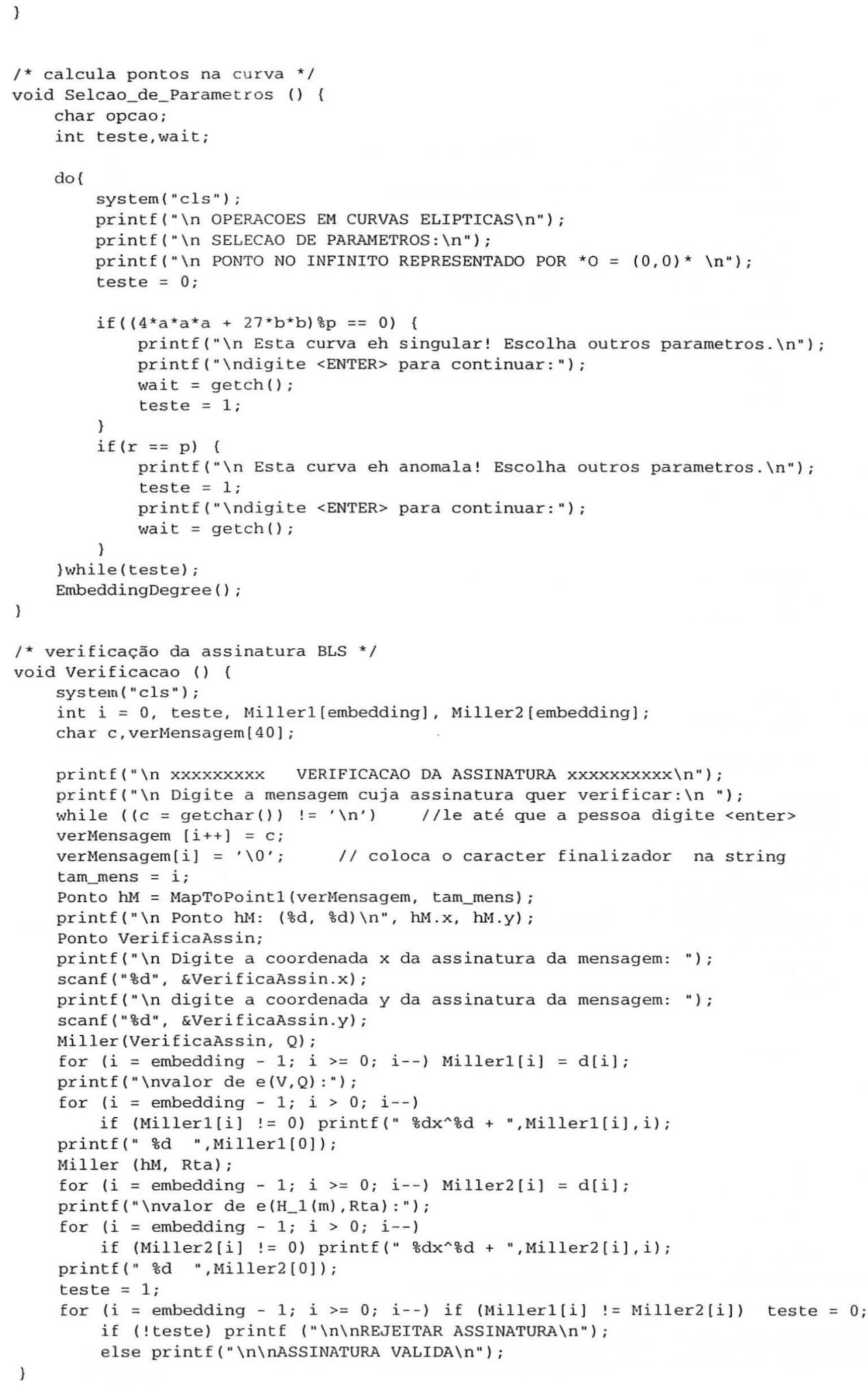




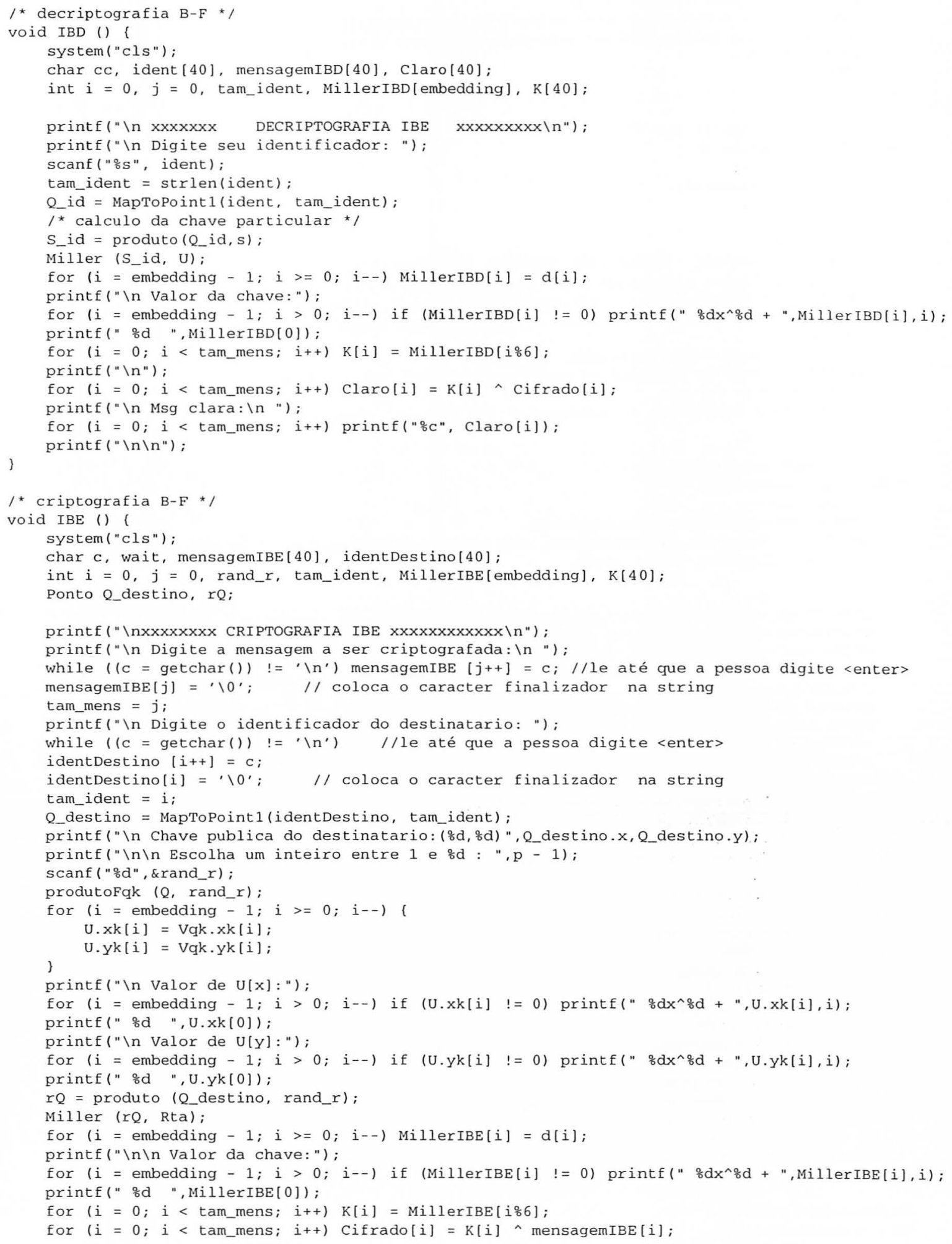


printf("\n\n Misg cifrada: \n ");

for $(i=0 ; i<$ tam_mens; $i++)$ printf("oc", Cifrado[i]);

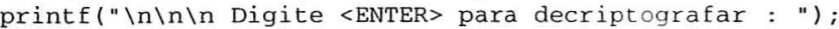

wait $=\operatorname{getch}()$

$\operatorname{IBD}()$;

I* assinatura compacta BLS */

void Shortsignature () (

system("cls");

char $c$, mensagem $[40]$

int $j=0$;

Ponto Sign

printf("\n xxxxxxx ASSINATURA COMPACTA $x \times x \times x \times x \times x \backslash n ")$;

printf("\n Digite a mensagem a ser criptografada: \n ");

while $\left((c=\right.$ getchar ()$\left.) !=\prime \backslash n^{\prime}\right)$ mensagem $[j++]=c ; / /$ le até que a pessoa digite <enter> mensagem $[j]=\prime \backslash 0^{\prime} ; \quad / /$ coloca o caracter finalizador na string

tam mens $=j$;

Ponto hP = MapToPoint1 (mensagem, tam_mens);

printf("\n Hash da mensagem na curva: (\%d, \%d) \n", hP.x, hP.y) ,

Sign $=$ produto $(\mathrm{hP}, \mathrm{s})$;

printf("\n A assinatura da mensagem eh: (\%d, \%d) \n\n", Sign.x, Sign.y);

I* verificação assinatura Hess */

void VerificaHess () (

system("cls");

char $c$, mensagem[40], idenorigem[40];

int $i, j$, hhess, hh, rr[embedding], tam_iden, Miller1[embedding], Miller2 [embedding] ;

Ponto UU, Q_origem, SimQ, hSimQ:

$i=0 ; j=0$;

printf("\n xxxxxxx VERIFICACAO DE ASSINATURA BASEADA EM IDENTIDADE xxxxxxxxx\n");

printf("\n Digite a mensagem cuja assinatura deseja verificar: \n ");

while $\left((c=\right.$ getchar ()$\left.) !=' \backslash n^{\prime}\right)$ mensagem $[j++]=c ; / /$ le até que a pessoa digite <enter> mensagem $[j]=' 10^{\prime} ; \quad / /$ coloca o caracter finalizador na string

tam_mens $=j$;

printf("\n Digite o identificador do origem: "),

while $\left((c=\right.$ getchar ()$\left.) \quad !={ }^{\prime} \backslash \mathrm{n}^{\prime}\right) \quad / /$ le até que a pessoa digite <enter>

idenOrigem $[\mathrm{i}++]=\mathrm{C}$;

idenorigem $[i]=' \backslash 0^{\prime} ; \quad / /$ coloca $\circ$ caracter finalizador na string

tam_iden $=i$;

Q_origem $=$ MapToPoint1(idenorigem, tam_iden):

Simo. $x=0$ origem. $x$;

SimQ.y = Simetrico(Q_origem.y);

printf("\n Digite a coordenada $\mathrm{x}$ do ponto $\mathrm{U}$ : " );

scanf ("\%d", \&UU.x)

printf("\n Digite a coordenada $y$ do ponto $U:$ " );

$\operatorname{scanf}(" \% d ", \& U U . y)$;

printf("\n Digite o valor de $h$ : ");

scanf ("\%d", \&hh);

hSimQ = produto $($ SimQ, hh $)$;

Miller (UU, Q) ;

for $(i=0 ; i<$ embedding; $i++) \operatorname{Miller}[i]=d[i]$;

Miller (hSimQ, Rta);

for $(i=0 ; i<$ embedding; $i++)$ Miller2[i] $=d[i]$;

MultiplicaPolinomios (Miller1, Miller2);

for $(i=0 ; i<$ embedding; $i++) \operatorname{rr}[i]=\operatorname{RESUL}[i]$;

for $(i=0 ; i<$ embedding; $i++)$ mensagem $[j++]=\operatorname{rr}[i]$

hhess $=$ MapToField (mensagem, $j$ )

if (hhess $==h \mathrm{~h}$ ) printf(" $\backslash \mathrm{n}$ ASSINATURA VALIDA $\backslash \mathrm{n} ")$;

else printf("\n REJEITAR ASSINATURA \n");

/ assinatura Hess */

void AssinaturaHess () ( 


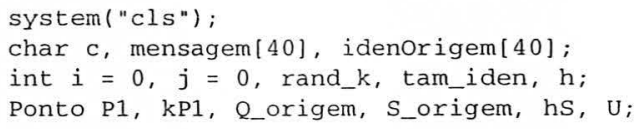

printf("\n $x \times x \times x \times x$ ASSINATURA BASEADA EM IDENTIDADE $x \times x \times x \times x \times x \backslash n ")$; printf("\n Digite a mensagem a ser assinada: \n ");

while $\left((c=\right.$ getchar ()$\left.) !=' \backslash n^{\prime}\right)$ mensagem $\left[j^{++}\right]=c ; / /$ le até que a pessoa digite <enter> mensagem $[j]=, \backslash 0^{\prime} ; \quad / /$ coloca o caracter finalizador na string tam_mens $=j$;

printf("\n Digite seu identificador: "); while $\left((c=\operatorname{getchar}()) !=' \backslash \mathrm{n}^{\prime}\right) \quad / /$ le até que a pessoa digite <enter> idenorigem $[\mathrm{i}++]=\mathrm{c}$;

idenorigem $[i]=\prime \backslash 0^{\prime} ; \quad / /$ coloca o caracter finalizador na string tam_iden $=i$;

Q_origem = MapToPoint1(idenorigem, tam_iden);

S_origem = produto (Q_origem, $s$ ) :

printf("\n Digite a coordenada $x$ do ponto escolhido: " );

scanf ("\%d", \&P1.x);

printf(" $\backslash n$ Digite a coordenada $y$ do ponto escolhido: " )

scanf ("\%d", \&P1.y);

printf("\n\n Escolha um inteiro entre 1 e $\% d:$ ", r - 1)

$\operatorname{scanf}(" \% d "$, \&rand $k)$;

$\mathrm{kP1}=$ produto $(\mathrm{P} 1$, rand_k $)$;

Miller $(\mathrm{kP} 1, \mathrm{Q})$;

for $(i=0 ; i<$ embedding; $i++)$ mensagem $[j++]=d[i]$;

$h=$ MapToField (mensagem, $j$ ) ;

printf("\n ASSINATURA: \n");

printf("\n $\mathrm{h}=\% \mathrm{~d} ", \mathrm{~h})$;

hS = produto(S_origem, h) ;

$\mathrm{U}=\operatorname{soma}(\mathrm{hS}, \mathrm{kP1})$;

printf("\n Ponto $U=(\% d, \% d) \backslash n ", U . x, U . y)$;

$I^{*}$ derciptografa e verifica assinatura

de mensagem criptoassinada *

void Unsigncryption () (

system("cls") :

char C, mensagemIBSC[40], identDestino[40], identorigem[40], concatenado[100]; ;

int $i, j$, tam_idend, shortkey[embedding], Chave[40], Claro[40], tam_ideno, hUnsign;

int MillerQR[embedding], flag;

Ponto Q_destino, S_destino

PontoFqk Q_origem;

printf ("\nxxxxxxxx UNSIGNCRYPTION $\mathrm{xxxx \times x \times x \times x \times x")}$

printf("\n FASE 1 - DECRIPTOGRAFIA $\backslash \mathrm{n} ")$;

printf("\n Digite seu identificador: "),

scanf ("\%s", identDestino);

tam_idenD $=$ strlen (identDestino)

Q_destino $=$ MapToPoint1 (identDestino, tam_idenD)

$\mathrm{S}$ destino $=$ produto $(0$ destino, $\mathbf{S})$;

I* $\mathrm{k}=\mathrm{e}$ (Sbeto, S) */

Miller (S_destino, Sqk);

for $(i=0 ; i<$ embedding; $i++)$ shortkey $[i]=d[i]$;

printf("\n Valor da chave: ");

for $(i=$ embedding $-1 ; i>0 ; i--)$ if (shortkey[i] $!=0)$ printf(" \%dx^od +, "shortkey[i], i), printf(" od ", shortkey[0]);

for $(i=0 ; i<$ tam_mens; $i++)$ Chave $[i]=\operatorname{shortkey[i\% 6];~}$

printf("\n");

$1 * \mathrm{~m}=\mathrm{k}$ XOR $\mathrm{C} * /$

for $(i=0 ; i<$ tammens; $i++)$ Claro[i] = Chave[i] ^ Cifrado[i]:

printf("\n Msg clara: \n ");

for ( $i=0 ; i<$ tam_mens; $i++)$ printf("\%c", $C l a r o[i])$

printf("\n\n FASE 2 - VERIFICACAO DA ASSINATURA \n"):

printf("\n Digite o identificador do assinante: "),

scanf ("\%", identorigem):

tam_ideno $=$ strlen (identorigem) 
MapToPoint4 (identorigem, tam_ideno)

for $(i=$ embedding $-1 ; i>=0 ; i--)\{$

Q origem.xk[i] $=$ Hash $4 \cdot x k[i]$

\}

Q_origem.yk[i] = Hash $4 \cdot y k[i]$;

* e(Sbeto, Qalice) */

Miller (S_destino, Q_origem);

$\mathrm{j}=0$;

/* $\mathrm{R} \|$ e(Sbeto, Qalice) || $\mathrm{m}$ */

for $(i=0 ; i<$ embedding; $i++)$ concatenado $[j++]=\operatorname{Rqk} \cdot x k[i]$;

for $(i=0 ; i<$ embedding; $i++)$ concatenado $[j++]=\operatorname{Rqk} \cdot y k[i]$;

for $(i=0 ; i<$ embedding; $i++)$ concatenado $[j++]=d[i] ;$

for $(i=0 ; i<$ tam_mens; $i++)$ concatenado $[j++]=$ claro $[i]$

$1^{*} \mathrm{~h}=\mathrm{H}_{-} 2$ (R || e(Sbeto, Qalice) || m) */

hUnsign $=$ MapToField $($ concatenado, $j) ;$

print $\mathrm{f}$ ("\n $\mathrm{h}=\% \mathrm{~d} \backslash \mathrm{n} "$, hUnsign);

Miller (Q_destino, Rqk);

for $(i=0 ; i<$ embedding; $i++)$ MillerQR[i] $=d[i]$

Tatepower (MillerQR, hUnsign);

$\mathrm{flag}=0$;

for $(\mathrm{i}=0 ; \mathrm{i}<$ embedding; $\mathrm{i}++)$ if (shortkey[i] $!=\mathrm{d}[\mathrm{i}]$ ) flag = 1 ;

if (flag) printf("\n REJEITAR ASSINATURA $\backslash n \backslash n ")$;

else printf("\n ASSINATURA VALIDA $\backslash n \backslash n ")$;

)

* criptoassinatura *

void Signcryption () (

system("cls")

char C, mensagemIBSC[40], identDestino [40], identorigem[40], concatena[100];

int hSign, ah, rand_a, $i=0, j=0$, tam_ideno, tam_idenD, MillerobSa [embedding] ;

int key[embedding], K[40], wait:

Ponto ahe, Q destino;

PontoFqk Q_origem, S_origem;

printf("\nxxxxxxxx SIGNCRYPTION $\mathrm{x} \times x \times x \times x \times x \times x \times \backslash n ")$;

printf("\n Digite a mensagem a ser assinada e criptografada: \n ");

while $\left((c=\right.$ getchar ()$\left.) !=' \backslash n^{\prime}\right)$ mensagemIBSC $[j++]=c ; / / l$ e até que a pessoa digite <enter>

mensagemIBSC $[j]=\cdot \backslash 0^{\prime} ; \quad / /$ coloca o caracter finalizador na string

tam_mens $=j$;

printf("\n Digite seu identificador: ");

while $\left((c=\right.$ getchar ()$\left.) !=' \backslash \mathrm{n}^{\prime}\right) \quad / /$ le até que a pessoa digite <enter>

identorigem $[i++]=c$;

identorigem $[i]=' 100^{\prime} ;$

tam_ideno $=i$

$/ /$ coloca o caracter finalizador na string

MapToPoint4 (identorigem, tam ideno)

for $(i=$ embedding $-1 ; i>=0 ; i--)\{$

Q origem.xk[i] $=$ Hash $4 \cdot x k[i]$

o origem.yk[i] = Hash $4 \cdot y k[i]$;

\}

produtoFqk (Q origem, s);

for ( $i=$ embedding $-1 ; i>=0 ; i--)($

S_origem.xk[i] $=$ Vqk. $x k[i]$;

s_origem.yk[i] $=$ Vqk. $y k[i]$;

$i=0$;

printf("\n Digite o identificador do destinatario: ");

while $\left((c=\right.$ getchar ()$\left.) \quad !={ }^{\prime} \backslash \mathrm{n}^{\prime}\right) \quad / /$ e até que a pessoa digite <enter>

identDestino $[i++]=c$;

identDestino[i] = ' $\backslash 0^{\prime} ; \quad / /$ coloca o caracter finalizador na string

tam_idenD $=i$;

Q_destino $=$ MapToPoint1 (identDestino, tam_idenD);

/* Escolhe inteiro aleatório *a* */

printf("\n Escolha um inteiro entre 1 e $\% d:$ : r - 1);

scanf ( "\%d" \& \&rand_a) ;

1 * $\mathrm{R}=$ asalice */

produtoFqk (S_origem, rand_a)

for $(i=$ embedding $-1 ; i>=0 ; i--)$ ( 


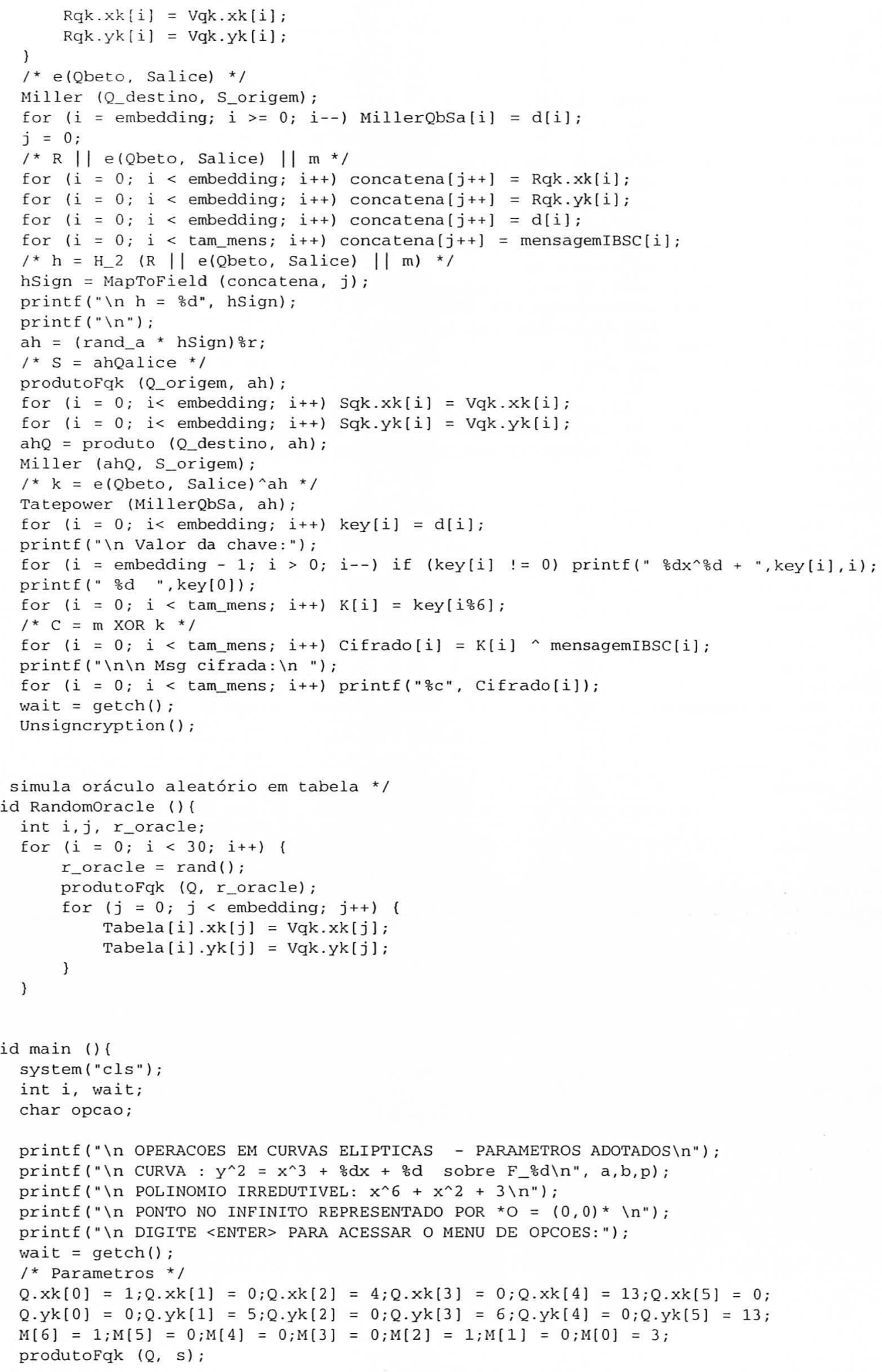




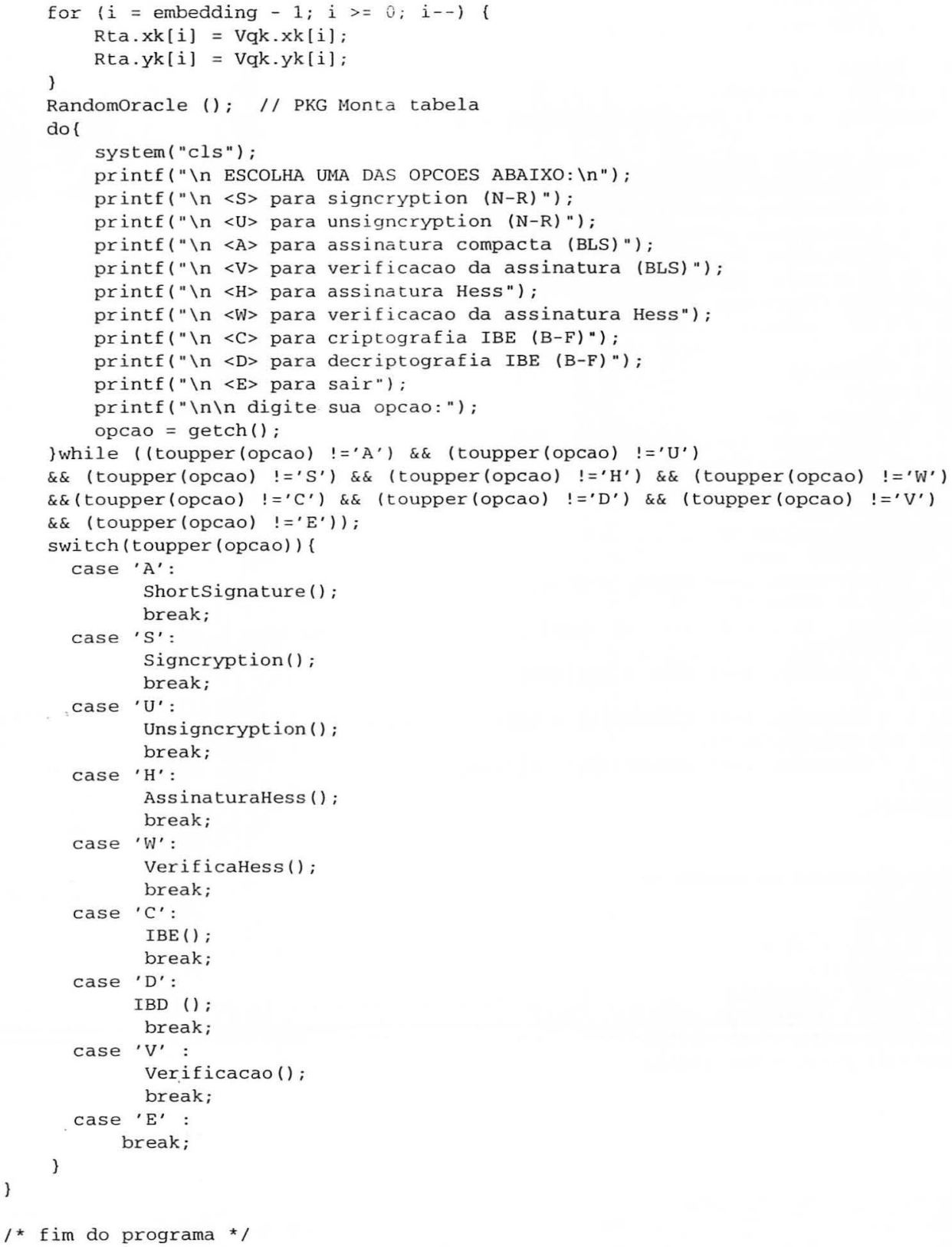




\section{Referências Bibliográficas}

[Al-Riyami e Paterson 2003] AL-RIYAMI, S. S.; PATERSON, K. G. Certificateless Public Key Cryptography. 2003. Disponível em <http://eprint.iacr.org/2003/126>. Acesso em: 23 jun. 2003.

[Barreto 1999] BARRETO, P. Curvas Elípticas e Criptografia: Conceitos e Algoritmos. 1999. Disponível em <http://planeta.terra.com.br/informatica/paulobarreto >. Acesso em: 25 mar. 2003.

[Barreto et al. 2002] BARRETO, P. et al. Efficient algorithms for pairing-based cryptosystems. In: Lecture Notes in Computer Science. [S.1.]: Springer-Verlag, 2002. v. 2442, p. 354-368. Advances in Cryptology - Crypto'2002.

[Barreto, Lynn e Scott 2003] BARRETO, P.; LYNN, B.; SCOTT, M. On the selection of Pairing-Friendly Groups. 2003. Disponível em <http://eprint.iacr.org/2003/086>. Acesso em: 04 mai. 2003.

[Barreto 2003] BARRETO, P. S. L. M. Criptografia Robusta e Marcas D’Água Frágeis: Construção e Análise de Algoritmos para Localizar Alterações em Imagens Digitais. Tese (Doutorado) - Universidade de São Paulo - Escola Politécnica, São Paulo, 2003.

[Bellare e Rogaway 1993] BELLARE, M.; ROGAWAY, P. Random oracles are practical: A paradigm for designing efficient protocols. In: First ACM Conference on Computer and Communications Security. Fairfax: ACM, 1993. p. 62-73.

[Boneh e Franklin 2001] BONEH, D.; FRANKLIN, M. Identity based encryption from the Weil pairing. In: Lecture Notes in Computer Science. [S.1.]: Springer-Verlag, 2001. v. 2139, p. 213-229. Advances in Cryptology - CRYPTO'2001. 
[Boneh, Lynn e Shacham 2001] BONEH, D.; LYNN, B.; SHACHAM, H. Short signature from the Weil pairing. In: Lecture Notes in Computer Science. [S.I.]: Springer-Verlag, 2001. v. 2248, p. 514-532. Advances in Cryptology - ASIACRYPT'2001.

[Borisov, Goldberg e Wagner 2001] BORISOV, N.; GOLDBERG, I.; WAGNER, D. Intercepting mobile communications: The insecurity of 802.11. In: Proceedings of the Seventh Annual International Conference on Mobile Computing and Networking (MOBICOM-01). New York: ACM Press, 2001. p. 180-188.

[Boyen 2003] BOYEN, X. Multipurpose Identity-Based Signcryption : A Swiss Army Knife for Identity-Based Cryptography. 2003. Disponível em <http://eprint.iacr.org/2003/163/>. Acesso em: 25 ago. 2003.

[Cha e Cheon 2002] CHA, J. C.; CHEON, J. H. An identity-based signature from gap DiffieHellman groups. In: Lecture Notes in Computer Science. [S.1.]: Springer-Verlag, 2002. v. 2567 , p. $18-30$.

[Chaum 1983] CHAUM, D. Blind signatures for untraceable payments. In: RIVEST, R. L.; SHERMAN, A.; CHAUM, D. (Ed.). Proc. CRYPTO 82. New York: Plenum Press, 1983. p. 199-203.

[Chen et al. 2002] CHEN, L. et al. Certification of public keys within an identity-based system. In: Lecture Notes in Computer Science. [S.I.]: Springer-Verlag, 2002. v. 2433, p. 322-333. 5th International Security Conference - ISC 2002.

[Chen, Zhang e Kim 2003] CHEN, X.; ZHANG, F.; KIM, K. A New ID-based Group Signature Scheme from Bilinear Pairings. 2003. Disponível em <http://eprint.iacr.org/2003/116>. Acesso em: 06 jun. 2003.

[Custodio 2000] CUSTODIO, R. F. 2000. Disponível em $<$ http://www.inf.ufsc.br/ custodio/cursos/INE6906/Notas_Aula.html >. Acesso em: 14 mai. 2003. 
[Custodio 2001] CUSTODIO, R. F. Crítica à ICP Brasil - Resposta à consulta pública. 2001.

Disponível em <http://www.inf.ufsc.br/ custodio/ICP-Brasil/ICP-Brasil.html >. Acesso em: 04 mai. 2003.

[Custodio 2002] CUSTODIO, R. F. Notas de aula. 2002.

[Desmedt e Quaisquater 1986] DESMEDT, Y.; QUAISQUATER, J. Public-key systems based on the difficulty of tampering. Springer-Verlag, v. 2139, p. 213, 1986. Advances in Cryptology - CRYPTO'2001.

[Diffie e Hellman 1976] DIFFIE, W.; HELLMAN, M. New directions in cryptography. IEEE Transactions on Information Theory, IT-22, n. 6, p. 644-654, 1976.

[Domingues e Iezzi 1979] DOMINGUES, H. H.; IEZZI, G. Álgebra Moderna. São Paulo: Atual Editora, 1979.

[Duursma e Lee 2003] DUURSMA, I.; LEE, H.-S. Tate-pairing implementations for tripartite key agreement. 2003. Disponível em <http://eprint.iacr.org/2003/053>. Acesso em: 05 ago. 2003.

[Ferreira 1999] FERREIRA, A. B. de H. Novo Aurélio - Dicionário da Língua Portuguesa século XXI. [S.1.]: Nova Fronteira, 1999.

[Galbraith 2001] GALBRAITH, S. Supersingular curves in cryptography. In: Lecture Notes in Computer Science. [S.1.]: Springer-Verlag, 2001. v. 2248, p. 495-513. ASIACRYPT 2001.

[Galbraith, Harrison e Soldera 2002] GALBRAITH, S.; HARRISON, K.; SOLDERA, D. Implementing the tate pairing. In: Lecture Notes in Computer Science. [S.1.]: Springer-Verlag, 2002. v. 2369, p. 324-337. ANTS 2002.

[GLOSSÁRIO de segurança 2003] GLOSSÁRIO de segurança. 2003. Disponível em $<$ http://www.portaldeinformatica.com.br/seguranca_glossario.htm $>$. Acesso em: 12 jan. 2003. 
[Godoy e Curti 2002] GODOY, H.; CURTI, J. C. O dinheiro eletrônico. 2002. Disponível em <http://www.claretianas.com.br/trabmp205.doc $>$. Acesso em: 12 jul. 2003. Trabalho de Mestrado Profissional submetido à Universidade de Campinas.

[Hernandez 2000] HERNANDEZ, J. C. L. Implementação Eficiente em Software de Criptossistemas de Curvas Elípticas. Tese (Doutorado) - Universidade Estadual de Campinas, São Paulo, 2000 . Disponível em <http://www.lca.ic.unicamp.br/portugues/principal.html>. Acesso em 10 jun. 2003.

[Hess 2002] HESS, F. Efficient identity based signature schemes based on pairings. In: Lecture Notes in Computer Science. [S.1.]: Springer-Verlag, 2002. v. 2595, p. 310-324.

[Horwitz e Lynn 2002] HORWITZ, J.; LYNN, B. Hierarchical identity-based encryption. In: Lecture Notes in Computer Science. [S.1.]: Springer-Verlag, 2002. v. 2332, p. 466-481. Advances in Cryptology - EUROCRYPT'2002.

[Koblitz 1994] KOBLITZ, N. A course in number theory and cryptography. In: Graduate Texts in Mathematics n. 114. 2. ed. New York: Springer-Verlag, 1994.

[Lin e Wu 2003] LIN, C.-Y.; WU, T.-C. An identity-based ring signature scheme from bilinear pairings. 2003. Disponível em <http://eprint.iacr.org/2003/117>. Acesso em: 12 jul. 2003.

[Malone-Lee 2002] MALONE-LEE, J. Signcryption with non-repudiation. 2002. Department of Computer Science, University of Bristol - Relatório técnico CSTR 02-004.

[Maurer e Yacobi 1991] MAURER, U.; YACOBI, Y. Non-interactive public-key cryptography. Springer-Verlag, v. 2139, p. 213, 1991. Advances in Cryptology - CRYPTO’2001.

[Menezes, Oorschot e Vanstone 1997] MENEZES, A.; OORSCHOT, P.; VANSTONE, S. Handbook of Applied Cryptography. 1. ed. California: CRC Press, 1997.

[Menezes, Vanstone e Okamoto 1991] MENEZES, A.; VANSTONE, S.; OKAMOTO, T. Reducing elliptic curve logarithms to logarithms in a finite field. In: Proc. 23rd Ann. ACM Symp. on Theory of Computing. New Orleans, LA: [s.n.], 1991. p. 80-89. Extended abstract in Proceedings of the 23rd ACM Symposium on Theory of Computing, 1991, ACM, pp. 80-89. 
[Miller 1986] MILLER, V. Short programs for functions on curves. Manuscrito não publicado. 1986.

[Nalla e Reddy 2003] NALLA, D.; REDDY, K. Signcryption scheme for Identity-based Cryptosystems. 2003. Disponível em <http://eprint.iacr.org/2003/066/>. Acesso em: 22 abr. 2003.

[Paterson 2002] PATERSON, K. ID-Based Signatures from Pairings on Elliptic Curves. 2002. Disponível em <http://eprint.iacr.org/2002/004.ps.gz>. Acesso em: 17 jan. 2002.

[Rivest, Shamir e Adleman 1978] RIVEST, R.; SHAMIR, A.; ADLEMAN, L. A method for obtaining digital signatures and public key cryptosystems. Communications of the ACM, v. 1, n. 2, p. 120-126, 1978.

[Rivest, Shamir e Tauman 2001] RIVEST, R. L.; SHAMIR, A.; TAUMAN, Y. How to leak a secret. Lecture Notes in Computer Science, v. 2248, p. 552-565, 2001.

[Schneier 1996] SCHNEIER, B. Applied Cryptography - Protoclos, algorithms and source code in C. 2. ed. New York: John Willey \& Sons, 1996.

[Schoof 1985] SCHOOF, R. Elliptic curves over finite fields and the computations of square roots mod p. p. 21, 1985.

[Shamir 1984] SHAMIR, A. Identity based cryptosystems and signature schemes. In: Lecture Notes in Computer Science. [S.1.]: Springer-Verlag, 1984. v. 196, p. 47-53. Advances in Cryptology: Proceedings of CRYPTO 84.

[Silverman 1986] SILVERMAN, J. The arithmetic of elliptic curves. In: Graduate Texts in Mathmatics n. 106. 1. ed. New York: Springer Verlag, 1986.

[Stallings 2002] STALLINGS, W. Cryptography and Network Security - Principles and Practice. 3. ed. New Jersey: Prentice Hall, 2002.

[Tanaka 1987] TANAKA, H. A realization scheme for the identity-based cryptosystem. Springer-Verlag, v. 2139, p. 213, 1987. Advances in Cryptology - CRYPTO'2001. 
[Terada 2000] TERADA, R. Segurança de Dados- Criptografia em Redes de Computador. 1. ed. São Paulo: Edgard Blücher, 2000.

[Tkotz 1999] TKOTZ, V. Página na Internet sobre Criptologia. 1999. Disponível em <http://www.numaboa.com/informatica/criptologia/>. Acesso em: 25 abr. 2003.

[Tsuji e Itoh 1989] TSUJI, S.; ITOH, T. An ID-based cryptosystem based on the discrete logarithm problem. Springer-Verlag, v. 2139, p. 213, 1989. Advances in Cryptology CRYPTO'2001.

[Zhang e Kim 2002] ZHANG, F.; KIM, K. ID-based Blind Signature and Ring Signature from Pairings. 2002. Disponível em <http://caislab.icu.ac.kr/paper/2002/zhang/paper177.pdf>. Acesso em: 12 mai. 2003.

[Zheng 1997] ZHENG, Y. Digital signcryption or how to achieve cost(signature \& encryption) « $\operatorname{cost}($ signature $)+\operatorname{cost}($ encryption). In: Lecture Notes in Computer Science. [S.l.]: SpringerVerlag, 1997. v. 1294, p. 165-179. Advances in Cryptology: Proceedings of CRYPTO 97. 


\section{Índice Remissivo}

adição de assinaturas, 92

algoritmo

tempo exponencial, 159

tempo polinomial, 159

tempo sub-exponencial, 159

algoritmo de Miller

eliminação de denominadores, 138

versão determinística, 137

algoritmos secretos, 7

anel, 161

anonimato

do assinante, 102

do usuário, 106

aritmética modular, 160

aritmética no corpo estendido, 133

assinatura

baseada em identidades, 58

cega, 106

com PKG não confiável, 114

compacta, 48

CZK, 114

digital, 17

em anel, 102

para fins específicos, 101 ataque, 8,10

adaptativo, 12, 13

ativo, 10

de bloqueio, 11

de fabricação, 11, 75

de interceptação, 11, 75

de interrupção, 11

de modificação, 11, 59, 75, 81

passivo, 11

por chave conhecida, 13

por dicionário, 13

por só-texto-ilegível, 12

por texto ilegível escolhido, 12

por texto legível conhecido, 12, 54, 75,

84

por texto legível escolhido, 12

autenticidade, 10, 81

mútua, 68, 72, 78

na origem, 18,70

no destino, 18,70

autoria garantida, 10

autoridade

certificadora, $8,20,22,23$

de confiança, 33, 48, 61, 62, 113 
de registro, 24

\section{BDHP, 44}

bilinearidade, 42,71

Boneh-Franklin

variação, 54

caminhos de certificação, 27

canal seguro, 13, 19, 31

CDHP, 44

certificação cruzada, 25

certificado digital, 8, 20-22

modelo em árvore, 25

modelo em floresta, 25

obtenção, 24

política de certificação, 25

verificação, 27

chave, 8

baseada em identidades, 48

custódia, 48, 61, 64

mestra, 52

pública, 15

pública global, 119

pública sem certificado, 121

padrão, 48

particular, 15, 17

particular global, 119

privada, 15

quantidade necessária, 13, 19

secreta, 14

tradicional, 48
co-BDHP, 44

comparação de desempenho, 65

comprometimento, 11, 21

confidencialidade, 10, 80

contribuições da dissertação, 5

corpo, 162

corpo finito, 36, 162

característica, 162

correio físico, 32, 155

criação de grupos, 91

criptanálise, 9

criptassinatura, 68, 72

criptografar, 9

criptografia

assimétrica, $7,8,15,21$

assimétrica tradicional, 21, 31, 32, 49, 154

baseada em identidades, 32, 33, 51, 155

chave pública, 7

chave secreta, 13

com múltiplos PKG, 118

conceitos básicos, 6

simétrica, 7, 13, 31

terminologia, 8

criptologia, 9

curvas elípticas, 8, 33, 35, 155, 162

anômalas, 37

degeneradas, 37

exemplos de cálculos, 163

grau de imersão, 37 
não adequadas, 37

ordem da curva, 36

ordem de um ponto, 37

ordinárias, 38,84

problema do logaritmo discreto, 34

singulares, 37

soma de pontos, 163

supersingulares, 37

traço de Frobenius, 36

DDHP, 43

decriptografar, 9

delegação de chaves para notebook, 89

delegação de direitos, 97

delegação de serviços, 90

diretório público, 17, 20, 60

distribuição de chaves, 7

emparelhamento, 38,42

cálculo, 136

custo computacional, 43

de Tate, 39

de Weil, 39

espalhamento, 45

esquema $\mathrm{BFH}$

contabilização, 70

esquema Malone-Lee, 72

assinatura e criptografia, 73

contabilização, 76

decriptografia e verificação, 73

esquema Nalla \& Reddy, 77 assinatura e criptografia, 78

contabilização, 82

decriptografia e verificação, 78

segurança, 79

fatores de ocultação, 111

função

bilinear, 42

linear, 42

funções de linha, 136

\section{GDHP, 44}

gerador de chaves particulares, 31

gerador de um grupo, 161

grupo, 35,160

abeliano, 161

aditivo, 161

comutativo, 161

multiplicativo, 161

hash, 45

hierarquia

de certificação, 93

identificador, 32, 48, 154

implementação

assinatura BLS, 142

assinatura Hess, 144

criptografia B-F, 146

escolha de parâmetros, 124

geração de chaves, 132

mudança de parâmetros, 151 
signcryption $\mathrm{N}-\mathrm{R}, 148$

soma e produto na curva, 131

importância do elemento aleatório, 53, 75,

82

infra-estrutura de chaves públicas, 6, 20, 22

hipótese fundamental, 27

problemas, 29

integridade, 10

irretratabilidade, 10, 81

key escrow, 48

mapeamento

admissível, 39, 41

bilinear, 39

computável, 39

não degenerado, 39

mensagem

oculta, 106

modelo híbrido PKI - IBE, 94

NONCE, 51

oráculo aleatório, 46

pagamento eletrônico, 106, 107

PKG, 31-33, 60

não confiável, 113

problema do logaritmo discreto, 34

problema matemático intratável, 8

problemas

criptografia assimétrica, 19

criptografia simétrica, 7, 19
Diffie-Hellman, 43

requisitos de segurança, 8,9

revogação, 21, 28

signcryption, 72

Malone-Lee, 72

Nalla \& Reddy, 77

sistema baseado em identidades

conceito, 31

revogação de chaves, 88

vantagens e desvantagens, 60

substituição, 7

texto

cifrado, 9

claro, 9

criptografado, 9

ilegível, 9

legível, 9

limpo, 9

pleno, 9

trabalhos futuros, 158

transferindo confiança, 96

transposição, 7

valor de resumo, 45

votação eletrônica, 106, 108 